Aus der Klinik für Nephrologie und Rheumatologie

(Prof. Dr. med. G. A. Müller)

der Medizinischen Fakultät der Universität Göttingen

\title{
Analyse organoprotektiver Effekte durch eine \\ Barorezeptorstimulationstherapie zur Behandlung der Therapie-refraktären arteriellen Hypertonie
}

\author{
INAUGURAL - DISSERTATION \\ zur Erlangung des Doktorgrades \\ der Medizinischen Fakultät der Georg-August-Universität zu Göttingen
}

vorgelegt von

Luca-Yves Lehnig

aus Berlin

Göttingen 2016 
Dekan :

Prof. Dr. rer. nat. H.K. Kroemer

Refrent :

Prof. Dr. med. M. Koziolek

Ko-Referent :

Prof. Dr. med. R. Wachter

Promotor:

Prof. Dr. med. M. Oppermann

Tag der mündlichen Prüfung:

Dienstag, den 07. März 2017 
Hiermit erkläre ich, die Dissertation mit dem Titel "Analyse organoprotektiver Effekte durch eine Barorezeptorstimulationstherapie zur Behandlung der Therapie-refraktären arteriellen Hypertonie" eigenständig angefertigt und keine anderen als die von mir angegebenen Quellen und Hilfsmittel verwendet zu haben.

Göttingen, den 


\section{Inhaltsverzeichnis}

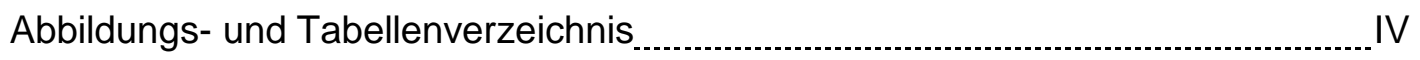

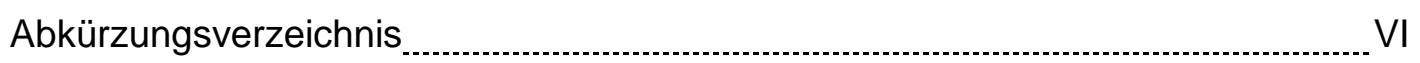

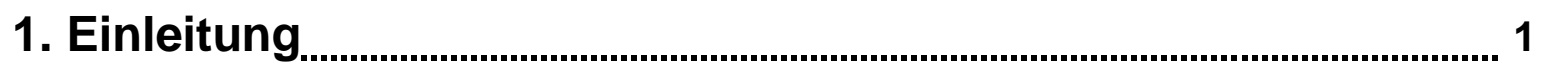

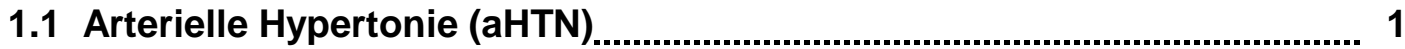

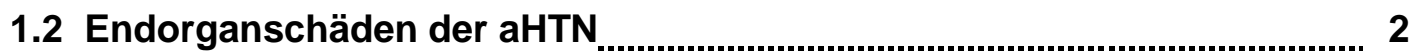

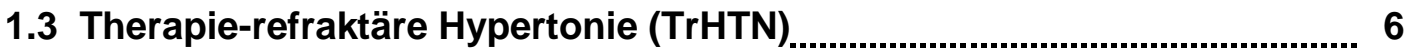

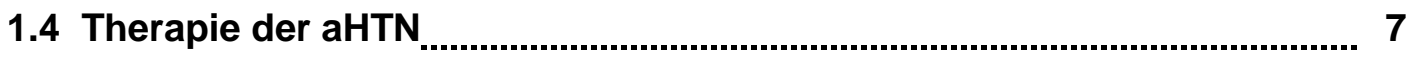

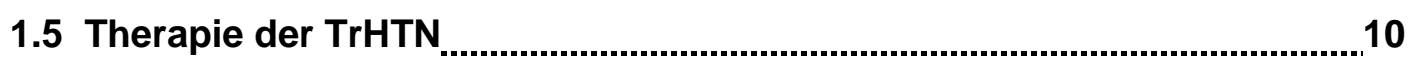

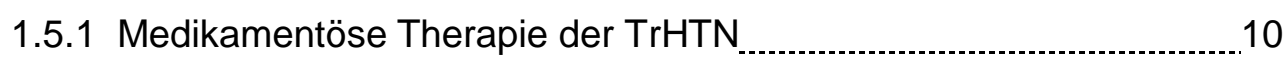

1.5.2 Invasiv-interventionelle Therapie der TrHTN _........................... 11

1.5.2.1 Die aktuelle Bewertung der renalen Denervierung..............11

1.5.2.2 Barorezeptorstimulationstherapie (BAT) ............................ 11

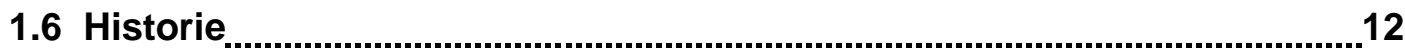

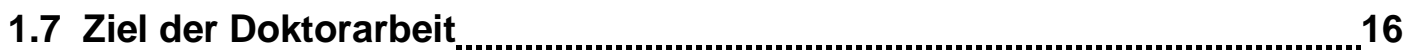

2. Material und Methoden

2.1 Verbrauchsmaterialien, Geräte und Software ....................................17

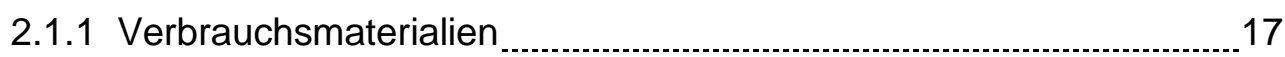

2.1.2 Geräte 18

2.1.3 Software und Datenbanken ............................................................ 19

2.2 Chemische und biologische Materialien ................................................20

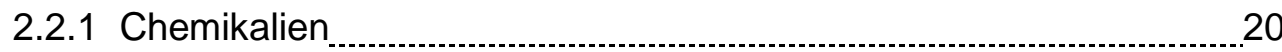

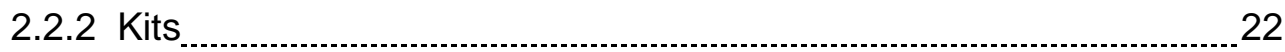

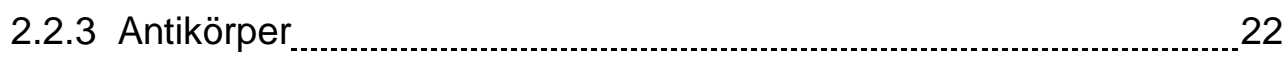

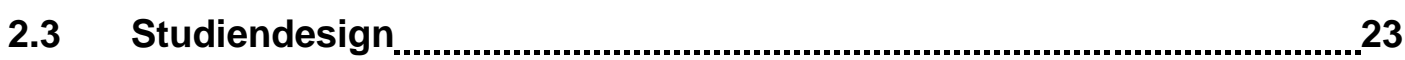

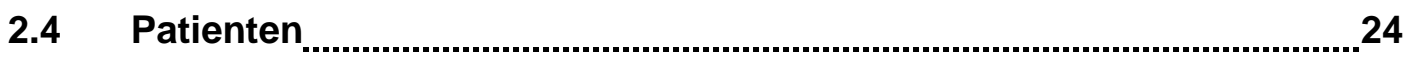

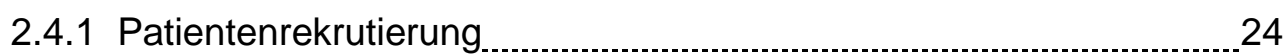

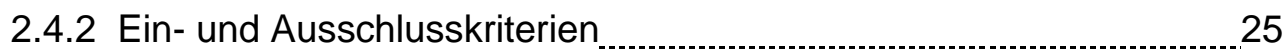

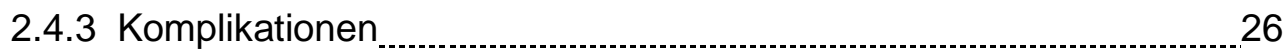

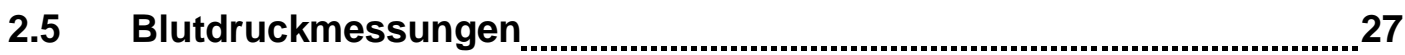

2.5.1 Blutdruck unter Praxisbedingungen (BuP) ....................................... 27

2.5.2 24-h Blutdruck-Messungen (ABPM) ............................................... 27

2.5.3 Definition von Therapie-Respondern ..............................................2 27 
2.6 Pulswellenanalyse und Bestimmung der Pulswellengeschwindigkeit (PWV) mittels Applanationstonometrie. 28

2.7 Routineanalysen und Probenverarbeitung .......................................30

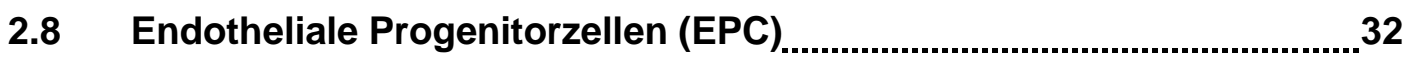

2.8.1 Analyse der EPC-Proliferationsfähigkeit .......................................... 32

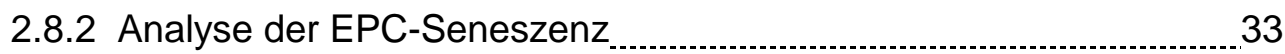

2.8.3 Analyse der EPC-Zellaktivität ....................................................... 35

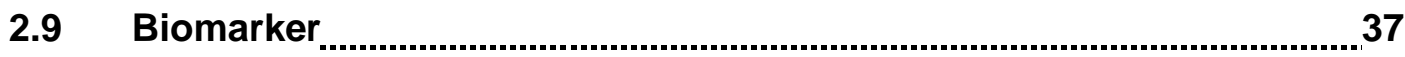

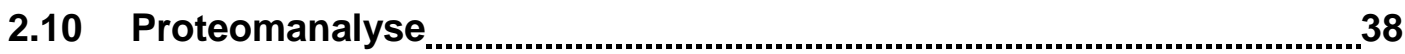

2.10.1 Proteinfällung, Proteinbestimmung und isoelektrische

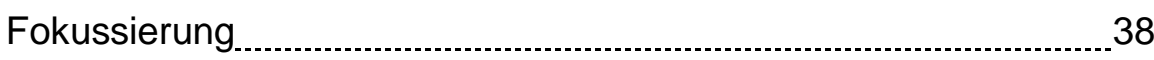

2.10.2 Zweidimensionale Proteinauftrennung (2D-DIGE) ......................... 40

2.10.3 Digitalisierung und Analyse der 2D-DIGE-Gele .............................. 41

2.10.4 Proteinverdau, MALDI-TOF-MS-Identifikation ..................................42

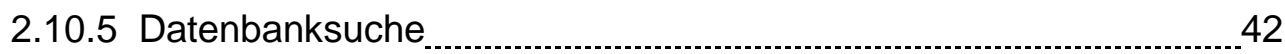

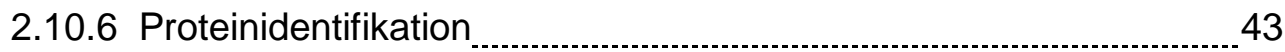

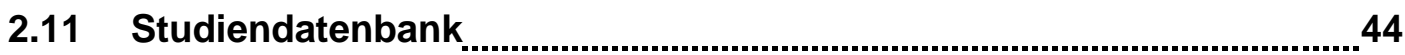

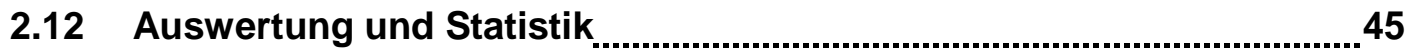

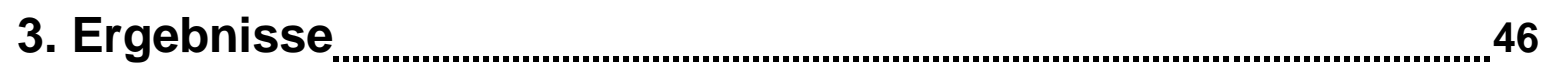

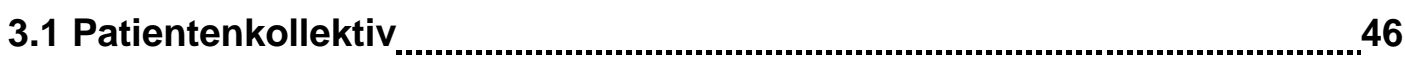

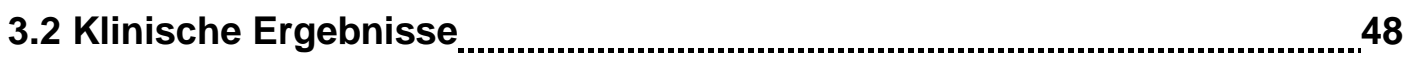

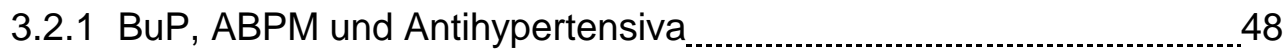

3.2.2 Patientencharakteristika, Symptome, Routineparameter .................. 51

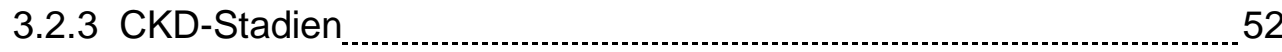

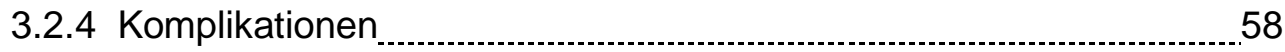

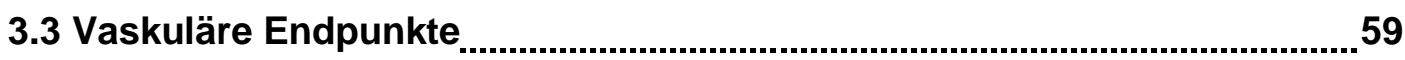

3.3.1 Pulswellenanalyse und Pulswellengeschwindigkeit ........................59

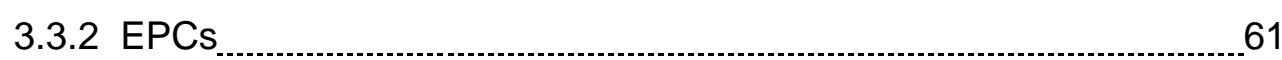

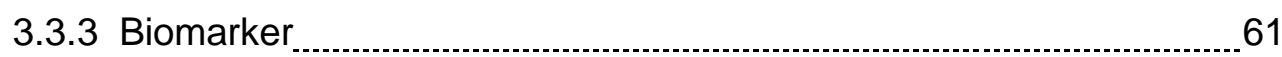

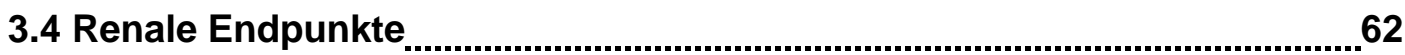

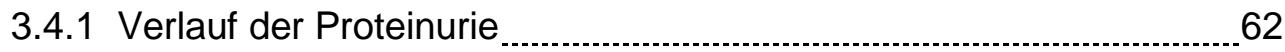

3.4.2 Verlauf der exkretorischen Nierenfunktionsparameter.......................65

3.4.3 Fraktionierte $\mathrm{Na}^{+}$-Ausscheidung, Renin-Aldosteron-Achse ...............66

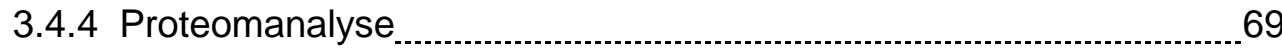


4. Diskussion

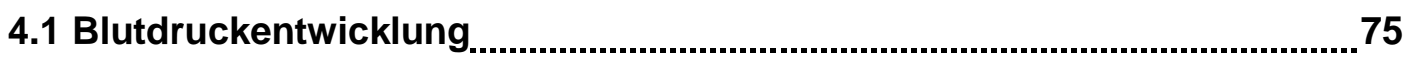

4.2 Responderrate und Medikation

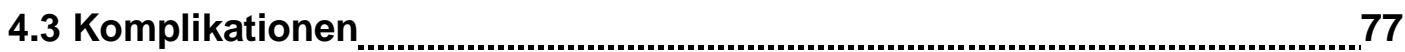

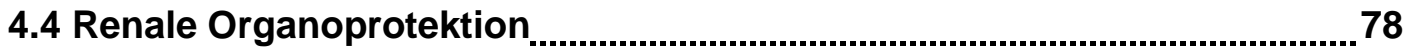

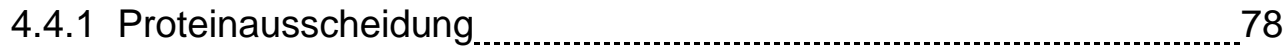

4.4.2 Renale Funktionsparameter

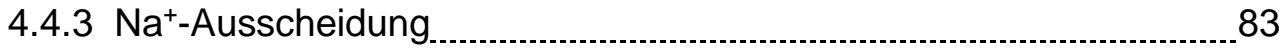

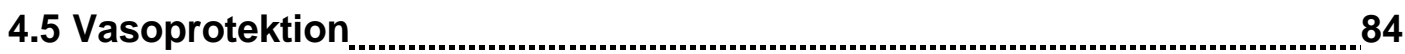

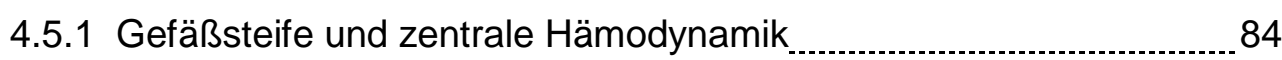

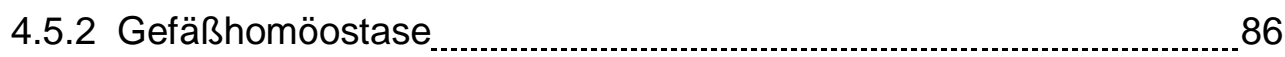

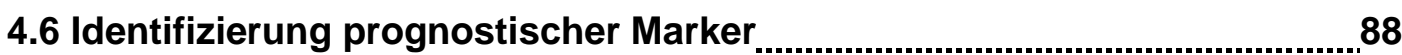

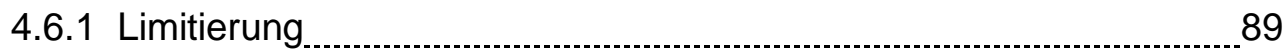

4.6.2 Ausblick auf eine potentielle Nephroprotektion .................................. 89

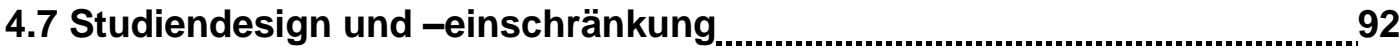

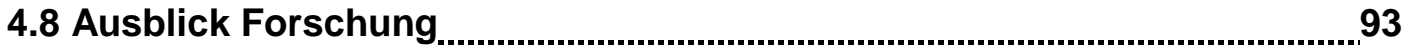

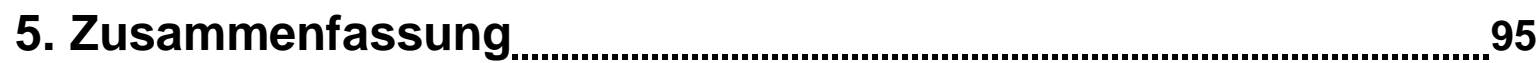

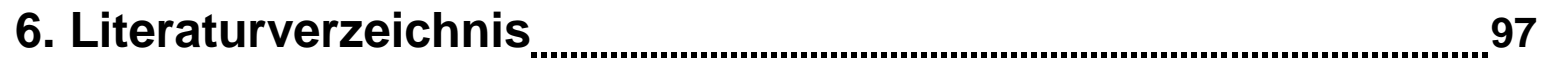

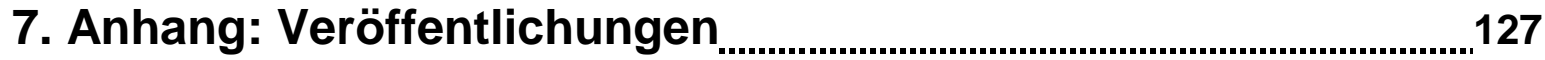




\section{Abbildungs- und Tabellenverzeichnis}

\section{Abbildungsnr. Titel}

Seite

\begin{tabular}{|lll|}
\hline 1.1 & Wirkung ausgewählter pro-und antiangiogener Biomarker auf die & 5 \\
\hline 1.2 & Implantationsort und Wirkweise der BAT & 12 \\
\hline 2.1 & Studiendesign & 23 \\
\hline 2.2 & Pulswellenanalyse im Rahmen der Studie & 29 \\
\hline 2.3 & Übersicht angewandter Methoden zur Charakterisierung der EPCs & 32 \\
\hline 2.4 & Morphologische Charakterisierung einzelner EPC-Kolonien & 33 \\
\hline 2.5 & Charakterisierung der EPC-Zellen mittels FACS-Messung & 34 \\
\hline 2.6 & Quantitative Bestimmung der EPC-Zellen mittels Laserscanner & 35 \\
\hline 2.7 & Visualisierung der EPC-Zellen mittels Laserscanner & 36 \\
\hline 2.8 & $\begin{array}{l}\text { Darstellung über die Verarbeitung der Urinproben und Erstellung der } \\
\text { 2D-DIGE-Gele }\end{array}$ & 39 \\
\hline 2.9 & Erstellung zweidimensionaler Gele & 41 \\
\hline 3.1 & Verlauf systolischer und diastolischer Werte des BuP im Zeitverlauf & 48 \\
\hline 3.2 & $\begin{array}{l}\text { Einfluss der RD auf den syst. BuP und des } \Delta \text { MAD sowie } \Delta \text { syst. BP } \\
\text { im zeitlichen Verlauf der ABPM }\end{array}$ & 50 \\
\hline 3.3 & Absenkung der Proteinurie und Albuminurie im Rahmen der BAT & 63 \\
\hline 3.4 & Veränderung der Proteinfraktionen im Verlauf der BAT & 63 \\
\hline 3.5 & $\begin{array}{l}\text { Beziehung zwischen systolischer BuP-Absenkung und Reduktion } \\
\text { der Albumin/Kreatinin-Ratio }\end{array}$ & 64 \\
\hline 3.6 & $\begin{array}{l}\text { Veränderung der Proteinurie im Vergleich zwischen den CKD- } \\
\text { Stadien I/II und III/IV }\end{array}$ & 64 \\
\hline 3.7 & $\begin{array}{l}\text { Beziehung zwischen systolischer BuP-Absenkung und Veränderung } \\
\text { der eGFR unter Anwendung der CKD-EPI Cystatin C-Formel }\end{array}$ & 65 \\
\hline 3.12 & $\begin{array}{l}\text { Geschätzte 24h-Na+-Exkretion (berechnet nach Kawasaki) } \\
\text { hinsichtlich der Einnahme von MCRAs }\end{array}$ & 67 \\
\hline Geschätzte 24h-Na+-Exkretion bei RD-Patienten mit und ohne der \\
\hline Einnahme von MCRAs zur Visit I und Visit II
\end{tabular}




\section{Tabellennr. Überschrift}

Seite

\begin{tabular}{|c|c|c|}
\hline 1.1 & Einteilung des Blutdrucks nach Schweregrad & 1 \\
\hline 1.2 & Endorganschäden der aHTN & 2 \\
\hline 1.3 & Risikofaktoren & 3 \\
\hline 1.4 & Ursachen sekundärer Hypertonieformen & 7 \\
\hline 1.5 & $\begin{array}{l}\text { Therapeutischer Zielblutdruck entsprechend aktuellen Leitlinien } \\
\text { verschiedener Fachgesellschaften }\end{array}$ & 8 \\
\hline 1.6 & Therapieregime in Abhängigkeit vom individuellen Risikoprofil & 9 \\
\hline 1.7 & Chronologische Übersicht ausgewählter Studien zum Thema BAT & 14 \\
\hline 2.1 & Ein- und Ausschlusskriterien & 25 \\
\hline 2.2 & Formeln renaler Funktionsparameter & 31 \\
\hline 2.3 & Erhobene Daten im Rahmen der Studie & $\overline{44}$ \\
\hline 3.1 & Patientencharakteristika & 47 \\
\hline 3.2 & Ergebnisse der BuP- und ABPM-Blutdruckmessungen und Responder & 49 \\
\hline 3.3 & Medikamentenübersicht & 50 \\
\hline 3.4 & Symptome & 51 \\
\hline 3.5 & Routineparameter & 52 \\
\hline 3.6 & Subgruppenanalyse von Patienten mit RD und ohne RD & 54 \\
\hline 3.7 & $\begin{array}{l}\text { Subgruppenanalyse von Patienten mit positiver Raucheranamnese } \\
\text { und Nichtrauchern }\end{array}$ & 55 \\
\hline 3.8 & $\begin{array}{l}\text { Subgruppenanalyse von Patienten mit Diabetes mellitus und } \\
\text { Nichtdiabetikern }\end{array}$ & 56 \\
\hline 3.9 & $\begin{array}{l}\text { Subgruppenanalyse zwischen Patienten mit weiblichem und } \\
\text { männlichem Geschlecht }\end{array}$ & 57 \\
\hline 3.10 & $\begin{array}{l}\text { Übersicht erhobener Komplikationen und Krankenhausaufenthalte im } \\
\text { Verlauf der BAT }\end{array}$ & 58 \\
\hline 3.11 & Ergebnisse der Pulswellenanalyse und - geschwindigkeit & 60 \\
\hline 3.12 & $\begin{array}{l}\text { Aortale Hämodynamik zweier Patienten nach initialem ON/OFF- } \\
\text { Versuch nach } 6 \text { Monaten BAT }\end{array}$ & 61 \\
\hline 3.13 & Serologische Biomarker & 62 \\
\hline 3.14 & Ergebnisse renaler Funktionsparameter & 68 \\
\hline 3.15 & $\begin{array}{l}\text { Spotvolumina der erfassten 2D-DIGE-Gel-Spots im Verlauf der BAT in } \\
\text { der D.m.-Gruppe }\end{array}$ & 70 \\
\hline 3.16 & Massenspektrometrisch analysierte Proteine & 72 \\
\hline 3.17 & Übersicht ausgewählter Proteine der Spots 23 und 36 & 74 \\
\hline 4.1 & Antiproteinurische Wirkung verschiedener Antihypertensiva & 79 \\
\hline 4.2 & $\begin{array}{l}\text { Übersicht renaler Funktionsparameter unter BAT versus RD in } \\
\text { verschiedenen Studien }\end{array}$ & 82 \\
\hline
\end{tabular}




\section{Abkürzungsverzeichnis}

2D-DIGE
6-MGT
AASK
ABPM
ACE
ACR
ADMA
aHTN
AIPRI
Aix
Aix@75
Ambic
AMBP
Ang-1
Ang-2
ANOVA
AV
BAT
BMI
BP
BuP
BSA
CAMs
CD
CFU
Chaps
CKD
CKD-EPI
CVD
CVRx
D. m.
DAPI
DBP
ddH $O$
DEBuT-HET
DGfN
DHB
DHL
DMF
D.m.-NP
DPTI
DTT
ECs
EDTA
EF

zweidimensionale differentielle Gelelektrophorese

6-Minuten-Geh-Test

African American Study of Kidney Disease and

Hypertension

ambulatory blood pressure monitoring/ambulante

Blutdruckmessung

angiotensin-converting-enzyme

Albumin-Kreatinin-Ratio

asymmetrisches Dimethylarginin

arterielle Hypertonie

ACE Inhibition in Progressive Renal Insufficiency Study

Augmentationsindex

korrigierter Augmentationsindex auf $75 / \mathrm{min}$

Ammoniumbicarbonat

$\alpha_{1}$-Mikroglobulin/Bikunin Precursor

Angiopoietin 1

Angiopoietin 2

analysis of variance/Varianzanalyse

atrioventrikulär

Barorezeptor-aktivierungs-/-stimulationstherapie body mass index/Körper-Massen-Index

blood pressure/Blutdruck

Blutdruck unter Praxisbedingungen (office-Blutdruck)

bovines serum-albumin

cell adhesion molecules/zelluläre Adhäsionsmoleküle

cluster of differentiation/Cluster der Differenzierung

colony forming units/Kolonie-bildende Einheiten

3- [(3-Cholamidopropyl) dimethylammonio]-propan-

sulfonat

chronic kidney disease/chronische Nierenerkrankung

Chronic Kidney Disease Epidemiology Collaboration

cardiovascular disease/kardiovaskuläre Erkrankungen

cardio vascular risks/kardiovaskuläre Risiken

Diabetes mellitus

4,6-Diamidin-2-phenylindol

diastolic blood pressure/diastolischer Blutdruck

destilliertes Wasser

Device Based Therapy in Hypertension Extension Trial

Deutsche Gesellschaft für Nephrologie

2,5-Dihydroxybenzoesäure

Deutsche Hochdruckliga

Dimethylformamid

diabetische Nephropathie

diastolic pressure time index/diastolischer Druck-Zeit Index

1,4 Dithiothreitol

endothelian cells/Endothelzellen

Ethylendiamintetraessigsäure

Ejektionsfraktion 
(e)GFR

eGFR-MDRD

EKG

ELISA

eNOS

EOS

EPC

ER

ERP57

ESC

ESH

ESRD

EZM

FACS

FITC

Flk-1

GRP78

$\mathrm{Hb}$

HBSS

$\mathrm{HCl}$

HOPE4HF

HTN-NP

ICAD

IDNT

$\lg$

IL-1b

IL-6

IP

IPG

IQR

JNC

KDIGO

KHK

LDL

L-FABP

$M A D$

MALDI-TOF-MS

MBP

MCRA

MDRD

MMP-9

MMPs

MNC's

$\mathrm{MOLCl}$

MOPS

MS (estimated) glomerular filtration rate/ (geschätzte)

glomeruläre Filtrationsrate

estimated glomerular filtration rate -modification of diet in renal disease

Elektrokardiographie

enzyme linked immunosorbent assay/Enzymimmunoassay

endotheliale Stickstoffmonoxid-Synthase

Endorganschäden

endothelial progenitor cells/endotheliale Vorläuferzellen

endoplasmatisches Retikulum

Protein disulfide-isomerase A3

European Society of Cardiology

European Society of Hypertension

end stage renal disease/terminales Nierenversagen

extrazelluläre Matrix

fluorescence activated cell sorting

fluorescein isothiocyanate

fetal liver kinase-1

$78 \mathrm{kDa}$ glucose-regulated protein

Hämoglobin

Hank's Balanced Salt Solution

Chlorwasserstoff

Health Outcomes Prospective Evaluation for Heart Failure with $\mathrm{EF} \geq 40 \%$

hypertensive Nephropathie

Inhibitor der Caspase-aktivierten DNase

Irbesartan Diabetic Nephropathy Trial

Immunoglobin

Interleukin 1b

Interleukin 6

Inflexionspunkt

immobilisierte $\mathrm{pH}$-Gradienten

interquartile range/Interquartilsabstand

Joint National Committee

Kidney Disease Improving Global Outcomes

koronare Herzerkrankung

low-density-lipoprotein

liver-type fatty acid-binding protein

mittlerer arterieller Druck

matrix assisted laser desorption ionization-time of flight-

mass spectrometry

mean blood pressure/mittlerer Blutdruck

Mineralokortikoidrezeptor-Antagonisten

modification of diet in renal disease

Matrix-Metallo-Proteinase 9

Matrix-Metallo-Proteinasen

mononukleäre Zellen

molecular \& optical live cell imaging

3 (N-Morpholino) Propansulfonsäure

mass spectrometry/Massenspektrometrie 


\begin{tabular}{|c|c|}
\hline MSDB & mass spectrometry protein sequences Datenbank \\
\hline MW & Mittelwert \\
\hline NCBInr & National Center for Biotechnology non-redundant \\
\hline NDM & Nicht-Diabetiker \\
\hline $\mathrm{NIH}$ & National Institutes of Health \\
\hline NO & Stickstoffmonoxid \\
\hline NTX & Nierentransplantation \\
\hline O. G. T. & oraler Glukose Toleranztest \\
\hline pAVK & periphere arterielle Verschluss Krankheit \\
\hline PBS & phosphate buffered saline \\
\hline PP & pulse pressure/Pulsdruck \\
\hline PWV & pulse wave velocity/Pulswellengeschwindigkeit \\
\hline RAAS & Renin-Angiotensin-Aldosteron-System \\
\hline RD & renale Denervierung \\
\hline REIN & Ramipril in non-diabetic renal failure \\
\hline RENAAL & $\begin{array}{l}\text { reduction of end-points in NIDDM with the Angiotensin II } \\
\text { antagonist Losartan }\end{array}$ \\
\hline RT & Raumtemperatur \\
\hline $\mathrm{RV}$ & rechtsventrikulär \\
\hline SBP & systolic blood pressure/systolischer Blutdruck \\
\hline (s)CAM-1 & $\begin{array}{l}\text { (soluble) cell adhesion molecules/(lösliche) } \\
\text { Zelladhäsionsmoleküle }\end{array}$ \\
\hline SD & standard deviation/Standardabweichung \\
\hline SDS & sodium dodecyl sulphate \\
\hline SEVR & subendokardiale Variabilitätsratio \\
\hline (s) ICAM-1 & $\begin{array}{l}\text { (soluble) intercellular adhesion molecule-1/(lösliches) inter- } \\
\text { zelluläres Adhäsionsmolekül } 1\end{array}$ \\
\hline Stabw. & Standardabweichung \\
\hline SPTI & systolic pressure time index/systolischer Druck-Zeit-Index \\
\hline (s) VCAM-1 & $\begin{array}{l}\text { (soluble) vascular cell adhesion molecule/lösliches } \\
\text { vaskuläres Zelladhäsionsmolekül }\end{array}$ \\
\hline syst. & Systolisch \\
\hline$(\Delta) S V$ & Spotvolumen (-Veränderung) \\
\hline TFA & Trifluoressigsäure \\
\hline TGF- $\beta_{1}$ & $\begin{array}{l}\text { transforming growth factor beta } 1 / \text { transformierender } \\
\text { Wachstumsfaktor beta1 }\end{array}$ \\
\hline TIA & transitorische ischämische Attacke \\
\hline TNF- $\alpha$ & Tumornekrosefaktor alfa \\
\hline TrHTN & Therapie-refraktäre Hypertonie \\
\hline TRIS & Tris(hydroxymethyl)-aminomethan \\
\hline UAKR & Urin-Albumin-Kreatinin-Ratio \\
\hline Ub52 & ubiquitin-60S ribosomal protein L40 \\
\hline UKPDS & United Kingdom Prospective Diabetes Study \\
\hline UMG & Universitätsmedizin Göttingen \\
\hline VEGF & $\begin{array}{l}\text { vascular endothelial growth factor/vaskulärer endothelialer } \\
\text { Wachstumsfaktor }\end{array}$ \\
\hline VEGF-FLT-1 & $\begin{array}{l}\text { vascular endothelial growth factor receptor -FMS like } \\
\text { tyrosine kinase } 1\end{array}$ \\
\hline VHF & Vorhofflimmern \\
\hline WHO & World Health Organization \\
\hline
\end{tabular}




\section{Einleitung}

Die arterielle Hypertonie ist eine der häufigsten Erkrankungen. Als führender Risikofaktor ist sie mit einem Anteil von 7\% an allen geschätzten krankheitsbedingten Todesfolgen und Behinderungen weltweit beteiligt (Lim et al. 2012). In Deutschland liegt ihre Prävalenz mit rund 55\% über dem europäischen Durchschnitt (Wolf-Maier et al. 2003), wobei durch den demographischen Wandel ein Anstieg der Prävalenz mit abnehmender Mortalität durch verbesserte medizinische Versorgung zu erwarten ist (Vasan et al. 2002).

Bei etwa 50\% der Hypertoniker ist der Bluthochdruck nicht diagnostiziert (Vasan et al. 2002) und bei mehr als der Hälfte aller bekannten Erkrankten nur mangelhaft eingestellt oder gar nicht therapiert (Wolf-Maier et al. 2003).

\subsection{Arterielle Hypertonie (aHTN)}

Laut gemeinsamer Kriterien der World Health Organization (WHO), European Society of Hypertension (ESH) und European Society of Cardiology (ESC) besteht eine aHTN, wenn die Blutdruckwerte unter Praxisbedingungen (BuP) dauerhaft über $140 \mathrm{mmHg}$ systolisch und $90 \mathrm{mmHg}$ diastolisch liegen (Mancia et al. 2007; WHO 2013). Je nach Ausmaß der Grenzwertüberschreitung, erfolgt die Einteilung der aHTN in verschiedene Schweregrade (siehe Tabelle 1) (Deutsche Gesellschaft für KardiologieHerz- und Kreislaufforschung e.V, Deutsche Hochdruckliga e.V. DHL, Deutsche Gesellschaft für Hypertonie und Prävention 2013; Mancia et al. 2013).

Tab. 1.1: Einteilung des Blutdrucks nach Schweregrad (nach Mancia et al. 2013, S.1286)

\begin{tabular}{|llll|}
\hline Gradeinteilung & systolisch & diastolisch \\
\hline Normal & $120-129 \mathrm{mmHg}$ & und/oder & $80-84 \mathrm{mmHg}$ \\
\hline Hochnormal & $130-139 \mathrm{mmHg}$ & und/oder & $85-89 \mathrm{mmHg}$ \\
\hline Grad 1 & $140-159 \mathrm{mmHg}$ & und/oder & $90-99 \mathrm{mmHg}$ \\
\hline Grad 2 & $160-179 \mathrm{mmHg}$ & und/oder & $100-109 \mathrm{mmHg}$ \\
\hline Grad 3 & $>180 \mathrm{mmHg}$ & und/oder & $>110 \mathrm{mmHg}$ \\
\hline Isolierte systolische Hypertonie & $\geq 140 \mathrm{mmHg}$ & und & $<90 \mathrm{mmHg}$ \\
\hline
\end{tabular}

Um die Diagnose einer aHTN zu stellen, bedarf es mindestens dreier ambulanter Gelegenheits-Blutdruckmessungen, die innerhalb von zwei Tagen und zeitlich 
voneinander getrennt durchzuführen sind. Neben diesem Verfahren zählt die 24Stunden-Blutdruckmessung (ABPM) inzwischen für Diagnostik und sichere Verlaufskontrolle zur präferierten Methode (Bakris et al. 2010).

\subsection{Endorganschäden der aHTN}

Die arterielle Hypertonie führt aufgrund ihrer systemischen Wirkung zu zahlreichen Endorganschäden (siehe Tabelle 1.2).

Tab. 1.2: Endorganschäden der aHTN (abgewandelt nach Schmieder 2010, S. 867)

\begin{tabular}{|c|c|}
\hline $\begin{array}{l}\text { Vaskulopathie } \\
\text { - } \text { endotheliale Dysfunktion } \\
\text { - } \text { Remodeling } \\
\text { - generalisierte Atherosklerose } \\
\text { - } \text { atherosklerotische Stenose } \\
\text { - } \text { Aortenaneurysma }\end{array}$ & $\begin{array}{l}\text { Nephropathie } \\
\text { - Albuminurie/Proteinurie } \\
\text { - } \text { chronische Niereninsuffizienz } \\
\text { - } \quad \text { Nierenversagen }\end{array}$ \\
\hline $\begin{array}{l}\text { Herzerkrankung(1) } \\
\text { - } \quad \text { linksventrikuläre Hypertrophie } \\
\text { - } \quad \text { Vorhofflimmern } \\
\text { - } \quad \text { koronare Mikroangiopathie } \\
\text { - } \quad \text { KHK, Myokardinfarkt } \\
\text { - } \quad \text { Herzinsuffizienz } \\
\text { Stoffwechsel } \\
\text { - } \quad \text { Insulinresistenz }\end{array}$ & $\begin{array}{l}\text { Zerebrovaskuläre Schädigung( } \\
\text { - } \quad \text { akute hypertensive Enzephalopathie } \\
\text { - Schlaganfall } \\
\text { - intrazerebrale Blutung } \\
\text { - } \quad \text { vaskuläre Demenz } \\
\text { - Retinopathie }\end{array}$ \\
\hline
\end{tabular}

(1)Collins und MacMahon 1994; Verdecchia et al. 1990; (2)Feigin et al. 2005; Finnerty 1972; Pache et al. 2002; (3) Martell et al. 2003; KHK = koronare Herzerkrankung

Hinsichtlich renaler Veränderungen kommt es, abhängig von Dauer und Schwere der aHTN, renaler Vorschädigung sowie anderer Risikofaktoren (siehe Tabelle 1.3) zur benignen oder malignen Nephrosklerose (hypertensive Nephropathie) (Caetano et al. 2001). Hierbei bewirkt die renale Druckbelastung, durch die Aktivierung zellulärer Stresssignale, eine Hochregulation der extrazellulären Matrix-Produktion (Peng et al. 2007). Diese führt zu nicht-entzündlichen Umbauprozessen (Remodeling) in der gesamten Niere, welche durch Fibrosierung, Sklerosierung und Hyalinose gekennzeichnet sind. Als Frühzeichen einer hypertensiven Nephropathie gilt eine erhöhte Eiweißausscheidung (Mikroalbuminurie $30-300 \mathrm{mg} / 24 \mathrm{~h}$ oder ein Albumin/Kreatinin-Quotient bei Männern bzw. Frauen $\geq 22 \mathrm{mg} / \mathrm{g}$ und $\geq 31 \mathrm{mg} / \mathrm{g}$ Kreatinin) sowie Kreatininclearance $<60 \mathrm{ml} / \mathrm{min}$, bedingt durch eine glomeruläre 
Schrankenstörung (Schmieder 2010). Eine pathologische Albuminurie deutet hierbei nicht nur auf renale Umbauprozesse hin, sondern reflektiert Veränderungen des gesamten arteriellen Gefäßsystems. So stellt eine erhöhte Albuminurie sowohl einen Prädiktor für die Entstehung und das Voranschreiten einer Niereninsuffizienz als auch für kardiovaskuläre Komplikationen dar (Mann et al. 2001; Schmieder et al. 2006).

Tab. 1.3: Risikofaktoren

\begin{tabular}{|l|}
\hline \multicolumn{1}{|c|}{ Kardiovaskuläre RF } \\
\hline Nicht-beeinflussbar \\
- Alter \\
- Geschlecht \\
- familiäre Belastung \\
beeinflussbar \\
- Nikotinkonsum \\
- aHTN \\
- Hypercholesterämie \\
- Diabetes mellitus \\
- Adipositas \\
- Stress \\
- Bewegungsmangel \\
- Ethnie \\
\hline Spezielle renale RF \\
- Proteinurie \\
- verminderte Niedrenfunktion sozioökonomischer Status \\
\hline RF = Risikofaktoren, aHTN = arterielle Hypertonie
\end{tabular}

Neben zahlreichen anderen Risikofaktoren (siehe Tabelle 1.3) nimmt die aHTN wesentlichen Anteil an der Schädigung und dem Fortschreiten vaskulärer Umbauprozesse. Die dabei wirkende Dauerbelastung auf die innerste Wandschicht des Gefäßsystems, das Endothel, ist dabei Ausgangspunkt kardiovaskulärer Erkrankungen und deren Komplikationen. In der Folge kommt es zur Endothelzellapoptose und zu feinsten Läsionen, in denen sich subendotheliale LDL (low density lipoprotein)-Plaques, als Ausgang einer Atherosklerose, bilden. Häufige Begleiterscheinungen der Atherosklerose sind chronisch unterschwellige Entzündungsprozesse der Gefäßwand, welche, durch Immunprozesse vermittelt, ein Fortschreiten der Organschäden fördern (Chae et al. 2001; Okazaki et al. 2014; Virdis und Schiffrin 2003). Wichtiger Trigger ist hierbei die Wirkung von $\mathrm{O}_{2}$-Radikalen, die, durch Gefäßwandstress ausgelöst, eine Expression proinflammatorischer Zytokine wie Tumornekrosefaktor $\alpha$ (TNF- $\alpha$ ) und Interleukin 6 (IL-6) induzieren (Acton et al. 
2002; Cottone et al. 2007; Michell et al. 2011, Virdis et al. 2014). Durch eine Endothelzellaktivierung kommt es zur Expression zellulärer Adhäsionsmoleküle (CAMs) auf der Endotheloberfläche, die Voraussetzung zum „Rolling“, also der Anheftung sowie der Migration von Leukozyten und Monozyten am Endothel, sind (Riou et al. 2007; Shalia et al. 2009). Die daraus entstehenden Schaumzellen sind Grundlage atherosklerotischer Plaques.

Eine Schlüsselrolle zur Aufrechterhaltung des physiologischen Gefäßmilieus wird dem Enzym eNOS (endotheliale Stickstoffmonoxid-Synthase) zugeschrieben. Dieses produziert Stickstoffmonoxid (NO) in ortsständigen Endothelzellen (ECs), welches über vasoprotektive Mechanismen entscheidenden Einfluss auf die Gefäßhomöostase nimmt. Über Diffusion vermittelt, bewirkt es eine Relaxation glatter Gefäßwandmuskelzellen und nimmt über eine Vasodilatation bedeutenden Einfluss auf die Blutdruckregulation (Förstermann 1986; Rapoport et al. 1983). Des Weiteren hemmt es die Plättchenaggregation (Alheid et al. 1987; Busse et al. 1987), Adhäsion und Migration von Leukozyten am Gefäßlumen, welche initiale Trigger bei der Entstehung von atherosklerotischen Plaques sind (Kubes et al. 1991). Darüber hinaus verhindert NO die Oxidation von LDL-Cholesterinen in Fresszellen, die wesentliche Bausteine bei der Entwicklung von Atherosklerose (Bonetti et al. 2003) sind und zusätzlich auf glatte Muskelzellen antiproliferativ und daher einer Gefäßverengung entgegenwirken (Garg und Hassid 1989). Der Verlust oder die Fehlfunktion der eNOS (Mueller et al. 2005) hat folglich eine zentrale Bedeutung bei der Entstehung von Gefäßkrankheiten und wird als endotheliale Dysfunktion bezeichnet (Zhang et al. 2013).

Infolge der o.g. Veränderungen und der abgeänderten Hämodynamik (Magid et al. 2003), der gesteigerten Entzündungsprozesse und Verletzungen sowie des oxidativen Stresses kommt es zu vaskulären und kardialen Umbauprozessen der extrazellulären Matrix (EZM), auch „Remodeling“ genannt (Intengan und Schiffrin 2001; Lehoux et al. 2004). Bedingt durch ein Ungleichgewicht gewebsstabilisierender Faktoren, hin zu gewebsabbauenden Mediatoren, kann es im Verlauf zu pathologischen Veränderungen kommen (Galis et al. 1994). Protagonisten in diesem Geschehen sind die Matrix-Metallo-Proteinasen (MMPs), welche durch den Abbau von Kollagenen und anderen Bestandteilen der EZM eine Veränderung ihrer Dichte, Zusammensetzung und Architektur bewirken. 


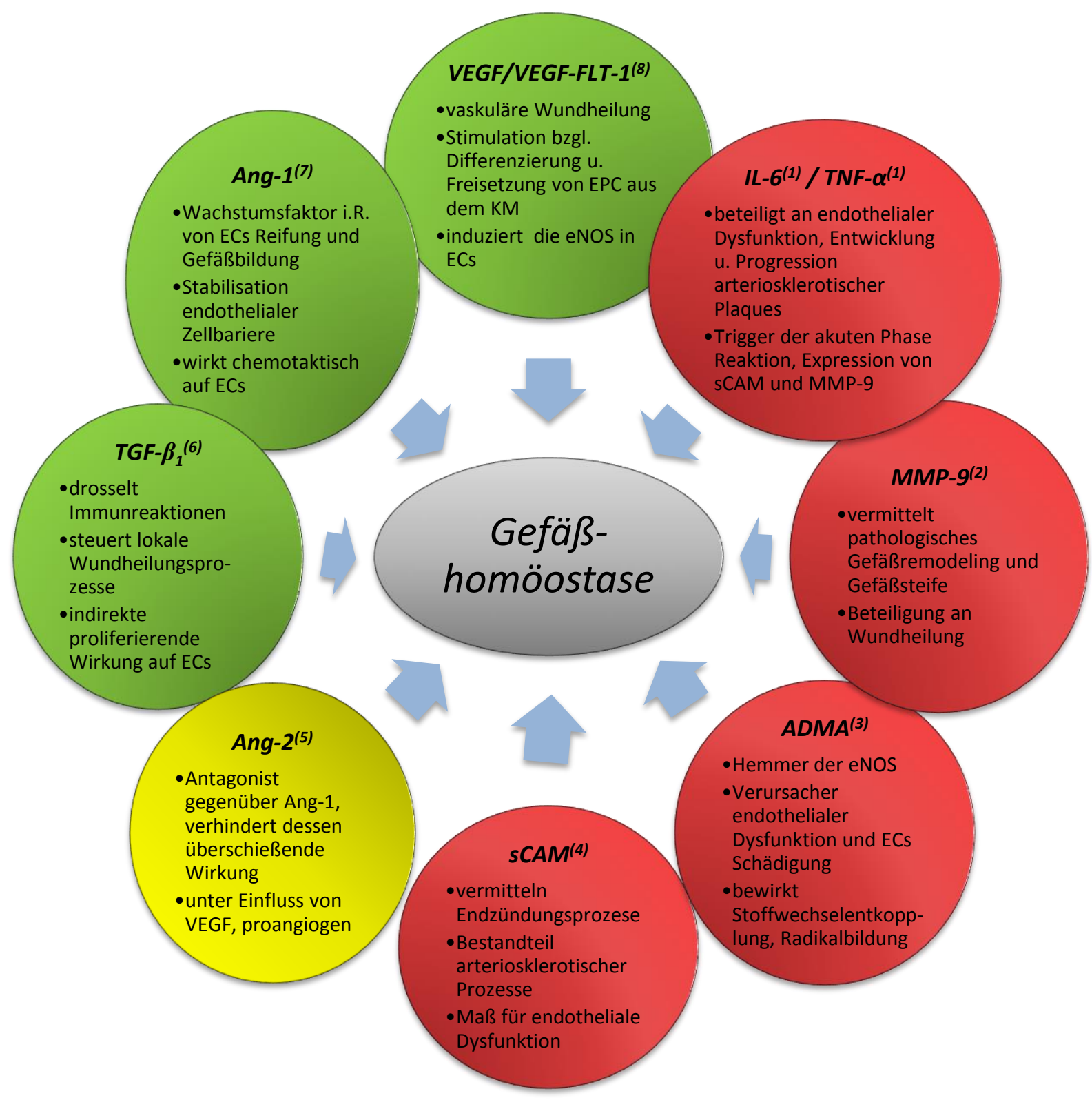

Abb. 1.1 Wirkung ausgewählter pro-und antiangiogener Biomarker auf die Gefäßhomöostase (rot) antiangiogen: ${ }^{(1)} / L-6 / T N F-\alpha=$ Interleukin 6/ Tumornekrosefaktor $\alpha$ (Harris et al. 1999; Romano et al. 1997; Schuett et al. 2009), (2) MMP-9 = Matrix-Metallo-Proteinas 9 (Brown et al. 1995; Buisson et al. 1996; Dhingra et al. 2009; Galis und Khatri 2002; Kobayashi et al. 2014; Mohan et al. 2002), ${ }^{(3)} A D M A=$ asymmetrisches Dimethylarginin (Cooke 2005; Perticone et al. 2005; Schnabel et al. 2005), ${ }^{(4)}$ sCAM = soluble cell adhesion molecules (Acton et al. 2002; Cottone et al. 2007; Kjaergaard et al. 2013; Shalia et al. 2009); (gelb) anti- und proangiogen ${ }^{(5)}$ Ang-2 = Angiopoitin 2 (Lobov et al. 2002); (grün) proangiogen: (6) TGF- $\beta_{1}=$ tissue growth factor $\beta_{1}$ (Roberts 1995; Wahl et al. 1987; Wahl et al. 1988), ${ }^{(7)}$ Ang-1 = Angiopoitin 1 (Suri et al. 1998; Thurston et al. 2000; Thurston 2002), ${ }^{(8)}$ VEGF/ VEGF-FLT-1 = vascular endothelial growth factor/vascular endothelial growth factor receptor -FMS like tyrosine kinase 1 (Asahara et al. 1999; Bussolati et al. 2001; Gill et al. 2001); KM = Knochenmark; bzgl. = bezüglich; u. = und; i.R. = im Rahmen; EPCs = endotheliale Progenitorzellen; eNOS = endotheliale Stickstoffmonoxid-Synthase; ECs = Endothelzellen

Dem gegenüber stehen pro-angiogene vaskuläre Wachstumsfaktoren, wie Angiopoietin 1 (Ang-1) (Suri et al. 1998; Thurston et al. 2000), Angiopoietin 2 (Ang-2) (Lobov et al. 2002), tissue growth factor $\beta_{1}$ (TGF- $\beta_{1}$ ) (Roberts 1995; Wahl et al. 1987), vascular endothelial growth factor receptor-FMS like tyrosine kinase 1 (VEGF- FLT- 1) und vascular endothelial growth factor (VEGF) (Asahara et al. 1999; Bussolati et al. 
2001; Gill et al. 2001), mit der Fähigkeit, vaskuläre Heilungsprozesse zu initiieren und zu steuern. Diese sollen einer fortschreitenden Gefäßschädigung entgegenwirken. Die wechselseitigen Wirkungen der verschiedenen Mediatoren sind in Abbildung 1.1 dargestellt.

Ein wichtiger Mechanismus zur Wiederherstellung und Aufrechterhaltung der Gefäßintegrität nutzt pluripotente, hämatopoetische, endotheliale Vorläuferzellen (EPCs, endothelial progenitor cells), welche durch lokale Mediatoren, wie z.B. VEGF aus dem Knochenmark, freigesetzt werden (Asahara et al. 1999). Im Blutsystem zirkulierend, haben sie die Eigenschaft, sich an das Gefäßlumen anlagern zu können und in ortständige Endothelzellen zu differenzieren (Bailey et al. 2004). Diese beteiligen sich an regenerativen Prozessen des Endothels, der Wiederherstellung ihrer Funktionalität und nehmen Einfluss auf Angiogenese sowie andere physiologische Gefäßprozesse (Asahara et al. 1997). Dank mikro- und makrovaskulärer Reparaturmechanismen tragen die EPCs daher zur Aufrechterhaltung des arteriellen Gefäßwandstoffwechsels - der vaskulären Homöostase - entscheidend bei (Khakoo und Finkel 2005).

\subsection{Therapie-refraktäre Hypertonie (TrHTN)}

Per definitionem liegt eine TrHTN dann vor, wenn die für die verschiedenen Patientengruppen definierten Zielblutdruckwerte - unter Verwendung einer antihypertensiven Dreifachmedikation - bei maximaler Dosierung und zusätzlichem Diuretikum nicht erreicht werden können (Deutsche Gesellschaft für Kardiologie-Herzund Kreislaufforschung e.V, Deutsche Hochdruckliga e.V. DHL, Deutsche Gesellschaft für Hypertonie und Prävention 2013).

Neben iatrogenen und patientenseitigen Ursachen müssen sekundäre Hypertonieformen ausgeschlossen werden (siehe Tab.1.4). Mit einem Anteil von etwa 4-19\% aller Bluthochdruckkranken (Alderman et al. 1988; Calhoun et al. 2008; Leshem et al. 2002; Reincke et al. 2009) weisen Patienten mit TrHTN - im Vergleich zu Patienten mit kontrollierten Blutdrücken - ein 2,7-fach erhöhtes Risiko für kardiovaskuläre Ereignisse auf (Isaksson und Ostergren 1994) und büßen deutlich an Lebensqualität ein. 
Tab. 1.4: Ursachen sekundärer Hypertonieformen (abgewandelt von Holzgreve H. et al. 1996, S. A2550)

\section{Ursachen einer Therapie-refraktären Hypertonie}

\begin{tabular}{|l|l|}
\hline Der Patient als Ursache & latrogen \\
\hline - mangelnde Therapietreue & $\bullet \quad$ inadäquate Therapie \\
- Einnahme entgegen der Verordnung & $\bullet \quad$ Arzneimittelinteraktionen \\
- keine Gewichtsreduktion & $\bullet \begin{array}{l}\text { mangelnde Informationen des } \\
\text { - } \text { Patienten }\end{array}$ \\
- hohe Kochsalzzufuhr & \\
- seker Alkoholkonsum & \\
- Nierenarterienstenose & \\
- Reno-parenchymatöse & \\
- Erkrankungen & \\
- Phimärer Hyperaldosteronismus & \\
- Hyperthyreose & \\
- Cushing-Syndrom & \\
- Schlafapnoesysndrom & \\
Pseudorefaktärität & \\
- Weißkittelsyndrom & \\
\hline
\end{tabular}

\subsection{Therapie der aHTN}

In Hinblick auf das breite Spektrum möglicher Endorganschäden und relevanter Langzeitfolgen ist die aHTN auch als Multiorganerkrankung zu verstehen. Wie wichtig dabei eine optimale Bluthochdrucktherapie ist (siehe Tabelle 1.5), veranschaulichten in den letzten Jahren zahlreiche Studien (Gueyffier et al. 1997). So konnte gezeigt werden, dass eine Minderung des arteriellen Bluthochdrucks von $20 \mathrm{mmHg}$ systolisch und $10 \mathrm{mmHg}$ diastolisch zu einer Halbierung des kardiovaskulären Risikos führt (Collins et al. 1990; Lewington et al. 2002; Neal et al. 2000). Von prognostischer Relevanz ist 1 . eine frühe Diagnosestellung und 2. eine konsequent eingeleitete Therapie in den individuellen Zielblutdruckbereich des Patienten (Collins und MacMahon 1994).

Wichtiger Baustein für eine erfolgreiche Bluthochdruckbehandlung ist die Einbeziehung des Patienten in das Therapieregime, vorzugsweise durch eine Veränderung von Lebensstil und Einschränkung beeinflussbarer Risikofaktoren (siehe Tabelle 1.3).

So bewirken die Regulation der Kochsalzzufuhr durch die Nahrungsmittelaufnahme, Gewichtsreduktion (Sacks et al. 2001; Vollmer et al. 2001), Einschränkung des Alkoholkonsums (Xin et al. 2001), Raucherentwöhnung und Ausdauertraining (Kelley 
und Kelley 2000; Whelton et al. 2002) eine effektive Senkung des Bluthochdrucks im Bereich von $11 \mathrm{mmHg}$ systolisch (Elmer et al. 2006). Ergänzend sollte eine optimale Stoffwechselführung mittels medikamentöser Maßnahmen bei Vorliegen von Diabetes mellitus, Hypercholesterinämie (Cushman et al. 2002) und Hyperurikämie (Feig et al. 2006) forciert werden.

Tab. 1.5: Therapeutischer Zielblutdruck entsprechend aktuellen Leitlinien verschiedener Fachgesellschaften

\begin{tabular}{|c|c|c|}
\hline $\begin{array}{l}\text { Zielblut- } \\
\text { druck }\end{array}$ & Ohne Vorerkrankungen & Hochrisikopatienten \\
\hline $\begin{array}{l}\mathrm{ESC} / \mathrm{ESH}^{(1)} \\
\mathrm{DHL}^{(2)}\end{array}$ & $\begin{array}{l}\text { < } 80 \text { Jahre: } \\
\text { 140-150/<90 mmHg (wenn BP } \geq 160 \mathrm{mmHg}) \\
<140 / 90 \mathrm{mmHg} \text { (wenn Pat. leistungsfähig) } \\
\text { > } 80 \text { Jahre: } \\
\text { 140-150/<90 mmHg (wenn BP } \geq 160 \mathrm{mmHg} \text { ) }\end{array}$ & $\begin{array}{ll}\text { Diabetes mellitus: } & <140 /<85 \mathrm{mmHg} \\
\text { CKD } \pm \text { D.m. : } \quad<140 /<85 \mathrm{bzW} .<90 \mathrm{mmHg} \\
\text { CKD + Prot.: } \geq 300 \mathrm{mg} / \mathrm{d}:<130 / \mathrm{k} . \mathrm{A} . \mathrm{mmHg} \\
\text { KHK: } & <140 /<90 \mathrm{mmHg} \\
\text { Z.n. TIA oder SA.: } & <140 /<90 \mathrm{mmHg} \\
\text { CVR (niedrig-erhöht): } & <140 /<90 \mathrm{mmHg}\end{array}$ \\
\hline JNC $8^{(3)}$ & $\begin{array}{l}<140 /<90 \mathrm{mmHg} \\
<150 /<90 \mathrm{mmHg}\end{array}$ & $\begin{array}{l}\geq 18 \text { Jahre + D. m.: } \\
\geq 18 \text { Jahre + CKD: }\end{array}$ \\
\hline $\mathrm{ASH} / \mathrm{ISH}^{(4)}$ & $\begin{array}{l}\text { Junge Erwachsene: } \\
\geq 80 \text { Jahre: }\end{array}$ & $\begin{array}{l}\text { D.m.: } \\
\text { KHK: } \\
\text { CKD: } \\
\text { CKD + Albuminurie: }\end{array}$ \\
\hline $\mathrm{NICE}^{(5)}$ & $\begin{array}{lr}<80 \text { Jahre: } & <140 / 90 \mathrm{mmHg} \\
<80 \text { Jahre: } & <135 / 85 \mathrm{mmHg}(\text { ABPM) } \\
\geq 80 \text { Jahre: } & <150 / 90 \mathrm{mmHg} \\
\geq 80 \text { Jahre: } & <145 / 85 \mathrm{mmHg} \text { (ABPM) }\end{array}$ & k. A. \\
\hline $\mathrm{KDIGO}^{(6)}$ & $\begin{array}{l}\text { CKD ohne Diabetes mellitus } \\
\text { Albuminurie }<30 \mathrm{mg} / 24 \mathrm{~h}: \leq 140 / \leq 90 \mathrm{mmHg} \\
\text { Albuminurie } 30-300 \mathrm{mg} / 24 \mathrm{~h}: \leq 130 / \leq 80 \mathrm{mmHg} \\
\text { Albuminurie }>300 \mathrm{mg} / 24 \mathrm{~h}: \leq 130 / \leq 80 \mathrm{mmHg}\end{array}$ & $\begin{array}{l}\text { CKD mit Diabetes mellitus / NTX* } \\
\text { Albuminurie }<30 \mathrm{mg} / 24 \mathrm{~h}: \leq 140 / \leq 90 \mathrm{mmHg} \\
\text { Albuminurie }>30 \mathrm{mg} / 24 \mathrm{~h}: \leq 130 / \leq 80 \mathrm{mmHg} \\
\text { unabhängig von Albumin*: } \leq 130 / \leq 80 \mathrm{mmHg}\end{array}$ \\
\hline
\end{tabular}

$\mathrm{ESC}=$ European Society of Hypertension, ESC $=$ European Society of Cardiology, DHL $=$ Deutsche

Hochdruckliga, $\mathrm{JNC}=$ Joint National Committee, $\mathrm{ASH}=$ American Society of Hypertension, ISH = International Society of Hypertension, NICE = National Institute for Health and Care Excellence, KDIGO $=$ Kidney Disease Improving Global Outcomes, $\mathrm{BP}=$ Blutdruck, Pat. $=$ Patient, $\mathrm{CKD}=$ chronic kidney disease, $\mathrm{ABPM}=$ ambulant blood pressure monitoring, NTX = Nierentransplantation, k.A. = keine Angabe, $\mathrm{KHK}=$ koronare Herzerkrankung, D.m. = Diabetes mellitus, Z.n. $=$ Zustand nach, $\mathrm{CVR}=$ kardiovaskuläre Risikofaktoren, $\mathrm{TIA}=$ transitorische ischämische Attacke, SA = Schlaganfall, Prot. = Proteinurie; (1)Mancia et al. 2013; (2)Deutsche Gesellschaft für Kardiologie-Herz- und Kreislaufforschung e.V, Deutsche Hochdruckliga e.V. DHL, Deutsche Gesellschaft für Hypertonie und Prävention 2013; (3) James et al. 2014; (4)Weber et al. 2014; (5)NICE 2011; (6) Verbeke et al. 2014, KDIGO Blood Pressure Work Group 2012

Wird der Zielblutdruck (siehe Tabelle 1.5) durch Allgemeinmaßnahmen oder individuell erhöhtes Risikoprofil nicht erreicht, ist eine medikamentöse Bluthochdrucktherapie gemäß den Leitlinien indiziert (siehe Tabelle 1.6). Zur Anwendung kommt klassischerweise ein Diuretikum in Kombination mit einem Antihypertonikum der 1. Wahl. Als typische Kombinationspartner sind die ACE-Hemmer, AngiotensinRezeptorblocker, langwirksame Kalziumantagonisten und Betablocker zu nennen (Mancia et al. 2007). Wird ungeachtet der Ausdosierung der Zielblutdruck nicht 
erreicht, sollte eine Dreifach-Kombination unter Hinzuziehung eines weiteren Antihypertonikums folgen.

Führt auch eine ausdosierte Dreifach-Kombination mit zusätzlichem Diuretikum zu

keiner adäquaten Blutdrucksenkung, besteht per definitionem eine TrHTN.

Tab. 1.6: Therapieregime in Abhängigkeit vom individuellen Risikoprofil (nach Leitlinien für das Management der arteriellen Hypertonie, deutsch, 2013, S.24-25)

\begin{tabular}{|c|c|c|c|c|}
\hline \multirow{2}{*}{$\begin{array}{c}\text { RF, } \\
\text { asymptomatische } \\
\text { Endorganschäden } \\
\text { (EOS) oder } \\
\text { Erkrankungen }\end{array}$} & \multicolumn{4}{|c|}{ Blutdruck (BP) in $\mathrm{mmHg}$} \\
\hline & $\begin{array}{c}\text { hochnormal } \\
\text { SBP 130-139 } \\
\text { oder DBP } 85-89\end{array}$ & $\begin{array}{c}\text { Grad } 1 \text { HTN } \\
\text { SBP 140-159 } \\
\text { oder DBP 90-99 }\end{array}$ & $\begin{array}{c}\text { Grad } 2 \text { HTN } \\
\text { SBP 160-179 } \\
\text { oder DBP 100-109 }\end{array}$ & $\begin{array}{c}\text { Grad } 3 \text { HTN } \\
\text { SBP } \geq 180 \text { oder } \\
\text { DBP } \geq 110\end{array}$ \\
\hline keine anderen RF & $\begin{array}{c}\text { keine } \\
\text { BP- Maßnahmen }\end{array}$ & $\begin{array}{l}\text { - Lebenstiländerung } \\
\text { über einige } \\
\text { Monate } \\
\text { - anschließend } \\
\text { BP- Medikamente, } \\
\text { Zielwert <140/90 }\end{array}$ & $\begin{array}{l}\text { - Lebenstiländerung } \\
\text { über einige } \\
\text { Wochen } \\
\text { - } \quad \text { anschließend } \\
\text { BP- Medikamente, } \\
\text { Zielwert <140/90 }\end{array}$ & $\begin{array}{l}\text { - } \quad \text { Lebenstiländerung } \\
\text { - } \quad \text { umgehend } \\
\text { BP-Medikamente, } \\
\text { Zielwert <140/90 }\end{array}$ \\
\hline 1-2 RF & $\begin{array}{l}\text { - Lebenstiländerung } \\
\text { - } \quad \text { keine } \\
\text { BP-Maßnahmen }\end{array}$ & $\begin{array}{l}\text { - Lebenstiländerung } \\
\text { über einige } \\
\text { Wochen } \\
\text { - anschließend } \\
\text { BP- Medikamente, } \\
\text { Zielwert <140/90 }\end{array}$ & $\begin{array}{l}\text { - Lebenstiländerung } \\
\text { über einige } \\
\text { Wochen } \\
\text { - } \quad \text { anschließend } \\
\text { BP- Medikamente, } \\
\text { Zielwert <140/90 }\end{array}$ & $\begin{array}{l}\text { - } \quad \text { Lebenstiländerung } \\
\text { - } \quad \text { umgehend } \\
\text { BP-Medikamente, } \\
\text { Zielwert <140/90 }\end{array}$ \\
\hline$\geq 3 \mathrm{RF}$ & $\begin{array}{l}\text { - Lebenstiländerung } \\
\text { - keine } \\
\text { BP-Maßnahmen }\end{array}$ & $\begin{array}{l}\text { - Lebenstiländerung } \\
\text { über einige } \\
\text { Wochen } \\
\text { - anschließend } \\
\text { BP- Medikamente, } \\
\text { Zielwert <140/90 } \\
\end{array}$ & $\begin{array}{l}\text { - Lebenstiländerung } \\
\text { - BP-Medikamente, } \\
\text { Zielwert <140/90 }\end{array}$ & $\begin{array}{l}\text { - } \quad \text { Lebenstiländerung } \\
\text { - } \quad \text { umgehend } \\
\text { BP-Medikamente, } \\
\text { Zielwert <140/90 }\end{array}$ \\
\hline $\begin{array}{l}\text { EOS, CKD St.3 } \\
\text { oder Diabetes }\end{array}$ & $\begin{array}{l}\text { - Lebenstiländerung } \\
\text { - keine } \\
\text { BP-Maßnahmen }\end{array}$ & $\begin{array}{l}\text { - Lebenstiländerung } \\
\text { - } \quad \text { BP-Medikamente, } \\
\text { Zielwert < } 140 / 90\end{array}$ & $\begin{array}{l}\text { - Lebenstiländerung } \\
\text { - } \quad \text { BP-Medikamente, } \\
\text { Zielwert < } 140 / 90\end{array}$ & $\begin{array}{ll}\text { - } & \text { Lebenstiländerung } \\
\text { - } & \text { umgehend } \\
& \text { BP-Medikamente, } \\
& \text { Zielwert }<140 / 90 \\
\end{array}$ \\
\hline $\begin{array}{c}\text { symptomatische } \\
\text { CVD, CKD St. } \geq 4 \\
\text { oder Diabetes mit } \\
\text { EOS/RF }\end{array}$ & $\begin{array}{l}\text { - Lebenstiländerung } \\
\text { - keine } \\
\text { BP-Maßnahmen }\end{array}$ & $\begin{array}{l}\text { - Lebenstiländerung } \\
\text { - BP-Medikamente, } \\
\text { Zielwert <140/90 }\end{array}$ & $\begin{array}{l}\text { - Lebenstiländerung } \\
\text { - BP-Medikamente, } \\
\text { Zielwert <140/90 }\end{array}$ & $\begin{array}{l}\text { - Lebenstiländerung } \\
\text { - } \quad \text { umgehend } \\
\text { BP-Medikamente, } \\
\text { Zielwert <140/90 }\end{array}$ \\
\hline
\end{tabular}

RF = Risikofaktoren (männliches Geschlecht, Alter [Männer $\geq 55$ Jahre; Frauen $\geq 65$ Jahre]), Raucher, Dyslipidämie, Nüchtern-Glukose 5,6-6,9 mmol/l (102-125 mg/dl), pathologischer Glukosetoleranztest, Adipositas [BMl $\left.\geq 30 \mathrm{~kg} / \mathrm{m}^{2}\right]$, abdominelle Adipositas (Taillenumfang: Männer $\geq 102 \mathrm{~cm}$; Frauen $\geq 88 \mathrm{~cm}$ ), positive Familienanamnese für frühzeitige kardiovaskuläre Erkrankungen (Männer < 55 Jahre; Frauen < 65 Jahre), EOS = Endorganschäden, CVD = cardiovascular disease, $\mathrm{CKD}=$ chronic kidney disease, $\mathrm{St} .=$ Stadium, $\mathrm{BP}=$ blood pressure, $\mathrm{DBP}=$ diastolic blood pressure, $\mathrm{SBP}=$ sytolic blood pressure, HTN = Hypertonie 


\subsection{Therapie der TrHTN}

Nicht selten bleibt jedoch eine TrHTN trotz bekannter Ursache und deren kausaler Behandlung inadäquat kontrolliert. Man nimmt an, dass Grundlage dafür renale und vaskuläre Chronifizierungsprozesse sowie gegenregulatorische Mechanismen sind (Dudenbostel et al. 2015). In ca. 90\% der Fälle lässt sich die Ursache für eine TrHTN nicht feststellen. Es wird empfohlen, einen erfahrenen Hypertensiologen hinzuzuziehen, um gegebenenfalls die medikamentöse Einstellung zu optimieren (Bansal et al. 2003).

\subsubsection{Medikamentöse Therapie der TrHTN}

Medikamentös sollten zur bestehenden Kombinationstherapie entsprechende Reserveantihypertonika hinzugezogen werden (Egan et al. 2013). Ein gutes Ansprechen zeigten Mineralokortikoidrezeptor-Antagonisten, der $\alpha_{1}$-Rezeptor-Blocker Doxazosin sowie das kaliumsparende Diuretika Amilorid (Deutsche Gesellschaft für Kardiologie-Herz- und Kreislaufforschung e.V, Deutsche Hochdruckliga e.V. DHL, Deutsche Gesellschaft für Hypertonie und Prävention 2013; Mancia et al. 2013, Williams et al. 2015).

Bleibt die medikamentöse Therapie trotz Reserveantihypertonika ineffektiv, können invasive Methoden zur Blutdrucksenkung in Betracht gezogen werden. Dies ist indiziert bei anhaltenden Blutdruckwerten von $\geq 160 \mathrm{mmHg}$ systolisch und $\geq 110 \mathrm{mmHg}$ diastolisch, die jedoch anhand von Langzeitblutdruckmessungen (ABPM) quantitativ bestätigt werden sollten (Empfehlungsgrad IC) (Mancia et al. 2013). Genaue, evidenz-basierte Daten zur Indikationsstellung liegen derzeit noch nicht vor. Da genaue Langzeitergebnisse über Wirksamkeit als auch Sicherheit invasiver Bluthochdrucktherapien noch nicht ausreichend vorliegen, sollte die Indikationsstellung, Operation und Nachsorge jener Patienten ausschließlich spezialisierten Bluthochdruckzentren vorbehalten sein, so die Empfehlung der ESH und ESC (Empfehlugsgrad IC) (siehe Mancia et al. 2013, S.1329).

Auffälliges Phänomen der essentiellen und TrHTN ist eine deutlich erhöhte Aktivität des efferenten Symphatikotonus im Vergleich zu gesunden Probanden. Aktuelle Studien bestätigten diese Beobachtung und zeigten die besondere Bedeutung des sympathisch-vegetativen Nervensystems bei der Entwicklung und dem 
Fortschreiten von aHTN sowie ihrer Komplikationen (Grassi, 2010; Di Bona, 2013; Esler, 1989). Darüber hinaus weisen erste Belege daraufhin, dass eine erhöhte Symphatikusaktivität als Ursache für das Versagen medikamentöser Therapiekonzepte anzunehmen ist (Dudenbostel et al. 2015). Invasive Therapieoptionen bieten dabei die Möglichkeit, symphatiko-exzitative Effekte unter TrHTN zu modulieren.

\subsubsection{Invasiv-interventionelle Therapie der TrHTN}

Als invasive Therapieverfahren der TrHTN in der Bluthochdruckbehandlung finden derzeit, der ESC/ESH-Leitlinie entsprechend, die Barorezeptorstimulationstherapie (BAT) und die renale Denervierung Anwendung.

\subsubsection{Die aktuelle Bewertung der renalen Denervierung}

Aufgrund aktueller Ergebnisse der SIMPLICITY HTN-3 Studie (Bhatt et al. 2014) wird die blutdrucksenkende Wirkung der renalen Denervierung bei TrHTN zunehmend mit Skepsis betrachtet. In diese prospektive, randomisierte Studie wurden 535 Patienten eingeschlossen. Dabei zeigte sich, dass der primäre Endpunkt, nämlich den ambulant gemessenen Blutdruck nach 6 Monaten zu senken, nicht erreicht wurde.

\subsubsection{Barorezeptorstimulationstherapie (BAT)}

Physiologische Grundlage für die Wirkweise der BAT ist ein neurovegetativer Regulationskreislauf, der Einfluss auf den systemischen Blutdruck nimmt (siehe Abb. 1.2). Die dabei vom Herzen ausgehende Pulswellenfortleitung bewirkt eine periphere Gefäßdehnung, welche Druckrezeptoren (Pressorezeptoren) in spezialisierten Arealen der Karotisgabel und des Aortenbogens aktiviert. Diese detektieren das Ausmaß der blutdruckabhängigen Gefäßerweitung und leiten die entstandenen Reize in Form elektrischer Impulse über viszerosensible Fasern des Nervus glossopharyngeus an venterolaterale Anteile der Medulla oblongata weiter.

Der Hirnstamm ist Sitz sympathoexzitatorischer Neurone, die mit ihrer Grundaktivität das sympathische Steuerzentrum bilden. Kommt es zu einer Aktivierung von Pressorezeptoren (Barorezeptoren) in Aorta und Karotiden, führen synaptische Verschaltungen im medialen Nucleus tractus solitarii zu einer Hemmwirkung auf den 
efferenten Symphatikotonus, mit der Konsequenz einer Blutdrucksenkung (Persson et al. 2005). Schon frühere Erkenntnisse deuteten darauf hin, dass eine Störung des Blutdrucks durch eine fehlende Sensitivität der Barorezeptoren bedingt sein könnte

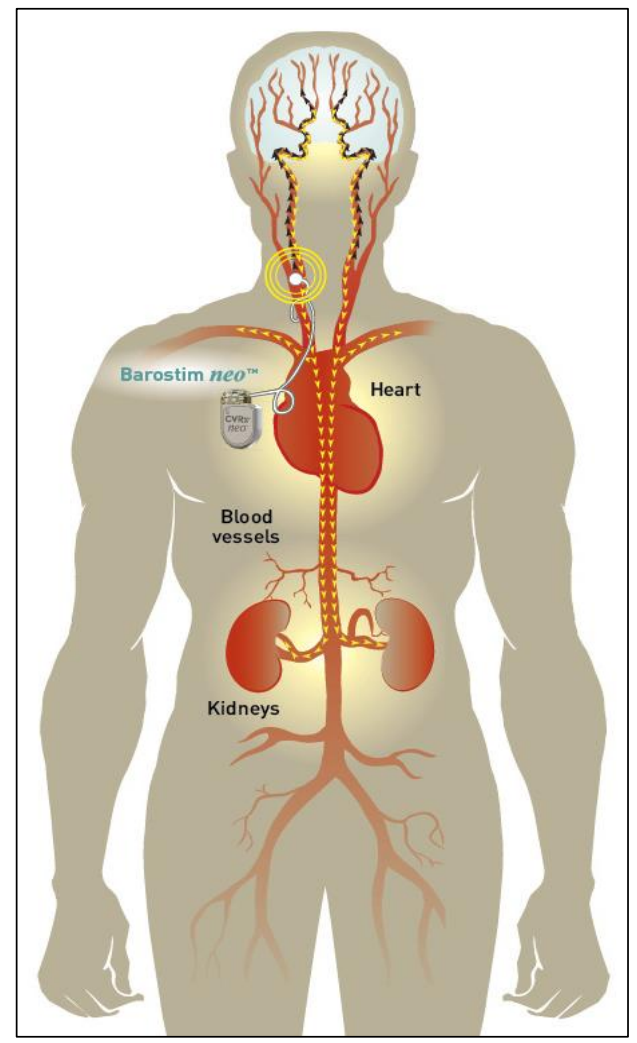

\begin{abstract}
Abb. 1.2: Implantationsort und Wirkweise der BAT (freundlicherweise von der Firma CVRx Inc. zur Verfügung gestellt.)
\end{abstract}

Der Schrittmacher stimuliert die Barorezeptoren. Diese senden Signale in den Hirnstamm (schwarze Pfeile). Dadurch wird die Aktivität des Sympathikus reduziert und des Parasympathikus gesteigert (gelbe Pfeile). Es resultiert ein Absenken des Blutdrucks und der Herzfrequenz (zitiert nach Wallbach und Koziolek 2015a, S.2, Abbildung 1).

und im Zusammenhang mit dem Grad von vaskulärer Kalzifikation und Versteifung stehen könnten (Chesterton et al. 2005). Die BAT greift in diesen fein abgestimmten Reflexbogen ein, indem sie einen externen Elektrostimulus auf die Barorezeptoren, unabhängig vom intravasalen Gefäßstatus, appliziert.

\title{
1.6 Historie
}

Grundlegende Erkenntnisse über die Wirkungsweise der Druckrezeptoren am Karotissinus wurden in den fünfziger Jahren des letzten Jahrhunderts am Tiermodell gewonnen. Obwohl diese Befunde eindeutig waren und theoretische Annahmen der Hochdruckphysiologie belegten, konnte erst im Jahre 1966 der erste funktionierende BAT erfolgreich am Menschen von den Wissenschaftlern Bilgutay und Lillehei implantiert werden (Bilgutay und Lillehei 1966).

Ein Meilenstein für die klinische Routineanwendung war die im Jahr 2007 erfolgte Marktzulassung (CE-zertifiziert) des ersten voll-implantierbaren BATSchrittmachersystems (Rheos®, CVRx. Inc., Minneapolis, MN, USA) in Europa. Grundlage dafür schaffte die DEBuT-HET-Studie (Device Based Therapy in 
Hypertension Extension Trial), welche die Sicherheit und Wirksamkeit des Verfahrens untersuchte und nach zwei Jahren Beobachtung eine signifikante Blutdrucksenkung nachwies.

Bisher einzig randomisierte und größte Studie zur BAT ist der Rheos® Pivotal Trial mit 322 eingeschlossenen Patienten. Die dabei beobachtete hochsignifikante Differenz $(p<0,005)$ des erreichten Zielblutdrucks von $\leq 140 \mathrm{mmHg}$ systolisch nach 6 Monaten von $42 \%$ in der Versuchsgruppe gegenüber $24 \%$ der Kontrollgruppe, bestätigte die effektive Wirkung der BAT (siehe Tab. 1.7).

Nach 12 Monaten Untersuchungszeitraum und Aktivierung des BAT-Schrittmachers nach 6 Monaten in der Kontrollgruppe erreichten insgesamt 50 \% der Patienten beider Kohorten Zielwerte von $\leq 140 \mathrm{mmHg}$ systolisch (Bisognano et al. 2011b). Bei Blutdruckkontrollen zum 22. und 53. Monat nach Therapiebeginn, zeigten bereits $76 \%$ aller Patienten im Langzeitverlauf einen bedeutenden Abfall mittlerer Blutdruckwerte um 35/16 mmHg systolisch/diastolisch (Bakris et al. 2012).

Der nachfolgende Barostim neo Trial untersuchte die Wirksamkeit eines neu eingeführten Zweitgenerations-BAT-Aggregats (Barostim neo ${ }^{\mathrm{TM}}$ system) unter einseitiger Karotisstimulation. Neben dem Nachweis eines signifikanten Blutdruckabfalls zeigte sich zusätzlich eine Senkung der Komplikationsrate (Hoppe et al. 2012).

Aktuelle Studien zeigten neben der blutdruck- und herzfrequenzsenkenden Wirkung der BAT (Wustmann et al. 2009) eine Verbesserung der geometrischen Herzkonfiguration (Bisognano et al. 2011a; de Leeuw et al. 2008) und einen Anstieg der körperlichen Leistungsfähigkeit (Kroon et al. 2010; Scheffers et al. 2010b). Abgesehen von diesen protektiven Effekten sind weitere interessante Erkenntnisse unter einer BAT zu erwarten, insbesondere hinsichtlich renaler, vaskulärer und metabolischer Auswirkungen (Grassi et al. 2014). Bis dato ist deren Bestätigung jedoch noch nicht erfolgt. Grund zur Annahme gibt die durch eine BAT vermittelte, zentrale Sympathikus-Inhibition (Heusser 2010; Wustmann et al. 2009). Als essentielles Erregungs- und Aktivierungssystem beeinflusst die sympathische Innervation zahlreiche Organsysteme und deren Funktionen. Eine chronische Überaktivität ist verknüpft mit einem metabolischen Syndrom (Esler et al. 2006; Landsberg und Young 1978), gekennzeichnet durch eine Insulinresistenz, Übergewicht (Grassi et al. 2000) und einer aHTN (Di Bona 2013). Patienten mit chronisch progredienter Niereninsuffizienz (CKD) zeigen eine signifikante Aktivierung 


\begin{tabular}{|c|c|c|c|c|}
\hline Studie & Studientyp & $\begin{array}{l}\text { randomisiert/ } \\
\text { nicht-randomisiert }\end{array}$ & $\mathrm{n}$ & Ergebnisse \\
\hline $\begin{array}{l}\text { McCubbin et al. } \\
1956\end{array}$ & $\begin{array}{l}\text { Tierversuch, } \\
\text { kontrolliert }\end{array}$ & nicht-randomisiert & 6 & $\begin{array}{l}\text { Während der elektrischen Stimulation an } \\
\text { Karotiden von Hunden wird eine Sollwert- } \\
\text { verschiebung der elektr. Reizschwelle detektiert. }\end{array}$ \\
\hline Warner 1958 & Tierversuch & nicht-randomisiert & - & $\begin{array}{l}\text { Die elektr. Stimulation variabler Frequenzen am } \\
\text { Karotis Sinus führt zum sofortigen BP-Abfall bei } \\
\text { Hunden. }\end{array}$ \\
\hline $\begin{array}{l}\text { Carlsten et al. } \\
1958\end{array}$ & Fallserie & nicht-randomisiert & 5 & $\begin{array}{l}\text { Erste Barorezeptorstimulation am Menschen mit } \\
\text { sofortigem BP-Abfall i.V. von Hals-OPs } \\
\text { onkologischer Patienten. }\end{array}$ \\
\hline $\begin{array}{l}\text { Bilgutay und Lillehei } \\
1966\end{array}$ & Fallserie & nicht-randomisiert & 2 & $\begin{array}{l}\text { Erste erfolgreiche Implantation eines BAT- } \\
\text { Schrittmachers bei Patienten mit BP-Werten } \\
>200 \text { mmHg systolisch und hypertensiven EOS. } \\
\text { Der BP sank i.V. um >50 mmHg systolisch. }\end{array}$ \\
\hline $\begin{array}{l}\text { Lohmeier et al. } \\
2004\end{array}$ & $\begin{array}{l}\text { Tierversuch, } \\
\text { kontrolliert }\end{array}$ & nicht-randomisiert & 6 & $\begin{array}{l}\text { Erfolgreiche Prüfung hinsichtlich anhaltender BP- } \\
\text { Senkung unter fortwährender elektrischer } \\
\text { Karotidenstimulation über } 7 \text { Tage am Hund. }\end{array}$ \\
\hline \multicolumn{5}{|c|}{2007 Marktzulassung des ersten Barorezeptorschrittmachers } \\
\hline Heusser et al. 2010 & $\begin{array}{l}\text { DEBuT-HET } \\
\text { Substudie, } \\
\text { prospektiv }\end{array}$ & nicht-randomisiert & 12 & $\begin{array}{l}\text { Die BAT zeigt eine zentrale Sympathikus- } \\
\text { Inhibition hinsichtlich einer signifikanten } \\
\text { Minderung der sympathischen Nervenaktivität in } \\
\text { Muskeln }\left(r^{2}=0,42 ; p<0,05\right) \text { u. Plasma- } \\
\text { Reninkonzentration um } 20 \pm 8 \%(p<0,05) \text {. }\end{array}$ \\
\hline $\begin{array}{l}\text { Scheffers et al. } \\
\text { 2010a }\end{array}$ & $\begin{array}{l}\text { DEBuT-HET- } \\
\text { Studie, } \\
\text { prospektiv }\end{array}$ & nicht-randomisiert & 45 & $\begin{array}{l}\text { Nachweis von Wirksamkeit und Sicherheit der } \\
\text { BAT. Nach } 2 \text { Jahren BAT sank der mittlere BP um } \\
33 \pm 8 \mathrm{mmHg} \text { systolisch }(p=0,001) \text { bzw. } \\
22 \pm 6 \mathrm{mmHg} \text { diastolisch }(p=0,002)\end{array}$ \\
\hline Kroon et al. 2010 & $\begin{array}{l}\text { Ergebnisse } \\
\text { unterschiedl. } \\
\text { Studien in der } \\
\text { EU u. den USA }\end{array}$ & nicht-randomisiert & 21 & $\begin{array}{l}\text { Verbesserung von funktioneller Kapazität und } \\
\text { kardialen Funktion- und Strukturparametern } \\
\text { nach } 12 \text { Mo. BAT: 6-MGT um }+37 \pm 60 \mathrm{~m} \\
\text { (p } \leq 0,01) \text {, LV-MI um }-25 \pm 18 \mathrm{~g} / \mathrm{m}^{2}(\mathrm{p}<0,001) \text {, } \\
\text { Schlagarbeit }-31 \pm 48 \mathrm{~g} / \mathrm{m}(\mathrm{p} \leq 0,01) .\end{array}$ \\
\hline $\begin{array}{l}\text { Bisognano et al. } \\
\text { 2011a }\end{array}$ & $\begin{array}{l}\text { DEBuT-HET } \\
\text { Substudie, } \\
\text { prospektiv }\end{array}$ & nicht-randomisiert & 34 & $\begin{array}{l}\text { Nach einem Jahr BAT Verbesserung kardialer } \\
\text { Struktur -und Funktionsparameter, wie } \\
\text { Minderung der LV-Wanddicke, des LV-MI, der LV- } \\
\text { Schlagarbeit } \\
(p<0.001) \text { sowie einer signifikanten Reduktion } \\
\text { der mitralen A-Wellen. }\end{array}$ \\
\hline $\begin{array}{l}\text { Bisognano et al. } \\
\text { 2011b } \\
\text { Bakris et al. } 2012\end{array}$ & $\begin{array}{l}\text { Rheos }{ }^{\circledR} \text { Pivotal } \\
\text { Trial, } \\
\text { kontrolliert, } \\
\text { doppelblind }\end{array}$ & randomisiert & 322 & $\begin{array}{l}\text { Hochsignifikante Differenz bzgl. des erreichten } \\
\text { Zielblutdruckes zw. Versuchs- und Kontrollgruppe } \\
\text { ( } p<0,005) \text {. Nach 22. und 53. Mo. bestand bei } \\
75 \% \text { aller Patienten ein mittlerer BP-Abfall von } \\
\text { 35/16 mmHg systolisch/diastolisch. }\end{array}$ \\
\hline Hoppe et al. 2012 & $\begin{array}{l}\text { Barostim neo } \\
\text { Trial, einarmig }\end{array}$ & nicht-randomisiert & 30 & $\begin{array}{l}\text { Nachweis von Wirksamkeit bei einseitiger } \\
\text { Karotidenstimulation durch } 2 \text {. Generation- } \\
\text { Aggregat bei BP-Senkung von } 26 \pm 4,4 \mathrm{mmHg} \\
\text { systolisch }(p<0,001) \text { nach } 6 \text { Monaten. }\end{array}$ \\
\hline
\end{tabular}

Tab. 1.7: Chronologische Ubersicht ausgewählter Studien zum Thema BAT DEBUT-HET = Device Based Therapy in Hypertension Extension Trial, i.V. $=$ im Verlauf, elektr. $=$ elektrisch, BP $=$ blood pressure, OPs $=$ Operationen, EOS $=$ Endorganschäden, BAT $=$ Barorezeptorimplantationstherapie, Mo $=$ = Monat, Pat.$=$ Patient, $6-$ MGT = 6 Minuten-Geh-Test, LV-MI = linksventrikulärer Massen-Index, LV-Wanddicke $=$ linksventrikuläre Wanddicke, EU = Europa, USA = United States of America; $\mathrm{n}=$ Stichprobengröße 
der Sympathikusaktivität im Vergleich zu Kontrollpersonen mit erhaltener Nierenfunktion (Orth et al. 2001; Grassi et al. 2011a, De Beus et al. 2015 ).

Die Suche nach einer einzigen Ursache des Bluthochdrucks bei Patienten mit CKD ist oft erfolglos. Grund hierfür ist die Tatsache, dass die Hypertonie und die Niereninsuffizienz in einem reziproken Kausalverhältnis stehen. Dabei verstärkt eine aHTN die Progression einer Niereninsuffizienz und umgekehrt eine Niereninsuffizienz die aHTN. Nach neueren Untersuchungen besteht Grund zur Annahme, dass sich durch eine Senkung der renalen Perfusion und glomerulären Filtrationsrate (GFR), der Erhöhung der Reninsekretion sowie der renalen Salz- und Wasserretention die Progression einer Niereninsuffizienz bei bestehender TrHTN, vor dem Hintergrund einer adrenergen Hyperaktivität, abspielt (Grassi 2010).

Schließlich scheint eine anhaltende aHTN in Kausalbeziehung zur Proteinurie mit einer exkretorischen Funktionseinschränkung der Niere und einer Steigerung kardiovaskulärer Ereignisse zu stehen (Ruilope 2011). 


\subsection{Ziel der Doktorarbeit}

Ziel dieser Dissertation ist es, Einflüsse der BAT auf die Nierenfunktion und der zentralen Hämodynamik des arteriellen Gefäßsystems zu detektieren. Als Arbeitshypothese wird angenommen, dass mit der BAT eine Organprotektion bei Therapie-refraktären Hypertonikern mit Niereninsuffizienz erzielt werden kann.

Folgende Parameter zur Beurteilung einer möglichen organprotektiven Wirkung der BAT wurden in die Studie einbezogen:

- Der Einfluss der BAT auf die Nierenfunktion bei Therapie-refraktären Hypertonikern, die eine chronische Niereninsuffizienz aufweisen, wurde bislang nicht untersucht. Es wurden Proteinurie, Filtrationsfähigkeit und $\mathrm{Na}^{+-}$ Ausscheidung im Verlauf der Therapie beobachtet und verglichen. Zusätzlich erfolgten weitere Urinuntersuchungen mittels Proteomanalyse. Hierbei wurden Proteine und Peptide identifiziert und deren Menge und Muster im Therapieverlauf verglichen, um Rückschlüsse auf das kardio-reno-vaskuläre Risiko ziehen zu können.

- Da der überwiegende Teil der Bluthochdruckpatienten an einer Atherosklerose und zunehmenden Versteifung der Gefäße leidet, stellt sich die Frage, welchen Einfluss die BAT neben einer Blutdrucksenkung auf die Gefäßsteifigkeit hat. Mit Hilfe der SphygmoCor-Untersuchung wurden unabhängige Prädiktoren zur Erfassung kardiovaskulärer Schäden und Gefäßsteifigkeit erhoben, wie z.B. Pulswellengeschwindigkeit, zentraler aortaler Blutdruck und Augmentationsindex. Seit 2007 wird deren Ermittlung in den Guidelines der Europäischen Gesellschaft für Hypertonie empfohlen (Mancia et al., 2013).

- Zusammen mit der Analyse von etablierten pro- und antiangiogenen Biomarkern sowie endothelialer Progenitorzellen wurde in der vorliegenden Arbeit der Effekt der BAT auf gefäßregenerative Effekte untersucht.

- Ferner wurde der Zeitverlauf des BuP, 24-h Blutdruck, Ansprech- und Komplikationsrate unter der BAT untersucht. 


\section{Material und Methoden}

\subsection{Verbrauchsmaterialien, Geräte und Software}

\subsubsection{Verbrauchsmaterialien}

Deckgläser

Einmalkanülen

Einmalpipette
$0,9 \times 70 \mathrm{~mm}$

$10 \mathrm{ml}$ in $1 / 10 \mathrm{ml}$

$25 \mathrm{ml}$ in $2 / 10 \mathrm{ml}$

$5 \mathrm{ml}$ in $1 / 10 \mathrm{ml}$

$2 \mathrm{ml}$ in $1 / 100 \mathrm{ml}$

EKG-Elektroden AmbußBlue Sensor L

Eppendorf Tubes $\quad 1,5 \mathrm{ml}$

$2,0 \mathrm{ml}$

Gelfärbeschalen

Gentle Skin Handschuhe

Glasröhrchen $5 \mathrm{ml} 75 \times 12 \mathrm{~mm}$

Halb-Mikroküvetten 10x4x45mm

Kimtech-Science Wipes

Leucosep-Röhrchen

Objektträger Thermo Scientific

Parafilm

Pasteurpipette Glas

Pipettenspitze $\quad 1000 \mu \mathrm{l}$

$$
200 \mu \mathrm{l}
$$

$10 \mu \mathrm{l}$

Reaction Tubes 1,5 ml PP graduated

Reaktionsgefäße 0,6 ml Dnase-, Rnasefrei Biozym Scientific, Hess. Oldendorf,

Röhre $15 \mathrm{ml}, 120 \times 17$ mm PP pyrogenfrei Sarstedt, Nümbrecht, Germany

Röhre 50 ml, 114 × 28 mm PP pyrogenfrei Sarstedt, Nümbrecht, Germany

Rührspatel

Safety-Multifly-Set

Serological Pipette $10 \mathrm{ml}$
Greiner Bio-One, Frickenhausen, Germany

Germany

Karl Hecht KG, Sondheim, Germany

Braun, Melsungen, Germany

Sarstedt, Nümbrecht, Germany

Ambu A/S, Ballerup, Danemark

Eppendorf AG, Hamburg, Germany

Carl Roth, Hamburg, Germany

Meditrade, Kiefersfelden, Germany

Sarstedt, Nümbrecht, Germany

Sarstedt, Nümbrecht, Germany

Kimberly-Clark, Mainz, Germany

Greiner Bio-One, Frickenhausen, Germany

Menzel, Braunschweig, Germany

Brand,Wertheim, Germany

BRAND, Wertheim, Germany

Sarstedt, Nürnberg, Germany

Sarstedt, Nürmbrecht, Germany

Sarstedt, Nümbrecht, Germany

Sarstedt, Nürnberg, Germany 
S-Monovette 2,7 ml K3E (EDTA)

S-Monovette 4,3 ml 9NC (Gerinnung)

S-Monovette 4,7 ml LH (Li-Heparinat)

S-Monovette $7,5 \mathrm{ml} 2$ Serum

S-Monovette 9,0 ml LH (Li-Heparinat)

Spritze Luer Lok ${ }^{\mathrm{TM}}$

Urin-Monovette 8,5 ml

Zellkulturplatte 24 Vertiefungen

Zellkulturplatte, 6 Vertiefungen
Sarstedt, Nümbrecht, Germany

Sarstedt, Nümbrecht, Germany

Sarstedt, Nümbrecht, Germany

Sarstedt, Nümbrecht, Germany

Sarstedt, Nümbrecht, Germany

Becton Dickson, Franklin Lakes, USA

Sarstedt, Nümbrecht, Germany

Greiner Bio-One, Frickenhausen, Germany

Becton Dickson Company, Franklin Lakes, USA

\subsubsection{Geräte}

20x Objektiv Olympus IX 71

3-Laser Scanner, Modell: FLA-5100

Ambulanter Blutdruckmonitor, Modell: 90207

Analysenwaage

Blutdruckmessgerät, Modell: boso-medicus

Bunsenbrenner, Modell: gasprofi1

Elektrophorese, Modell: Bio-Rad Citerion

Flow Cytometer, Modell: FacScan

Fluorescence Phase Contrast Microscope,

Modell: Axiovert S100 TV

Fokussiergerät, Modell: Bio-Rad Protean IEF Cell

iCys $®$ Research Imaging Cytometer

Kühlschrank $5^{\circ} \mathrm{C}$, Modell: Economy

Magnetrührer, Modell: IKAMAG ®RCT

Magnetstäbchen PTFE-beschichtet,

Modell: IKAFLON ${ }^{\circledR}$

Megafuge, Modell: 1.OR

Microzentrifuge, Modell: Sigma 1-15PK

Mikroskop, Modell: DIAVERT

Multichannel Pipette

Neubauer-Zählkammer

Pipette- Eppendorf, Modell: Reference

Pipette- pipetman, Modell: $P 1000$

Pipette- pipetman, Modell: P 20
Olympus, Hamburg, Germany

FUJIFILM, Kleve, Germany

Space Labs Medical, Snoqualmie, USA

Sartorius, Göttingen, Germany

Bosch+Sohn, Jungingen, Germany

WLP-TEC, Arenshausen, Germany

Bio-Rad, München, Germany

Becton Dickinson, Heidelberg, Germany

Carl Zeiss Meditec, Jena, Germany

Bio-Rad Laboratories, München, Germany

ComputeCyte, Westwood, USA

Liebherr, Bulle, Schwitzerland

IKA®-Werke, Staufen, Germany

IKA®-Werke, Staufen, Germany

Heraeus, Hanau, Germany

Sartorius, Göttingen, Germany

Leica, Wetzlar, Germany

Eppendorf, Hamburg, Germany

BRAND, Wertheim, Germany

Eppendorf, Hamburg, Germany

Gilson, Middleton, USA

Gilson, Middleton, USA 
Pipettierhilfe, Modell: Pipetus-Aku

Präzisionswaage

Schüttelwaage, Modell: GFL 3005

Spannungswander, Modell: LKB Bromma

2301 Macrodrive 1 Power Supply

Spectrometer, Modell: TecanSpectra

Spektrometer, Modell: Lambda 25 UV/Vis

SphygmoCor Px Puls Wave Analysis System,

Modell: SCOR-PX,

SphygmoCor Vx Pulse Wave Velocity System

Modell: SCOR- Vx

Standzentrifuge, Modell: ROTIXA/A

Sterilbank,

Schüttelwaage

Tiefkühlschrank $-20^{\circ} \mathrm{C}$, Modell: Comfort NoFrost

Tiefkühlschrank $-80^{\circ} \mathrm{C}$, Modell: Sanyo

VIP- Series -86

Ultrahochzentrifuge, Modell: Sigma 3K30

Vortexer

Wärmebad

Wärmeschrank, Modell: Sanyo $\mathrm{CO}^{2}$ Incubator

Zentrifuge, Modell: 5415 D

Zentrifuge, Modell: Allegra ${ }^{\mathrm{TM}} \mathrm{X}-12 \mathrm{R}$
Hirschmann, Eberstadt, Germany

Sartorius, Göttingen, Germany

GFL, Burgwedel, Germany

LKB-PRODUKTER, Bromma, Sweden

Tecan, Männedorf, Switzerland

Perkin Elmer, Waltham, USA

At Cor Medical Pty, Sydney, Australia

At Cor Medical Pty, Sydney, Australia

Andreas Hettich, Tuttlingen, Germany

Telstar B.V., Woerden, Netherlands

GFL, Burgwedel, Germany

Liebherr, Bulle, Schwitzerland

Panasonic, Wood Dale, USA

SIGMA, Osterode am Harz, Germany

Bohemia, New York, USA

GFL, Burgwedel, Germany

Panasonic, Wood Dale, USA

Eppendorf, Hamburg, Germany

Beckman Coulter, Krefeld, Germany

\subsubsection{Software und Datenbanken}

Cell^ $D$

\section{Citavi 5}

Delta2D-Software, Version 4.3

Fluorescence Phase Contrast Microscope Olympus, Hamburg, Germany

Software ${ }^{\circledR}$, Modell: Axiovert S100 TV

iCys ${ }^{\mathrm{TM}}$ Cytometric Analysis Software

Mascot Software Vision 2.4.1

Mass Spectrometry Protein Sequences

(MSDB) Datenbank

Microsoft Excel 2010
Olympus, Athen, Greece

Citavi, Wädenswil, Switzerland

DECODON, Greifswald, Germany

ComputeCyte, Westwood, USA

Matrix Science, London, UK

Imperial College School of Medicine, London, UK

Microsoft, Unterschleißheim, Germany 
National Center for Biotechnology nonredundant (NCBInr) Datenbank

Scaffold 4, Proteom-Software

SphygmoCor®Software Vision 8

Statistica 12

Swiss-Prot
NCBI, Bethesda, USA

Proteome Software, Inc., Portland, USA

At Cor Medical Pty, Sydney Australia

StatSoft, Berikon, Switzerland

Swiss Institute of Bioinformatics,

Lausanne, Switzerland

\subsection{Chemische und biologische Materialien}

\subsubsection{Chemikalien}

1,4 Dithiothreitol (DTT)

2,5-Dihydroxybenzoesäure (DHB)

3 (N-Morpholino) Propansulfonsäure (MOPS)

running buffer

4',6-Diamidin-2-phenylindol (DAPI)

Aceton

Acetonitril

Ammoniumbicarbonat (Ambic)

BD Perm/Wash,

BD Cytofix/ Cytopem

Biocoll Separating Solution

Bio-Lyte 3/10 Ampholyte

Bromphenolblau,

Bovine Serum Albumin (BSA)

CFU-Hill- Basal Medium

CFU-Hill- Medium Supplements 20ml

Chaps (3-[(3-Cholamidopropyl)-

dimethylammonio]-propan-sulfonat)

Chloroform

Chlorwasserstoff (HCL)

Criterion XT Precast Gel 12 \% BIS-Tris IPG+1

Well comp

Dextrose O. G. T., oraler Glukose-Toleranztest,
Carl Roth, Karlsruhe, Germany

Sigma-Aldrich, Steinheim, Germany

Bio-Rad, Hercules, USA

MoBiTec, Göttingen, Germany

Carl Roth, Karlsruhe, Germany

Carl Roth, Karlsruhe, Germany

Sigma-Aldrich, Steinheim, Germany

BD Bioscience, San Jose, USA

BD Bioscience, San Jose, USA

BIOCHROM, Berlin, Germany

Bio-Rad, Hercules, USA

Sigma-Aldrich, Steinheim, Germany

Sigma-Aldrich, Steinheim, Germany

STEMCELL Technologies SARL,

Grenoble, France

STEMCELL Technologies SARL,

Grenoble, France

Merck, Darmstadt, Germany

Merck, Darmstadt, Germany

Carl Roth, Karlsruhe, Germany

Bio-Rad, Hercules, USA

Roche, Grenach-Wyhlen, Germany 
Destilliertes Wasser (dd $\mathrm{H}^{2} \mathrm{O}$ )

Dimethylformamid (DMF)

Essigsäure

Fibronektin 0,1\%.(human)

Flamingo Farbstoff (Orale flureszent gel stain)

Formaldehydlösung min.37\%, säurefrei

Glycerol

Hautantiseptikum, kodan (farblos)

Hank`s Balanced Salt Solution (HBSS)

lodacetamid

Kalziumchlorid

Markerprotein (Bio-Rad procision plus protein

kaleidoskop standarts),

Methanol >99\%

Mineralöl

PBS pH 7,4 ; Phosphate Buffered Saline

Protein Assay (Farbstoffkonzentrat)

Ready Strip IPG Strips $11 \mathrm{~cm}, \mathrm{pH}$ 4-7

Sodium dodecyl sulphate (SDS), ultra-pure

Trifluoressigsäure (TFA)

Triphenylmethanfarbstoff

(Coomassie-Brillant-Blau)

Tris(hydroxymethyl)-aminomethan (TRIS)

Triton-x-100

Trypsin

Urea
Laboreinheit Dihazi, Göttingen, Germany

Sigma-Aldrich, St. Louis, USA

Carl Roth, Karlsruhe, Germany

Sigma-Aldrich, Steinheim, Germany

Bio-Rad, Hercules, USA

Merck, Darmstadt, Germany

Carl Roth, Karlsruhe, Germany

Schülke \& Mayr, Norderstedt, Germany

Lonza, Verviers, Belgium

Sigma-Aldrich, St.Luis, USA

Merck, Darmstadt, Germany

Bio-Rad, Hercules, USA

Carl Roth, Karlsruhe, Germany

Bio-Rad, Hercules, USA

GIBCO, New York, USA

Bio-Rad, München, Germany

Bio-Rad, Hercules, USA

Carl Roth, Karlsruhe, Germany

Merck, Darmstadt, Germany

Carl Roth, Karlsruhe, Germany

Carl Roth, Karlsruhe, Germany

Sigma-Aldrich, Steinheim, Germany

Promega, Madison, USA

Sigma-Aldrich, St. Louis, USA 


\subsubsection{Kits}

ADMA Enzymimmunoassay

FITC Active Caspase-3 Apoptosis Kit

Refraction-2D ${ }^{\mathrm{TM}}$ Labeling Kit

Quantikine Human sICAM Immunoassay

Quantikine Human sVCAM/CD106 Immunoassay

Quantikine Human TGF- $\beta 1$ Immunoassay

Quantikine Human sVEGF R1/Flt-1 Immunoassay R\&D Systems, Minneapolis, USA

Quantikine Human Angiopoietin 1 Immunoassay

Quantikine Human Angiopoietin 2 Immunoassay

Quantikine Human VEGF Immunoassay

Quantikine Human MMP-9 Immunoassay
DLD Diagnostika, Hamburg, Germany

BD Bioscience, San Jose, USA

NH DyeAGNOSTICS, Halle, Germany

R\&D Systems, Minneapolis, USA

R\&D Systems, Minneapolis, USA

R\&D Systems, Minneapolis, USA

R\&D Systems, Minneapolis, USA

R\&D Systems, Minneapolis, USA

R\&D Systems, Minneapolis, USA

R\&D Systems, Minneapolis, USA

\subsubsection{Antikörper}

\begin{tabular}{|l|l|l|}
\hline Name & Spezies & Herkunft \\
\hline Primäre Antikörper & & \\
\hline $\begin{array}{l}\text { FITC labeled Anti-Active } \\
\text { Caspase-3 Antibody }\end{array}$ & Rabbit & BD Bioscience, San Jose, USA \\
\hline Anti-3/eNOS/NOS TyplII & Mouse & BD Bioscience, San Jose, USA \\
\hline Sekundäre Antikörper & & \\
\hline Anti-mouse lgG-NL637 & Donkey & R\&D Systems, Minneapolis, USA \\
\hline
\end{tabular}




\subsection{Studiendesign}

Es handelt sich um eine nicht-randomisierte, monozentrische, prospektive, klinischexperimentelle Beobachtungsstudie, welche von der Ethikkommission Göttingen geprüft, unter der Antragsnummer 19/9/11 registriert sowie in Übereinstimmung mit den Grundsätzen der Deklaration von Helsinki genehmigt wurde.

Die Studie teilte sich in zwei zeitlich getrennte Untersuchungsabschnitte, bezeichnet als Studienvisiten I (Visit I) und II (Visit II). Studienvisite I umfasste klinischexperimentelle Patientenuntersuchungen, welche der operativen Implantation des BAT-Schrittmachers ein bis zwei Tage vorausgingen. Der zweite Untersuchungsabschnitt erfolgte nach 6 Monaten \pm 14 Tage aktiver BAT und umfasste Verlaufs- und Routineuntersuchungen (siehe Abbildung 2.1). Die Ergebnisse und gewonnenen Patientenproben wurden analysiert und verglichen.

\section{Studienplan}

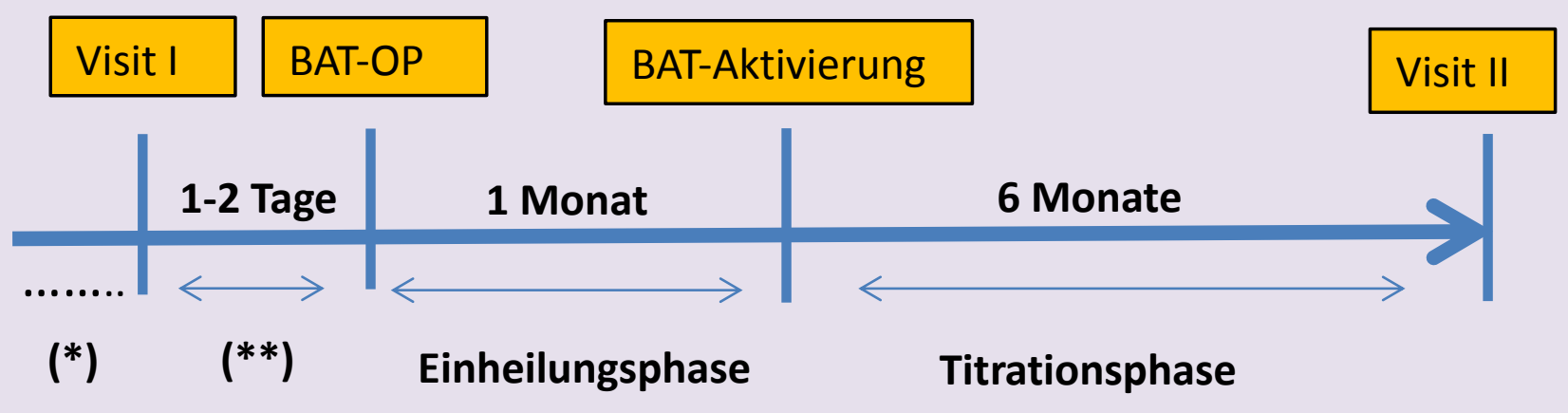

Abb. 2.1: Studiendesign *Screeningphase und Indikationsstellung, ** Phase des Studieneinschlusses/ ausschlusses

Die Erhebung klinischer Daten sowie die Durchführung spezieller klinischexperimenteller Untersuchungen wurde im Verlauf der Studienvisiten I und II stets von denselben Untersuchern durchgeführt.

Die operative Patientenversorgung fand durch die Klinik für Thorax-, Herz- und Gefäßchirurgie des Universitätsklinikums Göttingen statt. Abgesehen von einer perioperativen Erprobung des BAT-Schrittmachers und der Testung auf Ansprechen in Form eines Blutdruckabfalls, blieb das Aggregat post-operativ zunächst ausgestellt. 
Nach einer einmonatigen Einheilungsphase wurde der BAT-Schrittmacher aktiviert, dessen Funktion in den nächsten sechs Monaten gesteigert und auf die medikamentöse Therapie abgestimmt (siehe Titrationsphase in Abb.2.1). In dieser Zeit stellten sich die Patienten in Ein- bis Zweimonatsabständen bzw. nach Bedarf in der BAT-Ambulanz der Uniklinik vor. Bei jedem Patientenkontakt wurden Medikation und BAT-Wirkung geprüft und angepasst sowie Vitalparameter und Blutdruck erhoben.

Die Studie entstand in Zusammenarbeit der Abteilungen für Nephrologie und Rheumatologie, Kardiologie und Pneumologie sowie Psychosomatik und Psychiatrie der Universitätsmedizin Göttingen (UMG).

Jede dieser Abteilungen vergab eine wissenschaftliche Fragestellung zur Erlangung des Doktortitels an einen Studenten. Ausgehend von der gleichen Studienkohorte, gingen die Doktoranden unabhängig und eigenständig voneinander ihrem Thema nach. Eine gemeinsame Tätigkeit erfolgte lediglich bei der Erfassung von klinischen Daten und Routineparametern, die in die jeweiligen Dissertationen einflossen. Eine präzise Darstellung und Erklärung der einzelnen Doktoranden über den Umfang der Zusammenarbeit ist im Anhang beigefügt. Betreut von Prof. Dr. med. Christoph Herrmann-Lingen (Klinik für psychosomatische Medizin und Psychotherapie), befasste sich die Doktorandin Pia Kohlbecker mit Aspekten des psychischen Befindens und der Lebensqualität unter Einwirkung der BAT. Die Doktorandin Charlotte Schroer, betreut von Prof. Dr. med. Rolf Wachter (Klinik für Kardiologie und Pneumologie), widmete sich den Effekten der BAT auf kardiale Endpunkte.

Die vorliegende Arbeit zur „Analyse organoprotektiver Effekte durch eine Barorezeptorstimulationstherapie zur Behandlung der Therapie-refraktären arteriellen Hypertonie" entstand unter der Obhut von Prof. Dr. med. Michael Koziolek und Dr. med. Manuel Wallbach (beide Klinik für Nephrologie und Rheumatologie).

\subsection{Patienten}

\subsubsection{Patientenrekrutierung}

Die Rekrutierung der Patienten und Indikationsstellung zur BAT erfolgte in den Kliniken Nephrologie und Rheumatologie sowie Kardiologie und Pneumologie der Universitätsmedizin Göttingen. 
Gemäß der ESC/EHC-Leitlinien, wurden bei der Studienaufnahme die Erfüllung der Diagnosekriterien einer TrHTN geprüft (Mancia et al. 2013) und Patienten mit einer Niereninsuffizienz (CKD) nach den Kriterien der KDIGO definiert (Verbeke et al. 2014). Es erfolgte außerdem der Ausschluss sekundärer Hypertonieformen und die Kontrolle eines Bluthochdrucks $\geq 140 \mathrm{mmHg}$ systolisch bei mindestens drei zeitlich versetzten Messungen, der Einnahme von $\geq 3$ Medikamenten inkl. einem Diuretikum oder einer bestehenden Medikamentenunverträglichkeit sowie einer Bluthochdruckbehandlung von $\geq 1$ Jahr. Der Prüfarzt klärte die Patienten in einem Gespräch über Ablauf und Risiken der Studie auf.

\subsubsection{Ein- und Ausschlusskriterien}

Tab. 2.1: Ein- und Ausschlusskriterien

\begin{tabular}{|c|c|}
\hline Einschlusskriterien & Ausschlusskriterien \\
\hline $\begin{array}{l}\text { - Therapie-refraktärer } \\
\text { arterieller Hypertonus } \\
\text { - Indikation zur BAT } \\
\text { - unveränderte } \\
\text { Medikation für } \geq 3 \\
\text { Monate } \\
\text { - } \geq 18 \text { Jahre }\end{array}$ & $\begin{array}{l}\text { - } \quad 18 \text { Jahre } \\
\text { - } \quad \text { Kinderwunsch } \\
\text { - } \quad \text { Schwangerschaft und Stillzeit } \\
\text { - } \quad \text { unbehandelte sekundäre Hypertonie } \\
\text { - } \quad \text { Suchterkrankung } \\
\text { akute kardiovaskuläre Erkrankungen } \\
\text { - Karotisstenosen } \geq 70 \% \\
\text { - } \quad \text { instabile Angina } \\
\text { - } \quad \text { Schlaganfall } \\
\text { - } \quad \text { TIA in den letzten sechs Monaten }\end{array}$ \\
\hline $\begin{array}{l}\text { - Einwilligungsfähigkeit } \\
\text { - schriftliche Einwilligung }\end{array}$ & $\begin{array}{l}\text { - Umstände, die eine Durchführung oder } \\
\text { Interpretation der Messgrößen stören } \\
\text { - Teilnahme an anderen Studien } \\
\text { innerhalb der letzten vier Wochen }\end{array}$ \\
\hline
\end{tabular}

TIA = transischämische Attacke 


\subsubsection{Komplikationen}

Die Überwachung hinsichtlich möglicher Nebenwirkungen durch die BAT erfolgte mindestens viermalig im ersten Jahr nach Implantation in persönlichen Interviews und unter Anwendung eines standardisierten Protokolls. In Abhängigkeit von der klinischen Beeinträchtigung wurden die Nebenwirkungen (adverse events) drei Schweregraden zugeordnet $\left(1^{\circ}=\right.$.transiente Beschwerden, keine Intervention notwendig; $\|^{\circ}=$ ärztliche Intervention notwendig; $\mathrm{II}^{\circ}=$ lebensbedrohliche Komplikationen). 


\subsection{Blutdruckmessungen}

\subsubsection{Blutdruck unter Praxisbedingungen (BuP)}

Bei jeder Studienvisite wurden zu Beginn der Untersuchungen mindestens drei Blutdruckmessungen unter standardisierten Bedingungen (sitzende Position, drei bis fünf Minuten Ruhe, gleiche Tageszeit) im Mindestabstand von zwei Minuten mit dem Blutdruckmessgerät Modell boso-medicus (Bosch+Sohn GmbH UCO.KG, Jungingen, Deutschland) durchgeführt (Deutsche Gesellschaft für Kardiologie-Herz- und Kreislaufforschung e.V, Deutsche Hochdruckliga e.V. DHL, Deutsche Gesellschaft für Hypertonie und Prävention 2013). Es wurden die systolischen und diastolischen Blutdruckwerte sowie die Herzfrequenz ermittelt. Die Messungen erfolgten am rechten Oberarm im Sitzen auf Herzhöhe mit entsprechender Standardmanschette $(12-13 \mathrm{~cm}$ breit und $35 \mathrm{~cm}$ lang; bei Armumfängen $>32 \mathrm{~cm}$ Verwendung angepasster Manschetten). Der gemittelte Wert der Messungen wurde für die statistischen Auswertungen verwendet. Bei Messwertabweichungen von >15 mmHg erfolgten nach einer drei- bis fünfminütigen Ruhephase erneut Messwiederholungen.

\subsubsection{4-h Blutdruck-Messungen (ABPM)}

Die Langzeitblutdruckmessung (ABPM) erfolgte gemäß der empfohlenen Durchführung für Studien (Lüders et al. 2013) mit dem Gerät Space Labs Medical, Modell 90207 (Spacelabs Healthcare, Snoqualmie, USA). In der Zeit von 6:00 Uhr bis 22:00 Uhr erfolgten Messungen im zeitlichen Messabstand von 15 Minuten, der nächtliche Abstand von 22:00 Uhr bis 6:00 Uhr im Abstand von 30 Minuten. Die computergestützte Auswertung zeigte die Mittelwerte von systolischen, diastolischen und mittleren Blutdruckwerten, die Herzfrequenz über 24 Stunden im Tages- und Nachtverlauf sowie den maximalen und minimalen Messwert von systolischen, diastolischen und mittleren Blutdrücken. Eine gültige Blutdruckaufzeichnung lag vor, wenn mindestens $80 \%$ gültige Messungen erfolgten.

\subsubsection{Definition von Therapie-Respondern}

Ein Ansprechen der Therapie wurde definiert, wenn der systolische Blutdruck nach sechs Monaten BAT bei der BuP um $\geq 10 \mathrm{mmHg}$ und/oder bei dem ABPM $\geq 5 \mathrm{mmHg}$ sank. Ebenso galt das Erreichen des Zielblutdrucks von $\leq 140 \mathrm{mmHg}$ bzw. $\leq 130 \mathrm{mmHg}$ 
systolisch bei Patienten mit Diabetes oder Niereninsuffizienz als ein Ansprechen der Therapie.

\subsection{Pulswellenanalyse und Bestimmung der Pulswellen- geschwindigkeit (PWV) mittels Applanationstonometrie}

Die Messungen wurden unter Verwendung eines SphygmorCor Gerätes (Version 7.0; Atcor Medical, Sydney, Australia) unter standardisierten Bedingungen durchgeführt (annährend gleiche Zeit, auf dem Rücken liegend, nach zehnminütiger Ruhepause, temperatur-kontrollierter Raum, Medikamenteneinnahme zwei Stunden vor der Untersuchung, Karenz von Tee, Kaffee und Rauchen für sechs Stunden sowie Alkohol von 24 Stunden).

Die Messungen wurden von einem geschulten Untersucher vorgenommen, um intraindividuelle Schwankungen zu minimieren. Der Mittelwert von jeweils zwei durchgeführten Messungen wurde für weitere statistische Zwecke verwendet.

Die Qualität der Messungen wurde durch evaluierte Variablen und visuell akzeptable Pulswellenaufzeichnungen, deren Schwankungen von Pulsgröße und -länge sowie Diastole $\leq 5 \%$ und einer mittleren Pulsgröße von mindestens $80 \mathrm{mV}$ sein sollten, von der SphygmoCor Software zu einem Qualitätsindex (\%), berechnet. Im Falle der PWV Messung wurde die Zeitdifferenz zwischen EKG-Signal und Aufzeichnungsstelle mit einer Standardabweichung (SD) von $\leq 10 \%$ des Mittelwertes gewertet. Der Qualitätsindex wurde in Form eines Operator Indexes von der Software dargestellt und Messungen mit einem Mindestwert von 80 \% akzeptiert.

Anhand der im Vorfeld ermittelten mittleren systolischen und diastolischen BuP- Messungen wurde der mittlere Blutdruck (MBP) mit Hilfe der Formel $\mathrm{MBP}=\mathrm{DBP}+0,4 \times[\mathrm{SBP}-\mathrm{DBP}]$ berechnet und zur PWV Analyse verwendet. Zusätzlich erfolgte die Aufzeichnung der radialen Druckkurve über zehn Sekunden bei gleichbleibenden Bedingungen mit Hilfe des SphygmoCor Gerätes. Die SphygmoCor Software berechnete daraufhin den durchschnittlichen radialarteriellen Druckwellenverlauf und ermittelte - unter Anwendung einer validierten allgemeinen Umwandlungsformel - die entsprechende zentral arterielle Druckwellenkurve. Der zentrale Kurvenverlauf des Pulsdrucks (PP) wurde anhand der Aufzeichnungen der radialen Druckkurve erhoben, die ihrerseits durch den BuP kalibriert wurde. Vom 
aortalen Druckkurvenverlauf ausgehend, wurden im Verlauf dann weitere Analysen abgeleitet.

Der erste Druckwellenanstieg wurde als Inflexionspunkt-Gipfel (IP) (ausgehende Druckwelle) definiert und die Druckdifferenz zwischen IP und dem maximalen Druckanstieg (Augmentationsdruck (AP)) als reflektierte Druckwelle während der Systole identifiziert (siehe Abb. 2.2). Der Augmentationsindex (Alx) wurde durch das Verhältnis von Augmentation und zentralem PP berechnet $(\mathrm{Alx}=$ Augmentationsdruck/PP x 100). Um den Einfluss der Herzfrequenz auf den Alx zu senken, wurde der Alx von der SphygmoCor Software auf eine Herzfrequenz von 75 Schlägen pro Minute korrigiert (Alx@75). Darüber hinaus kalkulierte die SpyhgmoCor Software die Integrale der systolischen und diastolischen Druckzeiten (SPTI/DPTI). Hierbei steht das SPTI in Beziehung zur Herzarbeit und zum kardialen Sauerstoffverbrauch, wohingegen das DPTI ein Maß für die koronare Perfusionszeit

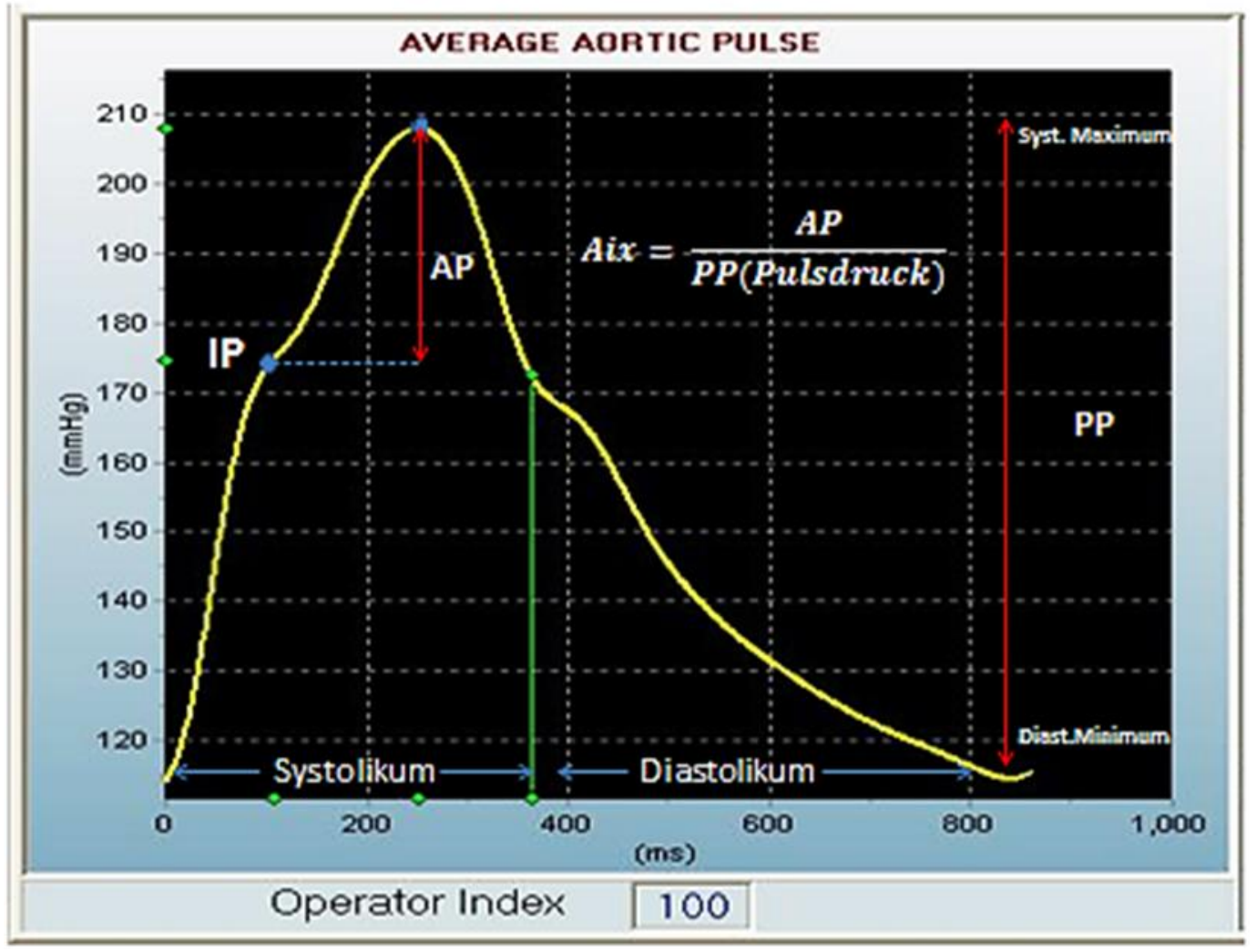

Abb. 2.2: Pulswellenanalyse im Rahmen der Studie (Patient 012, 29.10.2012) IP = Inflektionspunkt, wird mittels Pulswellenanalyse berechnet und gibt an wann sich die reflektierte Pulswelle in der aszendierenden Aorta wieder einfindet; PP = Pulsdruck, ist die Druckdifferenz zwischen systolischem Maximum und diastolischem Minimum; AP = Augmentationdruck, gibt die systolische Druckerhöhung an; Aix = Augmentationsindex, setzt AP mit PP ins Verhältnis

und den Perfusionsdruck ist. Das Verhältnis kardialer Energieversorgung und dessen Bedarf (SEVR = DPTI/SPTI) spiegeln sich in der subendokardialen Variabilitätsratio (SEVR) wider. Die Pulswellengeschwindigkeit wurde aus dem Quotienten von 
Pulslaufzeit und Distanz berechnet, wobei die Pulswellendistanz aus der Differenz zwischen Femoralarterie und Jugulum sowie Jugulum und Trigonum caroticum entstand. Die Bestimmung der PWV resultierte aus fortlaufend simultaner Aufzeichnung einer EKG-Ableitung nach Einthoven ( $\mathrm{I}^{\circ}$ Konfiguration) und des arteriellen Druckwellenverlaufes an rechter Femoralarterie und Karotide durch das SphygmoCor Gerät. Um intraindividuelle Abweichungen zu minimieren, erfolgten bei beiden Visits Doppelmessungen, deren Durchschnittswerte für die weitere statistische Analyse verwendet wurden. Bei Abweichungen von $\geq 2 \mathrm{~m} / \mathrm{s}$ wurden zur Bestimmung des Mittelwertes weitere Messwiederholungen durchgeführt. Mit Hilfe von Regressionsgleichungen wurden die PWV-Referenzwerte entsprechender Alterskategorien (PWV voraussichtlich) unter Einbeziehung des MBP berechnet.

\subsection{Routineanalysen und Probenverarbeitung}

\section{Probengewinnung}

Bei mindestens sechs Stunden nüchtern gewesenen Patienten wurde stets im gleichen Zeitraum Blut entnommen. Die Blutentnahme erfolgte während Studienvisite I und Studienvisite II, also morgens zwischen 7:00 und 10:00 Uhr.

Insgesamt wurden je Visite jeweils $70 \mathrm{ml}$ Blut intravenös an der Armbeuge entnommen und $50 \mathrm{ml}$ Mittelstrahlurin gewonnen. Der überwiegende Teil, $55 \mathrm{ml}$ Blut und $5 \mathrm{ml}$ Urin, waren für die Bestimmungen im Routinelabor vorgesehen. Der verbliebene Anteil des Patientenmaterials war für anschließende experimentelle Untersuchungen bestimmt.

Zur Pseudonymisierung wurde jedem Studienteilnehmer ein Nummerncode zugeordnet welcher auf den ensprechenden Protokollen und Patientenproben versehen wurde. Eine seperate Patientenidentifikationsliste wurde im Rahmen der ambulanten Nachsorge geführt.

\section{Routineanalysen}

Die Bestimmungen von Routinemarkern (siehe Tabelle 3.4) erfolgten anhand validierter Tests in den zertifizierten UMG-Laboren. Aus den gewonnenen Werten wurden nach den in Tabelle 2.2 aufgelisteten validierten Formeln die glomeruläre Filtrationsrate sowie die 24-Stunden-Na+-Exkretion berechnet. 


\section{Probenverarbeitung und Lagerung}

10-15 ml Serum wurden bei $2000 \mathrm{U} / \mathrm{min}$ für zehn Minuten zentrifugiert, anschließend aliquotiert und bei $-20^{\circ} \mathrm{C}$ zur späteren ELISA-Bestimmung von vaskulären Biomarkern eingefroren. Der Mittelstrahlurin wurde bei $3000 \mathrm{U} / \mathrm{min}, 4^{\circ} \mathrm{C}$ für zehn Minuten zentrifugiert, dekandiert, aliquotiert und bei $-80^{\circ} \mathrm{C}$ für die Proteom-Analyse eingefroren. Zusätzliche Urinproben wurden an das Zentrallabor zur Bestimmung der Proteinurie versandt. Sämtliche aliquotierten Patientenproben wurden innerhalb weniger Stunden verarbeitet, mit anonymisiert codierten Etiketten und einer Identifikationsnummer versehen sowie mit einem Platz im Probenarchiv gekennzeichnet.

Tab. 2.2: Formeln renaler Funktionsparameter

\begin{tabular}{|c|c|}
\hline & Formel \\
\hline GFR nach MDRD ${ }^{(1)}$ & $\begin{aligned} \mathrm{GFR}= & 175 \times S^{-1,154} \times \text { Alter }^{0,203} \times 1.212 \text { (falls schwarze } \\
& \text { Hautfarbe) } \times 0.742 \text { (falls weiblich) }\end{aligned}$ \\
\hline GFR nach CKD-EPI (Kreatinin) $^{(2)}$ & $\begin{aligned} \text { GFR }= & 141 \times \min (S c r / \kappa, 1)^{\alpha} \times \max (S c r / \kappa, 1)^{-1,209} \times \\
& 0,993^{\text {Alter }} \times 1.018 \text { [falls weiblich] } \times 1.159 \\
& \text { [falls schwarze Hautfarbe] }{ }^{*}\end{aligned}$ \\
\hline GFR nach CKD-EPI (Cystatin) $^{(3)}$ & $\begin{aligned} \mathrm{GFR}= & 133 \times \min (\text { Scys } / 0.8,1)^{-0.499} \times \max \\
& (\text { Scys } / 0.8,1)^{-1.328} \times 0.996^{\text {Alter }} \\
& {[\times 0.932 \text { falls weiblich }]^{* *} }\end{aligned}$ \\
\hline $\begin{array}{l}\text { GFR nach CKD-EPI (Kreatinin- } \\
\text { Cystatin) }^{(3)}\end{array}$ & $\begin{aligned} \mathrm{GFR}= & 135 \times \min (S c r / \kappa, 1)^{\beta} \times \max (S c r / \kappa, 1)^{-0.601} \times \\
& \min (\operatorname{Scys} / 0.8,1)^{-0.375 \times \max } \\
& (\text { Scys } / 0.8,1)^{-0.711} \times 0.996^{\text {Alter }} \\
& {[\times 0.969 \text { falls weiblich }] \times 1.08 \text { falls schwarz }] }\end{aligned}$ \\
\hline geschätzte $\mathrm{Na}^{+}-$Ausscheidung & $\begin{aligned} \mathrm{Na}^{+}= & \left.\text {(Urin- } \mathrm{Na}^{+} \times \text {Plasma-Kreatinin }\right) / \\
& \text { (Plasma- } \mathrm{Na}^{+} \times \text {Urin- Kreatinin) }\end{aligned}$ \\
\hline 24h-renale $\mathrm{Na}^{+}$- Exkretion ${ }^{(4)}$ & $\begin{array}{c}24 h \mathrm{Na}^{+}=16,3 \sqrt{\left(\text { Urin }-\mathrm{Na}^{+} / \text {Urin }- \text { Kreatinin }\right)} x \\
\text { geschätzte } 24 \text { Kreatinin }- \text { Exkretion }\end{array}$ \\
\hline $24 \mathrm{~h}$ - renale Kreatinin-Exkretion ${ }^{(5)}$ & $\begin{array}{l}\text { 24h Kreatinin } \\
\text { 24) }=-12,63 \times A+15,12 \times G+7,39 \times K G-79,90 \\
\text { Kreatinin }^{(I I)}=-4,72 \times A+8,58 \times G+5,09 \times K G-74,50\end{array}$ \\
\hline
\end{tabular}

CKD-EPI = Chronic Kidney Disease Epidemiology Collaboration; GFR = glomeruläre Filtrationsrate; MDRD = modification of diet in renal disease; $\mathrm{Scr}=$ standardisiertes Serum-Kreatinin; $\boldsymbol{\kappa}=0,7$ für Frauen und 0,9 für Männer; $\alpha=-0,329$ für Frauen und -0,411 für Männer; ${ }^{*}$ min deutet auf das Minimum des Scr/א oder 1; max deutet auf das Maximum des Scr/к; ${ }^{*}$ Scys = standardisiertes Serum-Cystatin C; min deutet auf Minimum von Scr/K oder 1; max deutet auf Maximum von Scys/K oder $1 ; \beta=-0.248$ für Frauen und $-0,207$ für Männer; $A=A l t e r, G=G e w i c h t, K G=$ Körpergröße; (I) = für Männer; (II) = für Frauen; (1)(Levey et al. 2007); (2)(Levey et al. 2009); (3)(Inker et al. 2012); ${ }^{(4)}$ (Kawasaki et al. 1993); (5) (Kawasaki et al. 1991) 


\subsection{Endotheliale Progenitorzellen (EPCs)}

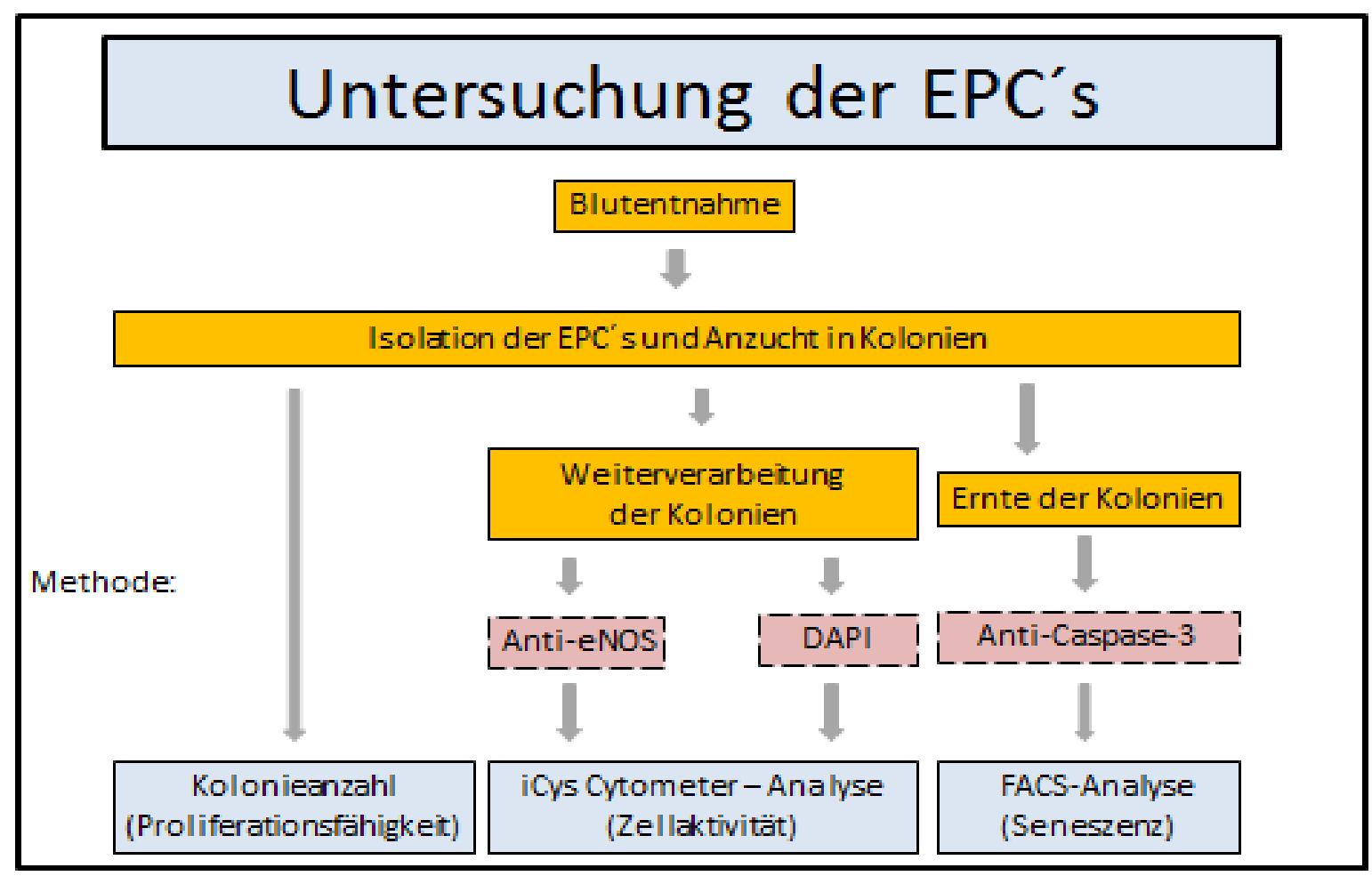

Abb. 2.3:Übersicht angewandter Methoden zur Charakterisierung der EPCs: eNOS = endotheliale Stickstoffmonoxid-Synthase; DAPI = 4,6-Diamidin-2-phenylindol; FACS = fluorescence activated cell sorting

\subsubsection{Analyse der EPC-Proliferationsfähigkeit}

Die Anzucht von EPCs wurde im Labor von Prof. Dr. med. Daniel Patschan, Klinik für Nephrologie und Rheumatologie, durchgeführt. Zunächst wurden 9 ml Blut bei $4{ }^{\circ} \mathrm{C}$ mit $1400 \mathrm{U} / \mathrm{min}$ für $10 \mathrm{~min}$ zentrifugiert, dem Dichtegradienten entsprechend in BiocollSeperations-Medium (BIOCHROM, Berlin, Germany) aufgetrennt und anschließend $5 \times 10^{6}$ mononukleäre Zellen (MNC`s)/2 ml Stammzellmedium (STEMCELL Technologies SARL, Grenoble, France)/Well auf eine mit humanem Fibronectin (Sigma-Aldrich, Steinheim, Germany) beschichtete 6 Well-Platte (Becton Dickson Company, Franklin Lakes, USA) gebettet. Es folgte eine 48-stündige Inkubation bei $37{ }^{\circ} \mathrm{C}, 5 \% \mathrm{CO}_{2}$-Gehalt und $\geq 95 \%$ Luftfeuchte im Wärmeschrank (Panasonic, Wood Dale, USA). Danach wurden die nicht-adhärenten Zellen in inrem Medium in eine Fibronectin beschichtete 24 Well-Platte (Greiner Bio-One, Frickenhausen, Germany) umgebettet und nach drei Tagen Inkubation die gewachsenen EPCs-Kolonien gezählt (Durchlichtlichtmikroskop; Leica, Wetzlar, Deutschland). Als Kolonie galt eine Ansammlung von mindestens 20 zentral gelegenen rundlichen Zellen, die von 
wenigstens drei lanzettförmigen EPC-Zellen in der Peripherie umgegeben sein sollten (siehe Abbildungen 2.4 A bis C).

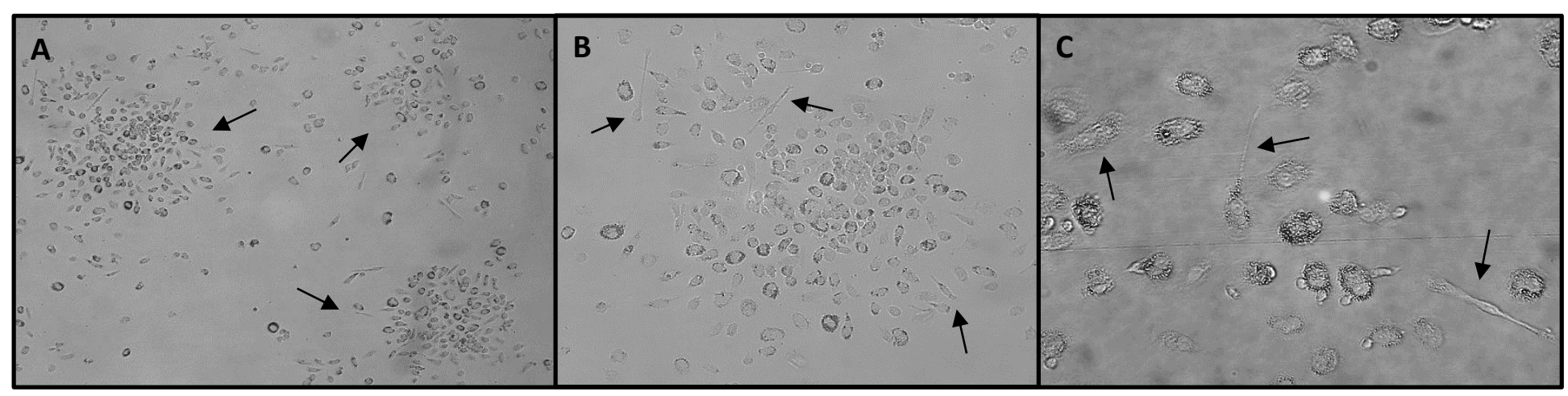

Abb. 2.4 A bis C : Morphologische Charakterisierung einzelner EPC-Kolonien (Probenmaterial: Patient 010 zur Visit II am 08.05.2013). Mikroskopische Darstellung mittels Konfokalmikroskop (Gerät: Axiovert S100 TV, Carl Zeiss Meditec, Jena, Germany; Software: Cell^D, Olympus, Athen, Greece); A = 100 fache Vergrößerung, der Bildausschnitt zeigt auf einer Zellkulturplatte drei Ansammlungen von Zellen (siehe Pfeile) welche die Kriterien einer EPC-Kolonie erfüllen (Ansammlung von mindestens 20 zentral gelegenen rundlichen Zellen und wenigstens drei lanzettförmigen EPC-Zellen in der Peripherie); B = 200 fache Vergrößerung eines Bildausschnittes der EPC-Kolonie von A (siehe Pfeil oben links); $C=400$ fache Vergrößerung, lanzettförmige EPC-Zellen einer Kolonie außerhalb der Bildabschnitte $A$ und $B$

Für weitere Untersuchungen zur Zellaktivität wurden die EPC-Kolonien mit Formaldehyd (Merck, Darmstadt, Germany) behandelt, PBS gewaschen und lichtgeschützt bei $4^{\circ} \mathrm{C}$ bis $5^{\circ} \mathrm{C}$ gekühlt gelagert. Die Verarbeitung erfolgte unter Verwendung des colony-forming-unit (CFU) Assays (Hill Liquid Medium Kits, STEMCELL Technologies, Grenoble, France) nach Herstellerangaben sowie nach einem abgewandelten Protokoll von Thum et al. 2007.

\subsubsection{Analyse der EPC-Seneszenz}

Die gewachsenen EPC-Kolonien wurden zunächst mit PBS kalt gewaschen und geerntet, sodann die Zellzahl/ml EPC-PBS-Lösung ermittelt, bei $1400 \mathrm{U} / \mathrm{min}$ für zehn Minuten bei Raumtemperatur (RT) zentrifugiert und anschließend jeweils $1 \times 10^{6}$ Zellen in zwei Messröhrchen überführt. Anhand eines abgewandelten Arbeitsprotokolls des Herstellers, erfolgte die weitere Verarbeitung sowie Färbung der EPCs unter Verwendung des FITC Active Caspase-3 Apoptosis Kits (BD Bioscience, San Jose, USA). Als Verdünnung wurde für die EPC-Färbung ein Verhältnis von $100 \mu \mathrm{l}$ Waschpuffer (BD Perm/Wash, BD Bioscience, San Jose, USA) zu $20 \mu \mathrm{l}$ Anti- Caspase- 3 gewählt. Bei dem Antikörper handelt es sich um einen FITCgekoppelten Rabbit-Antikörper, welcher gegen aktivierte Caspase-3 Antigene gerichtet ist. Zur Quantifizierung Caspase-3 positiver EPCs wurde die Antikörperlösung gegen eine EPCs Negativ-Kontrolle mittels FACS- (fluorescence 
activated cell sorting) Gerät (Becton Dickinson $\mathrm{GmbH}$, Heidelberg, Germany), bestehend aus einem $488 \mathrm{~nm}$ Argon Laser, gemessen und mit dem SoftwareProgramm Cell Quest (Becton Dickinson, San Jose, CA) analysiert (siehe Abb. 2.5). Während der FACS-Messungen wurden die vom Gerätehersteller empfohlenen Einstellungen und Hinweise befolgt und durch eine langjährig erfahrene MedizinischTechnische Angestellte (MTA) durchgeführt.

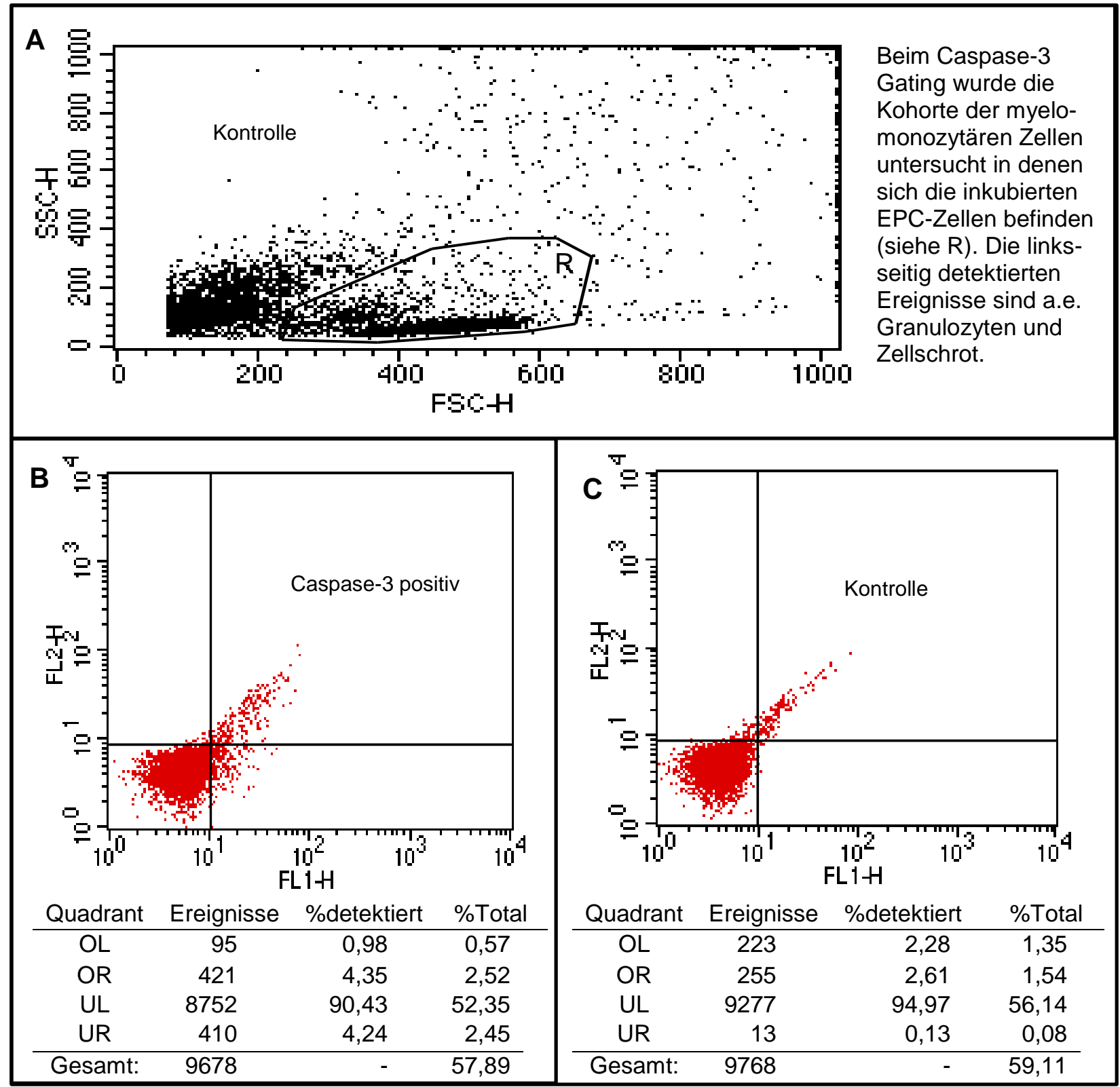

Abb.: 2.5 Charakterisierung der EPC-Zellen mittels FACS-Messung (Patient 032 am 30.04.2014): Jeder Datenpunkt entspricht einer erfassten Zelle. Abbildung A = lineare Darstellung der natürlichen Zelleigenschaften innerhalb der Kontrolle in Ampere (totale Ereignisse Kontrolle: 16525, für Caspase-3 positive Probe nicht dargestellt: 16719); SSC = side-scattered light (Seitenstreulicht) ist proportional zur Granularität bzw. internen Komplexität; $\mathrm{FSC}=$ forward-scattered light (Vorwärtsstreulicht) ist proportional zur Zelloberfläche bzw. -größe; $\mathrm{H}=$ definiert die Erfassung der maximalen Höhe des Spannungsimpulses pro Zelle; Abbildung B und C = logarithmische Darstellung flureszierender Zelleigenschaften innerhalb der Caspase-3 positiven Probe versus Kontrolle in Volt; FLT1-H = FITCActive Caspase-3 Färbung; Lokalisation des Quadrantenkreuzes: 10/8; OL = oben links, OR = oben rechts, UL = unten links, UR = unten rechts, $\mathrm{R}=$ rectangle (Karree) 


\subsubsection{Analyse der EPC-Zellaktivität}

Das Medium wurde aus den Kulturplatten abgesaugt, die EPC-Kolonien mit PBSgewaschen und in einer zehnminütigen Behandlung mit 0,1\% Triton-X-100 (SigmaAldrich, Steinheim, Germany) permeabilisiert (siehe Patschan et al. 2009, S.182). Um unspezifische Bindungen zu blocken, folgte die Waschung mit 0,1 prozentiger sterilen PBS-BSA Lösung (Sigma-Aldrich, Steinheim, Germany) für weitere zehn Minuten.

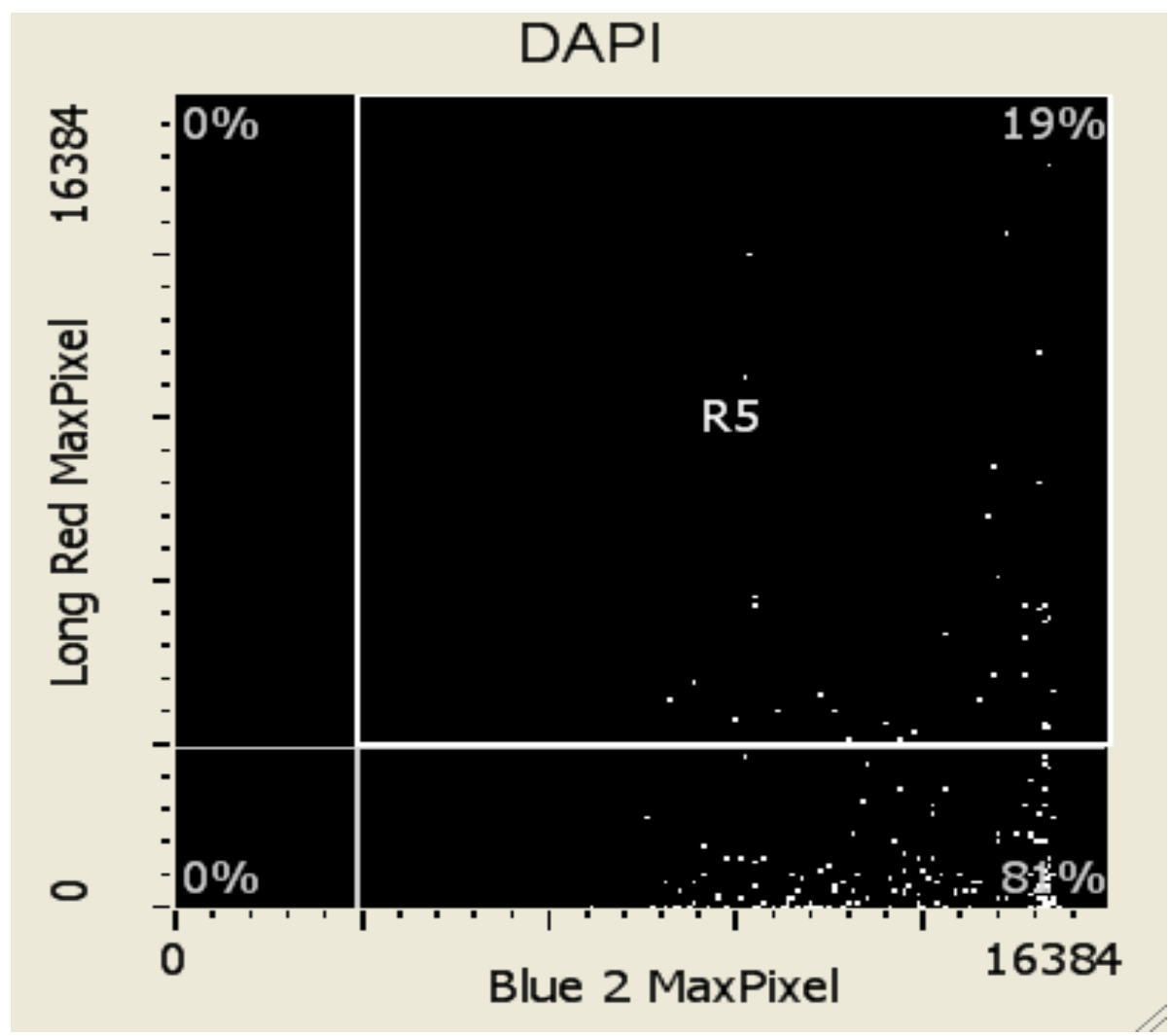

Abb. 2.6:Quantitative Bestimmung der EPC-Zellen mittels Laserscanner: Die x- und y-Achse geben die detektierten Pixelpunkte an (MaxPixel), wobei 16384 Pixel einen 14-Bit-Sättigungsgrad entsprechen. Pixelwerte die größer 16384 sind wurden als 16384 Pixelwerte gewertet. Das scatter R5 zeigt DAPI/eNOS doppelpositive EPCs an. y-Achse: Long Red = eNOS positive Zellen; $\underline{x-A c h s e: ~ B l u e ~=~ D A P I ~ p o s i t i v e ~ Z e l l e n ~}$

Daraufhin erfolgte die Behandlung der EPC-Kolonien für 24 Stunden bei $4 \mathrm{C}^{\circ}$ mit dem primären Maus Antikörper Anti-eNOS/NOS Type III (BD Bioscience, San Jose, USA) im Verhältnis 1:100 in PBS-Lösung. Nach erneuter Zellwaschung wurde die Zellkultur lichtgeschützt für eine Stunde mit dem sekundären Antikörper Northern Lights Antimouse IgG-NL637 (R\&D Systems, Minneapolis, USA) im Verhältnis 1:500 PBSLösung gefärbt.

Die Kernfärbung wurde mittels Vitalkernfarbstoff DAPI (MoBiTec, Göttingen, Germany) für zehn Minuten im Verhältnis 1:1000 in $\mathrm{H}_{2} \mathrm{O}$ vorgenommen. Anschließend erfolgte die quantitative Bestimmung der Fluoreszenz und die Visualisierung der Proben 
(siehe Abb. 2.6 und 2.7) mit Hilfe der Software CompuColor ${ }^{\mathrm{TM}}$ des hochauflösenden Laserscanners iCys®Research Imaging Cytometer (ComputeCyte, Westwood, USA) mit einem 20 x Objektiv (Olympus IX 71, Hamburg, Germany) [für DAPI 405 nm (violett) UV-Diode mit 30 mWatt, für Northern Lights Anti-mouse IgG-NL637 633 nm (rot) Helium Neon mit $5 \mathrm{mWatt}$. Die erhobenen Daten wurden automatisch von der iCys ${ }^{\mathrm{TM}}$ Cytometric Analysis Software (ComputeCyte, Westwood, USA) verarbeitet und ausgewertet.

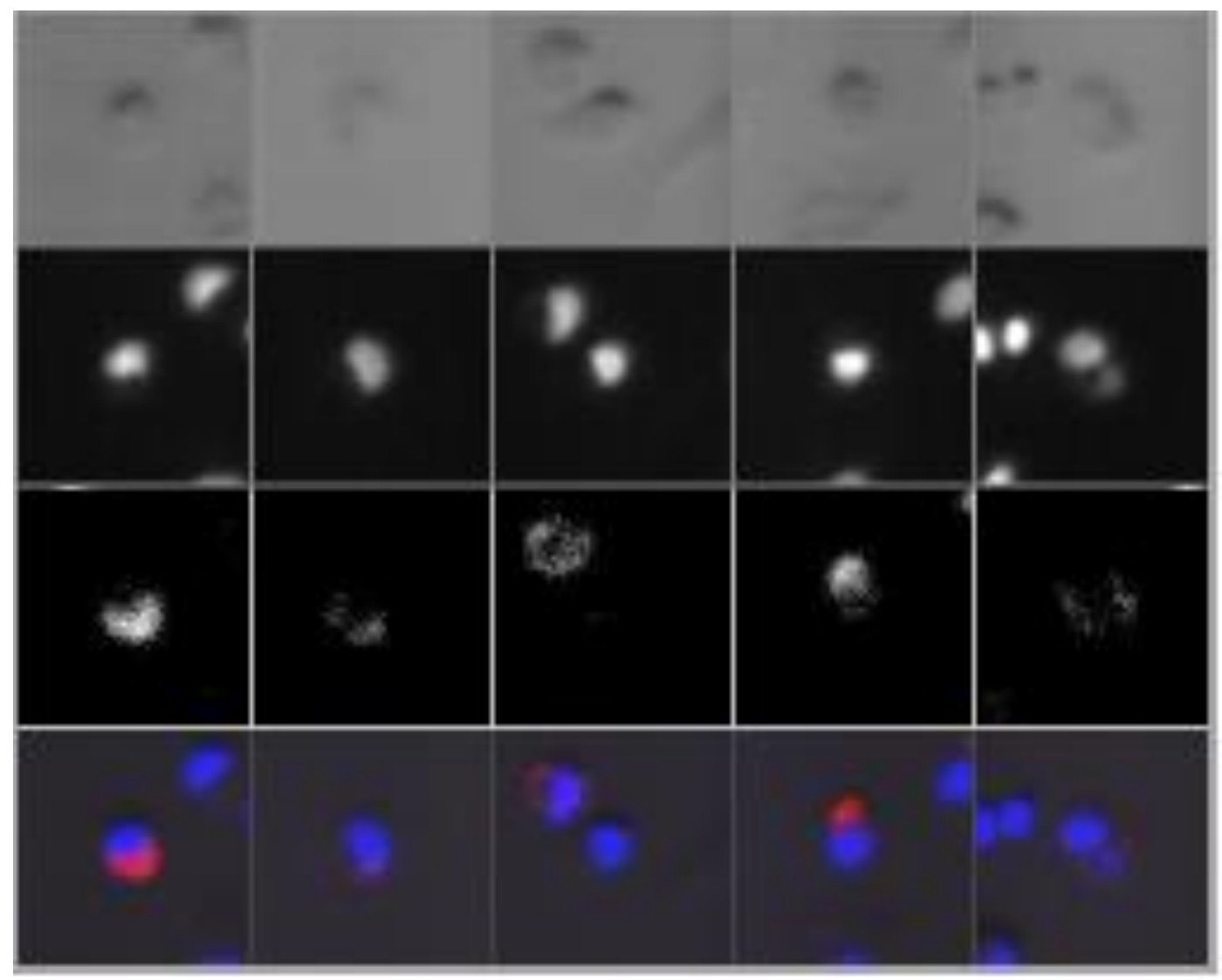

Abb. 2.7: Visualisierung der EPC-Zellen mittels Laserscanner (die in einer Spalte befindlichen Aufnahmen entsprechen jeweils einem Ausschnitt auf der Kulturplatte; eine Reihe stellt unterschiedliche Ausschnitte auf der Kulturplatte dar, die durch dieselbe Methode analysiert wurde): obere Reihe: mikroskopische Aufnahme nativer EPCs; zweite Reihe von oben: Flureszenz DAPI positiver EPCs bei $405 \mathrm{~nm}$; zweite Reihe von unten: Flureszenz eNOS positiver EPCs bei $633 \mathrm{~nm}$; untere Reihe: Darstellung doppelpositiver EPCs (eNOS = rot, $\mathrm{DAPI}=$ blau) 


\subsection{Biomarker}

Serumwerte der Biomarker sICAM, sVCAM, TGF- $\beta_{1}$, sVEGF R1/FLT-1, Ang-1, Ang-2, MMP-9 und VEGF wurden mit Hilfe von standardisierten ELISAs (enzyme linked immunosorbent assays) der Firma R\&D Systems (Minneapolis, USA) quantitativ ermittelt. Die Angabe vom Hersteller über Sensitivität (untere Nachweisgrenze) und des gemittelten Inter-Assay-Variationskoeffizienten sind für sICAM $0,049 \mathrm{ng} / \mathrm{ml}$ und $5,5 \%$, sVCAM $0,17 \mathrm{ng} / \mathrm{ml}$ und $7 \%$, TGF- $\beta_{1} 1,7 \mathrm{pg} / \mathrm{ml}$ und $8,26 \%$, sVEGF R1/FLT-1 $1,5 \mathrm{pg} / \mathrm{ml}$ und $7,4 \%$, VEGF $5,0 \mathrm{pg} / \mathrm{ml}$ und $7,33 \%$, Ang- $11,36 \mathrm{pg} / \mathrm{ml}$ und $5,8 \%$, Ang- 2 $1,2 \mathrm{pg} / \mathrm{ml}$ und $8,97 \%$ sowie für MMP-9 $0,156 \mathrm{ng} / \mathrm{ml}$ und 7,53 \%.

ADMA wurde durch ein ELISA der Firma DLD Diagnostika (Hamburg, Germany) mit einer Sensitivität von $0,05 \mu \mathrm{mol} / \mathrm{I}$ und einem mittlerem Inter-AssayVariationskoeffizient von $9,45 \%$ bestimmt.

Sämtliche Messungen erfolgten in Doppelbestimmung, und der Durchschnitt beider Assays wurde ermittelt.

Die Biomarker TNF- $\alpha$, IL- 6 und CRP wurden unter Verwendung validierter Messmethoden im nephrologischen Routinelabor der UMG-Labore bestimmt. 


\subsection{Proteomanalyse}

\subsubsection{Proteinfällung, Proteinbestimmung und isoelektrische Fokussierung}

Im Verlauf der sechsmonatigen BAT wurden Patienten mit einem signifikanten Abfall der Proteinurie identifiziert und anschließend in folgende Gruppen unterteilt: 1. TrHTN mit hypertensiver Nephropathie (HTN-NP), 2. TrHTN mit diabetischer Nephropathie (D.m.-NP). Je Gruppe wurden sechs Patienten mit ausreichend zur Verfügung stehendem Urin und ausreichender Proteinmenge ausgewählt. Ferner wurde der jeweilige Urinanteil mit einem Proteingehalt von $150 \mu \mathrm{g}$ berechnet und gemeinsam zu einer Gesamtproteinmenge von $900 \mu \mathrm{g}$ gepoolt (siehe Abb. 2.8). Zur Befreiung der Urinproben von interagierenden Substanzen erfolgten die Fällung der Proteine mit Aceton (Carl Roth, Karlsruhe, Germany) im Verhältnis 1:3 und diverse Trocknungsvorgänge sowie Wasch- und Proteolyseschritte zur Aufbereitung für die weitere Proteinbestimmung (Dihazi et al. 2008). Hierbei bediente man sich der photometrischen Methode nach Bradford, bei welcher der Farbstoff CoomassieBrillant-Blau [Triphenylmethanfarbstoff (Carl Roth, Karlsruhe, Germany)] Komplexe der zu untersuchenden Proteine bildet und durch Deprotonierung sowie Stabilisierung einen Farbumschlag bewirkt, sodass sich dessen Absorptionsmaximum von $470 \mathrm{~nm}$ auf $595 \mathrm{~nm}$ verschiebt (Bradford 1976). Mit Hilfe einer Kalibrierkurve konnte aus der erfassten Absorptionsänderung die Konzentration der aufbereiteten Proteinlösung bestimmt werden. Um eine optimale Markierung der Urinproteine mit Fluoreszenzfarbstoffen zu gewährleisten, wurden diese in einer Pufferlösung mit $60 \mathrm{mM}$ Tris [(Trishydroxymethyl-aminomethan) Carl Roth, Karlsruhe, Germany] und einem $\mathrm{pH}$-Wert von 8,5 gelöst.

Insgesamt wurden acht 2D-DIGE-Gele in Doppelbestimmung angefertigt, wobei jeweils die Gruppe der gepoolten D.m.-NP sowie HTN-NP im Zeitverlauf der Visits I und II ein zu untersuchendes Paar ergab. Nach der kovalenten Bindung der Fluoreszenzmarker G-Dyes (NH DyeAGNOSTICS GmbH, Halle, Germany) an Lysinresten der aufbereiteten Urinproteine $(50 \mu \mathrm{g})$ wurden alle drei Proben der jeweiligen Gruppe in einem Gel untersucht (G-Dye100 für internen Standard, GDye200 für D.m.-NP/HTN-NP zur Visit I, G-Dye300 für D.m.-NP/HTN-NP zur Visit II) (siehe Abb. 2.8). Um Unterschiede in der Bindungsaffinität von Fluoreszenzfarbstoffen sowie Proteinen zu erkennen, Variabilitäten zwischen verschiedenen 2D-DIGE-Gelen 


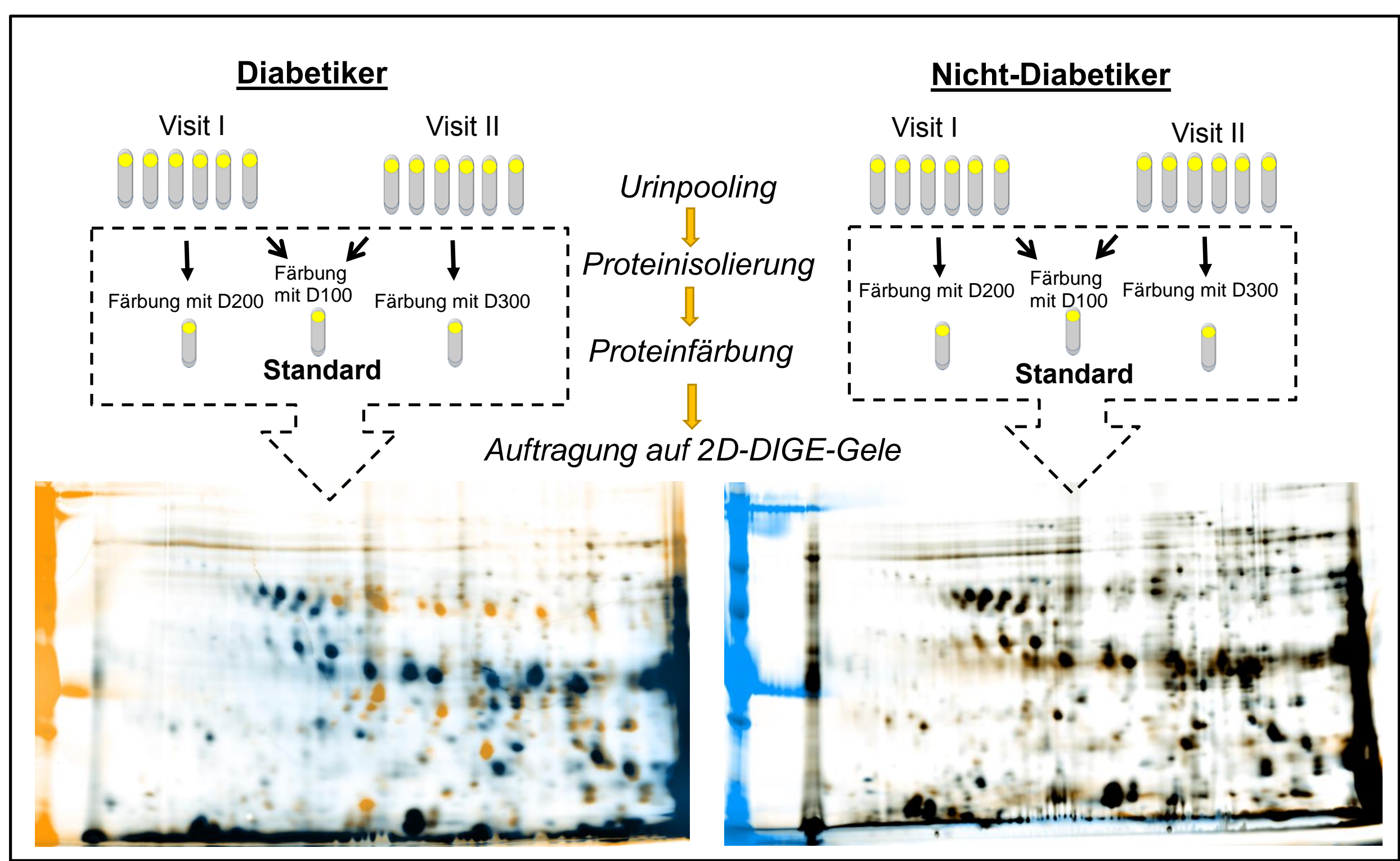

Abb. 2.8: Darstellung über die Verarbeitung der Urinproben und Erstellung der 2D-DIGE-Gele; Diabetiker: mit diabetischer Nephropathie, einer Therapie-refraktären Hypertonie und Proteinurie, blau = Proteinspots der Urine zur Visit I, gelb = Proteinspots der Urine zur Visit II, schwarz = überlagerte Proteinspots der Visit I und II NichtDiabetiker: mit hypertensiver Nephropathie, einer Therapie-refraktären Hypertonie und Proteinurie, blau = Proteinspots der Urine zur Visit I, gelb $=$ Proteinspots der Urine zur Visit II, schwarz = überlagerte Proteinspots der Visit I und II 
zu überbrücken und die Daten statistisch quantifizieren zu können, erfolgte die zusätzliche Anfertigung von Gelen mit vertauschter Proteinmarkierung (G-Dye100 für internen Standard, G-Dye300 für D.m.-NP/HTN-NP zur Visit I, G-Dye200 für D.m.NP/HTN-NP zur Visit II), wie bereits im Vorfeld beschieben (Pesic et al. 2011). Zuvor wurden die aminreaktiven Cyaninfarbstoffe (CyDye) jeweils in dehydriertem N- Dimethylformamid (DMF, Sigma-Aldrich, St. Louis, USA) zu einer Stammlösung von $1000 \mathrm{pmol} / \mu \mathrm{l}$ gelöst und das Volumen von 1,5 $\mu \mathrm{l}$ DMF ergänzt, sodass entsprechend Herstellerprotokoll (NH DyeAGNOSTICS GmbH, Halle, Germany) mindestens 400 pmol CyDye, 50 mg Protein markierte. Die Markierungsreaktion wurde im Dunkeln bei $4{ }^{\circ} \mathrm{C}$ durchgeführt, nach 10 Minuten mit $10 \mathrm{nmol}$ Lysinpuffer gestoppt, in Puffer (30 mM Tris-HCl pH 8.5, 9.5 M Urea, 2\% CHAPS, $130 \mathrm{mM}$ DTT and $2 \%$ ampholytes pl 4-7) gelöst und die entsprechenden Proteinproben (G-Dye100, GDye300, G- Dye200) vereint.

Das markierte Proteingemisch wurde anschließend mit Rehydrationspuffer um ein Gesamtvolumen von $185 \mu$ l ergänzt, auf einen $11 \mathrm{~cm}$ IPG pH-Streifen der Skala 4-7 (Bio-Rad Laboratories, CA, USA) aufgetragen und bei Spannungen von $200 \mathrm{~V}$ bis 8000 V über 24 Stunden bei RT isoelektrisch fokussiert (siehe Abb. 9a).

\subsubsection{Zweidimensionale Proteinauftrennung (2D-DIGE)}

Zur Stabilisierung und Reduktion neuentstandener Disulfidbrücken sowie Proteinadsorption folgte im Anschluss an die eindimensionale Proteinaufteilung die Inkubation des IPG-Streifens in SDS [(Sodium Dodecyl Sulfat) Carl Roth, Karlsruhe, Germany] mit DTT- [(1,4Dithiothreitol) Carl Roth, Karlsruhe, Germany] und lodacetamid- (Sigma-Aldrich, St. Louis, USA) Equilibrierpuffer für jeweils 20 Minuten bei RT. Ferner wurden die Proteine mit 0,25\% Bromophenolblau (Sigma-Aldrich, Steinheim, Germany) gefärbt. Die in Elektrophoreseboxen (Bio-Rad, München, Germany) befindlichen Gelkassetten (Bio-Rad, Hercules, USA) wurden mit einem Markerprotein (Bio-Rad Precision Plus Protein Kaleidoskop Standard, Bio-Rad, Hercules, USA) und einem IPG-pH Streifen (Bio-Rad, Hercules, USA) bestückt. Die darin enthaltenen Proteine wurden bei einer Spannung von $200 \mathrm{~V}$ etwa 40 Minuten nach ihrem spezifischen Molekulargewicht zweidimensional aufgetrennt (2D-DIGE = two dimensional differential in gel electrophoresis) (siehe Abb. 9b-c). 


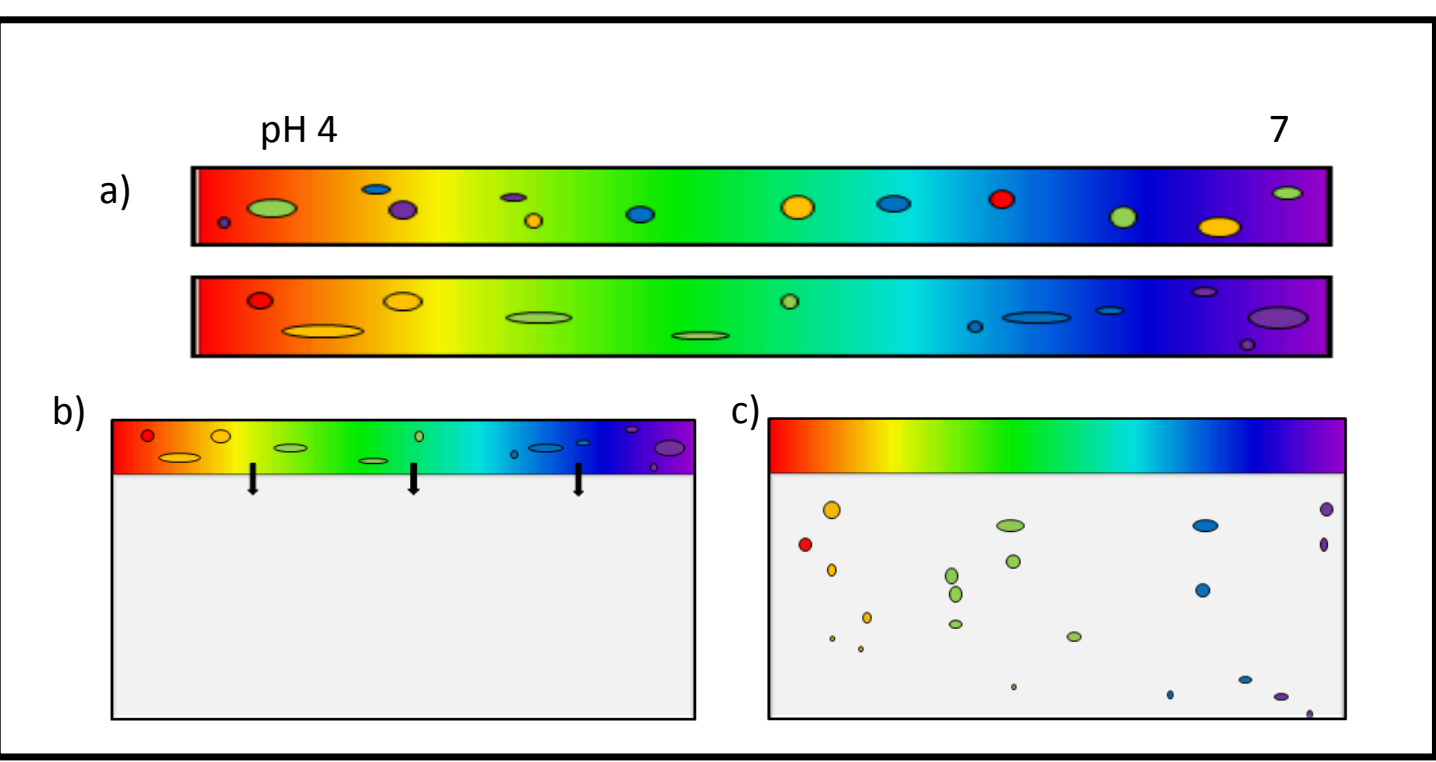

Abb. 2.9 a bis c: Erstellung zweidimensionaler Gele: a) isoelektrische Fokussierung der Proteine entsprechend ihrer Ladung in der 1.Dimension; b und c) zweidimensionale Proteinaufteilung entsprechend dem spezifischen Molekulargewicht

\subsubsection{Digitalisierung und Analyse der 2D-DIGE-Gele}

Die Fluoreszenzdarstellung der Gele erfolgte unter Verwendung des FLA-5100 LaserScanners (FUJIFILM Electronic Imaging Europe GmbH, Kleve, Germany) mit Wellenlängen von $473 \mathrm{~nm}$ (für G-Dye100) und einem 510LP Filter, $532 \mathrm{~nm}$ (für G- Dye200) und einem 575LPFilter sowie 635 nm (für G-Dye300) und einem 665LP Filter bei einer Spannung von 600 V. Die Bilddateien wurden in einem 16-bit TIFFFormat akquiriert. Im Anschluss daran wurden die Gele in einer Lösung aus Methanol (Carl Roth, Karlsruhe, Germany) und Essigsäure (Carl Roth, Karlsruhe, Germany) für mindestens 60 Minuten fixiert.

Die digitalisierten Gel-Darstellungen wurden mittels der Delta 2D-Software Vision 4.3 (DECODON, Greifswald, Germany) automatisch analysiert, aufeinander abgestimmt und übereinandergelegt, sodass Proteinspots der Visits I und II in einer Darstellung detektiert, eingegrenzt und deren Spotvolumen (entspricht der Pixelintensität über der Spotfläche, siehe auch Appel et al. 1997) bestimmt werden konnten. Abweichungen zwischen den Gelen wurden über das errechnete Spotvolumen der Visit I (D.m.NP/HTN-NP) und II (D.m.-NP/HTN-NP) sowie des internen Standards durch die Ermittlung eines Volumenstandards korrigiert. Um signifikante Veränderungen der Proteinspots zu detektieren wurde der t-Test mit einem Signifikanzniveau von $<0,01$ durchgeführt. Proteinspots, die im Vergleich zwischen Visit I und II verschwanden, 
sichtbar wurden oder in ihren Spotvolumen starke Veränderungen zeigten, wurden für die weitere Identifikation markiert.

\subsubsection{Proteinverdau, MALDI-TOF-MS-Identifikation}

Nach Fixierung und Färbung der Gele mit Coomassieblau wurden die zu untersuchenden Proteinspots ausgeschnitten, entfärbt und mit Trypsin (Promega, Madison, USA) bei $37^{\circ} \mathrm{C}$ über 24 Stunden verdaut (Dihazi et al. 2008). Die Peptidfragmente wurden anschließend aus den Gel-Spots herausgelöst, getrocknet und mit einer Matrix aus $\alpha$-Cyano-4-hydroxycinnamidsäure auf einer Zielplatte aus Edelstahl kristallisiert. Der Massen-Ladungs-Quotient trypsinverdauter Peptide wurde nach gängigen externen und internen Kalibrierungsstandards am Voyager DE-STR MALDI-TOF (matrix assisted laser desorption ionization-time of flight; Applied Biosystems, Darmstadt, Germany) Massenspektrometer (MS) festgesetzt (Dihazi et al. 2008).

\subsubsection{Datenbanksuche}

Die detektierten Peptidmassen, lieferten einen massenspezifischen Fingerabdruck entsprechender Proteine in Form von Tandem-Massenspektren. Zur Identifikation, Charakterisierung und Quantifizierung von Proteinen erfolgte mit Hilfe der Mascot Software (Matrix Science, London, UK, Vision 2.4.1) eine Datenbanksuche in der mass spectrometry protein sequences Datenbank (MSDB) bzw. der National Center for Biotechnology non-redundant (NCBInr) Datenbank Die Ergebnisse wurden anschließend mit der SwissProt Datenbank (für Homo sapiens, 20338 Einträge und Enzymverdauung mit Trypsin) abgeglichen. Während der Datenanalyse erfolgte keine Entpackung oder Deisotopisierung. Als Programm wurde eine Mascot Software gewählt welche eine Fragment-Ionen-Massentoleranz von 0,050 Da und lonentoleranz von 20 PPM nutzte. Der Cysteinbestandteil Carbamidomethyl wurde in der Mascot Software als spezifische Modifikation festgesetzt. Durch Desaminierung entstandene Aminogruppen der Aminosäuren Asparagin und Glutamin sowie Oxidationsprodukte von Methionin wurden in Mascot als variable Modifikationen festgelegt. 


\subsubsection{Proteinidentifikation}

Für die Validierung detektierter Peptide und der Proteinidentifikation wurde die Software Scaffold verwendet (Version: Scaffold_4.4.1.1, Proteom Software Inc., Portland, USA). Die Identifikation eines Peptids wurde akzeptiert, wenn eine Wahrscheinlichkeit $>95 \%$ durch den Peptid-Vorhersage-Algorithmus (Keller et al. 2002) unter Anwendung der Scaffold-delta-Massenkorrektur vorlag. Ein Protein galt erst ab einer Wahrscheinlichkeit von $>99 \%$ und mindestens 2 erkannten Peptiden als identifiziert. Dabei wurde für die Zuordnung von Proteinwahrscheinlichkeiten der Protein-Vorhersage-Algorithmus (Nesvizhskii et al. 2003) verwendet. Konnten Proteine aufgrund ähnlicher Peptide anhand der MS/MS-Analysen nicht unterschieden werden, wurden diese aus Gründen des Platzmangels gemeinsam gruppiert. Im Falle von Proteinen mit gemeinsamen signifikanten Peptidnachweisen wurden diese in Cluster zusammengefasst. Allen identifizierten Proteinen wurde zusätzlich eine entsprechende GO-Bezeichnung der NCBI (Ashburner et al. 2000) zugeordnet. 


\subsection{Studiendatenbank}

Inhalte der Datenbank enthalten Mess- und Untersuchungsergebnisse der Studienvisiten I und II, um diese gegenüberstellen zu können und eine statistische Auswertung zu ermöglichen.

Tab. 2.3: Erhobene Daten im Rahmen der Studie

\section{Patientenbezogene Daten}

Klinische Daten

- Risikofaktoren

- Endorganschäden

- Therapie der Endorganschäden

- Andere Begleiterkrankungen

Therapiebedingte Komplikationen Medikamente

Laborwerte

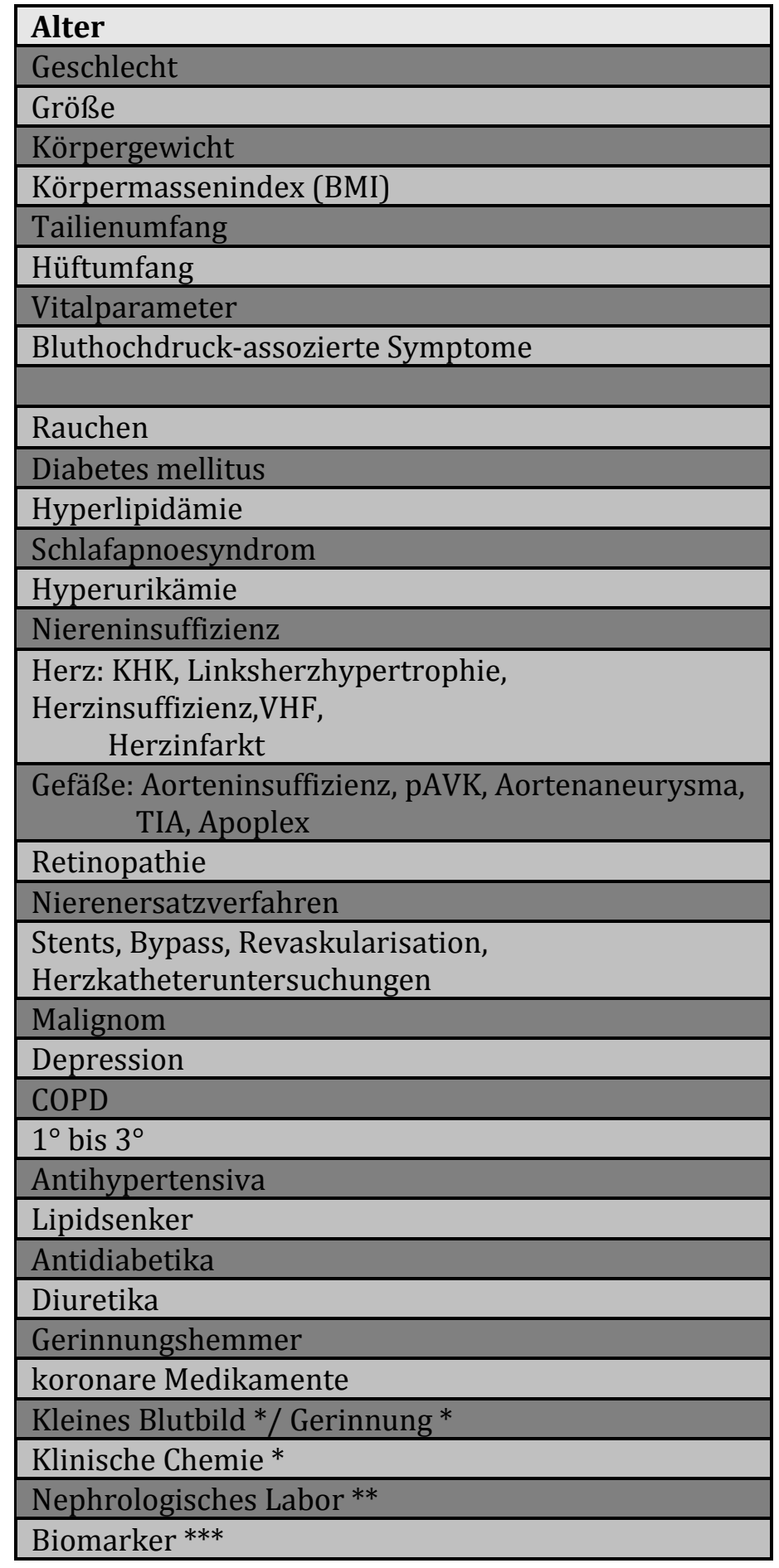

$\mathrm{BMI}=$ body-mass-index VHF = Vorhofflimmern; KHK = koronare Herzkrankheit; TIA = transitorische ischämische Attacke; COPD = chronisch-obstruktive Lungenerkrankung; ${ }^{*}$ siehe Tabelle 3.5, ${ }^{* *}$ siehe Tabelle $3.14,{ }^{* * *}$ siehe Tabellen 3.13 sowie 3.14 


\subsection{Auswertung und Statistik}

Die Statistiksoftware Statistica 12 und Microsoft Excel 2010 werteten die Daten aus. Vor Therapiebeginn (Visit I) wurden diese mit der BAT (Visit II) und Kontrollgruppe verglichen. Entweder wurde dabei ein unabhängiger Einstichproben-t-Test oder ChiQuadrat-Test zur Ermittlung der Mittelwerte und Verteilungen benutzt.

Abhängig vom Verlauf, wurden die zu untersuchenden Variablen mittels eines Zweistichproben-t-Tests oder Wilcoxon-Vorzeichen-Rang-Tests analysiert. Um die Daten auf ihre Normalverteilung hin zu prüfen, wurde der Shapiro-Wilk-Test angewendet. Eine Untersuchung auf mögliche Störfaktoren erfolgte mit Hilfe der Varianzanalyse (ANOVA). Der Chi-Quadrat-Test diente bei der statistischen Auswertung zum Vergleich von Kategorien. Die Ergebnisse wurden als mittlere \pm Standardabweichung (SD) oder als medianer Interquartilsabstand (IQR) für entsprechende Werte der Visits I und II angegeben. Über den PearsonsKorrelationkoeffizienten wurden Beziehungen von zwei linearen Variablen beschrieben, wobei Extremwerte in einigen Fällen von den Berechnungen ausgeschlossen wurden. Der Grenzwert für eine statistische Signifikanz wurde auf $p<0.05$ festgelegt. 


\section{Ergebnisse}

\subsection{Patientenkollektiv}

Von insgesamt 33 aufgenommenen Studienteilnehmern wurden im Verlauf zwei Patienten ausgeschlossen: Ein Patient verstarb aufgrund einer Pneumonie und ein weiterer Patient verpasste die Nachfolgeuntersuchungen.

Bei der anschließenden Auswertung $(n=31)$ wurden des Weiteren drei Patienten von der Analyse der SphygmoCor-Messung ausgeschlossen: Zwei Patienten zeigten ein Vorhofflimmern, ein Patient hatte einen Qualitätsindex $<80 \%$, und ein Patient musste wegen unzureichend vorliegender Urinproben von der Urinanalytik ausgeschlossen werden.

Das mittlere Alter der Patienten lag bei 60,74 \pm 10,49 Jahren, der mittlere body mass index (BMI) bei 32,23 $\pm 6,89 \mathrm{~kg} / \mathrm{m}^{2} .28$ Patienten (90\%) hatten Übergewicht mit einem BMI > $25 \mathrm{~kg} / \mathrm{m}^{2}$, wovon $17(55 \%)$ an Adipositas $\left(\mathrm{BMl}>30 \mathrm{~kg} / \mathrm{m}^{2}\right)$ litten.

Von den 31 Patienten (davon $45 \%$ männlich und $55 \%$ weiblich) hatten $90 \%$ eine chronische Niereninsuffizienz (CKD). Bei der Betrachtung des Nephropathie (NP)Typs konnten bei $58 \%$ der Patienten eine hypertensive NP, bei $26 \%$ eine diabetische/hypertensive NP und bei 6,5\% eine IgA-Nephritis unterschieden werden (siehe Tab. 3.1). Ein Patient war Nierentransplantatempfänger und zwei Patienten waren dialysepflichtig. Als weiterer kardio-vaskulärer Risikofaktor war bei $32 \%$ der Patienten ein Diabetes mellitus vorhanden, der seit mindestens zwölf Monaten vorlag. Bei $77 \%$ der Patienten kam eine Hyperlipoproteinämie vor, $71 \%$ hatten eine positive Raucheranamnese und $35 \%$ ein Schlafapnoesyndrom. Bei $32 \%$ der Patienten lag außerdem eine KHK sowie bei $16 \%$ ein Herzinfarkt vor (siehe Tab. 3.1).

Die Einteilung des Grades der Niereninsuffizienz erfolgte anhand der errechneten GFR unter Anwendung der CKD-EPI Cystatin C-Formel. Hierbei fanden sich ein Niereninsuffizienz-Stadium $\geq 3$ bei 17 Patienten, darunter zwei Patienten mit dialysepflichtigem ESRD-Stadium 5D und ein Nierentransplantatempfänger im Stadium 4T.

Bei zwölf Patienten wurde mindestens neun Monate im Vorfeld der BAT-Therapie eine renale Denervierung durchgeführt, die jedoch nicht zur erwünschten Blutdruckkontrolle 
Tab. 3.1: Patientencharakteristika

\begin{tabular}{|c|c|}
\hline$n=31$ & Baseline \\
\hline $\begin{array}{l}\text { Ethnie (kaukasisch) } \\
\text { Geschlecht: } \begin{array}{l}\text { männlich } \\
\text { weiblich }\end{array}\end{array}$ & $\begin{array}{l}31(100 \%) \\
14(45 \%) \\
17(55 \%)\end{array}$ \\
\hline $\begin{array}{l}\text { Alter, Jahre } \\
\text { Körpergröße, m } \\
\text { Hüftumfang, cm } \\
\text { Taillenumfang, cm } \\
\text { Taille-Hüft Ratio: männlich } \\
\quad \text { weiblich }\end{array}$ & $\begin{aligned} 60,74 & \pm 10,49 \\
1,67 & \pm 0,086 \\
109,74 & \pm 16,21 \\
107,03 & \pm 15,68 \\
1,1 & \pm 0,97 \\
0,9 & \pm 0,73\end{aligned}$ \\
\hline $\begin{array}{l}\text { Gewicht, } \mathrm{kg} \\
\mathrm{BMI}, \mathrm{kg} / \mathrm{m}^{2} \\
\text { Normalgewicht } \\
\text { Übergewicht }(\mathrm{BMI}>25 \text { bis }<30) \\
\text { Fettleibigkeit }(\mathrm{BMI}>\mathbf{3 0})\end{array}$ & $\begin{array}{l}90,14 \pm 20,61 \\
32,23 \pm 6,89 \\
3(10 \%) \\
11(35 \%) \\
17(55 \%)\end{array}$ \\
\hline $\begin{array}{l}\text { Relevante Begleiterkrankungen: } \\
\text { Diabetes mellitus } \\
\quad \text { orale Antidiabetika } \\
\quad \text { insulinabhängig } \\
\text { Hyperlipoproteinämie } \\
\text { Herzinsuffizienz } \\
\text { koronare Herzerkrankung } \\
\text { Z.n. Herzinfarkt } \\
\text { Schlafapnoesyndrom } \\
\text { CKD } \\
\text { I } \\
\text { II } \\
\text { III } \\
\text { IV } \\
\text { V }\end{array}$ & $\begin{aligned} & 10(32 \%) \\
& 3(10 \%) \\
& 8(26 \%) \\
& 24(77 \%) \\
& 5(16 \%) \\
& 10(32 \%) \\
& 5(16 \%) \\
& 11(35 \%) \\
& 3(9,7 \%) \\
& 11(35 \%) \\
& 10(32 \%) \\
& 5(16 \%) \\
& 2(6,5 \%)\end{aligned}$ \\
\hline $\begin{aligned} \text { Typ der Nephropathie } \\
\bullet \quad \text { hypertensive Nephropathie } \\
\bullet \quad \text { diabetisch/hypertensive } \\
\text { Nephropathie } \\
\bullet \quad \text { IgA-Nephritis } \\
\text { Nierentransplantation } \\
\text { dialysepflichtige Patienten }\end{aligned}$ & $\begin{aligned} 18 & (58 \%) \\
8 & (26 \%) \\
& \\
2 & (6,5 \%) \\
1 & (3 \%) \\
2 & (6,5 \%)\end{aligned}$ \\
\hline Raucheranamnese & $22(71 \%)$ \\
\hline $\begin{array}{l}\text { Z.n. renaler Denervierung } \\
\text { koronare Revaskularistation } \\
\text { periphere Revaskularistation } \\
\text { Bypass-Operation } \\
\text { RV-Schrittmacher } \\
\text { zerebrovaskuläre Erkrankung } \\
\text { AV-Block }{ }^{\circ}\end{array}$ & $\begin{aligned} & 12(39 \%) \\
& 4(13 \%) \\
& 1(3 \%) \\
& 2(6,5 \%) \\
& 1(3 \%) \\
& 2(6,5 \%) \\
& 2(6,5 \%)\end{aligned}$ \\
\hline
\end{tabular}

Daten dargestellt als $\mathrm{MW} \pm$ Stabw. oder $\mathrm{n}(\%) ; \mathrm{BMI}=$ body-mass-index, Z.n. $=$ Zustand nach, $\mathrm{CKD}=$ chronic kidney disease, IgA = Immunglobulin der Gruppe $\mathrm{A} ; \mathrm{RV}=$ rechtsventrikulär; $\mathrm{AV}$ = atrioventrikulär; $\mathrm{CKD}-\mathrm{EPI}=$ Chronic Kidney Disease Epidemiology Collaboration; die Einteilung der CKD-Stadien erfolgte anhand der CKD-EPI Cystatin C-Formel 
führte. Weitere Interventionen waren koronare und periphere Revaskularisationen, Bypass-Operationen, eine Resynchronisationstherapie mittels RV-Schrittmacher und zerebrovaskuläre Erkrankungen (siehe Tab. 3.1). Die Routineparameter der Gerinnung, Blutzellen, Elektrolyten sowie Leber- und Entzündungswerte waren zum Studieneinschluss unauffällig (siehe Tab. 3.5). Die Baseline-Charakteristika sind in Tabelle 3.1. zusammengefasst.

\subsection{Klinische Ergebnisse}

\subsubsection{BuP, ABPM und Antihypertensiva}

Nach sechs Monaten BAT sank der periphere systolische, diastolische und MAD des BuP signifikant $(p<0,01)$ (siehe Abb. 3.1 und Tab. 3.2). Der mittlere Abfall der systolischen 24h-Langzeitblutdruckmessungen (ABPM) lag bei $-3,9 \mathrm{mmHg} \pm 17,7$ $(p=0,24)$. Wegen Fehlmessungen der ABPM-Geräte im Verlauf der Studienvisiten, mussten zwei Patienten von der statistischen Auswertung ausgeschlossen werden.

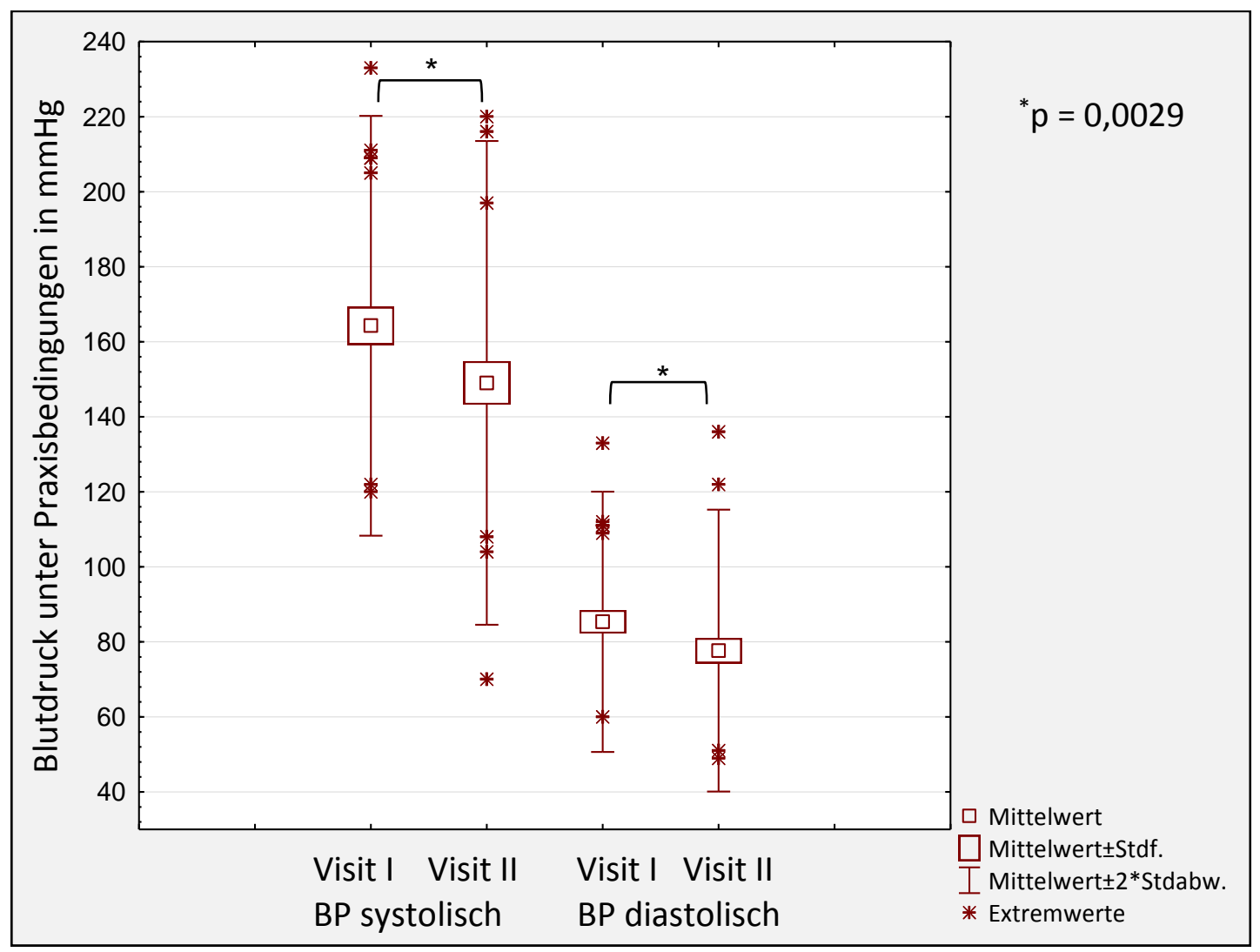

Abb. 3.1: Verlauf systolischer und diastolischer Werte des BuP im Zeitverlauf; BP = Blutdruck, Stdf. $=$ Standardfehler, Stdabw. $=$ Standardabweichung 
Tab. 3.2: Ergebnisse der BuP- und ABPM-Blutdruckmessungen und Responder

\begin{tabular}{|c|c|c|c|}
\hline & Baseline & Monat 6 & $\mathbf{P}$ \\
\hline \multicolumn{4}{|l|}{ BuP, $n=31$} \\
\hline systolisch, mmHg & $164,3 \pm 27,98$ & $149,0 \pm 32,2$ & 0,0029 \\
\hline diastolisch, mmHg & $85,4 \pm 17,4$ & $77,7 \pm 18,8$ & 0,0029 \\
\hline MAD, mmHg & $116,9 \pm 19,9$ & $106,2 \pm 22,9$ & 0,0017 \\
\hline Herzfrequenz (/min) & $71,7 \pm 12,3$ & $68,7 \pm 10,7$ & 0,15 \\
\hline \multicolumn{4}{|l|}{ ABPM, $n=29$} \\
\hline \multicolumn{4}{|l|}{ Gesamt (mmHg) } \\
\hline MAD & $102,7 \pm 13,2$ & $100,7 \pm 20,96$ & 0,49 \\
\hline systolisch & $144,6 \pm 17,0$ & $140,7 \pm 26,3$ & 0,24 \\
\hline diastolisch & $79,3 \pm 13,1$ & $76,8 \pm 18,2$ & 0,29 \\
\hline Herzfrequenz (/min) & $70,2 \pm 9,98$ & $69,1 \pm 11,3$ & 0,54 \\
\hline systolisch max. & $182,6 \pm 21,4$ & $183,5 \pm 36,2$ & 0,89 \\
\hline systolisch min. & $107,4 \pm 17,9$ & $100,5 \pm 23,1$ & 0,09 \\
\hline diastolisch max. & $110,9 \pm 19,9$ & $107,1 \pm 29,7$ & 0,43 \\
\hline diastolisch min. & $54,07 \pm 10,8$ & $52,1 \pm 13,4$ & 0,45 \\
\hline MAD max. & $133,9 \pm 15,4$ & $130,7 \pm 27,5$ & 0,53 \\
\hline MAD min & $74,2 \pm 9,7$ & $69,6 \pm 14,8$ & 0,17 \\
\hline Pulsdruck & $61,8 \pm 12,6$ & $60,5 \pm 14$ & 0,41 \\
\hline \multicolumn{4}{|l|}{ Nachtverlauf (mmHg) } \\
\hline MAD & $97,0 \pm 13,4$ & $93,7 \pm 19,3$ & 0,2 \\
\hline systolisch & $138,3 \pm 17,3$ & $132,3 \pm 24,2$ & 0,057 \\
\hline diastolisch & $73,8 \pm 12,9$ & $71,1 \pm 16,3$ & 0,19 \\
\hline Herzfrequenz (/min) & $65,8 \pm 8,3$ & $64,6 \pm 9,6$ & 0,34 \\
\hline Dipper & $16(55,2 \%)$ & $12(41,4 \%)$ & 0,26 \\
\hline Non-Dipper & $13(44,8 \%)$ & $17(58,6 \%)$ & 0,26 \\
\hline Inverted Dipper & $1(3,5 \%)$ & $4(13,8 \%)$ & 0,22 \\
\hline \multicolumn{4}{|l|}{ Tagesverlauf (mmHg) } \\
\hline MAD & $106,3 \pm 13,6$ & $103,5 \pm 22,4$ & 0,4 \\
\hline systolisch & $148,3 \pm 17,7$ & $143,9 \pm 28,4$ & 0,26 \\
\hline diastolisch & $82,4 \pm 13,3$ & $79,6 \pm 18,9$ & 0,25 \\
\hline Herzfrequenz (/min) & $71,8 \pm 10,3$ & $71,5 \pm 13,0$ & 0,91 \\
\hline Responder & & $19 / 31(61 \%)$ & \\
\hline
\end{tabular}

Daten dargestellt als MW \pm Stabw. sowie absoluter bzw. prozentualer Anteil, $\mathrm{n}(\%) ; \mathrm{MAD}=$ mittlerer arterieller Druck, $\min .=$ Minimum, max.$=$ Maximum

Hinsichtlich der durchschnittlichen Veränderung und Standardabweichungen (SD) systolischer ABPMs zeigten Poweranalysen einer Stichprobengröße von 63 Patienten mit einer Stärke von $80 \%$ und $\alpha=0.05$ eine statistische Signifikanz zwischen Baselineund Sechsmonatsdaten.

Bei der ANOVA zwischen möglichen Störvariablen (RD, D.m., Geschlecht und Raucher) und dem Blutdruck zeigte sich, dass eine RD Einfluss auf systolische Werte des BuP $(p=0,049)$ zur Visit I sowie auf den zeitlichen Verlauf der mittleren arteriellen und systolischen Blutdruckmessungen in der ABPM nimmt ( $p=0,03$ bzw. $p=0,04$ ) (siehe Abb. 3.2) Die Variablen D.m., Geschlecht und Raucher waren im zeitlichen Verlauf gegenüber den BuP-Blutdruckwerten unabhängig und in der ABPM unauffällig. 
Eine genaue Darstellung der einzelnen Subgruppenanalysen zeigen die Tabellen 3.6 bis 3.9 .

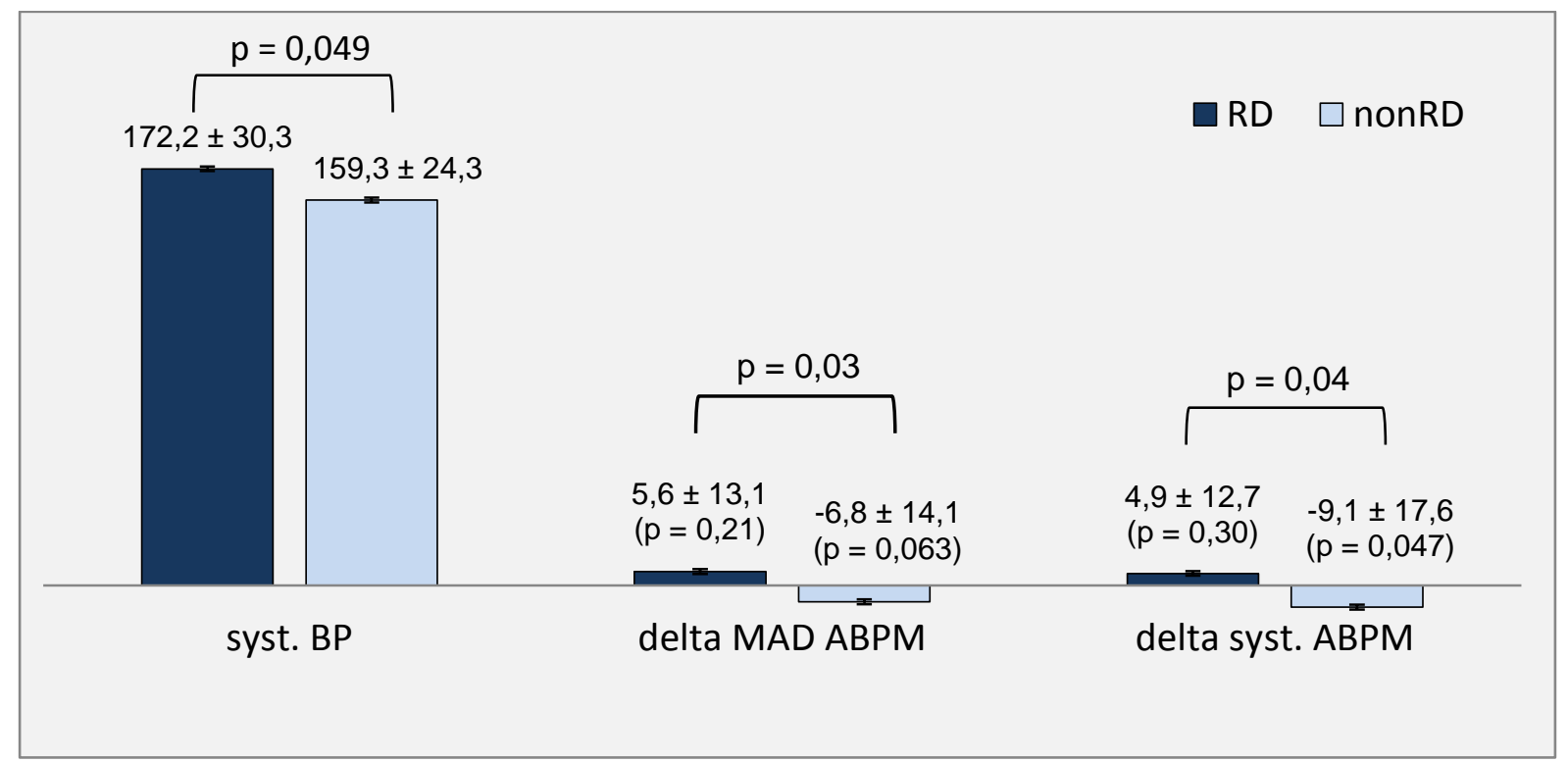

Abb. 3.2: Einfluss der RD auf den syst. BuP und des $\triangle M A D$ sowie $\triangle$ syst. BP im zeitlichen Verlauf der ABPM; Daten dargestellt als $\mathrm{MW} \pm$ Stabw, $\mathrm{RD}=$ renale Denervierung, $\mathrm{BP}=$ blood pressure, $\mathrm{MAD}=$ mittlerer arterieller Druck, $\mathrm{ABPM}=$ ambulantory blood pressure mesurement, $\Delta$ (delta) $=$ Veränderung

Die durchschnittliche Anzahl verschriebener antihypertensiver Medikamente fiel von $6,5 \pm 1,6$ auf 6,1 $\pm 1,7(p=0,09)$ ab. Die Menge und/oder Dosis antihypertensiver Arzneien konnte bei 21 von 31 Patienten (68\%) reduziert werden (siehe Tab. 3.3). Analog zur Einteilung nach RD in Responder und Nicht-Responder [i.e. Responder mit einer systolischen BuP-Senkung von $\geq 10 \mathrm{mmHg}$ und/oder $\geq 5 \mathrm{mmHg}$

Tab. 3.3: Medikamentenübersicht

\begin{tabular}{|l|r|r|l|}
\hline $\mathbf{n = 3 1}$ & \multicolumn{1}{|c|}{ Baseline } & \multicolumn{1}{c|}{ Monat 6 } & $\boldsymbol{p}$ \\
\hline Anzahl der Antihypertensiva & $6,5 \pm 1,6$ & $6,1 \pm 1,7$ & 0,09 \\
Aufteilung nach Klassen: & & & \\
$\quad$ ACE-Hemmer & $14(45 \%)$ & $14(45 \%)$ & \\
AT 1 -Blocker & $18(58 \%)$ & $17(54 \%)$ & \\
Aldosteronrezeptorantagonisten & $7(23 \%)$ & $6(19 \%)$ & \\
Renininhibitoren & $7(23 \%)$ & $6(19 \%)$ & \\
Beta-Blocker & $24(77 \%)$ & $24(77 \%)$ & \\
Kalzium-Kanalblocker & $23(74 \%)$ & $23(74 \%)$ & \\
Schleifendiuretika & $17(54 \%)$ & $19(61 \%)$ & \\
Thiaziddiuretika & $25(80 \%)$ & $23(74 \%)$ & \\
Alpha-1-Rezeptorblocker & $22(71 \%)$ & $19(61 \%)$ & \\
Alpha-2-adrenerge Agonisten & $28(90 \%)$ & $20(64 \%)$ & \\
Direkte Vasodilatoren & $14(45 \%)$ & $15(48 \%)$ & \\
\hline Beenden oder Dosisreduktion von & & $21 / 31(68 \%)$ & \\
mind. einer Antihypertensivaklasse: & & & \\
\hline
\end{tabular}

Daten dargestellt als MW \pm Stabw. oder absoluten bzw. prozentualen Anteil, $\mathrm{n}(\%)$; $\mathrm{ACE}=$ angiotensin-converting-enzyme, $\mathrm{AT}_{1}=$ Angiotensin $_{1}$ 
in der ABPM (Mahfoud et al. 2013)], wurden zwölf Patienten (39\%) als NichtResponder der BAT klassifiziert. Die Ansprechrate lag bei $61 \%$ bezüglich des Abfalls systolischer BuP-Werte (siehe Tab. 3.2). Die Veränderungen in den ABPMMessungen erreichten nicht das Signifikanzniveau.

\subsubsection{Patientencharakteristika, Symptome, Routineparameter}

Die Einteilung in entsprechende BMI-Stadien verbesserte sich bei vier Patienten bzw. führte bei einem Patienten zur Verschlechterung. Zu den Symptomen - die $\geq 50 \%$ der Patienten bei der Visit I angaben - zählten eine innere Unruhe (52\%), Tagesmüdigkeit und Leistungsschwäche (52\%), eine auffallend rote Gesichtsfarbe (52\%) und eine Nykturie (65\%). Eine signifikante Veränderung zeigte sich im Verlauf der BAT hinsichtlich der Müdigkeit bzw. Leistungsschwäche und der empfundenen inneren Unruhe $(p<0,05)$ (siehe Tab. 3.4).

Tab. 3.4: Symptome

\begin{tabular}{|l|r|r|r|}
$\mathbf{n} \mathbf{n} 3 \mathbf{3 1}$ Baseline & $\mathbf{6}$ Monate BAT & \multicolumn{1}{c|}{$\mathbf{3 1}$} & $\mathbf{3 1}$ \\
\hline Belastungsdyspnoe & $14(45 \%)$ & $15(48 \%)$ & 0,69 \\
Ruhedyspnoe & $0(0 \%)$ & $3(10 \%)$ & 0,11 \\
Orthopnoe & $7(23 \%)$ & $9(29 \%)$ & 0,58 \\
Periphere Ödeme & $9(29 \%)$ & $8(26 \%)$ & 0,74 \\
Pulmonale Rasselgeräusche & $1(3 \%)$ & $3(10 \%)$ & 0,18 \\
Kopfschmerzen & $14(45 \%)$ & $9(29 \%)$ & 0,18 \\
Innere Unruhe & $16(52 \%)$ & $9(29 \%)$ & $\mathbf{0 , 0 3 8}$ \\
Schwindelgefühl & $14(45 \%)$ & $11(35 \%)$ & 0,37 \\
Müdigkeit/Leistungsschwäche & $16(52 \%)$ & $21(68 \%)$ & $\mathbf{0 , 0 4 3}$ \\
Nasenbluten & $3(10 \%)$ & $1(3 \%)$ & 0,18 \\
Kurzatmigkeit & $10(32 \%)$ & $7(23 \%)$ & 0,31 \\
rote Gesichtsfarbe & $16(52 \%)$ & $13(42 \%)$ & 0,31 \\
Sehstörungen & $10(32 \%)$ & $10(32 \%)$ & 1,00 \\
Übelkeit & $5(16 \%)$ & $4(13 \%)$ & 0,69 \\
Nykturie & $20(65 \%)$ & $24(77 \%)$ & 0,21 \\
1 x nachts & 6 & 11 & 0,18 \\
2 x nachts & 11 & 8 & 0,31 \\
$3 x$ nachts & 2 & 3 & 0,69 \\
4 x nachts & 1 & 2 & 0,6 \\
\hline
\end{tabular}

Die Daten geben den absoluten und prozentualen Anteil an, $\mathrm{n}(\%)$.

Die Routineparameter stellten sich, bis auf die aktivierte partielle Thromboplastinzeit (aPTT) $(p<0,001)$ und alkalische Phosphatase (AP) $(p<0,05)$, im Vergleich zum präinterventionellen Status im gesamten Beobachtungszeitraum unverändert stabil dar (siehe Tab. 3.5). 
Tab. 3.5: Routineparameter

\begin{tabular}{|c|c|c|c|}
\hline & Baseline & Monat 6 & $\boldsymbol{P}$ \\
\hline \multicolumn{4}{|l|}{ Gerinnung } \\
\hline $\begin{array}{l}\text { Quick (\%) } \\
\text { aPTT (sec) }\end{array}$ & $\begin{array}{c}103,8 \pm 19,8 \\
27,7 \pm 4,9\end{array}$ & $\begin{array}{l}98,8 \pm 25,2 \\
30,7+5,8\end{array}$ & $\begin{array}{l}0,21 \\
0.00028\end{array}$ \\
\hline \multicolumn{4}{|l|}{ Blutbild } \\
\hline $\mathrm{Hb}(\mathrm{g} / \mathrm{dl})$ & $13,6 \pm 1,4$ & $13,6 \pm 1,5$ & 0,92 \\
\hline Hk (\%) & $40,7 \pm 4,3$ & $40,9 \pm 4,5$ & 0,7 \\
\hline Erythrozyten $\left(10^{6} / \mu \mathrm{l}\right)$ & $4,6 \pm 0,5$ & $4,6 \pm 0,6$ & 0,86 \\
\hline $\operatorname{MCV}(\mathrm{fl})$ & $88,8 \pm 6,1$ & $89,6 \pm 6,2$ & 0,08 \\
\hline $\mathrm{MCH}(\mathrm{pg})$ & $29,7 \pm 2,3$ & $29,9 \pm 2,5$ & 0,39 \\
\hline $\mathrm{MCHC}(\mathrm{g} / \mathrm{dl})$ & $33,5 \pm 1,0$ & $33,3 \pm 0,9$ & 0,34 \\
\hline Thrombozyten $\left(10^{3} / \mu \mathrm{l}\right)$ & $233,4 \pm 67,4$ & $230,7 \pm 70,7$ & 0,65 \\
\hline Leukozyten $\left(10^{3} / \mu \mathrm{l}\right)$ & $7,6 \pm 2,7$ & $7,1 \pm 2,3$ & 0,13 \\
\hline \multicolumn{4}{|l|}{ Elektrolyte } \\
\hline Natrium (mmol/l) & $140,9 \pm 2,5$ & $140,8 \pm 2,3$ & 0,86 \\
\hline Kalium (mmol/l) & $4,0 \pm 0,6$ & $4,1 \pm 0,6$ & 0,28 \\
\hline Calcium(mmol/l) & $2,4 \pm 0,1$ & $2,4 \pm 0,1$ & 0,60 \\
\hline \multicolumn{4}{|l|}{ Leberwerte } \\
\hline AST (U/I) & $27,0 \pm 5,3$ & $27,1 \pm 7,0$ & 0,96 \\
\hline ALT (U/I) & $27,4 \pm 10,2$ & $27,7 \pm 13,0$ & 0,89 \\
\hline$A P(U / I)$ & $75,9 \pm 18,2$ & $81,3 \pm 21,0$ & 0,0156 \\
\hline GGT (U/I) & $46,7 \pm 30,5$ & $46,6 \pm 34,3$ & 0,98 \\
\hline \multicolumn{4}{|l|}{ Entzündungswerte } \\
\hline CRP (mg/l) & $3,8 \pm 3,9$ & $5,5 \pm 5,4$ & 0,09 \\
\hline
\end{tabular}

Daten dargestellt als MW \pm Stabw.; aPTT = aktivierte partielle Thromboplastinzeit, $\mathrm{Hb}=$ Hämoglobin, $\mathrm{Hk}=$ Hämatokrit, $\mathrm{MCV}=$ mean corpuscular volume, $\mathrm{MCH}=$ mean cellular hemoglobin, $\mathrm{MCHC}=$ mean corpuscular hemoglobin concentration, AST = Aspartat-Aminotransferase, ALT = Alanin-Aminotransferase, AP = alkalische Phosphatase, GGT = Gamma-Glutamyl-Transferase, CRP = C-reaktives Protein

\subsubsection{CKD-Stadien}

Im Verlauf der sechsmonatigen BAT kam es in jeweils fünf Fällen zu einer Verbesserung bzw. Verschlechterung der eGFR-abhängigen CKD-Stadien-Einteilung. Bei der Betrachtung der Variablen Geschlecht, RD/keine RD und D.m./kein D.m. auf die CKD-Stadien-Einteilung bei der Visit I und Visit II, zeigte sich im Kruskal-WallisANOVA-Test kein signifikanter Unterschied (Geschlecht: CKD-Stadien zur Visit I $p=$ 0,63; CKD-Stadien zur Visit II p=0,24| RD: CKD-Stadien zur Visit I p =0,48; CKDStadien zur Visit II $p=0,69 \mid D . m .:$ CKD-Stadien zur Visit I $p=0,96$; CKD-Stadien zur Visit II $p=0,33)$. Ein signifikanter Einfluss dieser Variablen auf eine Verbesserung bzw. Verschlechterung des CKD-Stadiums im Verlauf der sechsmonatigen BAT konnte nur für die Variable D.m. ( $p=0,04$ ) gefunden werden (für Geschlecht: $p=0,211$; für RD: $p$ $=0,058)$. Eine genauere Untersuchung deckte bei vier von neun Diabetikern gegenüber einem von zwanzig Nichtdiabetikern eine Verschlechterung ihres CKD- 
Stadiums auf. Eine daraufhin durchgeführte Korrelation der Variable D.m. gegenüber dem CKD-Stadium I bis IV zur Visit I und II zeigte, dass Diabetiker im Verlauf der Therapie zu einer Änderung ihres CKD-Stadiums neigen (für D.m. $r=0,63$; für kein D.m., $r=0,76)$. Bei einer geringen Stichprobengröße und einem $p<0,05$ wurde im Vergleich zwischen der CKD-Stadien-Verschlechterung beider Gruppen (D.m. versus kein D.m.) im Fisher-Test ein signifikanter Unterschied knapp verfehlt $(p=0,0586)$. 
Tab. 3.6:Subgruppenanalyse von Patienten mit RD und ohne RD

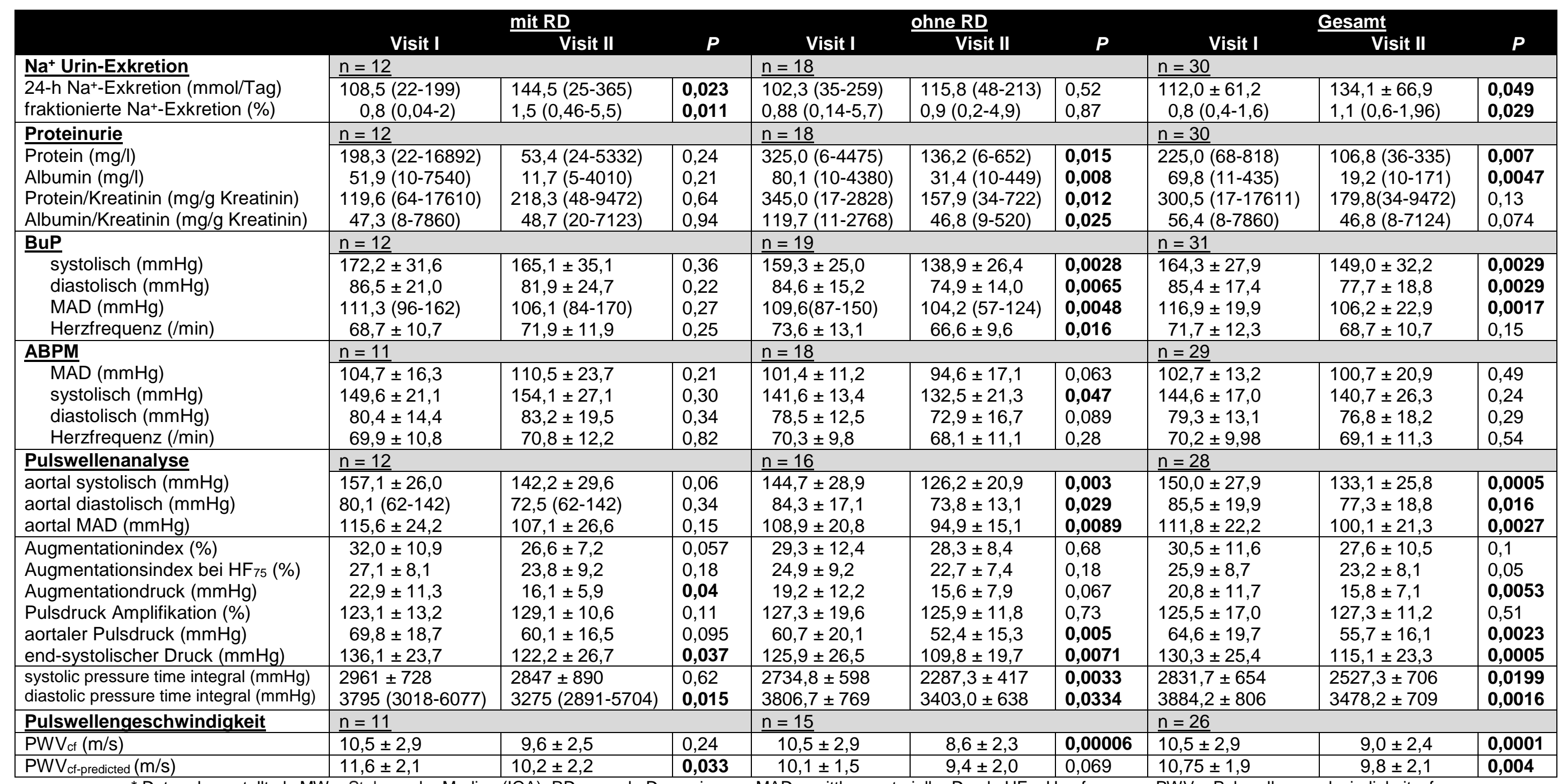

${ }^{*}$ Daten dargestellt als MW \pm Stabw. oder Median (IQA); RD = renale De
carotidofemoral, $\mathrm{n}=$ Fallzahl, BuP = Blutdruck unter Praxisbedingungen 
Tab. 3.7:Subgruppenanalyse von Patienten mit positiver Raucheranamnese und Nichtrauchern (Beschriftung und Erläuterung entspricht Tab. 3.6*)

\begin{tabular}{|c|c|c|c|c|c|c|c|c|c|}
\hline & \multicolumn{3}{|c|}{ Raucher } & \multicolumn{3}{|c|}{ Nicht-Raucher } & \multicolumn{3}{|c|}{ Gesamt } \\
\hline & \multirow{2}{*}{\multicolumn{3}{|c|}{$\mathrm{n}=22^{\text {Visit I }}$}} & & Visit II & $\boldsymbol{P}$ & Visit I & Visit II & $\boldsymbol{P}$ \\
\hline \multirow{2}{*}{$\begin{array}{l}\mathrm{Na}^{+} \text {Urin-Exkretion } \\
\text { 24-h } \mathrm{Na}^{+}-\text {Exkretion (mmol/Tag) } \\
\text { fraktionierte } \mathrm{Na}^{+}-\text {Exkretion (\%) }\end{array}$} & & & & \multicolumn{3}{|l|}{$\mathrm{n}=8$} & \multicolumn{3}{|l|}{$\underline{n}=30$} \\
\hline & $\begin{array}{l}\overline{107(22-259)} \\
0,8(0,04-5,8)\end{array}$ & $\begin{array}{l}141(25-365) \\
1,4(0,5-5,5)\end{array}$ & $\begin{array}{l}0,019 \\
0,088\end{array}$ & $\begin{array}{l}\overline{90(61-225)} \\
0,8(0,2-1,6)\end{array}$ & $\begin{array}{l}105(48-193) \\
0,7(0,2-4,7)\end{array}$ & $\begin{array}{l}0,28 \\
0,48\end{array}$ & $\begin{array}{r}\overline{112,0} \pm 61,2 \\
0,8(0,4-1,6)\end{array}$ & $\begin{array}{l}134,1 \pm 66,9 \\
1,1(0,6-1,96)\end{array}$ & $\begin{array}{l}0,049 \\
0,029\end{array}$ \\
\hline \multirow[b]{2}{*}{$\begin{array}{l}\text { Proteinurie } \\
\text { Protein }(\mathrm{mg} / \mathrm{l}) \\
\text { Albumin (mg/l) } \\
\text { Protein/Kreatinin (mg/g Kreatinin) } \\
\text { Albumin/Kreatinin (mg/g Kreatinin) }\end{array}$} & \multicolumn{3}{|l|}{$\underline{n}=22$} & \multicolumn{3}{|l|}{$\mathrm{n}=8$} & \multicolumn{3}{|l|}{$n=30$} \\
\hline & $\begin{array}{c}225(6-16892) \\
80(10-7540) \\
352(17-17611) \\
162(8-7861)\end{array}$ & $\begin{array}{c}144(6-5332) \\
45(7-4010) \\
204(34-9472) \\
60(9-7124)\end{array}$ & $\begin{array}{l}\mathbf{0 , 0 0 7 8} \\
\mathbf{0 , 0 1 5} \\
0,32 \\
0,35\end{array}$ & $\begin{array}{l}181(22-4475) \\
40(10-4380) \\
182(50-2828) \\
50(14-2768)\end{array}$ & $\begin{array}{l}69(12-582) \\
12(5-366) \\
126(48-249) \\
35(10-135)\end{array}$ & $\begin{array}{l}0,67 \\
0,12 \\
0,21 \\
\mathbf{0 , 0 3 5}\end{array}$ & $\begin{array}{l}225(68-818) \\
69,8(11-435) \\
300,5(17-17611) \\
56,4(8-7860)\end{array}$ & $\begin{aligned} 106,8 & (36-335) \\
19,2 & (10-171) \\
179,8 & (34-9472) \\
46,8 & (8-7124)\end{aligned}$ & $\begin{array}{l}\mathbf{0 , 0 0 7} \\
\mathbf{0 , 0 0 4 7} \\
0,13 \\
0,074\end{array}$ \\
\hline \multirow{2}{*}{$\begin{array}{l}\text { BuP } \\
\text { systolisch }(\mathrm{mmHg}) \\
\text { diastolisch }(\mathrm{mmHg}) \\
\text { MAD }(\mathrm{mmHg}) \\
\text { Herzfrequenz (/min) }\end{array}$} & \multicolumn{3}{|l|}{$\underline{n=22}$} & \multicolumn{3}{|l|}{$\underline{\mathrm{n}=9}$} & \multicolumn{3}{|l|}{$\mathrm{n}=31$} \\
\hline & $\begin{array}{r}163,7 \pm 28,9 \\
86,8 \pm 18,7 \\
117,6 \pm 21,0 \\
69,0 \pm 10,5 \\
\end{array}$ & $\begin{aligned} 148,4 & \pm 35,1 \\
79,2 & \pm 20,2 \\
106,9 & \pm 24,8 \\
68,5 & \pm 9,7\end{aligned}$ & $\begin{array}{l}0,02 \\
0,02 \\
0,015 \\
0,83\end{array}$ & $\begin{aligned} 165,6 & \pm 27,1 \\
81,9 & \pm 13,9 \\
115,4 & \pm 18 \\
78,4 & \pm 14,3\end{aligned}$ & $\begin{array}{r}150,6 \pm 25,6 \\
73,9 \pm 15,1 \\
104,6 \pm 18,7 \\
69,0 \pm 13,7\end{array}$ & $\begin{array}{l}0,056 \\
0,067 \\
\mathbf{0 , 0 4 7} \\
0,06\end{array}$ & $\begin{array}{r}164,3 \pm 27,9 \\
85,4 \pm 17,4 \\
116,9 \pm 19,9 \\
71,7 \pm 12,3\end{array}$ & $\begin{array}{r}149,0 \pm 32,2 \\
77,7 \pm 18,8 \\
106,2 \pm 22,9 \\
68,7 \pm 10,7\end{array}$ & $\begin{array}{l}0,0029 \\
0,0029 \\
0,0017 \\
0,15\end{array}$ \\
\hline \multirow{2}{*}{$\begin{array}{l}\text { ABPM } \\
\text { MAD }(\mathrm{mmHg}) \\
\text { systolisch }(\mathrm{mmHg}) \\
\text { diastolisch }(\mathrm{mmHg}) \\
\text { Herzfrequenz }(/ \mathrm{min})\end{array}$} & \multicolumn{3}{|l|}{$\mathrm{n}=20$} & \multicolumn{3}{|l|}{$\mathrm{n}=9$} & \multicolumn{3}{|l|}{$\mathrm{n}=29$} \\
\hline & $\begin{array}{c}103,7 \pm 14,3 \\
144,0 \pm 19,3 \\
81,4 \pm 13,4 \\
69,9 \pm 9,9\end{array}$ & $\begin{array}{r}102,2 \pm 22,9 \\
141,3 \pm 28,6 \\
78,7 \pm 19,9 \\
69,0 \pm 10,1\end{array}$ & $\begin{array}{l}0,69 \\
0,46 \\
0,36 \\
0,69\end{array}$ & $\begin{array}{r}\overline{100,5} \pm 10,6 \\
145,9 \pm 11,4 \\
74,6 \pm 11,5 \\
70,9 \pm 10,8\end{array}$ & $\begin{array}{r}97,2 \pm 16,3 \\
139,5 \pm 22,0 \\
72,6 \pm 13,8 \\
69,2 \pm 14,3\end{array}$ & $\begin{array}{l}0,53 \\
0,38 \\
0,63 \\
0,64\end{array}$ & $\begin{array}{r}102,7 \pm 13,2 \\
144,6 \pm 17,0 \\
79,3 \pm 13,1 \\
70,2 \pm 9,98\end{array}$ & $\begin{array}{r}100,7 \pm 20,9 \\
140,7 \pm 26,3 \\
76,8 \pm 18,2 \\
69,1 \pm 11,3\end{array}$ & $\begin{array}{l}0,49 \\
0,24 \\
0,29 \\
0,54\end{array}$ \\
\hline \multirow{2}{*}{$\begin{array}{l}\text { Pulswellenanalyse } \\
\text { aortal systolisch }(\mathrm{mmHg}) \\
\text { aortal diastolisch }(\mathrm{mmHg}) \\
\text { aortal MAD }(\mathrm{mmHg})\end{array}$} & \multicolumn{3}{|l|}{$\underline{n}=19$} & \multicolumn{3}{|l|}{$\underline{n=9}$} & \multicolumn{3}{|l|}{$\mathrm{n}=28$} \\
\hline & $\begin{array}{r}151,6 \pm 31,2 \\
88,2 \pm 21,5 \\
113,9 \pm 24,7 \\
\end{array}$ & $\begin{array}{r}133,3 \pm 26,9 \\
79,5 \pm 19,3 \\
101,7 \pm 21,8\end{array}$ & $\begin{array}{l}0,0019 \\
0,019 \\
0,005\end{array}$ & $\begin{array}{r}146,8 \pm 20,6 \\
79,8 \pm 15,7 \\
107,3 \pm 15,9\end{array}$ & $\begin{array}{r}132,5 \pm 24,9 \\
72,6 \pm 17,7 \\
96,7 \pm 20,9\end{array}$ & $\begin{array}{l}0,12 \\
0,35 \\
0,21\end{array}$ & $\begin{array}{r}150,0 \pm 27,9 \\
85,5 \pm 19,9 \\
111,8 \pm 22,2\end{array}$ & $\begin{array}{r}133,1 \pm 25,8 \\
77,3 \pm 18,8 \\
100,1 \pm 21,3\end{array}$ & $\begin{array}{l}0,0005 \\
0,016 \\
0,0027\end{array}$ \\
\hline $\begin{array}{l}\text { Augmentationindex (\%) } \\
\text { Augmentationsindex bei HF } 75 \text { (\%) } \\
\text { Augmentationdruck (mmHg) } \\
\text { Pulsdruck Amplifikation (\%) } \\
\text { aortaler Pulsdruck (mmHg) } \\
\text { end-systolischer Druck }(\mathrm{mmHg})\end{array}$ & $\begin{array}{r}33,1 \pm 9,7 \\
27,4 \pm 8,8 \\
21,9 \pm 10,9 \\
122,2 \pm 12,4 \\
63,2 \pm 20,6 \\
133,1 \pm 27,7\end{array}$ & $\begin{aligned} 27,7 & \pm 8,3 \\
22,9 & \pm 8,7 \\
15,2 & \pm 6,9 \\
127,7 & \pm 11,7 \\
53,8 & \pm 16,7 \\
116,9 & \pm 23,6\end{aligned}$ & $\begin{array}{l}0,0013 \\
0,008 \\
0,002 \\
0,025 \\
0,013 \\
0,0015\end{array}$ & $\begin{aligned} 24,9 & \pm 14,0 \\
22,7 & \pm 8,0 \\
18,6 & \pm 13,6 \\
132,4 & \pm 23,6 \\
67,6 & \pm 18,3 \\
124,3 & \pm 19,9\end{aligned}$ & $\begin{array}{r}27,4 \pm 7,1 \\
23,9 \pm 7,0 \\
17,1 \pm 7,5 \\
126,4 \pm 10,7 \\
59,8 \pm 14,7 \\
111,2 \pm 23,5\end{array}$ & $\begin{array}{l}0,54 \\
0,56 \\
0,64 \\
0,39 \\
0,1 \\
0,14\end{array}$ & $\begin{aligned} 30,5 & \pm 11,6 \\
25,9 & \pm 8,7 \\
20,8 & \pm 11,7 \\
125,5 & \pm 17,0 \\
64,6 & \pm 19,7 \\
130,3 & \pm 25,4\end{aligned}$ & $\begin{aligned} 27,6 & \pm 10,5 \\
23,2 & \pm 8,1 \\
15,8 & \pm 7,1 \\
127,3 & \pm 11,2 \\
55,7 & \pm 16,1 \\
115,1 & \pm 23,3\end{aligned}$ & $\begin{array}{l}0,1 \\
0,05 \\
0,0053 \\
0,51 \\
0,0023 \\
0,0005\end{array}$ \\
\hline $\begin{array}{l}\text { systolic pressure time integral }(\mathrm{mmHg}) \\
\text { diastolic pressure time integral }(\mathrm{mmHg})\end{array}$ & $\begin{array}{l}2824,9 \pm 747,8 \\
4025,4 \pm 837,1\end{array}$ & $\begin{array}{l}2492,8 \pm 733,1 \\
3609,9 \pm 709,3\end{array}$ & $\begin{array}{l}0,021 \\
0,0036\end{array}$ & $\begin{array}{l}2846,1 \pm 428,9 \\
3586,0 \pm 684,2\end{array}$ & $\begin{array}{l}2600,1 \pm 683 \\
3200,2 \pm 661\end{array}$ & $\begin{array}{l}0,39 \\
0,18\end{array}$ & $\begin{array}{l}2831,7 \pm 654 \\
3884,2 \pm 806\end{array}$ & $\begin{array}{l}2527,3 \pm 706 \\
3478,2 \pm 709\end{array}$ & $\begin{array}{l}0,0199 \\
0,0016\end{array}$ \\
\hline Pulswellengeschwindigkeit & \multicolumn{3}{|l|}{$\mathrm{n}=18$} & \multicolumn{3}{|l|}{$\mathrm{n}=8$} & \multicolumn{3}{|l|}{$n=26$} \\
\hline $\mathrm{PWV}_{\mathrm{cf}}(\mathrm{m} / \mathrm{s})$ & $\overline{10,3 \pm 3,1}$ & $8,8 \pm 2,5$ & 0,0038 & $\overline{10,8} \pm 2,6$ & $9,4 \pm 2,3$ & 0,0076 & $\overline{10,5} \pm 2,9$ & $9,0 \pm 2,4$ & 0,0001 \\
\hline $\mathrm{PWV}_{\text {cf-predicted }}(\mathrm{m} / \mathrm{s})$ & $10,9 \pm 1,9$ & $9,5 \pm 1,6$ & 0,0009 & $10,5 \pm 1,7$ & $10,4 \pm 3,0$ & 0,81 & $10,75 \pm 1,9$ & $9,8 \pm 2,1$ & 0,004 \\
\hline
\end{tabular}


Tab. 3.8:Subgruppenanalyse von Patienten mit Diabetes mellitus und Nichtdiabetikern (Beschriftung und Erläuterung entspricht Tab. 3.6)

\begin{tabular}{|c|c|c|c|c|c|c|c|c|c|}
\hline & \multicolumn{3}{|c|}{ D.m. } & \multicolumn{3}{|c|}{ NDM } & \multicolumn{3}{|c|}{ Gesamt } \\
\hline & Visit I & Visit II & $\boldsymbol{P}$ & Visit I & Visit II & $\boldsymbol{P}$ & Visit I & Visit II & $\boldsymbol{P}$ \\
\hline \multirow{2}{*}{$\begin{array}{l}\mathrm{Na}^{+} \text {Urin-Exkretion } \\
24-\mathrm{h} \mathrm{Na} \mathrm{N}^{-} \text {-Exkretion (mmol/Tag) } \\
\text { fraktionierte } \mathrm{Na}^{+} \text {-Exkretion (\%) } \\
\text { Na Exkretion/CKD-Kreatinin* }\end{array}$} & \multicolumn{3}{|l|}{$\mathrm{n}=9$} & \multicolumn{3}{|l|}{$\mathrm{n}=21$} & \multicolumn{3}{|l|}{$\mathrm{n}=30$} \\
\hline & $\begin{array}{l}130(22-225) \\
1,1(0,03-2,0) \\
2,2(0,3-6,3)\end{array}$ & $\begin{array}{l}106(25-365) \\
0,7(0,3-5,5) \\
2,1(0,5-13,9)\end{array}$ & $\begin{array}{l}0,44 \\
0,5 \\
0,68\end{array}$ & $\begin{array}{l}94(35-259) \\
1,3 \pm 1,4 \\
1,5(0,5-8,3)\end{array}$ & $\begin{array}{l}133(48-213) \\
1,8 \pm 1,5 \\
1,8(0,8-7,8)\end{array}$ & $\begin{array}{l}0,053 \\
0,058 \\
\mathbf{0 , 0 4 6}\end{array}$ & $\begin{array}{r}112,0 \pm 61,2 \\
0,8(0,4-1,6) \\
1,8(0,9-3,1)\end{array}$ & $\begin{array}{c}134,1 \pm 66,9 \\
1,1(0,6-1,96) \\
2,0(1,4-3,9)\end{array}$ & $\begin{array}{l}\mathbf{0 , 0 4 9} \\
0,029 \\
0,079\end{array}$ \\
\hline \multirow{5}{*}{$\begin{array}{l}\text { Proteinurie } \\
\text { Protein }(\mathrm{mg} / \mathrm{l}) \\
\text { Albumin (mg/l) } \\
\text { Protein/Kreatinin (mg/g Kreatinin) } \\
\text { Albumin/Kreatinin (mg/g Kreatinin) }\end{array}$} & \multicolumn{3}{|l|}{$n=9$} & \multicolumn{3}{|l|}{$\mathrm{n}=21$} & \multicolumn{3}{|l|}{$\mathrm{n}=30$} \\
\hline & 457 (132-16892) & 364 (24-5332) & 0,066 & $118(6-4475)$ & $68(6-870)$ & 0,09 & $225(68-818)$ & $106,8(36-335)$ & 0,007 \\
\hline & $341(10-7540)$ & $244(7-4010)$ & 0,16 & $41(10-4380)$ & $16(5-727)$ & 0,006 & $69,8(11-435)$ & $19,2(10-171)$ & 0,0047 \\
\hline & $598(81-17611)$ & 214 (48-9472) & 0,14 & $122(17-2828)$ & $136(34-4073)$ & 0,6 & $300,5(17-17611)$ & $179,8(34-9472)$ & 0,13 \\
\hline & $446(8-7861)$ & $135(9-7124)$ & 0,21 & $52(12-2768)$ & $54(10-3406)$ & 0,22 & $56,4(8-7860)$ & $46,8(8-7124)$ & 0,074 \\
\hline \multirow{2}{*}{$\begin{array}{l}\text { BuP } \\
\text { systolisch }(\mathrm{mmHg}) \\
\text { diastolisch }(\mathrm{mmHg}) \\
\text { MAD (mmHg) } \\
\text { Herzfrequenz (/min) }\end{array}$} & \multicolumn{3}{|l|}{$\mathrm{n}=10$} & \multicolumn{3}{|l|}{$\mathrm{n}=21$} & \multicolumn{3}{|l|}{$\mathrm{n}=31$} \\
\hline & $\begin{array}{r}159,0 \pm 26,3 \\
78,5 \pm 13,3 \\
110,7 \pm 17,0 \\
71,9 \pm 15,5\end{array}$ & $\begin{array}{r}154,6 \pm 35,2 \\
77,1 \pm 17,9 \\
108,1 \pm 23,7 \\
70,6 \pm 9,7\end{array}$ & $\begin{array}{l}0,61 \\
0,69 \\
0,59 \\
0,72\end{array}$ & $\begin{array}{r}166,8 \pm 29 \\
88,6 \pm 18,4 \\
119,9 \pm 20,9 \\
71,7 \pm 10,8\end{array}$ & $\begin{array}{r}146,4 \pm 31,3 \\
77,9 \pm 19,6 \\
105,3 \pm 23,1 \\
67,7 \pm 11,3\end{array}$ & $\begin{array}{l}0,001 \\
0,0017 \\
0,001 \\
0,16\end{array}$ & $\begin{array}{r}164,3 \pm 27,9 \\
85,4 \pm 17,4 \\
116,9 \pm 19,9 \\
71,7 \pm 12,3\end{array}$ & $\begin{array}{r}149,0 \pm 32,2 \\
77,7 \pm 18,8 \\
106,2 \pm 22,9 \\
68,7 \pm 10,7\end{array}$ & $\begin{array}{l}0,0029 \\
0,0029 \\
0,0017 \\
0,15\end{array}$ \\
\hline \multirow{5}{*}{$\begin{array}{l}\text { ABPM } \\
\text { MAD }(\mathrm{mmHg}) \\
\text { systolisch }(\mathrm{mmHg}) \\
\text { diastolisch }(\mathrm{mmHg}) \\
\text { Herzfrequenz }(/ \mathrm{min}) \\
\end{array}$} & \multicolumn{3}{|l|}{$\underline{n}=8$} & \multicolumn{3}{|l|}{$n=21$} & \multicolumn{3}{|l|}{$\mathrm{n}=29$} \\
\hline & $\overline{104,6} \pm 15,3$ & $104,9 \pm 26,4$ & 0,97 & $101,9 \pm 12,5$ & $99,0 \pm 19,0$ & 0,33 & $102,7 \pm 13,2$ & $100,7 \pm 20,9$ & 0,49 \\
\hline & $151,1 \pm 20,3$ & $147,5 \pm 35,7$ & 0,696 & $142,2 \pm 15,5$ & $138,1 \pm 22,4$ & 0,23 & $144,6 \pm 17,0$ & $140,7 \pm 26,3$ & 0,24 \\
\hline & $78,3 \pm 13,3$ & $77,0 \pm 19,8$ & 0,80 & $79,6 \pm 13,3$ & $76,7 \pm 18,0$ & 0,28 & $79,3 \pm 13,1$ & $76,8 \pm 18,2$ & 0,29 \\
\hline & $71,3 \pm 10,7$ & $70,6 \pm 9,1$ & 0,86 & $69,7 \pm 9,9$ & $68,4 \pm 12,3$ & 0,55 & $70,2 \pm 9,98$ & $69,1 \pm 11,3$ & 0,54 \\
\hline \multirow{2}{*}{$\begin{array}{l}\text { Pulswellenanalyse } \\
\text { aortal systolisch }(\mathrm{mmHg}) \\
\text { aortal diastolisch }(\mathrm{mmHg}) \\
\text { aortal MAD }(\mathrm{mmHg})\end{array}$} & \multicolumn{3}{|l|}{$\mathrm{n}=10$} & \multicolumn{3}{|l|}{$\mathrm{n}=18$} & \multicolumn{3}{|l|}{$\mathrm{n}=28$} \\
\hline & $\begin{array}{r}150,7 \pm 27,6 \\
79,0 \pm 16,1 \\
107,2 \pm 20,8\end{array}$ & $\begin{array}{r}135,4 \pm 28,8 \\
74,9 \pm 13,9 \\
99,9 \pm 20,7\end{array}$ & $\begin{array}{l}0,057 \\
0,17 \\
0,12\end{array}$ & $\begin{array}{r}149,7 \pm 28,8 \\
89,1 \pm 21,3 \\
114,4 \pm 23,1\end{array}$ & $\begin{array}{r}131,8 \pm 24,8 \\
78,6 \pm 21,2 \\
100,3 \pm 22,1\end{array}$ & $\begin{array}{l}0,0046 \\
0,039 \\
0,011\end{array}$ & $\begin{array}{r}150,0 \pm 27,9 \\
85,5 \pm 19,9 \\
111,8 \pm 22,2\end{array}$ & $\begin{array}{r}133,1 \pm 25,8 \\
77,3 \pm 18,8 \\
100,1 \pm 21,3\end{array}$ & $\begin{array}{l}0,0005 \\
0,016 \\
0,0027\end{array}$ \\
\hline Augmentationindex (\%) & $30,9 \pm 8,1$ & $26,6 \pm 7,1$ & 0,07 & $30,2 \pm 13,4$ & $28,1 \pm 8,3$ & 0,39 & $30,5 \pm 11,6$ & $27,6 \pm 10,5$ & 0,1 \\
\hline Augmentationsindex bei $\mathrm{HF}_{75}(\%)$ & $24,9 \pm 5,4$ & $23,2 \pm 6,5$ & 0,27 & $26,4 \pm 10,2$ & $23,2 \pm 9,0$ & 0,11 & $25,9 \pm 8,7$ & $23,2 \pm 8,1$ & 0,05 \\
\hline Augmentationdruck (mmHg) & $22,6 \pm 8,9$ & $16,4 \pm 7,2$ & 0,03 & $19,9 \pm 13,2$ & $15,5 \pm 7,2$ & 0,067 & $20,8 \pm 11,7$ & $15,8 \pm 7,1$ & 0,0053 \\
\hline Pulsdruck Amplifikation (\%) & $122,9 \pm 12,1$ & $128,9 \pm 9,2$ & 0,097 & $126,9 \pm 19,4$ & $126,5 \pm 12,3$ & 0,89 & $125,5 \pm 17,0$ & $127,3 \pm 11,2$ & 0,51 \\
\hline $\begin{array}{l}\text { aortaler Pulsdruck (mmHg) } \\
\text { end-svstolischer Druck (mmHa) }\end{array}$ & $\begin{array}{r}71,7 \pm 15,2 \\
1274+229\end{array}$ & $\begin{array}{r}60,3 \pm 17,7 \\
1146+234\end{array}$ & $\begin{array}{l}0,06 \\
0,049\end{array}$ & $60,7 \pm 21,1$ & $\begin{array}{r}53,2 \pm 14,9 \\
1154+239\end{array}$ & $\begin{array}{l}0,02 \\
0,005\end{array}$ & $\begin{array}{r}64,6 \pm 19,7 \\
1303+254\end{array}$ & $\begin{array}{r}55,7 \pm 16,1 \\
115+23 ?\end{array}$ & 0,0023 \\
\hline & $2768 \pm 782$ & $2676 \pm 766$ & 0,59 & $2867 \pm 593$ & $2444 \pm 679$ & 0,019 & $2831,7 \pm 654$ & $2527,3 \pm 706$ & 0,0199 \\
\hline diastolic pressure time integral $(\mathrm{mmHg})$ & $3679 \pm 602$ & $3314 \pm 494$ & 0,019 & $3998 \pm 895$ & $3569 \pm 803$ & 0,021 & $3884,2 \pm 806$ & $3478,2 \pm 709$ & 0,0016 \\
\hline Pulswellengeschwindigkeit & \multicolumn{3}{|l|}{$\mathrm{n}=8$} & \multicolumn{3}{|l|}{$\mathrm{n}=18$} & \multicolumn{3}{|l|}{$n=26$} \\
\hline$\overline{P W V_{\text {cf }}(\mathrm{m} / \mathrm{s})}$ & $9,8 \pm 2,6$ & $8,9 \pm 1,9$ & 0,34 & $\overline{10,8 \pm 3,1}$ & $9,0 \pm 2,7$ & 0,000026 & $10,5 \pm 2,9$ & $9,0 \pm 2,4$ & 0,0001 \\
\hline PWV & $10,6 \pm 1,8$ & $10,0 \pm 1,8$ & 0,12 & $10,8 \pm 1,9$ & $9,7 \pm 2,3$ & 0,015 & $10,8 \pm 1,9$ & $9,8 \pm 2,1$ & 0,004 \\
\hline
\end{tabular}




\subsubsection{Komplikationen}

Tabelle 3.10 zeigt eine Übersicht der beobachteten Komplikationen im Verlauf der sechsmonatigen BAT, aufgeteilt in Schweregrade zwischen adverse events $1^{\circ}$ bis adverse events $1 \mathrm{II}^{\circ}$. Bei $77 \%$ der Patienten traten lokale Missempfindungen als häufigste Beschwerdeform in Erscheinung. Diese wurden entweder als Zahnschmerzen, elektrisierende Wahrnehmung oder ziehender Schmerz, welcher vom Operationsgebiet bis nach submandibulär ausstrahlte, beschrieben. Nach Erstaktivierung des BAT-Schrittmachers und nach dessen Aktivitätsadaption, die im Anschluss an die einmonatige Einheilungsphase vorgenommen wurde, zeigten sich neben Missempfindungen auch pulsatile Muskelkontraktionen im Kopf-Halsbereich (48\%), Heiserkeit (39\%), Dysphagie (26\%) oder Hypotension (19\%).

Tab. 3.10: Übersicht erhobener Komplikationen und Krankenhausaufenthalte im Verlauf der BAT

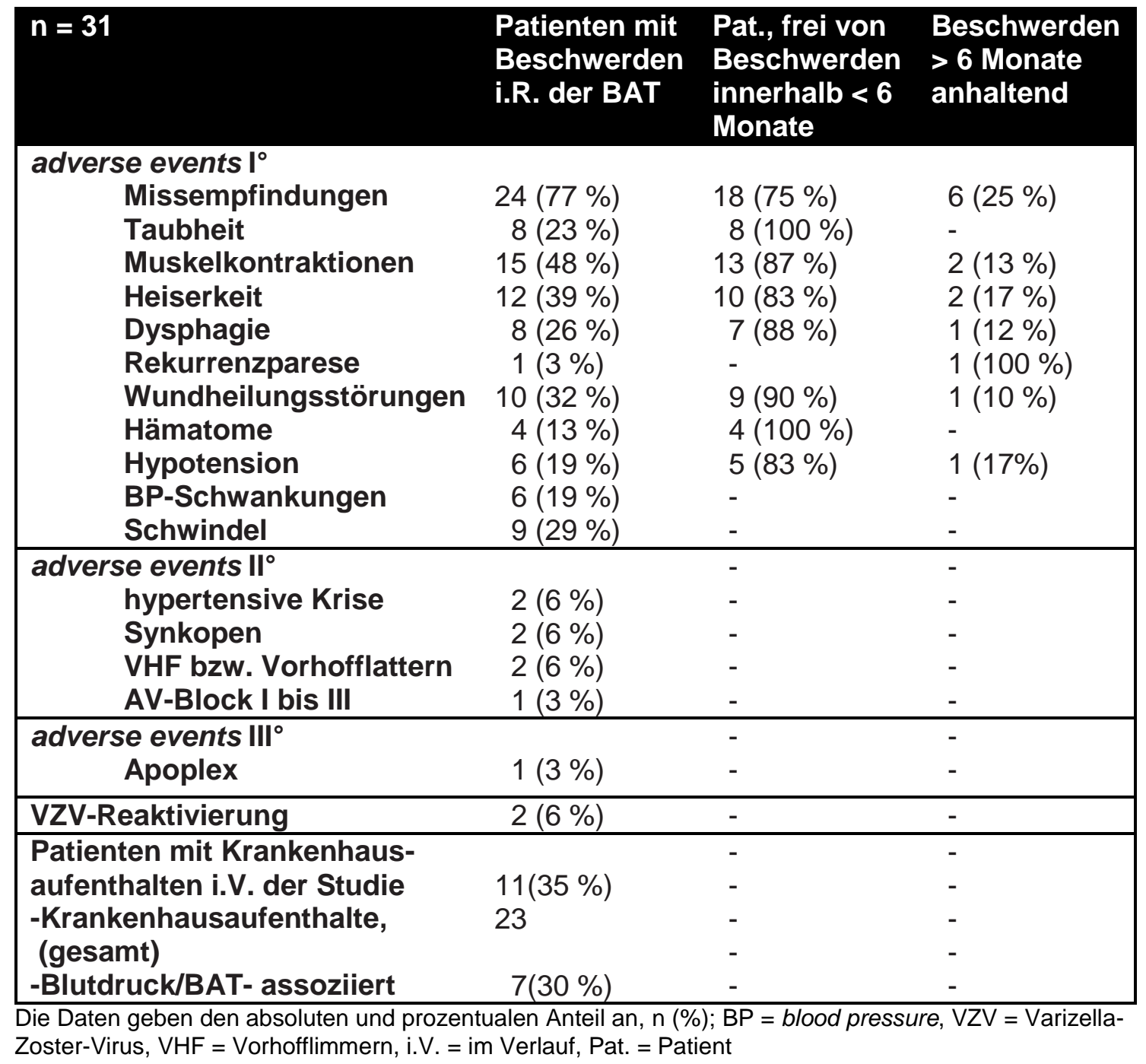


Nach Anpassung der BAT-Schrittmacheraktivität verschwanden die vorgenannten Beschwerden in über 80 \% der Fälle innerhalb von sechs Monaten. Perioperativ kam es bei einer Patientin zum Apoplex mit hemifacialer Parese und unter aktivierter BAT zur Trigeminusneuralgie, was eine vorübergehende Abschaltung des Gerätes erforderte. In einem weiteren Fall trat eine einseitige Rekurrenzparese auf. Parallel zum Studienverlauf mussten sich elf der Patienten (35\%) einer stationären Behandlung unterziehen (Cholezystektomie, Magen-CA, Pneumonie, Pneumothorax [drei Monate postoperativ, nicht mit BAT assoziert], psychosomatische Therapie, Septumplastik, Ablatio retinae, Myokardinfarkt), wovon $30 \%$ der stationären Aufnahmen durch Blutdruckentgleisungen und einer Verschlechterung oder neu aufgetretenen Niereninsuffizienz bedingt waren. Während der BAT kam es bei jeweils zwei Patienten zu einer Reaktivierung der Varizella-Zoster-Infektion (VZV), einem neu aufgetretenen Vorhofflimmern oder -flattern und bei einem weiteren Patienten zu einem AV-Block I.

\subsection{Vaskuläre Endpunkte}

\subsubsection{Pulswellenanalyse und Pulswellengeschwindigkeit}

Alle analysierten Pulswellenmessungen $(n=28)$ erfüllten die zuvor beschriebenen Qualitätsstandards (Tomlinson 2012). So lag der mittlere Qualitätsindex bei $94 \pm 6 \%$ und der Intraklassen-Korrelationskoeffizient für die PWV Messungen bei 9,8 \%.

Die BAT senkte nach sechs Monaten Aktivierung den zentral aortalen systolischen Blutdruck von 150,0 $\pm 27,9$ auf 133,1 $\pm 25,8 \mathrm{mmHg}(\mathrm{p}<0,01)$, den zentral aortalen diastolischen Blutdruck von 85,5 \pm 19,9 auf 77,3 $\pm 18,8 \mathrm{mmHg}(p=0,016)$ sowie den zentralen Pulsdruck von $64,6 \pm 19,7$ auf $55,7 \pm 16,1 \mathrm{mmHg}(p<0,01)$ signifikant. Darüber hinaus fielen der zentrale Augmentationsdruck von 20,8 $\pm 11,7$ auf 15,8 \pm 7,1 und der end-systolische Druck von 130,3 $\pm 25,4 \mathrm{mmHg}$ auf $115,1 \pm 23,3 \mathrm{mmHg}$ $(\mathrm{p}<0,01$ bzw. $\mathrm{p}<0,001)$ ab. Der Augmentationsindex (Alx) blieb unverändert, wohingegen der frequenzkorrigierte Alx@75 von 25,9 $\pm 8,7$ auf 23,2 $\pm 8,1 \%$ $(p=0,05006)$ sank. Der SPTI verminderte sich von 2831,7 $\pm 653,7$ auf 2527,3 $\pm 706,5$ $(p<0,05)$ und der DPTI von 3884,2 $\pm 805,96$ auf 3478,2 $\pm 709,1 \mathrm{mmHg}(p<0,01)$ signifikant, wohingegen die SEVR und Ejektionsdauer konstant blieben (siehe Tab. 3.11). 
Die Erhebung der PWV erfolgte an 26 Patienten, da bei zwei Patienten Signale der tonometrisch carotido-femoralarteriellen (cf) Messung konstitutionell nur eingeschränkt möglich waren. Hier zeigte sich eine signifikante Reduktion der $\mathrm{PWV}_{\mathrm{cf}}$ von $10,5 \pm 2,9$ auf $9,0 \pm 2,4 \mathrm{~m} / \mathrm{s}(\mathrm{p}<0,001)$ sowie der $\mathrm{PWV}_{\text {cf-predicted }}$ von 10,75 $\pm 1,9$ auf $9,8 \pm 2,1 \mathrm{~m} / \mathrm{s}(p<0,05)$. Die Differenz aus $P W V_{\text {cf }}$ minus $P W V_{\text {cf-predicted }}(p=0,24)$ erfüllte nach sechsmonatiger BAT nicht das Signifikanzniveau.

Tab. 3.11: Ergebnisse der Pulswellenanalyse und -geschwindigkeit

\begin{tabular}{|c|c|c|c|}
\hline $\mathbf{n}=\mathbf{2 8}$ & Baseline & 6 Monate & $\boldsymbol{p}$ \\
\hline peripher systolisch $(\mathrm{mmHg})$ & $163,3 \pm 27,5$ & $146,8 \pm 27,8$ & 0,0017 \\
\hline peripher diastolisch $(\mathrm{mmHg})$ & $84,1 \pm 19,7$ & $76,2 \pm 18,5$ & 0,017 \\
\hline peripher MAD $(\mathrm{mmHg})$ & $112,1 \pm 22,1$ & $99,8 \pm 20,97$ & 0,0015 \\
\hline aortal systolisch $(\mathrm{mmHg})$ & $150,0 \pm 27,9$ & $133,1 \pm 25,8$ & 0,0005 \\
\hline aortal diastolisch (mmHg) & $85,5 \pm 19,9$ & $77,3 \pm 18,8$ & 0,016 \\
\hline aortal MAD (mmHg) & $111,8 \pm 22,2$ & $100,1 \pm 21,3$ & 0,0027 \\
\hline Herzfrequenz (Schläge/min) & $65,5 \pm 11,1$ & $65,9 \pm 10,5$ & 0,8 \\
\hline Augmentationindex (\%) & $30,5 \pm 11,6$ & $27,6 \pm 10,5$ & 0,1 \\
\hline Augmentationsindex bei $\mathrm{HF}_{75}(\%)$ & $25,9 \pm 8,7$ & $23,2 \pm 8,1$ & 0,05006 \\
\hline Augmentationdruck $(\mathrm{mmHg})$ & $20,8 \pm 11,7$ & $15,8 \pm 7,1$ & 0,0053 \\
\hline Pulsdruck Amplifikation (\%) & $125,5 \pm 17,0$ & $127,3 \pm 11,2$ & 0,51 \\
\hline aortaler Pulsdruck (mmHg) & $64,6 \pm 19,7$ & $55,7 \pm 16,1$ & 0,0023 \\
\hline end-systolischer Druck (mmHg) & $130,3 \pm 25,4$ & $115,1 \pm 23,3$ & 0,00047 \\
\hline systolic pressure time integral $(\mathrm{mmHg})$ & $2831,7 \pm 653,7$ & $2527,3 \pm 706,5$ & 0,0199 \\
\hline diastolic pressure time integral (n & $3884,2 \pm 805,96$ & $3478,2 \pm 709,1$ & 0,0016 \\
\hline Ejection duration (ms) & $330,6 \pm 32,0$ & $326,5 \pm 28,1$ & 0,5 \\
\hline Ejection duration (\%) & $35,7 \pm 3,9$ & $35,6 \pm 4,1$ & 0,9 \\
\hline SEVR (\%) & $140,9 \pm 25,7$ & $143,4 \pm 31,1$ & 0,6 \\
\hline$P W V_{\text {cf }}(\mathrm{m} / \mathrm{s})$ & $10,5 \pm 2,9$ & $9,0 \pm 2,4$ & 0,00013 \\
\hline $\operatorname{PWV}_{\text {cf-predicted }}(\mathrm{m} / \mathrm{s})$ & $10,75 \pm 1,9$ & $9,8 \pm 2,1$ & 0,004 \\
\hline$P W V_{c f}-P W V_{\text {cf-predicted }}(\mathrm{m} / \mathrm{s})$ & $-0,28 \pm 2,9$ & $-0,75 \pm 2,8$ & 0,24 \\
\hline
\end{tabular}

Daten dargestellt als MW \pm Stabw.; MAD = mittlerer arterieller Druck, HF = Herzfrequenz, SEVR = subendocardial viability ratio, $\mathrm{PWV}=$ puls wave velocity, $\mathrm{cf}=$ carotido-femoralarteriell

Es wurde eine ANOVA-Analyse durchgeführt, um festzustellen, ob eine im Voraus erfolgte RD, ein bestehender D.m., das Geschlecht sowie das Stadium einer bestehenden chronischen Nierenerkrankung (CKD) oder Proteinurie Einfluss auf die Effekte der BAT haben.

Es zeigten sich bei den zu untersuchenden Variablen keine Unterschiede. Im Fall der positiven Raucheranamnese konnte in der ANOVA-Analyse ein signifikanter Einfluss auf die Zielvariablen Alx@75 ( $p=0,037)$ und der Pulsdruckamplifikation $(p=0,047)$ 
festgestellt werden. Eine genaue Betrachtung jeweiliger Subgruppen findet sich in den Tabellen 3.6 bis 3.9 .

Um die Ergebnisse auf Störfaktoren zu testen (z.B. Regression zur Mitte oder nonAdhärenz), wurden nach sechs Monaten bei zwei Patienten Messungen mit angestelltem/ausgestelltem Aggregat durchgeführt. Dabei zeigten sich akut und reversibel feststellbare Effekte hinsichtlich untersuchter Variablen (siehe Tab. 3.12).

Tab. 3.12: Aortale Hämodynamik zweier Patienten nach initialem ON/OFF-Versuch nach 6 Monaten BAT

\begin{tabular}{|lcccc|}
\hline \multicolumn{1}{|c}{ BAT } & \multicolumn{2}{c}{ Patient 1 } & \multicolumn{2}{c|}{ Patient 2 } \\
\hline aortal systolisch $(\mathbf{m m H g})$ & 127 & 143 & ON & OFF \\
\hline aortal diastolisch (mmHg) & 89 & 95 & 92 & 131 \\
\hline aortal MAD (mmHg) & 104 & 114 & 105 & 108 \\
\hline Augmentationsindex (\%) & 31 & 41 & 17 & 24 \\
\hline Augmentationsindex bei @75 (\%) & 30 & 39 & 12 & 17 \\
\hline Augmentationdruck (mmHg) & 12 & 19 & 6 & 9 \\
\hline aortaler Pulsdruck (mmHg) & 38 & 48 & 37 & 38 \\
\hline SEVR (\%) & 139 & 130 & 155 & 152 \\
\hline PWVcf (m/s) & 9,0 & 9,6 & 7,6 & 8,1 \\
\hline
\end{tabular}

$\mathrm{MAD}=$ mittlerer arterieller Druck, SEVR $=$ subendothetial variability ratio, $\mathrm{PWV}_{\mathrm{cf}}=$ Pulswellengeschwindigkeit carotidofemoral, BAT $=$ Barorezeptorstimulationstherapie

\subsubsection{EPCs}

Nach sechsmonatiger BAT zeigte sich bei der Anzahl gezählter EPCs-Kolonien keine Veränderungen $(47,54 \pm 57,73$ vs. $32,75 \pm 60,5$ colonies/Well $(p=0,125))[n=30]$. Des Weiteren blieben Caspase-3 positive $(n=19)$ als auch eNOS $(n=11)$ positive EPCs unverändert $4,7 \pm 2,8$ vs. $6,8 \pm 5,8 \%$ ( $p=0,19), 29,7 \pm 26,7$ vs. $27,9 \pm 31,3 \%$ $(p=0,86))$. Aufgrund bakterieller Verunreinigung wurden Proben von einem Patienten von der EPCs-Inkubation ausgeschlossen. Die weitere Analytik des Aktivitätsmarkers eNOS und Apoptosemarkers Caspase-3 konnte aufgrund der Kolonienzahlen nur bei elf bzw. 19 von 31 Patienten durchgeführt werden.

\subsubsection{Biomarker}

Die vaskulären Biomarker wiesen nach sechs Monaten BAT keine Unterschiede auf. Neben serologischer Routineanalysen der Biomarker IL-6 und TNF- $\alpha$ wurden im Rahmen der zur Verfügung stehenden Mittel weitere serologische Untersuchungen auf 20 Patienten beschränkt. In diese Betrachtung flossen Proben von 13 
Studienteilnehmern mit einem Abfall der Proteinurie sowie sieben Studienteilnehmer ohne Rückgang der Proteinurie ein (siehe Tab. 3.13).

Mittels Varianzanalyse wurde der Einfluss der Proteinurieveränderung gegenüber dem Verhalten der Biomarker im zeitlichen Verlauf der BAT betrachtet. Hierbei zeigten sich keine signifikanten Effekte [VEGF: $p=0,73$, VEGF-FLT-1: $p=0,85$, Ang-2: $p=0,58$, sICAM: $p=0,53$, sVCAM: $p=0,6$, TGF- $\beta_{1}: p=0,69$, ADMA: $p=0,85$, TNF- $\alpha p=0,42$, IL-6 $p=0,54$ und MMP-9: $p=0,82]$.

Tab. 3.13: Serologische Biomarker

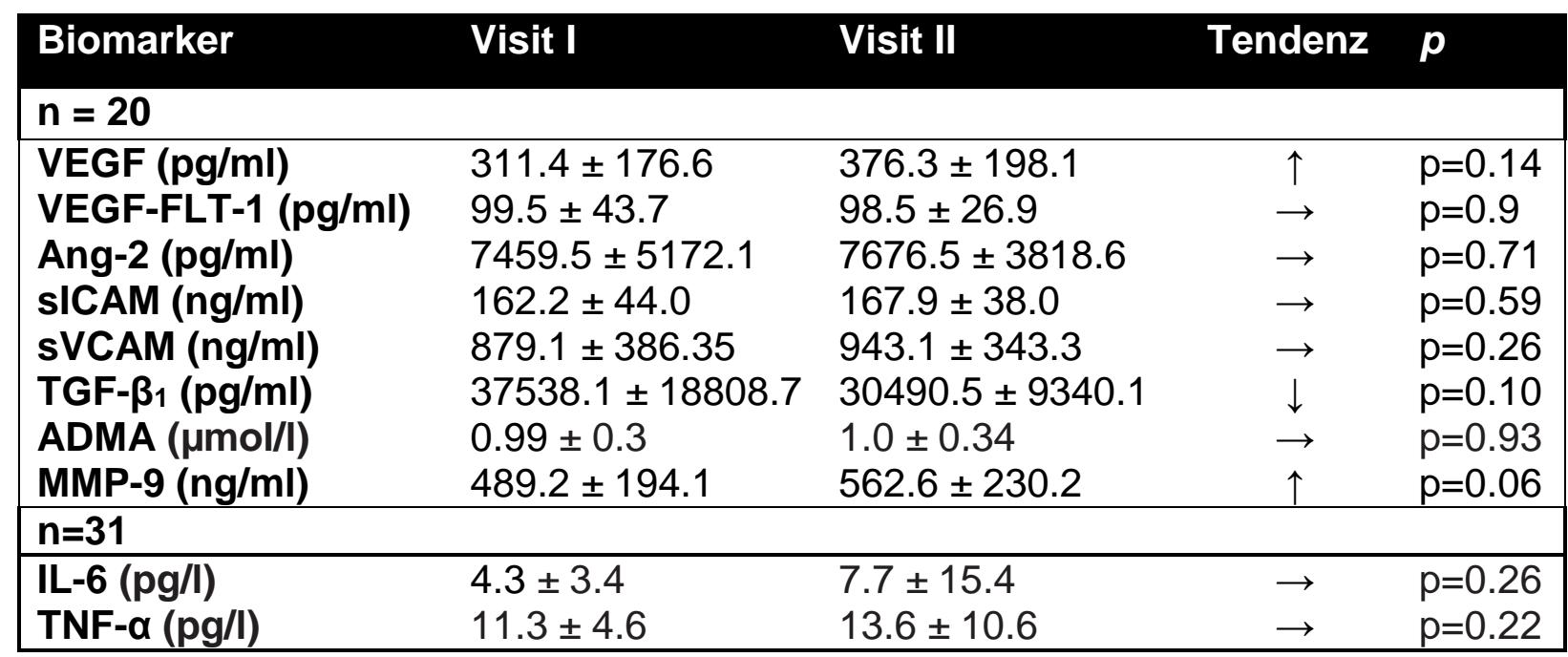

Daten dargestellt als MW \pm Stabw.; VEGF = vascular endothelial growth factor, VEGF-FLT-1 = vascular endothelial growth factor receptor FMS like tyrosine kinase 1, Ang-2 = Angiopoitin 2, sICAM = soluble intercellular adhesion molecule 1 , sVCAM = soluble vascular cell adhesion molecule, TGF- $\beta 1$ = transformierender Wachstumsfaktor beta 1, ADMA = asymmetrisches Dimethylarginin, MMP-9 = Matrix-Metallo-Proteinase $9, \uparrow=$ ansteigend, $\downarrow=$ abfallend, $\rightarrow$ = gleichbleibend

\subsection{Renale Endpunkte}

\subsubsection{Verlauf der Proteinurie}

Zur Aufnahmeuntersuchung fand sich bei 21 von 29 Patienten (72,5\%) eine Albuminurie. Nach sechs Monaten BAT sank die Albuminurie um einen Median von $-36 \%(-77,4-0,0 \%)(p=0,0047)$ und die Gesamt-Proteinurie um einen Median von $-38,96 \%(-79,1-27,4 \%)(p=0,007)$. Die Ergebnisse sind in der Tabelle 3.14 und Abbildung 3.3 dargestellt. Die Anzahl der Patienten mit Mikroalbuminurie veränderte sich von 13 auf 14, die mit Makroalbuminurie von 8 auf $6(p=0,42)$ (siehe Abb. 3.4). Der systolische BuP-Abfall und die Reduktion der Albuminurie zeigten eine signifikante positive Korrelation von $r=0,44$ und $p=0,017$ (siehe Abb. 3.5). BaselineProteinurie und systolischer BuP zeigten bei 31 Patienten keine 


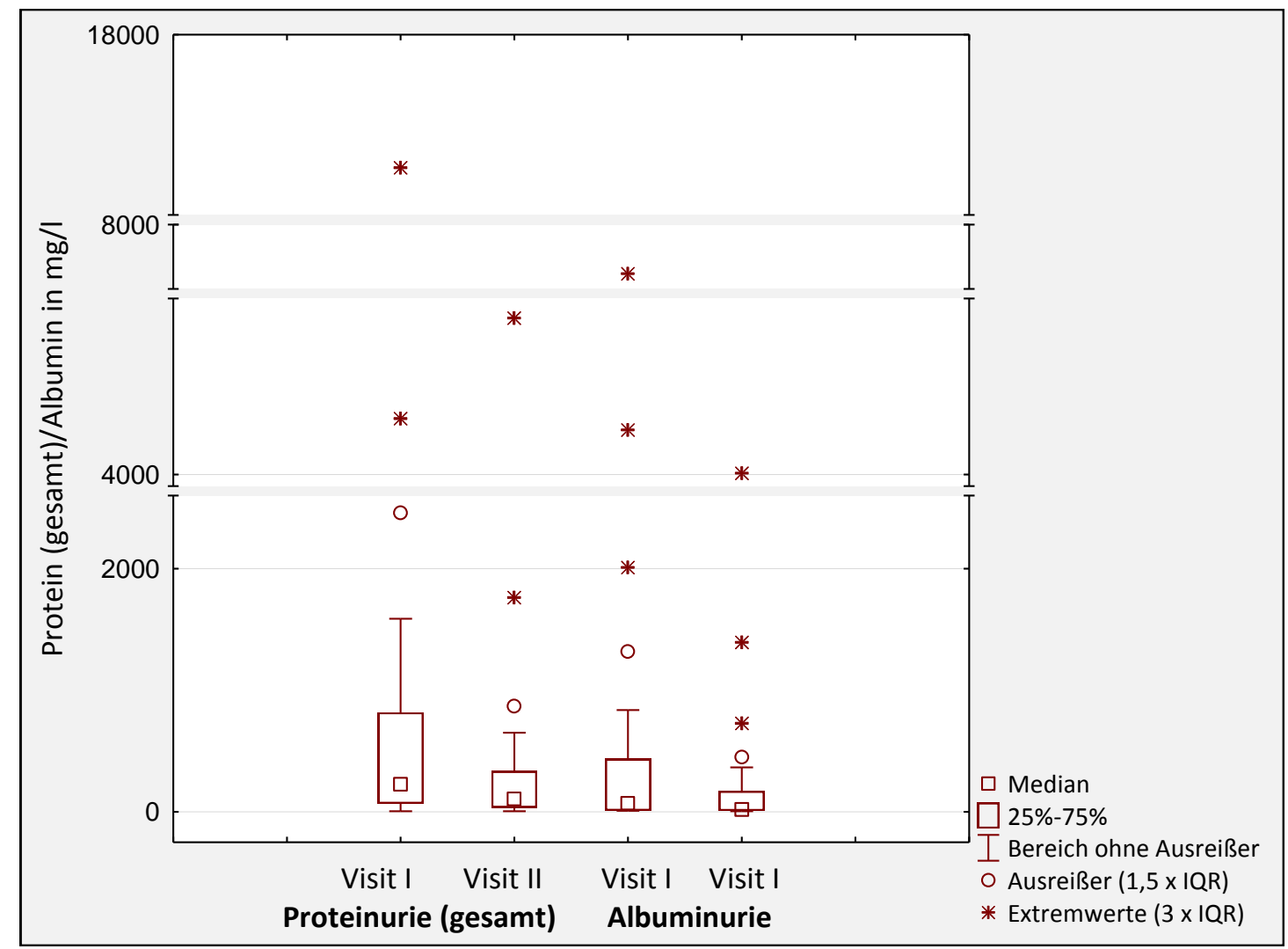

Abb. 3.3: Absenkung der Proteinurie und Albuminurie im Rahmen der BAT: Darstellung der Daten als Boxplot sowie Skalenunterbrechung der y-Achse. IQR = interquartile range,

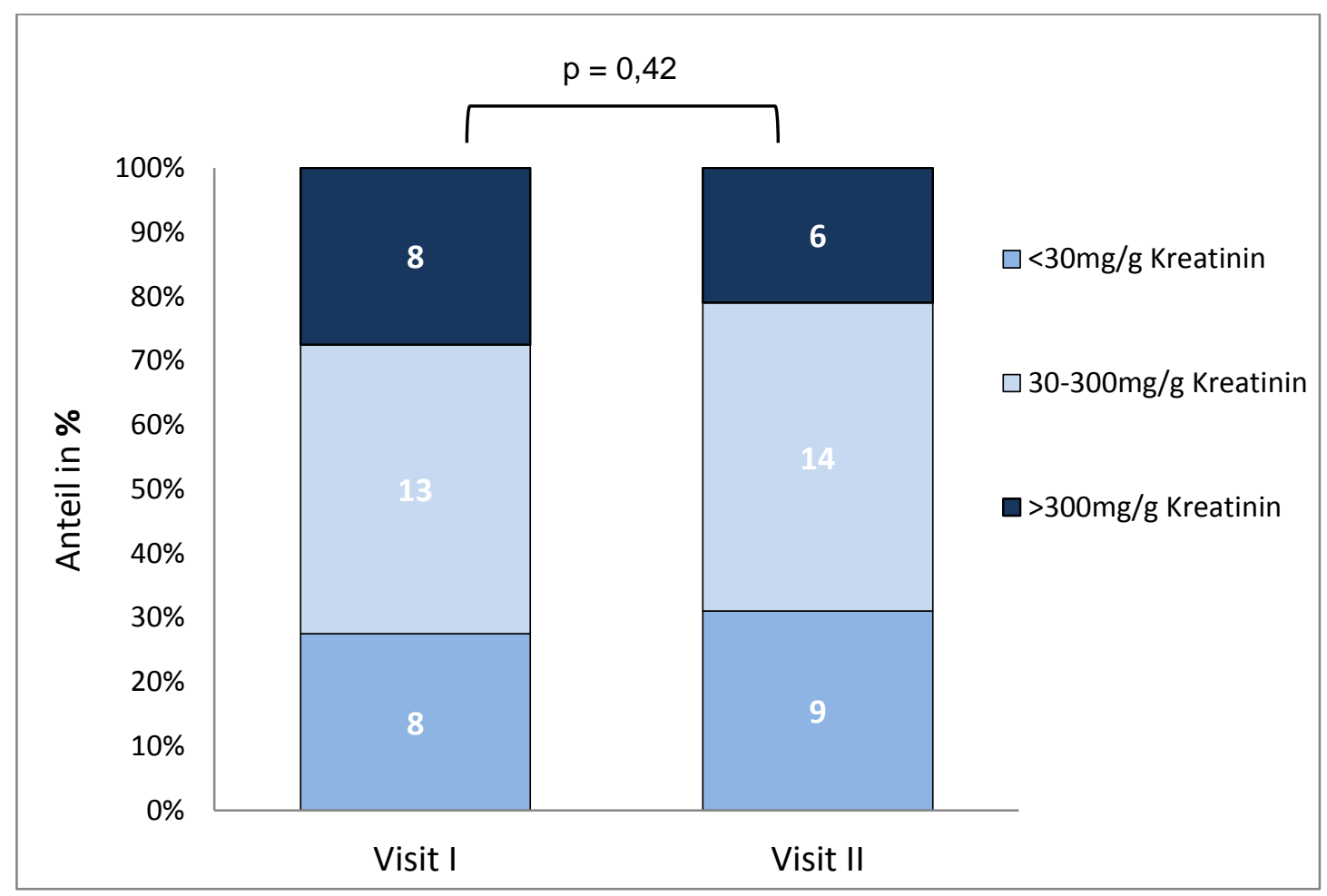

Abb. 3.4: Veränderung der Proteinfraktionen im Verlauf der BAT. Darstellung als gestapelte Säulen mit Angabe des absoluten und prozentualen Anteils der Patienten. 


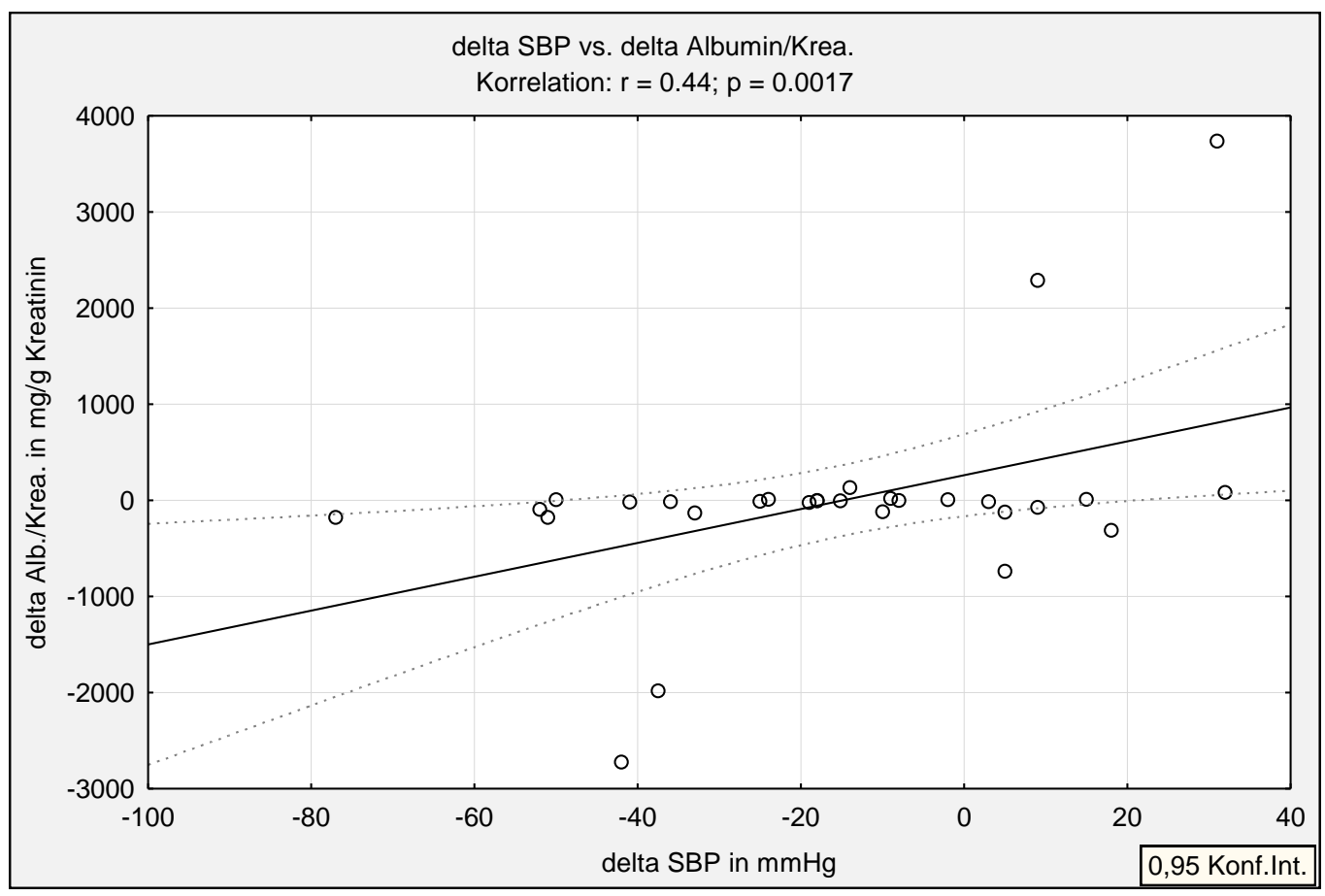

Abb. 3.5: Beziehung zwischen systolischer BuP-Absenkung und Reduktion der Albumin/ Kreatinin-Ratio. Darstellung als Korrelation mit Regressionsbändern und Konfidenzniveau von 0,95. $\mathrm{SPB}=$ systolic blood pressure; Krea. = Kreatinin; Alb. = Albumin

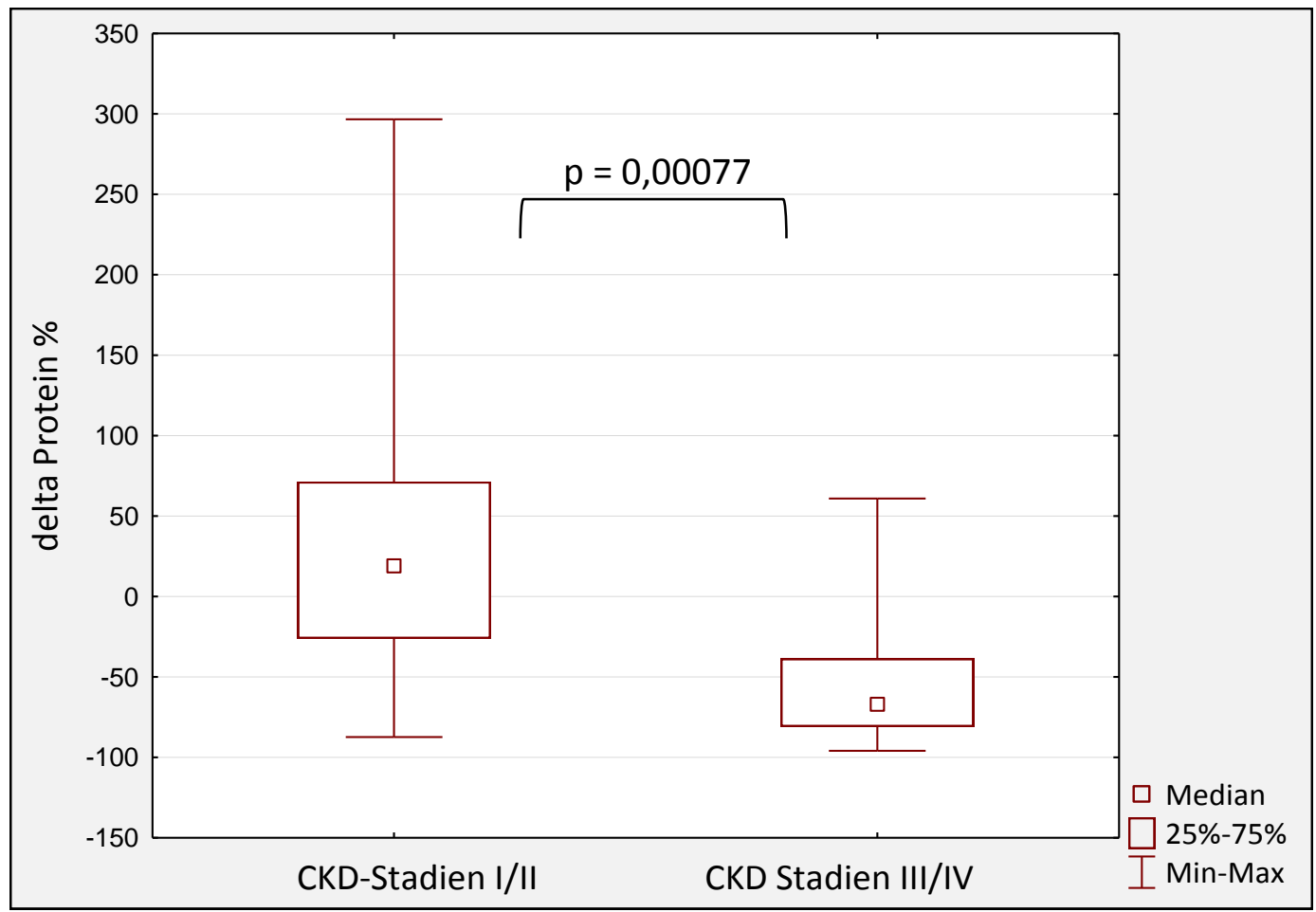

Abb. 3.6: Veränderung der Proteinurie im Vergleich zwischen den CKD-Stadien I/II und III/IV. Darstellung der Daten als Boxplot (statistische Methode: Mann-Whitney U-Test). CKD = chronic kidney disease

signifikante Korrelation $(r=0,12 ; p=0,54)$. Eine Veränderung der Proteinurie $(\Delta$ Proteinurie in \%) war vom jeweiligen CKD-Stadium abhängig [CKD I und CKD II: 
10,9 \% (-574,4 - 173,4), $n=14$; CKD III und CKD IV: $-67,7 \%(-95,9-60,9), n=15]$ und zeigte im Vergleich zwischen den Stadien I/II gegenüber III/IV einen signifikanten Unterschied von $p=0,00077$ (siehe Abb. 3.6.).

Das Stadium CKD V wurde von der Analyse ausgeschlossen. Im Hinblick auf den Nierenfunktionsparameter Serum-Cystatin C zeigte sich kein signifikanter Unterschied $(p=0,43)$ [CKD I und CKD II: 0,2 $\pm 13,0 \%, n=14$; CKD III und CKD IV: $-5,5 \pm 23,7 \%$, $\mathrm{n}=15]$.

\subsubsection{Verlauf der exkretorischen Nierenfunktionsmarker}

Das Serum-Kreatinin $(p=0,89)$ und die Ergebnisse der eGFR, errechnet mittels eGFR-MDRD-Formel bzw. der CKD-EPI-Kreatinin-Formel, zeigten in den Nachfolgeuntersuchungen keinen Unterschied im Vergleich zur Baseline $(p=0,92$ bzw. 0,74$)$, ebenso wie für das Cystatin $C(p=0,67)$ und die Filtrationsrate, berechnet mit der CKD-EPI-Kreatinin-Cystatin C-Formel $(p=0,33)$. Eine nicht signifikante Verbesserung der Nierenfunktion zeigte sich unter Anwendung der CKD-EPICyststin C-Gleichung $(p=0,09)$. Die Korrelation zwischen einer Veränderung der eGFR (unter Anwendung der CKD-EPI-Cyststin C-Gleichung) gegenüber dem Verlauf des systolischen BuP, zeigte eine negative signifikante Korrelation $(r=-0,37, p=0,048)$ (siehe Abb. 3.7).

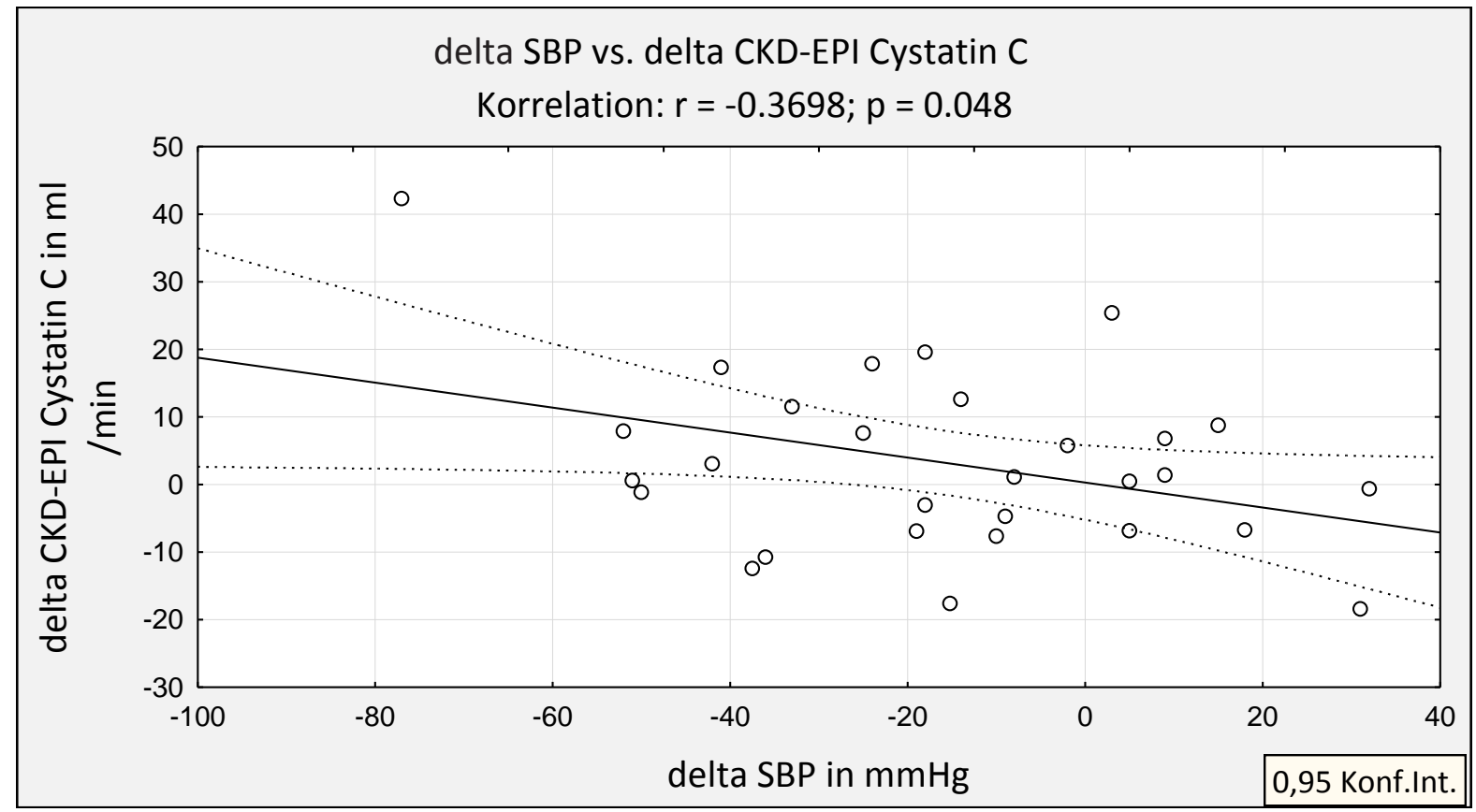

Abb. 3.7: Beziehung zwischen systolischer BuP-Absenkung und Veränderung der eGFR unter Anwendung der CKD-EPI Cystatin C-Formel. Darstellung als Korrelation mit Regressionsbändern und Konfidenzniveau von 0,95. SBP = systolic bood pressure; CKD-EPI = Chronic Kidney Disease Epidemiology Collaboration 


\subsubsection{Fraktionierte $\mathrm{Na}^{+}$-Ausscheidung, Renin-Aldosteron-Achse}

Renin, Aldosteron und der Renin/Aldosteron-Quotient blieben nach sechs Monaten BAT-Behandlung unverändert ( $p=0,67 ; 0,59$ und 0,65$)$. Jedoch zeigte sich bei der mit der Kawasaki-Formel berechneten fraktionierten $\mathrm{Na}^{+}$-Exkretion ein signifikanter Anstieg $(p=0,029)$. Ebenso stellte sich die geschätzte $24 \mathrm{~h}-\mathrm{Na}^{+}-$Exkretion mit signifikantem Anstieg $(p=0,049)$ dar. Bei der Anpassung von 24-stündiger $\mathrm{Na}^{+}-$ Exkretion an die CKD-Kreatinin-Formel, zeigte sich eine Zunahme von 1,8 $(0,99-3,07)$ auf $2,0(1,4-3,9) \mathrm{mmol} / \mathrm{Tag} / \mathrm{ml} / \mathrm{min}(\mathrm{p}=0,079)$. Die Ergebnisse der ANOVA-Analyse waren hinsichtlich des Einflusses der kategorialen Variablen RD, Geschlecht, D.m. und Raucher gegenüber der fraktionierten $\mathrm{Na}^{+}$-Exkretion und geschätzten 24h-Na+-Exkretion unauffällig. Die Daten sind in den Tabellen 3.14 und 3.6 bis 3.9 zusammengefasst.

Da sowohl Diuretika als auch Mineralokortikoidrezeptor-Antagonisten (MCRA) Einfluss auf die $\mathrm{Na}^{+}$-Exkretion während der BAT nehmen können, wurden weitere statistische Analysen durchgeführt. Eine kontinuierliche Einnahme von Diuretika erfolgte bei allen eingeschlossen Studienpatienten wobei während der BAT bei 2 Patienten eine Dosiserhöhung und 4 Patienten eine Dosiserniedrigung vorgenommen wurden. Patienten mit konstanter Dosis $(n=24$, Patient mit fehlender Urinprobe nicht betrachtet) zeigten einen nicht signifikanten Anstieg der geschätzten $24 \mathrm{~h}-\mathrm{Na}^{+}$Exkretion von 121,9 $\pm 63,1$ auf 137,8 $\pm 72,1 \mathrm{mmol} / \mathrm{Tag}(p=0,19)$. Beim Vergleich der 24h-Na+-Exkretion im BAT-Verlauf zwischen Patienten mit konstanter, erhöhter und gesunkener Diuretikadosis, zeigten sich im Kruskal-Wallis-ANOVA-Test keine signifikanten Unterschiede $(p=0,34)$. Zusätzlich nahmen während der BAT 6 von 31 Patienten zusätzlich einen MCRA ein. Es zeigte sich zur Visit I kein signifikanter Unterschied zwischen Patienten mit bzw. ohne MCRA $(p=0,65)$ (siehe Abb. 3.8). Auch der Verlauf hinsichtlich der $24 \mathrm{~h}-\mathrm{Na}^{+}$-Exkretion stellte sich innerhalb und zwischen den beiden Gruppen nicht signifikant dar (siehe Abb. 3.8).

Die Subgruppenanalyse für Patienten mit vorheriger $\mathrm{RD}$ zeigte für die renale $\mathrm{Na}^{+}-$ Exkretion einen signifikanten Anstieg (siehe Tab. 3.6). Bei RD-Patienten mit MCRAs zeigte die geschätzte 24h-Na+-Exkretion zur Visit I einen signifikanten Unterschied von $\mathrm{p}<0,05$ gegenüber RD-Patienten ohne MCRAs. Im Verlauf der sechsmonatigen BAT war der Anstieg der geschätzte $24 \mathrm{~h}-\mathrm{Na}^{+}$-Exkretion im Vergleich nicht signifikant $(p=0,68)$ (siehe Abb.3.9). 


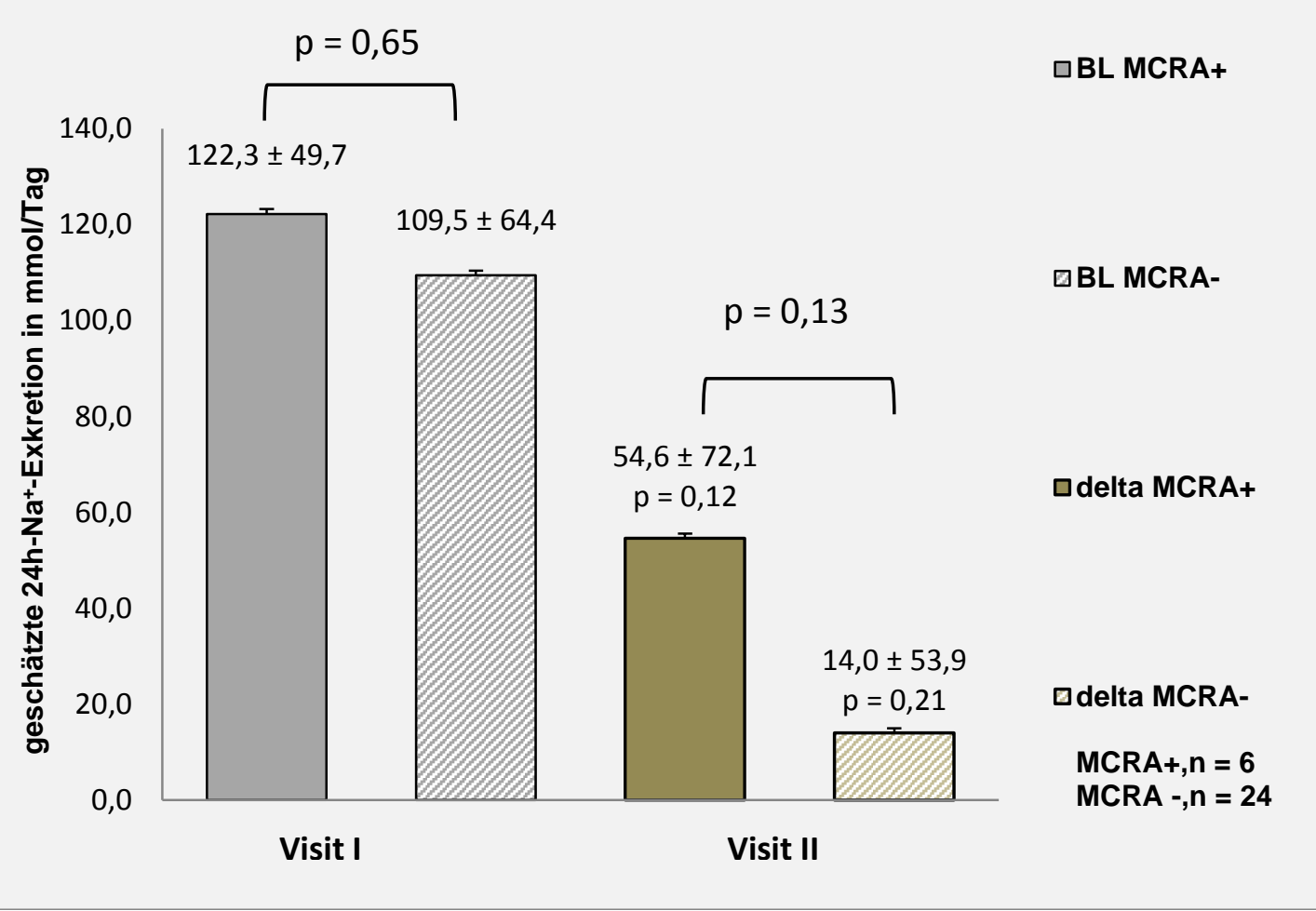

Abb. 3.8: Geschätzte 24h-Na+-Exkretion (berechnet nach Kawasaki) hinsichtlich der Einnahme von MCRAs: $\mathrm{BL}=$ Baseline-Daten zur Visit I, MCRA = Mineralokortikoidrezeptor-Antagonisten; delta = Veränderung innerhalb der Subgruppe zwischen Visit I und Visit II; +/- = mit /ohne.

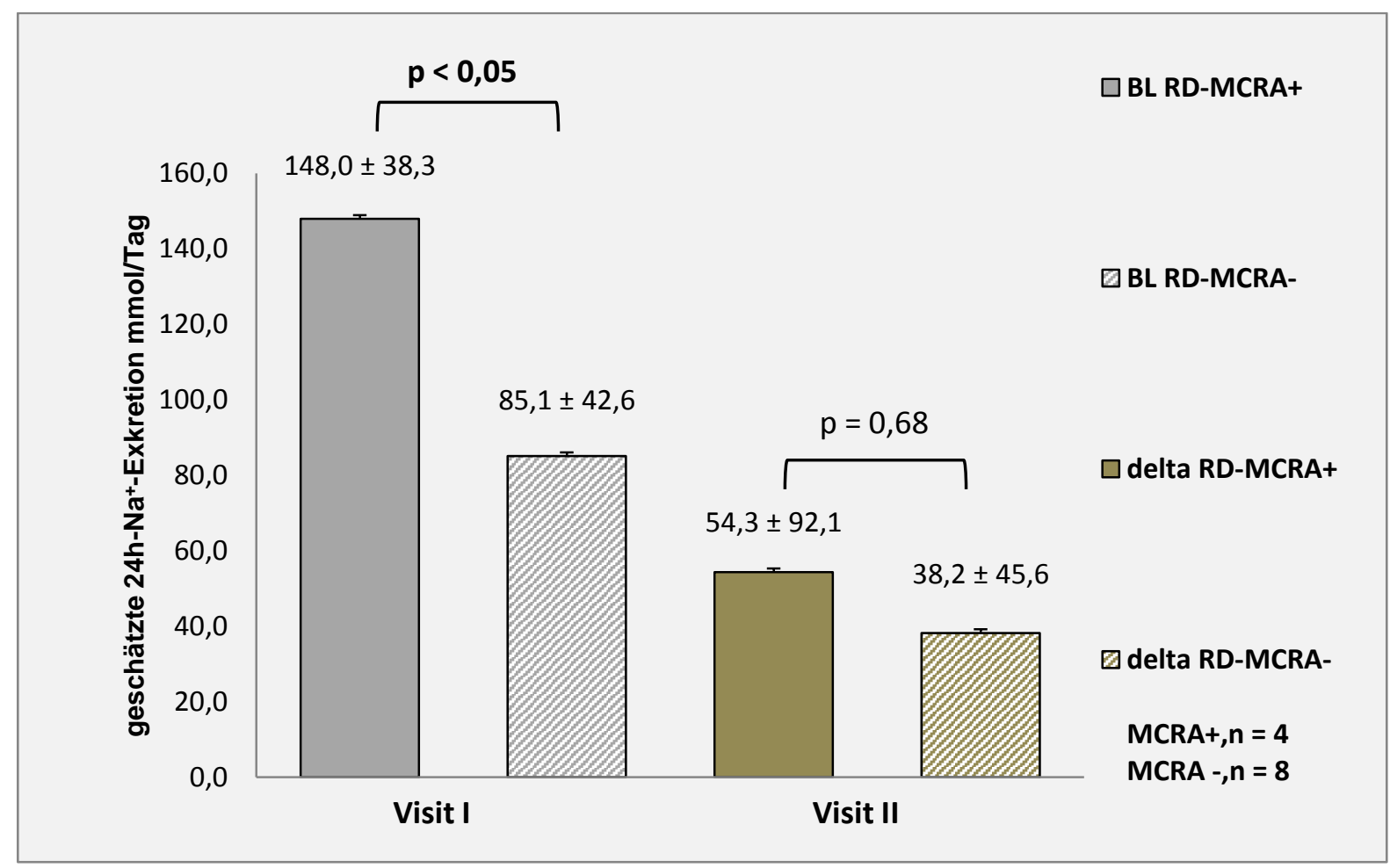

Abb. 3.9: Geschätzte 24h-Na+-Exkretion bei RD-Patienten mit und ohne der Einnahme von MCRAs zur Visit I und Visit II: RD = renale Denervierung, MCRA = Mineralokortikoidrezeptor-Antagonisten, $\mathrm{BL}=\mathrm{Baseline-}$ Daten zur Visit I; delta = Veränderung innerhalb der Subgruppe zwischen Visit I und Visit II; +/- = mit /ohne 
Tab. 3.14: Ergebnisse renaler Funktionsparameter

\begin{tabular}{|c|c|c|c|}
\hline \\
\hline $\begin{array}{l}\text { Proteinurie, } \mathrm{n}=30 \\
\text { Proteinurie, } \mathrm{ma} / \mathrm{l}\end{array}$ & 2218 (680-8180) & & \\
\hline & & $106,8(36,0-335,0)$ & 0,007 \\
\hline $\begin{array}{l}\text { Albuminurie, } \mathrm{mg} / \mathrm{l} \\
\mathrm{g}_{1} \text { Mikroglobulinurie } \mathrm{ma} / \mathrm{l}\end{array}$ & $69,8(11,0-435,0)$ & 19,2 (10,0-171,0) & 0,0047 \\
\hline 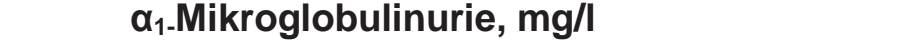 & $9,5(6,0-22,5)$ & $7,7(6,0-15,3)$ & 0,01 \\
\hline Keine Albuminurie, $<30 \mathrm{mg} / \mathrm{g}$ Kreatinin & $8(27,5 \%)$ & $9(31 \%)$ & \\
\hline Mikroalbuminurie, $30-300 \mathrm{mg} / \mathrm{g}$ Kreatinin & $13(45 \%)$ & $14(48 \%)$ & 0,42 \\
\hline Makroalbuminurie, > $300 \mathrm{mg} / \mathrm{g}$ Kreatinin & $8(27,5 \%)$ & $6(21 \%)$ & \\
\hline Protein/Kreatinin, mg/g Kreatinin & $300,5(17-17611)$ & $179,8(34-9472)$ & 0,13 \\
\hline Albumin/Kreatinin, mg/g Kreatinin & $56,4(8-7860)$ & $46,8(8-7124)$ & 0,074 \\
\hline \multicolumn{4}{|l|}{ Renin-Aldosteron-Achse, $\mathrm{n}=\mathbf{3 1}$} \\
\hline Aldosteron, $\mathrm{pg} / \mathrm{ml}$ & $98,0(82-174)$ & $110,0(77,0-199,0)$ & 0,59 \\
\hline Renin, $\mu \mathrm{lU} / \mathrm{ml}$ & $32,8(10,1-107,2)$ & $25,7(8,9-123,3)$ & 0,67 \\
\hline Aldosteron-Renin-Qutient & $5,4(1,3-13,8)$ & $6,8(1,8-20,6)$ & 0,65 \\
\hline \multicolumn{4}{|l|}{ Exkretorische Nierenfunktion, $\mathbf{n}=31$} \\
\hline Serum-Kreatinin, mg/dl & $1,7 \pm 1,6$ & $1,7 \pm 1,6$ & 0,89 \\
\hline Urin-Kreatinin, mg/dl $(n=30)$ & $97,5 \pm 63,0$ & $72,2 \pm 61,4$ & 0,047 \\
\hline eGFR-MDRD, $\mathrm{ml} / \mathrm{min}$ & $61,7 \pm 30,5$ & $61,6 \pm 31,5$ & 0,92 \\
\hline Cystatin C, mg/l & $1,7 \pm 1,2$ & $1,7 \pm 1,3$ & 0,67 \\
\hline CKD-EPI-Kreatinin-Formel, $\mathrm{ml} / \mathrm{min}$ & $60,9 \pm 30,1$ & $60,4 \pm 30,7$ & 0,74 \\
\hline CKD-EPI-Cystatin C-Formel, $\mathrm{ml} / \mathrm{min}$ & $54,2 \pm 27,6$ & $58,4 \pm 28,8$ & 0,09 \\
\hline $\begin{array}{l}\text { CKD-EPI-Kreatinin-Cystatin C-Formel, } \\
\mathrm{ml} / \mathrm{min}\end{array}$ & $56,7 \pm 27,9$ & $58,3 \pm 30,0$ & 0,33 \\
\hline \multicolumn{4}{|l|}{$\mathrm{Na}^{+}$-Urin-Exkretion, $\mathrm{n}=30$} \\
\hline 24h-Na+-Exkretion, mmol/Tag & $112,0 \pm 61,2$ & $134,1 \pm 66,9$ & 0,049 \\
\hline $\begin{array}{l}\mathrm{Na}^{+} \text {-Exkretion/CKD-Cystatin C-Gleichung, } \\
\mathrm{mmol} / \mathrm{Tag} / \mathrm{ml} / \mathrm{min}\end{array}$ & $2,6 \pm 1,8$ & $3,1 \pm 2,6$ & 0,17 \\
\hline $\mathrm{Na}^{+}$-Exkretion /CKD-Kreatinin-Gleichung, & $1,8(0,99-3,07)$ & $2,0(1,4-3,9)$ & 0,079 \\
\hline fraktionierte $\mathrm{Na}^{+}$-Exkretion, \% & $0,8(0,4-1,6)$ & $1,1(0,6-1,96)$ & 0,029 \\
\hline
\end{tabular}

Daten dargestellt als MW \pm Stabw. oder Median (IQA); eGFR-MDRD = estimating glomerular filtration ratemodification of diet in renal disease, CKD-EPI = Chronic Kidney Disease Epidemiology Collaboration, $\mathrm{CKD}=$ chronic kidney disease $; \mathrm{n}=$ Stichprobenröße 


\subsubsection{Proteomanalyse}

Im Vergleich der Proteinspotmuster von Visit I gegenüber Visit II zeigte sich im 2DDIGE-Gel der Nicht-Diabetiker-Gruppe (NDM-Gruppe) keine statistisch signifikante Spotvolumen-Veränderung $(\Delta \mathrm{SV})$, sodass von einer weiteren MS-Untersuchung einzelner Spots abgesehen wurde (siehe Abb. 3.10).

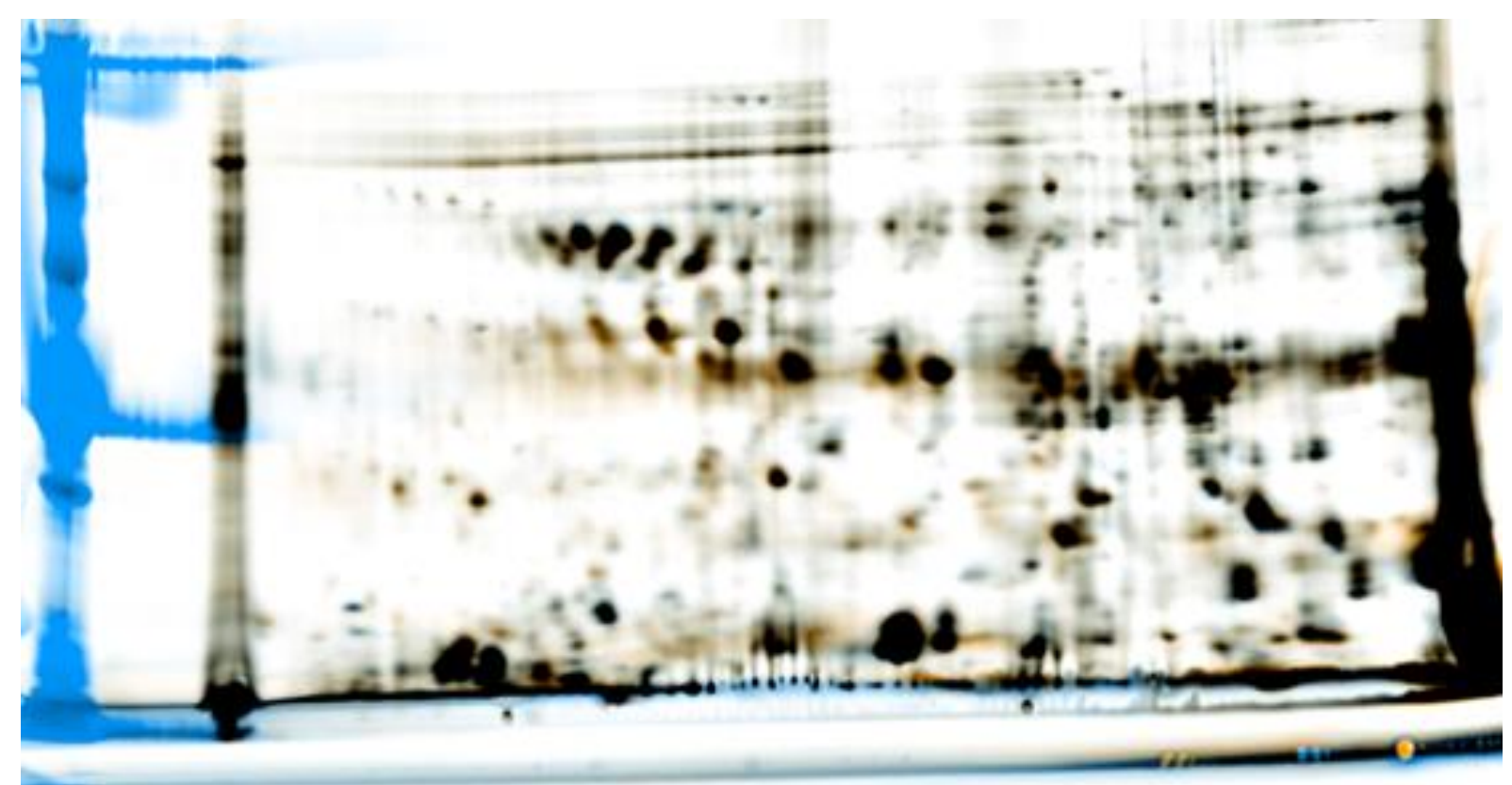

Abb. 3.10: Ergebnis der 2D-DIGE-Gele der NDM-Gruppe: blau = Visit I; orange = Visit II, schwarz = Visit I und II

Im Gegensatz dazu wurden in der 2D-DIGE-Gel Untersuchung der Diabetiker-Gruppe (D.m.-Gruppe) etwa 90 Spots detektiert, wovon 38 näher analysiert wurden und dabei 19 Proteinspots eine signifikante $\Delta S V$ (Spotvolumen-Veränderung) im Verlauf des sechsmonatigen Beobachtungszeitraums (bei 12 Spots eine Abnahme des SV bzw. bei 7 Spots eine Zunahme des SV) aufwiesen (siehe Abb. 3.11 und Tab. 3.15).

Bei der anschließenden Analyse mittels MOLDI-TOF-MS wurden insgesamt 1121 einzigartige Spektren und 1030 einzigartige Peptide detektiert, welche 186 verschiedenen Proteinen zugeordnet werden konnten (siehe Tab. 3.16). Davon konnten 105 Proteine ausschließlich in den Spots 23 und 36 nachgewiesen werden. Bei einer Verringerung des Spotvolumens ( $\mathrm{x}$-fache von $\Delta \mathrm{SV}$ ) von -1,82 für Spot 23 bzw. -2,71 für Spot 36 fanden sich neben zahlreichen Proteinen des Zytoskeletts und - metabolismus auch die ER-Stressmarker heat shock protein 90-beta und alpha, 


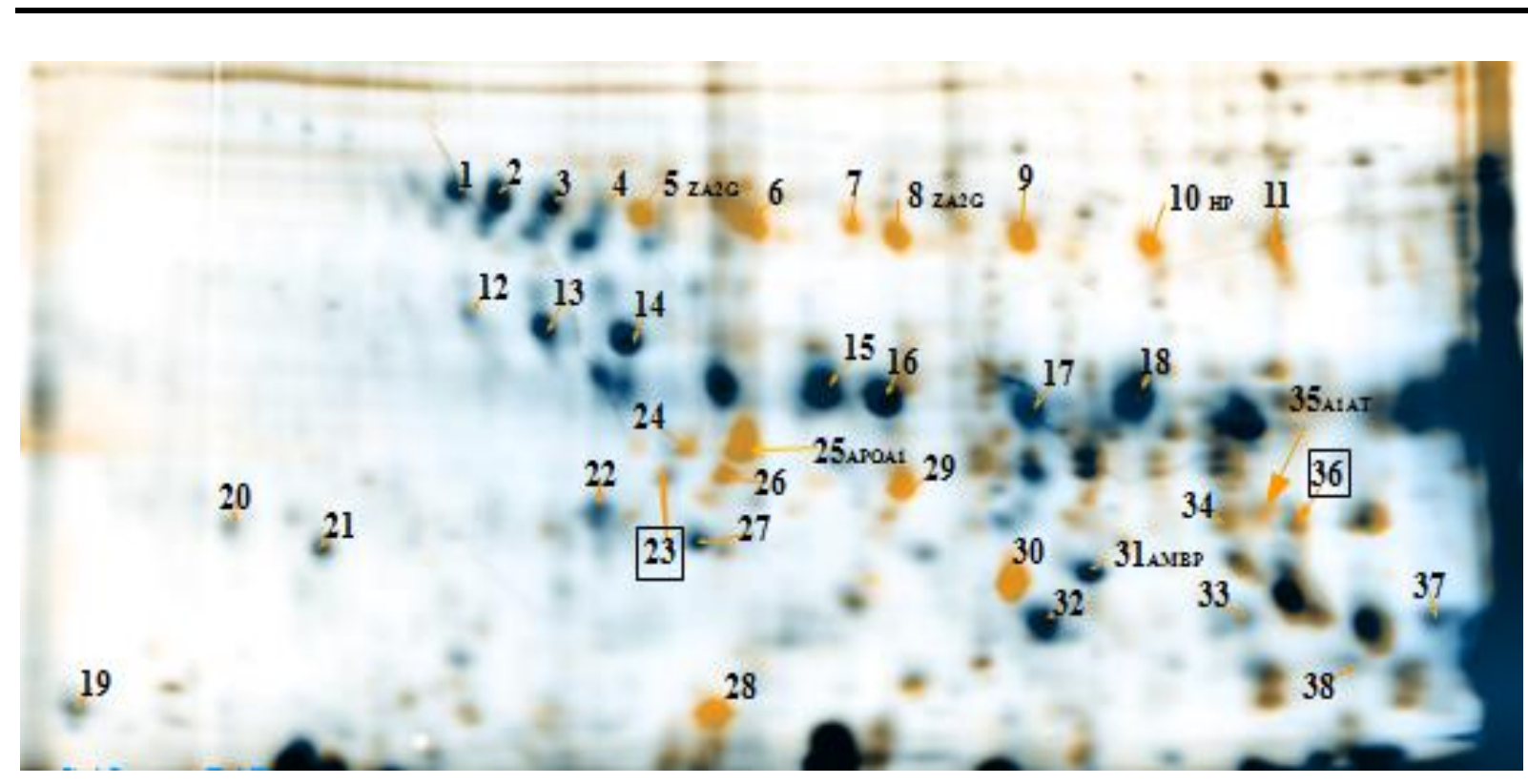

Abb. 3.11: Ergebnis der 2D-DIGE-Gele der D.m.-Gruppe: gelb = Visit I, blau = Visit II; APOA1 = Apolipoprotein $A-I, \quad H P=$ Haptoglobin, $\quad A 1 A T=\alpha_{1}$-Antitrypsin, $\quad A M B P=\alpha_{1}-$ Mikroglobulin/Bikunin Precursor, $Z A 2 G=Z$ Zink- $\alpha_{2}-$ Glycoprotein

Tab. 3.15: Spotvolumina der erfassten 2D-DIGE-Gel-Spots im Verlauf der BAT in der D.m.-Gruppe

\begin{tabular}{|lclccc|}
$\begin{array}{l}\text { Spot } \\
\text { Nr. }\end{array}$ & Protein & $\begin{array}{l}\boldsymbol{\phi} \text { Visit 1 } \\
\text { (norm. SV) }\end{array}$ & $\begin{array}{l}\boldsymbol{\phi} \text { Visit 2 } \\
\text { (norm. SV) }\end{array}$ & $\boldsymbol{P}$ & -fache $\mathbf{\Delta S V}$ \\
\hline $\mathbf{1}$ & - & 1,27 & 2,93 & $<0,0001$ & $+\mathbf{2 , 3 1}$ \\
\hline $\mathbf{5}$ & ZA2G & 4,77 & 1,41 & 0,0002 & $-3,38$ \\
\hline $\mathbf{8}$ & ZA2G & 3,44 & 0,31 & $<0,0001$ & $-11,28$ \\
\hline $\mathbf{1 0}$ & HP & 2,90 & 0,11 & $<0,0001$ & $-26,89$ \\
\hline $\mathbf{1 7}$ & - & 2,81 & 6,03 & $<0,0001$ & $+2,14$ \\
\hline $\mathbf{1 8}$ & - & 3,29 & 10,0 & $<0,0001$ & $+3,04$ \\
\hline $\mathbf{1 9}$ & - & 0,5 & 2,01 & 0,0102 & $+4,05$ \\
\hline $\mathbf{2 1}$ & - & 0,17 & 1,71 & 0,0005 & $+9,82$ \\
\hline $\mathbf{2 2}$ & - & 0,55 & 2,37 & 0,0008 & $+4,32$ \\
\hline $\mathbf{2 3}$ & - & 1,02 & 0,56 & $<0,0001$ & $-1,82$ \\
\hline $\mathbf{2 4}$ & - & 2,46 & 1,0 & $<0,0001$ & $-2,46$ \\
\hline $\mathbf{2 5}$ & APOA1 & 6,88 & 1,6 & 0,0001 & $-4,31$ \\
\hline $\mathbf{2 6}$ & - & 1,45 & 0,24 & 0,0001 & $-5,91$ \\
\hline $\mathbf{2 8}$ & - & 5,37 & 0,69 & $<0,0001$ & $-7,79$ \\
\hline $\mathbf{2 9}$ & - & 4,22 & 0,71 & $<0,0001$ & $-5,91$ \\
\hline $\mathbf{3 0}$ & - & 5,39 & 0,76 & $<0,0001$ & $-7,09$ \\
\hline $\mathbf{3 1}$ & AMBP & 1,99 & 3,79 & 0,0009 & $+1,90$ \\
\hline $\mathbf{3 5}$ & A1AT & 2,72 & 0,73 & $<0,0001$ & $-3,75$ \\
\hline $\mathbf{3 6}$ & - & 2,37 & 0,88 & 0,0001 & $-2,71$ \\
\hline
\end{tabular}

Die Spalte „Protein“ führt lediglich die analysierten Proteine auf, welche mit einem Anteil von $\geq 40 \%$ der totalen Spektren detektiert wurden. Nr. $=$ Nummer, norm. SV $=$ normiertes Spotvolumen, $\Delta=$ Durchschnitt, $\varnothing=$ Mittelwert, ZA2G = Zink- $\alpha_{2}$-Glycoprotein, $\Delta S V=$ Spotvolumenveränderung, APOA1 = Apolipoprotein A-I, HP = Haptoglobin, $A 1 A T=\alpha_{1}-$ Antitrypsin, $A M B P=\alpha_{1}-$ Mikroglobulin/Bikunin Precursor

heat shock cognate $71 \mathrm{kDa}$ protein, $78 \mathrm{kDa}$ glucose- regulated protein (GRP78), protein disulfide isomerase A 3 (ERP57) sowie ubiquitin-60S ribosomal protein L40 
(UbA-52) (siehe Tab. 3.15, 3.17 und Abb. 3.12). Des Weiteren konnten die renalen Proteine Alpha-Enolase, Triose-Phosphate-Isomerase, Lactat-Dehydrogenase, die im Zusammenhang mit osmotischem Stress auf Epithelzellen der aufsteigenden Henleschleife stehen, sowie das intrazelluläre Transportprotein fatty acid binding protein nachgewiesen werden (siehe Tab. 3.17).

Da sich in nahezu allen analysierten Spots mehrere Proteine wiederfanden und in unterschiedlichen Spots detektiert werden konnten, war eine paarweise „ProteinSpot"-Zuordnung selten möglich (siehe Tab.3.15). Eine Ausnahme stellten die Proteinspots $8(\Delta S V=-11,28)$ und $5(\Delta S V=-3,38)$ dar, in denen überwiegend das Protein Zinc-alpha-2-glycoprotein detektiert wurde sowie das Protein Alpha-1antitrypsin in Spot $35(\Delta S V=-3,75)$, Apolipoprotein A-I in Spot $25(\Delta S V=-4,31)$, Haptoglobin in Spot $10(\Delta S V=-26,89)$ und Protein AMBP in Spot $31(\Delta S V=0,53)$, deren Anteil der analysierten totalen Spektren bei $\geq 40 \%$ lag.

Zu den Biomarkern, die eine geringe Anzahl analysierter totaler Spektren sowohl in Spots mit einer $\Delta S V$-Zunahme als auch Abnahme vorwiesen, gehörten das Serotransferrin, Cueroluplasmin, Semenogelin-1 und 2, Apolipoprotein A-IV, Prostaglandin-H2 D-Isomerase, Vitamin-D binding Protein und Uromodulin. Die Marker alpha1-Antichymotrypsin und Afamin ließen sich ausschließlich in den Spots 22 und 21 nachweisen (siehe Tab. 3.16).

$\mathrm{Da}$ es sich hierbei lediglich um eine Discovery Methode handelt, sind zur Quantifizierung und Validierung der detektierten Biomarker weitere Untersuchungen in bereits geplanten Projekten vorgesehen. 
Tab. 3.16: Massenspektrometrisch analysierte Proteine

\begin{tabular}{|c|c|c|c|c|c|c|c|}
\hline $\begin{array}{l}\text { SwissPro } \\
\text { /Acc. Nr. }\end{array}$ & Proteinname & Spot Nr. & $\begin{array}{l}\text { MG } \\
(\mathrm{kDa})\end{array}$ & $\begin{array}{l}\text { Total Spectrum } \\
\text { Treffer }\end{array}$ & $\begin{array}{l}\text { Totale einzigartige } \\
\text { Peptid Treffer }\end{array}$ & $\mathrm{pl}$ & Funktion \\
\hline P15924 & Desmoplakin & $1,19,23,24,26,28,30,36$ & 332 & 70 & 66 & 6,44 & Zytoskelett \\
\hline P02647 & Apolipoprotein $\mathrm{A}-\mathrm{I}^{2}$ & $22-26,28-31$ & 31 & 44 & 30 & 5,27 & Stoffwechsel \\
\hline P00738 & Haptoglobin ${ }^{2,8}$ & $1,10,15,17,18,28,30,31$ & 45 & 32 & 21 & 6,13 & Transport \\
\hline P31947 & Cluster of 14-3-3 Protein Sigma & 23,36 & 28 & 30 & 28 & 4,68 & Signaltransduktion \\
\hline P02787 & Serotransferrin ${ }^{2}$ & $10,17,18,22,23,25,26,29-31,35,36$ & 77 & 24 & 24 & 6,7 & Transport \\
\hline P29508 & Serpin B3 & 23,36 & 45 & 24 & 22 & 6,35 & Zellmetabolismus \\
\hline P02760 & Protein $\mathrm{AMBP}^{1,2,9}$ & $17-19,21-26,28-31,35$ & 39 & 23 & 14 & 6,13 & Stoffwechsel \\
\hline P01009 & Alpha-1-antitrypsin ${ }^{2}$ & $1,10,17-19,21,23-25,29,30,35,36$ & 46,7 & 22 & 18 & 5,37 & Immunabwehr \\
\hline P25311 & Zinc-alpha-2-glycoprotein ${ }^{1,2}$ & $1,5,8,10,23-25,30,31,35,36$ & 34 & 19 & 17 & 5,58 & Immunabwehr \\
\hline P68371 & Tubulin beta $4 \mathrm{~B}^{6}$ & 23,36 & 50 & 17 & 14 & 4,79 & Zytoskeltett \\
\hline P04279 & Semenogelin-1 & $1,10,17,18,22-26,28-31,35,36$ & 52 & 14 & 12 & 9,26 & Stoffwechsel \\
\hline P14923 & Junction plakoglobin & $1,19,23,26,36$ & 82 & 14 & 12 & 5,75 & Zytoskelett \\
\hline P41222 & Prostaglandin-H2 D-Isomerase ${ }^{2}$ & $17-19,21-26,29-31,35$ & 21 & 13 & 5 & 8,37 & Stoffwechsel \\
\hline P02774 & Vitamin-D binding Protein ${ }^{2}$ & $22,23,25,26,29$ & 53 & 13 & 12 & 5,22 & Transport \\
\hline P07339 & Cathepsin & $23,25,26,36$ & 45 & 13 & 10 & 5,6 & Zellmetabolismus \\
\hline P07355 & Annexin $\mathrm{A} 2^{6}$ & 23,36 & 39 & 12 & 12 & 7,56 & Zytoskeltett \\
\hline P07900 & Heat shock protein 90 -alpha ${ }^{6}$ & 23,36 & 85 & 11 & 11 & 4,94 & Zellmetabolismus \\
\hline P08238 & Heat shock protein 90 -beta ${ }^{6}$ & 23,36 & 83 & 11 & 11 & 4,96 & Zellmetabolismus \\
\hline P07911 & Uromodulin $^{7,8}$ & $1,19,21,22,24-26,30,31$ & 70 & 11 & 9 & 4,96 & Signaltransduktion \\
\hline P04792 & Heat shock protein beta-1 & 23,36 & 23 & 10 & 9 & 5,98 & Zellmetabolismus \\
\hline P11142 & Heat shock cognate $71 \mathrm{kDa}$ protein & 23,36 & 71 & 10 & 9 & 5,37 & Zellmetabolismus \\
\hline P98160 & $\begin{array}{l}\text { Basement membrane-specific heparan } \\
\text { sulfate proteoglycan core }\end{array}$ & $29,30,31$ & 469 & 9 & 9 & 6,03 & Stoffwechsel \\
\hline P01024 & Complement C3 & $1,17,23,29,36$ & 178 & 9 & 9 & 6,0 & Immunabwehr \\
\hline P06733 & Alpha-Enolase ${ }^{6}$ & 23,36 & 47 & 9 & 9 & 6,99 & Zellmetabolismus \\
\hline P04406 & Glyceraldehyd-3-Phosphat Dehydrogenase ${ }^{6}$ & $1,23,36$ & 36 & 9 & 9 & 8,58 & Zellmetabolismus \\
\hline P68366 & Tubulin alpha $4 A^{6}$ & 23,36 & 50 & 9 & 8 & 4,93 & Zytoskeltett \\
\hline P06727 & Apolipoprotein A-IV² & $10,17,35$ & 45 & 8 & 8 & 5,18 & Stoffwechsel \\
\hline
\end{tabular}




\begin{tabular}{|c|c|c|c|c|c|c|c|}
\hline P11021 & 78 kDa glucose-regulated protein ${ }^{5,6,10}$ & 23,36 & 72 & 8 & 8 & 5,01 & Zellmetabolismus \\
\hline P06396 & Gelsolin & $23,25,36$ & 86 & 8 & 8 & 5,72 & Zytoskelett \\
\hline Q02383 & Semenogelin-2 & $10,17,18,22,23,25,26,29,35$ & 65 & 6 & 6 & 9,04 & Stoffwechsel \\
\hline P68104 & Elongationsfaktor 1alpha & 23,36 & 50 & 6 & 6 & 9,1 & Zellmetabolismus \\
\hline P00450 & Cueroluplasmin ${ }^{2}$ & $1,10,22,26,30$ & 122 & 5 & 5 & 5,41 & Transport \\
\hline P06702 & Protein S100A9 & 23,36 & 13 & 5 & 5 & 5,71 & Zellmetabolismus \\
\hline P13639 & Elongationsfaktor 2 & 23,36 & 95 & 5 & 5 & 6,42 & Zellmetabolismus \\
\hline P31944 & Caspase 14 & 23,36 & 28 & 5 & 5 & 9,13 & Signaltransduktion \\
\hline P60174 & Triose-Phosphate Isomerase & 23,36 & 31 & 5 & 4 & 5,65 & Zellmetabolismus \\
\hline P19320 & Vascular cell adhesion protein 1 & 24 & 81 & 4 & 4 & 5,11 & Signaltransduktion \\
\hline P29373 & Cellular retinoic acid-binding protein 2 & 23,36 & 16 & 4 & 4 & 5,38 & Transport \\
\hline P62987 & Ubiquitin-60S ribosomal protein L40 (UbA-52) & $1,23,36$ & 15 & 4 & 4 & 10,32 & Signaltransduktion \\
\hline P00338 & Lactat-Dehydrogenase $^{6}$ & 23,36 & 37 & 4 & 4 & 8,46 & Stoffwechsel \\
\hline P04083 & Annexin $\mathrm{A}^{6}{ }^{6}$ & 23,36 & 39 & 4 & 4 & 6,64 & Zytoskeltett \\
\hline P22352 & Glutathione peroxidase 3 & 29 & 26 & 3 & 3 & 7,85 & Stoffwechsel \\
\hline P30101 & Protein disulfide-isomerase A3 (ERP57) ${ }^{6}$ & 36 & 57 & 3 & 3 & 5,61 & Zellmetabolismus \\
\hline Q01469 & Fatty acid binding protein ${ }^{3}$ & 23,36 & 15 & 3 & 3 & 6,82 & Transport \\
\hline P02790 & Hemopexin $^{2}$ & 18,35 & 52 & 3 & 3 & 6,43 & Transport \\
\hline P10599 & Thioredoxin & 23,36 & 12 & 3 & 3 & 4,82 & Zellmetabolismus \\
\hline P09211 & Glutathione S-Transferase $^{6}$ & 36 & 23 & 3 & 3 & 5,44 & Transport \\
\hline P30101 & Protein Disulfid-Isomerase A3 & 36 & 57 & 3 & 3 & 5,61 & Zellmetabolismus \\
\hline P00747 & Plasminogen & 35 & 91 & 2 & 2 & 7,08 & Stoffwechsel \\
\hline P05109 & Protein S100A8 & 23,36 & 11 & 2 & 2 & 6,5 & Zellmetabolismus \\
\hline P07384 & Calpain-1 & 36 & 82 & 2 & 2 & 5,49 & Zellmetabolismus \\
\hline P02766 & Transthyretin & 28 & 16 & 2 & 2 & 5,31 & Stoffwechsel \\
\hline P01011 & Alpha1-Antichymotrypsin² & 22 & 48 & 2 & 2 & 5,32 & Immunabwehr \\
\hline P43652 & Afamin $^{2}$ & 21 & 69 & 2 & 2 & 5,58 & Transport \\
\hline P20073 & Annexin A7 & 36 & 53 & 2 & 2 & 5,52 & Zytoskeltett \\
\hline P67936 & Tropomyosin alpha-4 & 23,36 & 29 & 2 & 2 & 4,67 & Zytoskeltett \\
\hline
\end{tabular}

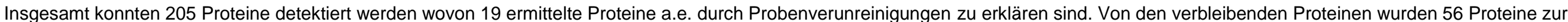

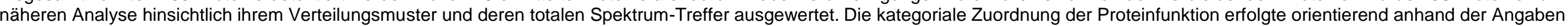

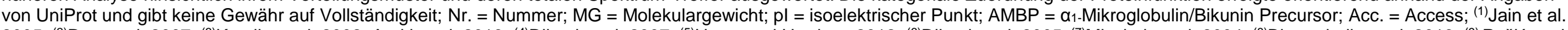

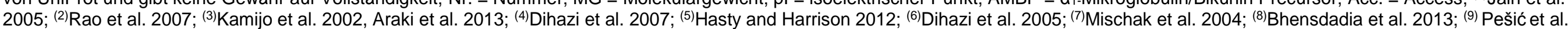
2011, Yokota et al. 2007, Hong et al. 2003; (10)Inagi 2011 
Tab. 3.17: Übersicht ausgewählter Proteine der Spots 23 und 36

\begin{tabular}{|c|c|c|c|c|}
\hline \multirow{2}{*}{$\begin{array}{l}\text { Swiss } \\
\text { Prot/Access } \\
\text { Nr. }\end{array}$} & \multirow{2}{*}{ Proteinname } & \multicolumn{2}{|c|}{ Totale Spektrum-Treffer } & \multirow[b]{2}{*}{ Gesam } \\
\hline & & Spot 23 & Spot 36 & \\
\hline P29508 & Serpin B3 & 9 & 34 & 43 \\
\hline P68371 & Tubulin beta 4B & 11 & 14 & 25 \\
\hline P08238 & Heat shock protein 90-beta & 9 & 11 & 20 \\
\hline P07355 & Annexin A2 & 9 & 10 & 19 \\
\hline P07900 & Heat shock protein 90 -alpha & 10 & 9 & 19 \\
\hline P04792 & Heat shock protein beta-1 & 7 & 9 & 16 \\
\hline P11142 & Heat shock cognate $71 \mathrm{kDa}$ protein & 6 & 9 & 15 \\
\hline P11021 & $78 \mathrm{kDa}$ glucose-regulated protein (GRP78) & 4 & 10 & 14 \\
\hline P06733 & Alpha-Enolase & 2 & 10 & 12 \\
\hline P68366 & Tubulin alpha 4A & 5 & 7 & 12 \\
\hline P68104 & Elongationsfaktor 1alpha & 3 & 7 & 10 \\
\hline P06702 & Protein S100A9 & 3 & 7 & 10 \\
\hline P60174 & Triose-Phosphate-Isomerase & 2 & 5 & 7 \\
\hline P13639 & Elongationsfaktor 2 & 4 & 3 & 7 \\
\hline P31944 & Caspase 14 & 1 & 5 & 6 \\
\hline P04083 & Annexin A1 & 2 & 4 & 6 \\
\hline P00338 & Lactat-Dehydrogenase & 2 & 4 & 6 \\
\hline P62987 & Ubiquitin-60S ribosomal protein L40 (UbA-52) & 3 & 3 & 6 \\
\hline Q01469 & Fatty acid binding protein & 2 & 3 & 5 \\
\hline P05109 & Protein S100A8 & 2 & 2 & 4 \\
\hline P09211 & Glutathione S-Transferase & - & 3 & 3 \\
\hline P10599 & Thioredoxin & 2 & 1 & 3 \\
\hline P67936 & Tropomyosin alpha-4 & 2 & 1 & 3 \\
\hline P20073 & Annexin A7 & - & 2 & 2 \\
\hline P30101 & Protein disulfide-isomerase A3 (ERP57) & - & 2 & 2 \\
\hline
\end{tabular}

Nr. = Nummer

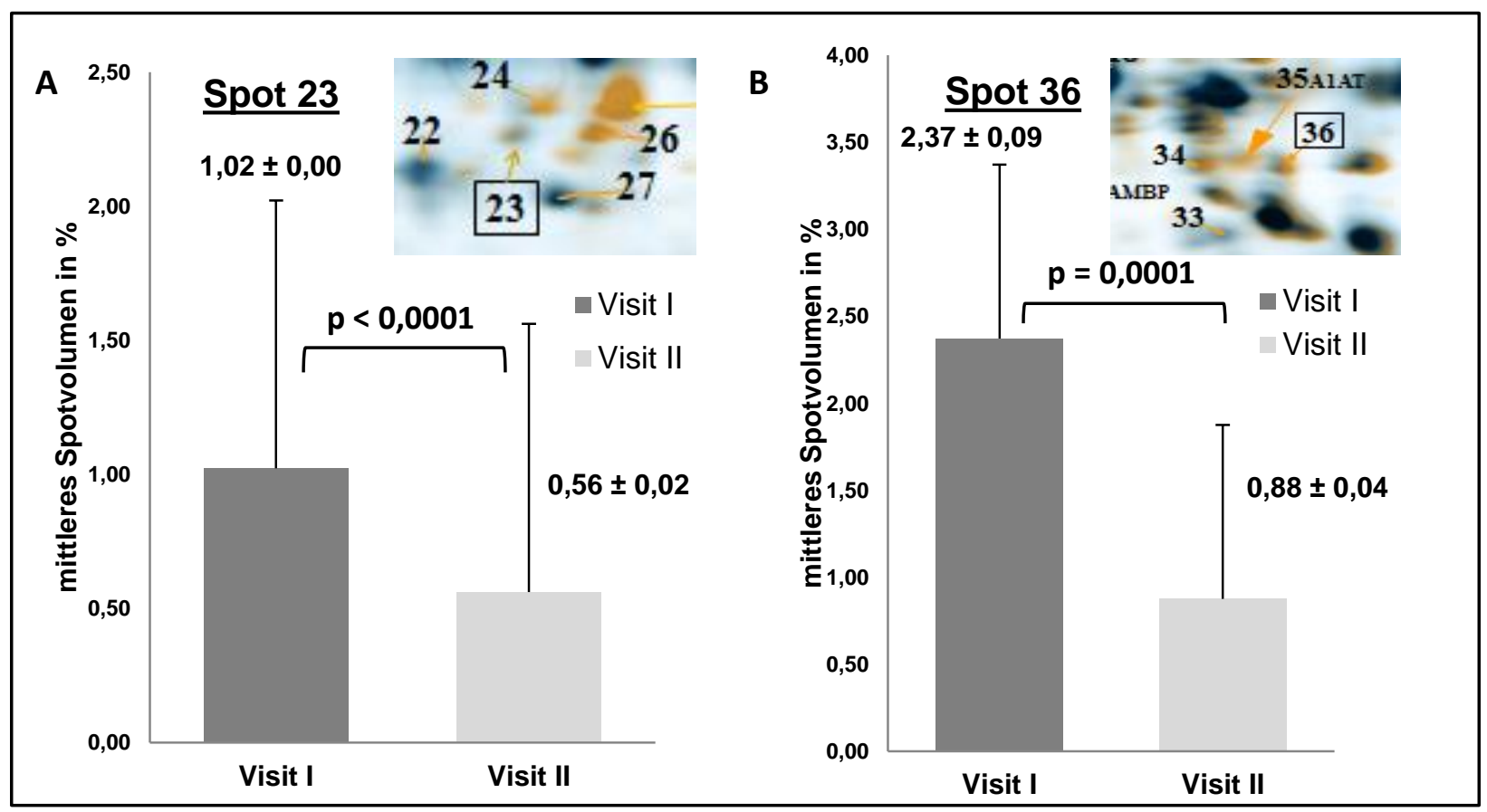

Abb: 3.12: Veränderung der Spotvolumina der Spots 23 (A) sowie 36 (B) in \% zur Visit Il gegenüber Visit $I$. 


\section{Diskussion}

Die vorliegende Studie bestätigt die Ergebnisse vorangegangener Untersuchungen zur Blutdrucksenkung durch die BAT und zeigt erstmals, welche Effekte die BAT auf die renale Funktion, zentrale Hämodynamik, die Gefäßsteife und Gefäßhomöostase nimmt.

\subsection{Blutdruckentwicklung}

In unserer Studie zeigte die BAT nach sechs Monaten eine durchschnittliche Senkung systolischer Blutdruckwerte um $-15,2 \pm 26 \mathrm{mmHg}$ in der BuP-Messung. Dagegen unterscheiden sich die Ergebnisse aktueller Studien mit einer Reduktion des BuP von - $16 \pm 3 \mathrm{mmHg}$ systolisch im Rheos Pivotel Trial und $-26 \pm 4 \mathrm{mmHg}$ systolisch im Barostim neo Trial (Hoppe et al. 2012; Bisognano et al. 2011b). Bei der Betrachtung der Therapieresponder befinden sich unsere Daten mit - 25,2 $\pm 22,7 \mathrm{mmHg}$ systolisch $(p=<0,05)$ jedoch im Bereich veröffentlichter Studienergebnisse.

Die Ergebnisse unserer ABPM-Messungen dokumentierten nach sechs Monaten BAT eine nicht signifikante BP-Reduktion von - 3,9 $\pm 26 \mathrm{mmHg}(p=0,24)$. Im Hinblick auf bereits veröffentlichte Beobachtungen ist die Bewertung unserer Daten jedoch nur eingeschränkt möglich. Zum einen ist die von uns betrachtete Patientenkohorte sehr klein - was die nicht signifikanten Ergebnisse begründen könnte - und zum anderen ergaben sich bei der Erfassung der ABPM-Daten methodische Unterschiede.

Im Falle des kleinen Patientenkollektivs zeigte sich in der anschließenden Poweranalyse bei einer Stichprobengröße von 63 Patienten ein signifikanter Abfall der ABPM-Werte. Als Konsequenz wurden daher weitere BAT-Patienten im Rahmen eines Amendement-Antrages für die Studie rekrutiert. In einer Kohortenstärke von 51 Patienten zeigte sich in der ABPM-Messung eine signifikante Reduktion der systolischen und diastolischen Blutdruckwerte $(p<0,01)$ (Wallbach et al. 2016).

Eine unterschiedliche Methode zur Erfassung der Blutdruckwerte wurde neben einigen offenen Studien auch bei der bisher einzig randomisiert kontrollierten Doppelblindstudie $(n=322)$ durchgeführt. Anstelle von ABPM-Messungen erfolgte eine 6-fach-Messung des BuP im Abstand von jeweils einer Minute. Veröffentlichte Daten schreiben dem ermitteltem Mittelwert dieser Messreihe eine signifikante Korrelation gegenüber ABPM-Werten sowie die Reduktion falsch hoher 
Blutdruckwerte infolge des Weißkittelsysndroms zu (Beckett et al. 2005). Trotz dieser scheinbaren Beziehung unterstreichen die Autoren deutlich, dass eine Beurteilung der Daten im Vergleich zum 24h-Langzeit-Profil bei dieser Methode nur eingeschränkt möglich sei und in zukünftigen Untersuchungen die ABPM durchgeführt werden sollte (Hoppe et al. 2012; Bisognano et al. 2011b, Doumas et al. 2012).

Im Rahmen der DEBuT-HT-Studie erfolgte erstmals eine Erfassung des 24-StundenBlutdruckprofils nach drei $(n=26)$, zwölf $(n=15)$ und 24 Monaten $(n=8)$ (Scheffers et al. 2010a). Hier präsentierten sich die Patienten nach drei Monaten BAT mit einer signifikanten Reduktion des BuP von $-21 \pm 4 \mathrm{mmHg}$ systolisch $(p<0,001)$, wohingegen die ABPM-Messungen, ähnlich unserer Studie, lediglich einen nichtsignifikanten Blutdruckabfall $(p=0,1)$ andeuteten. Erst nach einem Jahr BAT zeigte sich in der Nachfolgeuntersuchung eine systolische Blutdruckreduktion von - $13 \pm 3$ $(p<0,001)$ im ABPM.

\subsection{Responderrate und Medikation}

Die durchschnittliche Responderrate bei einer systolischen Blutdruckreduktion liegt in offenen Studien zwischen $75 \%$ bis $85 \%$ unter einer BAT (Wachter et al. 2015). Die in unserer Studie ermittelte Responderrate ist jedoch deutlich niedriger. Eine Ursache hierfür könnte das selektierte Patientenkollektiv sein, welches zu $90 \%$ eine CKD aufweist. Innerhalb dieser Hochrisikogruppe ist bereits durch andere CKD-Studien das schlechtere Ansprechen einer anithypertensiven Therapie bei TrHTN bekannt (Calhoun et al. 2008). In unserer Patientenkohorte spiegelt sich dies in einer durchschnittlichen Medikation von 6,5 Antihypertensiva zur Visit I wider, die damit deutlich über dem Durchschnitt von etwa 5,5 anderer Studien liegt (Bisognano et al. 2011b, Scheffers et al. 2010a, Hoppe et al. 2012). Auch wenn sich die Medikation zur Visit II nicht signifikant ändert $(\mathrm{p}=0,09)$, kommt es fast ausschließlich in der Substanzklasse der $\alpha_{2}$-Agonisten zu einer medikamentösen Reduktion (von $90 \%$ auf $64 \%$ ). Dieser Sachverhalt deutet auf eine falsche Annahme bzgl. eines nicht signifikanten Unterschiedes in der Medikation im Sinne eines Fehlers 2. Art hin, welcher sich aus der kleinen Fallzahl ergibt und durch eine Anhebung der Stichprobe geprüft werden sollte. Das Absetzten zentral wirksamer Sympatholytika als auch die Dosisreduktion anderer Antihypertensivaklassen (bei $68 \%$ der Patienten) könnte ein indirekter Hinweis auf eine effektive BAT-Wirkung sein, auch wenn das Einsparen von 
Medikamenten und möglicher Nebenwirkungen kein primäres Therapieziel ist. Ebenfalls unklar ist die Therapieadhärenz. Stichprobenartige massenspektrometrische Untersuchungen bei Non-Respondern zeigten eine eingeschränkte Adhärenz. Dieser Aspekt wird in weitergehenden Analysen noch untersucht.

\subsection{Komplikationen}

Komplikationen, die vornehmlich mit der operativen Versorgung am Anfang einer BATTherapie assoziiert sind und zu beträchtlichen Einschränkungen führen können, standen in vergangenen Studien zur Sicherheit der BAT im Vordergrund. Hierbei traten im Verlauf der DEBuT-HET-Studie bei acht von 42 Patienten interventionell bedingte Komplikationen auf [angioneurotisches Ödem $(n=1)$, Aggregat-Explantation aufgrund von Wundinfekten $(n=3)$, Schlaganfall $(n=1)$, Zungenparese $(n=1)$, Lungenödem $(n=1)$, Aggregat in Tasche verrutscht $(n=1)$ ] (19\%) (Scheffers et al. 2010a). Hoppe et al. verzeichneten im Rahmen des Barostim neo Trials bei drei von 30 Patienten einen komplizierten Wundinfekt, ein Hämatom der Aggregattasche sowie die Notwendigkeit einer Reposition des Aggregats aufgrund dislokationsbedingter Beschwerden (10\%). In einem Fall bestanden nach Aktivierung des BATSchrittmachers intermittierende Schmerzen der Generatortasche (3,3\%) welche, als Aggregat-assoziierte Nebenwirkungen gewertet wurden (Hoppe et al. 2012).

Entsprechende interventionelle Komplikationen innerhalb unserer Kohorte fanden sich bei drei von 31 Patienten in Form eines Apoplex, einer komplizierten Wundheilungsstörung und einer Rekurrenzparese (9,7\%). Insgesamt ist die Nebenwirkungsrate unserer Studie deutlich höher, wobei wir im Vergleich zu den oben genannten Studien auch geringfügige Nebenwirkungen einer kontinuierlichen BATAktivierung untersuchten. Diese wurden in bisherigen Studien nicht erfasst. Für viele Patienten stellen diese minimalen Beschwerden eine nicht unerhebliche Belastung im Alltag dar. Hierzu zählen die im Rahmen dieser Studie erfassten Parameter wie Missempfindungen, Muskelkontraktionen, Heiserkeit, Dysphagie, Hörminderung und Schwindel, welche oft ein engmaschiges Monitoring erfordern und über die regelmäßigen BAT-Anpassungen hinausgehen. In Anbetracht dessen sollten Patienten vor Therapiebeginn nicht nur über das Risiko schwerwiegender BAT assoziierter Komplikationen, sondern auch über scheinbar unbedeutende Nebenwirkungen aufgeklärt werden. Im Rahmen der Studie konnten wir zeigen, dass 
geringfügige Beschwerden im Verlauf von sechs Monaten überwiegend sistierten. Einschließlich operativ- und blutdruckbedingter Komplikationen des Grades I konnte nach sechs Monaten BAT in > $88 \%$ der Fälle eine Beschwerdefreiheit erreicht werden. Dies entspricht den Angaben von $87 \%$ bis $97 \%$ vorangegangener BAT- und Schrittmacherimplantationsstudien (Hoppe et al. 2012, Udo et al. 2012 [FOLLOWPACE Study]). Die Häufigkeiten von Komplikationen des Schweregrades III lagen in unserer Studie unter denen veröffentlichter chirurgischer Eingriffe am Hals (Ferguson et al. 1999; Dziewanowski 2005). Die vorliegende Studie bestätigt daher, dass die BAT ein sicheres und patientenseitig tolerables Verfahren zur Behandlung der TrHTN ist.

\subsection{Renale Organoprotektion}

\subsubsection{Proteinausscheidung}

Hypertoniker mit einer bestehenden CKD sind für eine Resistenz gegenüber einer konventionellen antihypertensiven Therapie prädisponiert. Der Anteil für einen unkontrollierten Blutdruck liegt bei einer bestehenden Mikroalbuminurie bei $80 \%$ (Fraser et al. 2013). Die Anwendung von mindestens vier oder mehr Antihypertensiva ist häufig und unterstreicht, dass eine optimale Blutdruckeinstellung in dieser Patientengruppe oft sehr problematisch ist (Egan et al. 2013). Publizierte Daten verdeutlichen, dass das Ausmaß der Proteinurie und dessen therapiebedingte Reduktion einen Prädiktor für das renale Outcome darstellen (Cravedi et al. 2012; Lea et al. 2005). Eine Senkung der Proteinurie um bis zu $20 \%-50 \%$ reduziert das Risiko, ein dialysepflichtiges Nierenversagen (ESRD) zu erleiden, um ca. 50 \% - $75 \%$ (Lea et al. 2005). Leider wird eine adäquate antihypertensive Therapie bei Vorliegen einer CKD zusätzlich erschwert, da zahlreiche Medikamente als auch interventionelle Verfahren, wie die RD, bei CKD-Patienten kontraindiziert sein können. So zählen Patienten mit einer CKD und einer TrHTN zur Hochrisikogruppe, kardiovaskuläre Ereignisse und/oder ein dialysepflichtiges Nierenversagen zu entwickeln. Diese Studie zeigt, dass die BAT in dieser Hochrisikogruppe nicht nur ein sicheres Verfahren ist, sondern neben einer signifikanten Blutdrucksenkung auch zu einer Reduktion der Proteinurie führt.

Eine drastische Senkung der Proteinurie ist insbesondere für ACE-Hemmer und AT1Blocker bekannt und konnte eindrücklich bei hyper- wie auch normotensiven Patienten 
mit einer bestehenden Nephropathie oder vorliegenden Mikroalbuminurie nachgewiesen werden (siehe Tab.4.1). Darüber hinaus konnten Studien zur Wirksamkeit von Renin-Angiotensin-Hemmern neben der Nephroprotektion eine Senkung zentraler und peripherer adrenerger Effekte zeigen (Xie et al. 2011; Grassi et al. 2011b). In ähnlichem Maße wurde für zentral wirksame Antihypertensiva sowohl eine Sympathikoinhibition als auch ein Rückgang der Albuminurie bei HTN-Patienten nachgewiesen (Vongpatanasin et al. 2011; Krespi et al. 1998). Diese Beobachtungen lassen den Schluss zu, dass eine Hemmung des Sympathikus nephroprotektive Wirkungen vermitteln könnte. Wissend um den sympathikoinhibierenden Stimulus der BAT, untersuchten wir unsere Kohorte auf ähnliche Effekte.

Tab. 4.1: Antiproteinurische Wirkung verschiedener Antihypertensiva

\begin{tabular}{|c|c|c|}
\hline Antihypertensivaklasse & Antiproteinurische Wirkung & Studien \\
\hline ACE-Hemmer & $\begin{array}{l}\text { stark antiproteinurisch } \\
\text { (bis zu } 55 \%) \\
\text { antiproliferativ/renoprotektiv }\end{array}$ & $\begin{array}{l}\text { AlPRI-Studie }^{1} \\
\text { REIN-Studie } \\
\text { Bohlen et al. } 1994 \\
\text { Jafar et al. } 2001\end{array}$ \\
\hline $\begin{array}{l}\text { AT-II-Rezeptor- } \\
\text { Antagonisten }\end{array}$ & $\begin{array}{l}\text { stark antiproteinurisch (bis zu } \\
35 \% \text { ) } \\
\text { antiproliferativ/renoprotektiv }\end{array}$ & $\begin{array}{l}\text { RENAAL-Studie } \\
\text { IDNT-Studie }\end{array}$ \\
\hline Calciumantagonisten & $\frac{\text { mittelmäßig bis stark }}{\text { antiproteinurisch (bis zu } 50 \% \text { ) }}$ & $\begin{array}{l}\text { Maki et al. } 1995 \\
\text { Bakris et al. } 1992 \\
\text { Mosconi et al. } 1996 \\
\text { Nosadini et al. } 2002\end{array}$ \\
\hline Betablocker & $\begin{array}{l}\text { schwach antiproteinurisch } \\
\text { (unverändert bis } 10 \% \text { ) }\end{array}$ & $\begin{array}{l}\text { UKPDS-Studie } \\
\text { Apperloo et al. } 1991 \\
\text { Bjorck et al. } 1990\end{array}$ \\
\hline$\alpha_{1}$-Blocker & $\begin{array}{l}\text { schwach antiproteinurisch } \\
\text { (unter } 10 \%)\end{array}$ & Rosenberg et al. 1991 \\
\hline Diuretika & $\begin{array}{l}\text { schwach bis stark } \\
\text { antiproteinurisch } \\
\text { - } \quad \text { Kalium sparende Diuretika } \\
\text { zw. } 20 \text { und } 55 \% \\
\text { - Thiazid-ähnliche Diuretika } \\
\text { bis } 30 \% \\
\text { renoprotektiv }\end{array}$ & $\begin{array}{l}\text { Wolf und Risler, } 2004 \\
\text { Roush et al. } 2014 \\
\text { Saklayen et al. } 2008 \\
\text { Netchessova et al. } \\
2014 \\
\text { Nielsen et al. } 2012\end{array}$ \\
\hline Sympathikolytika & Antiproteinurisch (bis $20 \%$ ) & Krespi P. et al. 1998 \\
\hline
\end{tabular}

(1)Maschio et al. 1996; (2)GISEN Group 1997; (3)Brenner et al. 2001; (4)Lewis et al. 2001; (5) UK Prospective Diabetes Study Group 1998;

Hierbei fand sich eine signifikante mediane Reduktion der Proteinurie um -38,96\% (- 79,1 - 27,4\%; $p=0,007)$, welche in der Subgruppenanalyse vorwiegend die CKDStadien III und IV betraf. Eine vergleichbare Absenkrate beobachtete man im Rahmen 
von Studien zur Wirksamkeit von ACE-Hemmern. Interessanterweise zeigte sich in Analogie zu unseren Daten ein verstärkter Abfall der Proteinurie unter ACE-Hemmern, bei initial erhöhter Sympathikusaktivität in fortgeschrittenen CKD-Stadien (Hou et al. 2006; Rosenkranz 2004). Dieses legt den Schluss nahe, dass die BAT neben einer Sympathikoinhibition antiproteinurisch wirksam sein könnte. Bislang unklar bleibt, ob dies über blutdruckabhängige und/oder auch -unabhängige Mechanismen vermittelt wird. Eine Untersuchung der Proteinurie im Rahmen anderer BAT-Studien erfolgte bisher nur im randomisiert-kontrollierten Rheos Pivotal Trial, deren Albuminverlauf im Urin unverändert blieb (Alnima et al. 2013). Diese Studie unterschied sich von unserer Untersuchung dahingehend, dass die renalen Funktionsparameter zur Baseline deutlich besser waren und ein geringeres kardiovaskuläres Risikoprofil im Patientenkollektiv bestand (eGFR $92 \pm 20 \mathrm{ml} / \mathrm{min}$ für BAT-Aktivierung nach einem Monat und $91 \pm 22 \mathrm{ml} / \mathrm{min}$ für BAT-Aktivierung nach sechs Monaten vs. $61,7 \pm 31 \mathrm{ml} / \mathrm{min}$ und 61,6 $\pm 31,5 \mathrm{ml} / \mathrm{min}$; Albumin-Kreatinin-Ratio (ACR) 1,8 mg/mmol für BAT-Aktivierung nach einem Monat und 3,2 $\mathrm{mg} / \mathrm{mmol}$ für BAT-Aktivierung nach sechs Monaten vs. $6,37 \mathrm{mg} / \mathrm{mmol}$ und $5,28 \mathrm{mg} / \mathrm{mmol}$ ). Im Vergleich zu unseren Daten, zeigten RD-Studien bei CKD-Patienten mit TrHTN widersprüchliche Daten mit einem signifikanten Abfall in einer, jedoch unveränderten, renalen Eiweißausscheidung in der anderen Studie (Hering et al. 2012; Kiuchi et al. 2013) (siehe Tabelle 4.2). Ein Nachteil dieser Studien ist deren kleine Fallzahl und das Fehlen einer randomisierten Kontrollgruppe. Ausnahme ist die Symplicitcy HTN-2 Studie zur Wirksamkeit der RD, die gleichzeitig renale Parameter erfasste. Im Vergleich zur Kontrollgruppe zeigte sich hier ein nicht signifikanter Abfall der ACR im Urin, wobei die Patienten zu Studienbeginn eine mittlere ACR von $128 \pm 363 \mathrm{mg} / \mathrm{g}$, eine eGFR von $77 \pm 19 \mathrm{ml} / \mathrm{min}$ und Cystatin C-Werte von 0,9 \pm 0,2 mg/l hatten (Symplicity HTN-2 Investigators 2010). Eine head-to-head Studie mit einem Vergleich von BAT und RD liegt bis dato nicht vor. Solange bleibt es schwierig, Schlussfolgerungen hinsichtlich möglicher Unterschiede bzw. Parallelen bei der renalen Wirkung beider Verfahren zu ziehen.

\subsubsection{Renale Funktionsparameter}

In bereits publizierten Daten zur renalen Funktion unter BAT konnten wir anhand einer Kontrollgruppe von 21 rein medikamentös behandelten Patienten mit TrHTN gegenüber 23 BAT-Patienten eine jährliche GFR-Reduktion von 2,95 ml/min und einer 
ESRD-Rate von 1,1\% mit Hilfe der AASK-Studie schätzen (Lea et al 2005). In Abhängigkeit von der GFR-Berechnung zeigte sich bei Anwendung der MDRD-Formel ein signifikanter Abfall der GFR von - 8,3 ml/min $(p<0,01)$ in einer konservativ behandelten Kontrollgruppe. Dahingegen blieb in der BAT-Gruppe die GFR mit - 0,05 $\mathrm{ml} / \mathrm{min}(\mathrm{p}=0,82)$ annähernd unverändert. Bei Anwendung der CKD-EPICystatin C-Formel lag sogar eine signifikante Verbesserung der GFR um + 6,8 ml/min ( $p=0,02)$ vor (Wallbach et al. 2014).

Unabhängig von der angewandten GFR-Formel, blieb die exkretorische Nierenfunktion bei der hier untersuchten Kohorte von 31 Patienten unverändert, indes eine nicht signifikante Verbesserung bei Anwendung der CKD-EPI-Cystatin C-Formel von $54,2 \pm 27,6 \mathrm{ml} / \mathrm{min}$ auf $58,4 \pm 28,8 \mathrm{ml} / \mathrm{min}(p=0,09) \mathrm{zu}$ sehen ist. Dabei scheint die Nierenfunktion durch die CKD-EPI-Cystatin C-Formel mit höherer Präzision beschrieben zu sein (Inker et al.2012).

Wir konnten feststellen, dass die ermittelte Zunahme der eGFR, unter Annahme der CKD-EPI-Cystatin C-Gleichung, invers zur systolischen Blutdrucksenkung signifikant korreliert $(r=-0,37, p=0,048)$. Dieser Sachverhalt steht im Widerspruch zu den Daten des Rheos Pivotal Trial, welcher nach sechs und elf Monaten eine Absenkung der GFR von - 5 bzw. - $11 \mathrm{ml} / \mathrm{min}$ zeigte. Interessanterweise beschränkte sich dieser Filtrationsverlust lediglich auf Patienten mit einer anfänglichen GFR von $>60 \mathrm{ml} / \mathrm{min}$, wohingegen die GFR bei Patienten mit einer anfänglichen GFR $<60 \mathrm{ml} / \mathrm{min}$ im Therapieverlauf stabil blieb (Bisognano et al. 2011b). Die eGFR in unserer Studie lag zu Beginn bei 61,7 \pm 30,5 ml/min (MDRD-Formel), wobei 54,5\% ein CKD-Stadium $\geq 3$ hatten. Ähnlich stellt sich ein unveränderter Verlauf bei Patienten mit einer GFR $<60 \mathrm{ml} / \mathrm{min}$ und CKD bei einer TrHTN nach RD dar. Auch hier blieb die GFR im Therapieverlauf bei CKD-Studien mit RD konstant (Hering et al. 2012; Kiuchi et al. 2013). In randomisierten RD-Studien zeigte sich bei der GFR kein signifikanter Unterschied gegenüber der Kontrollgruppe (Symplicity HTN-2 Investigators 2010; Bhatt et al. 2014). Da eine genauere Unterteilung der Verläufe nach CKD-Subgruppen in diesen Studien überwiegend fehlt, sind genaue Schlussfolgerungen gegenwärtig schwer möglich.

Bei der Anwendung der BAT im Rahmen der Herzinsuffizienz zeigten aktuell Gronda et al. 2014 eine Zunahme der eGFR nach drei und sechs Monaten um 2,1 ml/min bzw. $5,7 \mathrm{ml} / \mathrm{min}$. Die eGFR der Patienten dieser Studie lag zu Beginn bei $65,1 \pm 27,7 \mathrm{ml} / \mathrm{min}$. 
Tab.4.2: Übersicht renaler Funktionsparameter unter BAT versus RD in verschiedenen Studien

\begin{tabular}{|c|c|c|c|c|c|c|}
\hline BAT-Studien & Studientyp & +/-randomisiert & GFR & $\begin{array}{c}\text { Renaler } \\
\text { Eiweißverlust }\end{array}$ & $\mathbf{n}$ & Ergebnisse \\
\hline $\begin{array}{l}\text { Alnima et al. } \\
2013\end{array}$ & $\begin{array}{l}\text { Rheos®Pivotal } \\
\text { Trial, kontrolliert, } \\
\text { doppelblind }\end{array}$ & randomisiert, & $\downarrow / \rightarrow$ & $\longrightarrow$ & 236 & $\begin{array}{l}\text { Die Proteinurie blieb unverändert. Die eGFR } \\
\text { sank von } 92 \pm 20 \text { auf } 87 \pm 22 \mathrm{ml} / \mathrm{min} \text { signifikant } \\
(p=0,004) \text {, wobei bei Patienten mit einer } \\
\text { eGFR }<60 \mathrm{ml} / \mathrm{min} \text {, diese über zwölf Mo. } \\
\text { konstant blieb }(p=>0,05) .\end{array}$ \\
\hline $\begin{array}{l}\text { Wallbach et al. } \\
2014\end{array}$ & $\begin{array}{l}\text { Pilotstudie, } \\
\text { kontrolliert, } \\
\text { prospektiv über } \\
6 \text { Monate, } \\
\text { CKD II-V }\end{array}$ & $\begin{array}{l}\text { nicht } \\
\text { randomisiert }\end{array}$ & $\rightarrow$ & $\downarrow$ & 23 & $\begin{array}{l}\text { Die Proteinurie und Albuminurie sanken } \\
\text { signifikant }(-29 \% \text { bzw. }-21 \%) \text {, wobei sich ein } \\
\text { stärkerer Abfall in den CKD-Stadien III/IV }>\text { I/II } \\
\text { abzeichnete. Die eGFR }(64 \pm 28 \mathrm{ml} / \mathrm{min}) \text { blieb } \\
\text { in der BAT-Gruppe konstant }(\mathrm{p}=0,82) \text {, in der } \\
\text { Kontrollgruppe fiel diese signifikant ab } \\
(p<0,01) \text {. }\end{array}$ \\
\hline \multicolumn{7}{|l|}{ RD-Studien } \\
\hline \multirow{2}{*}{$\begin{array}{l}\text { Krum et al. } \\
2009 \\
\text { Krum et al. } \\
2014\end{array}$} & \multirow[t]{2}{*}{$\begin{array}{l}\text { Symplicity } \\
\text { HTN-1, } \\
\text { prostpektiv }\end{array}$} & \multirow[t]{2}{*}{$\begin{array}{l}\text { nicht } \\
\text { randomisiert }\end{array}$} & \multirow[t]{2}{*}{$\uparrow$} & \multirow[t]{2}{*}{-} & \multirow{2}{*}{$\begin{array}{l}25 \\
153\end{array}$} & $\begin{array}{l}\text { Die eGFR stieg von } 79 \pm 21 \text { auf } 83 \pm 25 \mathrm{ml} / \mathrm{min} \\
\text { nach sechs Monaten an ( } 6 \text { Pat. hatten einen } \\
\text { Anstieg um } 20 \%, 1 \text { Pat. einen Abfall um } 20 \%) \text {. }\end{array}$ \\
\hline & & & & & & $\begin{array}{l}\text { Das S-Kreatinin stieg von } 83,8 \pm 20,1 \text { auf } \\
92,0 \pm 32,5 \mu \mathrm{mol} / \mathrm{l}(\mathrm{p}=0,05) \text { an. Die eGFR fiel } \\
\text { von } 83,6 \pm 19,7 \text { auf } 73,3 \pm 28,0 \mathrm{ml} / \mathrm{min} \\
(p=0,05) \text { nach } 36 \text { Monaten ab. }\end{array}$ \\
\hline $\begin{array}{l}\text { Symplicity } \\
\text { HTN-2 } \\
\text { Investigators } \\
2010\end{array}$ & $\begin{array}{l}\text { Symplicity } \\
\text { HTN-2, } \\
\text { kontrolliert, } \\
\text { prospektiv }\end{array}$ & randomisiert & $\rightarrow$ & $(\downarrow)$ & 49 & $\begin{array}{l}\text { Die eGFR, S-Kreatinin und Cystatin C blieben } \\
\text { in Pat. mit RD und Kontrollgruppe nach sechs } \\
\text { Mo. unverändert. Die Änderung der Albumin/ } \\
\text { Kreatinin-Ratio in Patienten mit RD betrug } \\
-3 \mathrm{mg} / \mathrm{g}(-1089-76) \text { und } 1 \mathrm{mg} / \mathrm{g}(-538-227) \text { in } \\
\text { der Kontrollgruppe }(p=0,26) \text {. }\end{array}$ \\
\hline $\begin{array}{l}\text { Mahfoud et al. } \\
2012\end{array}$ & $\begin{array}{l}\text { kontrolliert, } \\
\text { prospektiv, } \\
\text { eGFR } \\
>45 \mathrm{ml} / \mathrm{min}\end{array}$ & $\begin{array}{l}\text { nicht } \\
\text { randomisiert }\end{array}$ & $\longrightarrow$ & $\longrightarrow$ & 88 & $\begin{array}{l}\text { Cystatin C-GFR und Urin-Albumin-Kreatinin- } \\
\text { Ratio blieben in RD- und Kontrollgruppe nach } \\
\text { sechs Mo. unverändert }(p=0,16 \text { und } p=0,47 \\
\text { bzw. } p=0,21 \text { und } p=0,57) \text {. }\end{array}$ \\
\hline $\begin{array}{l}\text { Hering et al. } \\
2012\end{array}$ & $\begin{array}{l}\text { propektiv, } \\
\text { CKD III/IV }\end{array}$ & $\begin{array}{l}\text { nicht } \\
\text { randomisiert, }\end{array}$ & $\rightarrow$ & $\longrightarrow$ & 8 & $\begin{array}{l}\text { Die eGFR änderte sich von } 31,2 \pm 8,9 \text { auf } \\
29,04 \pm 7,3 \mathrm{ml} / \mathrm{min} \text { nach sechs Mo. nicht } \\
\text { signifikant }(\mathrm{p}=0,22) \text {. Ebenso verhielten sich } \\
\text { die UAKR und } 24 \mathrm{~h}-\text { Proteinurie }(592 \pm 955 \mathrm{mg} / \mathrm{g} \\
\text { vs. } 355 \pm 276 \mathrm{mg} / \mathrm{g}, \mathrm{p}=0,21 \mathrm{bzw} .1,41 \pm 0,52 \mathrm{~g} \\
\text { vs. } 0,81 \pm 0,76 \mathrm{~g}, \mathrm{p}=0,24) \text {. Die } 24 \mathrm{~h}-\mathrm{Na}^{+}- \\
\text {Ausscheidung stieg nach drei Mo. von } 169,3 \pm \\
56,7 \mathrm{mmol} \text { auf } 187,3 \pm 59,4 \mathrm{mmol} \text { an und sank } \\
\text { nach sechs Mo. auf } 152,0 \pm 86,9 \mathrm{mmol} \\
(\mathrm{p}=0,77) \text { ab. }\end{array}$ \\
\hline $\begin{array}{l}\text { Kiuchi et al. } \\
2013\end{array}$ & $\begin{array}{l}\text { prospektiv, } \\
\text { CKD II bis IV }\end{array}$ & $\begin{array}{l}\text { nicht } \\
\text { randomisiert }\end{array}$ & $\uparrow / \rightarrow$ & $\downarrow$ & 24 & $\begin{array}{l}\text { Es zeigte sich nach sechs Mo. eine signifikante } \\
\text { Reduktion des S-Kreatinins und der UAKR bei } \\
\text { signifikantem Anstieg der eGFR ( } p=0,001) \text {. } \\
\text { Die GFR blieb bei Pat. mit einer eGFR }<45 \\
\text { ml/min unverändert. Eine Reduktion der UAKR } \\
\text { zeichnete sich vorwiegend bei Pat. mit einer } \\
\text { eGFR }>45 \mathrm{ml} / \mathrm{min} \text { ab. }\end{array}$ \\
\hline $\begin{array}{l}\text { Zhang et al. } \\
2014\end{array}$ & $\begin{array}{l}\text { kontrolliert, } \\
\text { propektiv, eGFR } \\
>45 \mathrm{ml} / \mathrm{min}\end{array}$ & $\begin{array}{l}\text { nicht } \\
\text { randomisiert }\end{array}$ & . & $\downarrow$ & 39 & $\begin{array}{l}\text { Cystatin C-GFR und S-Kreatinin veränderten } \\
\text { sich über zwölf Mo. nicht signifikant. Die Pro- } \\
\text { teinurie sank signifikant nach sechs und zwölf } \\
\text { Mo. um }-14,9 \pm 6,4 \text { bzw. }-16,9 \pm 5,8 \mathrm{mg} / \mathrm{dl} \text { i. V. } \\
\text { zur Baseline und Kontrollgruppe }(p<0,01) \text {. }\end{array}$ \\
\hline $\begin{array}{l}\text { Bhatt et al. } \\
2014\end{array}$ & $\begin{array}{l}\text { Symplicity } \\
\text { HTN- } 3 \\
\text { kontolliert, } \\
\text { prospektiv, } \\
\text { Scheinprozedur }\end{array}$ & randomisiert & $\rightarrow$ & - & 535 & $\begin{array}{l}\text { Es zeigte sich kein signifikanter Unterschied } \\
\text { zw. RD, Kontrollgruppe sowie der Subgruppe } \\
\text { mit einer GFR }<60 \mathrm{ml} / \mathrm{min} \text { hinsichtlich der } \\
\text { Parameter eGFR, Cystatin C und S-Kreatinin. }\end{array}$ \\
\hline
\end{tabular}

GFR = glomeruläre Filtrationsrate, $\mathrm{u} .=$ und, BAT = Barorezeptorstimulationstherapie, CKD = chronic kidney disease, $\mathrm{S}=$ Serum, $\mathrm{RD}$ = renale Denervierung, Mo. = Monat, UAKR = Urin-Albumin-Kreatinin-Ratio, HTN = Hypertonie, Pat. = Patient, i. V. = im Vergleich 
Neben einer verbesserten Ejektionsfraktion sollte ebenso eine effektive Sympathikusinhibition als Ursache der GFR-Zunahme durch die BAT diskutiert werden. Die Betrachtung kardialer und renaler Verlaufsparameter könnte im Fall der randomisierten BAT-Herzinsuffizienzstudie Barostim HOPE4HF-Studie womöglich weitere Anhalte über die Wirkung der BAT auf die Nierenfunktion geben, deren Endergebnisse bei Fertigstellung der Dissertation noch nicht vollständig vorlagen (Abraham et al. 2015). Die Auswirkungen einer interventionellen Sympathikoinhibition durch die BAT oder RD sind in Tabelle 4.2 zusammengefasst.

\subsection{3 $\mathrm{Na}^{+}$-Ausscheidung}

Unabhängig von der antihypertensiven Medikation (Mineralokortikoide oder Diuretika) veränderte sich die $\mathrm{Na}^{+}$-Ausscheidung signifikant (24h-Na+-Exkretion, $\mathrm{p}=0,049$; fraktionierte $\mathrm{Na}^{+}$-Exkretion, $\mathrm{p}=0$,029). Dieser Trend wurde im Rahmen einer weitergehenden Analyse nach Amendment-Antrag bei 42 Patienten bestätigt. Zusätzlich zeigte sich hier eine signifikante Verbesserung der um die $\mathrm{Na}^{+}$-Exkretion adaptierten Cystatin C-Gleichung (Wallbach et al. 2015b). Ähnliche Ergebnisse wurden für die renale Denervierung gefunden. Pöss et al. konnten sowohl einen signifikanten Anstieg der $24 \mathrm{~h}-\mathrm{Na}^{+}$-Exkretion $(\mathrm{p}=0,003)$ als auch der fraktionierten $\mathrm{Na}^{+}$-Ausscheidung $(\mathrm{p}=0,0001)$ finden. Die Steigerung der renalen $\mathrm{Na}^{+}$-Ausscheidung war nach sechs Monaten unabhängig von der antihypertensiven Medikation sowie der Nierenfunktion. Die Parameter der Renin-Aldosteron-Achse blieben hierbei, ähnlich unseren Ergebnissen, zwischen Visit I und Visit II ohne signifikante Veränderung, wobei sich die eGFR leicht verschlechterte $(p=0,062)$ (Pöss et al. 2015). Wir konnten zeigen, dass es hinsichtlich der $\mathrm{Na}^{+}$-Ausscheidung bei Visit I und Visit II keinen signifikanten Unterschied zwischen Patienten mit oder ohne Mineralokortikoidrezeptor-Antagonisten (MCRAs) gibt. Die signifikante Veränderung der $\mathrm{Na}^{+}$-Ausscheidung kann durch die Einnahme von Diuretika und MCRAs nicht erklärt werden, da die Medikation weitestgehend konstant blieb. In experimentellen Studien konnte gezeigt werden, dass die Modulation der Sympathikusaktivität Einfluss auf die $\mathrm{Na}^{+}$-Exkretion nimmt (Di Bona et al. 2005). In der Subgruppenanalyse beschränkt sich die signifikante Absenkung der $\mathrm{Na}^{+}$-Retention ausschließlich auf die Patientengruppe mit einer vorherigen RD. Es kann daher nicht ausgeschlossen werden, dass die signifikante Änderung der $\mathrm{Na}^{+}$-Exkretion durch die RD und nicht 
durch die BAT verursacht sein könnte. Aufgrund erheblicher Unterschiede in der Kohortengröße (Pöss et al. 2015: 137 Patienten vs. zwölf Patienten) bleiben definitive Erkenntnisse abzuwarten. Wichtige Einschränkungen ergeben sich daraus, dass wir weder eine $\mathrm{Na}^{+}$-Bestimmung im 24h-Sammelurin noch eine tägliche Kontrolle der Salzzufuhr durchführten. Das Serumnatrium blieb bei unseren Patienten im Zeitverlauf stabil. Eine Mobilisierung von Narium aus dem dritten Raum muss deshalb diskutiert werden. Grund zu dieser Annhame geben aktuelle MRT-Untersuchungen zur Salzhomöostase, die eine Akkumulation von Natriumionen in sogenannten Gewebespeichern nachweisen konnten. Nach neuesten Erkenntnissen sind diese eng mit einer bestehenden Hypertonie verknüpft (Hofmeister et al. 2015, Linz et al. 2015). Kopp et al. zeigten, dass im Vergleich zu normotensiven Kontrollpersonen eine nicht signifikante Erhöhung von Natriumionen bei weiblichen Patientinnen $(n=10)$ mit einer TrHTN in der Haut bzw. männlichen Patienten $(n=23)$ in der Muskulatur besteht (Kopp et al. 2013). In zukünftigen Studien sollte daher die Untersuchung des Salzhaushaltes auf die renale $\mathrm{Na}^{+}$-Exkretion unter einer BAT mit/ohne RD ergänzt werden, auch wenn die geschätzte $24 \mathrm{~h}-\mathrm{Na}^{+}$-Exkretion anhand eines repräsentativen Patientenkollektivs von Hypertonikern validiert wurde.

\subsection{Vasoprotektion}

\subsubsection{Gefäßsteife und zentrale Hämodynamik}

Die arterielle Gefäßsteife ist ein wichtiger Marker zur Beurteilung des kardiovaskulären Risikos. Sie wird mit einer systolischen Hypertonie assoziiert. Der zentrale Blutdruck ist dabei von den peripheren BuP-Werten unabhängig und zeigt eine nähere Korrelation zu Endorganschäden (Palatini et al. 2011). Darüber hinaus korrelieren zentraler Blut- und Pulsdruck mit dem Ausmaß der arteriellen Atherosklerose, der karotiden Intima-Media-Dicke, der linksventrikulären diastolischen Dysfunktion und linksventrikulären Hypertrophie (Palatini et al. 2011). Für verschiedene Antihypertensivaklassen konnte eine zentrale Blutdruckreduktion im Bereich von neutral bis zu $-20 \mathrm{mmHg}$ gezeigt werden, die u.a. zum differierenden klinischen Outcome unter der jeweiligen Medikation beitragen könnte (Williams et al. 2006). In der vorliegenden Studie sanken unter einer BAT der zentrale systolische, diastolische und mittlere Blutdruck signifikant um - 16,9 $\pm 22,1 \mathrm{mmHg}$; - 8,3 $\pm 16,7 \mathrm{mmHg}$ bzw. - 11,7 $\pm 18,4 \mathrm{mmHg}$ und der aortale Pulsdruck um - 8,9 $\pm 13,7 \mathrm{mmHg}$. 
Bei der Erhebung hämodynamischer Parameter wurde von der Durchführung einer direkten Messung abgesehen, da aktuelle Erkenntnisse eine Übereinstimmung zwischen errechneten und direkt erfassten Werten des zentral-aortalen systolischen Blutdrucks und Pulsdrucks mit Schwankungen von $<1 \mathrm{mmHg}$ zeigen (Pauca et al. 2001).

Die PWV gilt bei der Messung der arteriellen Gefäßsteife als der Goldstandard. So ist bei einem 60-jährigen Mann ein Anstieg der PWV um $1 \mathrm{~m} / \mathrm{s}$ mit einer Erhöhung des Risikos für kardiovaskuläre Ereignisse um 7\% assoziiert (Ben-Shlomo et al. 2014). Der Alx spiegelt eine komplexe Messung der Wellenreflektion wider und ist Ausdruck der arteriellen Gefäßsteife. Hinsichtlich der Angaben des Grenzwertes der PWV von 9,6 m/s, basierend auf der ESC/ESH-Leitlinie, zeigen die Patienten unserer Studie bei der Visit I eine deutliche Erhöhung der Ausgangswerte von 10,5 2,9 m/s. Unter der BAT erfolgte dabei ein signifikanter Abfall des Ausgangswertes auf $9,0 \pm 2,4$ $(p=0,00013)$. Die PWV ist eine Variable, die zum einem vom Blutdruck zum anderem von der arteriellen Gefäßelastizität beeinflusst wird. Letztere ist abhängig von den strukturellen Eigenschaften der arteriellen Gefäßwand und dem vaskulären Gefäßwandmuskeltonus (Quinn et al. 2012). Der Aktivität des Sympathikus kommt dabei eine unabhängige Einflussgröße auf die PWV zu (Palatini et al. 2011). Hinsichtlich der Abhängigkeit der PWV vom Blutdruck präsentierte sich eine Reduktion der PWV um -1,5 \pm 1,6 m/s parallel zu einer Blutdruck- und AIX@75-senkung in der untersuchten Kohorte. Bei der Betrachtung der voraussichtlichen PWV $\mathrm{Cf}_{\text {cfedicted }}$, welche um den MBP und das Alter korrigiert wird, zeigte sich bei der Visit I gegenüber der ermittelten PWV kein Unterschied, wohingegen in den Messungen zur Visit II die ermittelte PWV deutlich unter der PWV dass innerhalb der sechs Monate BAT vaskuläre Umbauprozesse stattgefunden haben könnten. Daher wurden im Rahmen der Studie funktionelle und strukturelle Faktoren hinsichtlich eines vaskulären Remodelings untersucht (siehe Kapitel 4.5.2). Ungeachtet der zahlreichen Antihypertensiva und deren Wirkung scheint bei Betrachtung von aortalem Blutdruck, Pulsdruck, Augmentationsdruck und Alx@75 die BAT einen Zusatznutzen auf die zentrale Hämodynamik zu haben. Diese Schlussfolgerung trifft auch auf die Patienten zu, die sich im Vorfeld der BAT einer RD unterzogen. Auch diese zeigten einen Abfall des zentralen systolischen Blutdrucks, der sich bisher noch nicht signifikant darstellte $(p=0,06)$. Verlaufsdaten nach zwölf Monaten und eine Fallzahlerhöhung werden zeigen, ob sich dieser Trend bestätigt. 
Dessen ungeachtet legen die bisherigen Daten nahe, dass die BAT vasoprotektive Effekte durch eine Verbesserung der zentralen Hämodynamik vermittelt. Deren Prüfung und prognostischer Nutzen in Bezug auf eine kardiovaskuläre Risikoreduktion steht im Langzeitverlauf jedoch noch aus.

\subsubsection{Gefäßhomöostase}

Studien zum Verhalten von zirkulierenden EPCs wiesen nach, dass - neben anderen chronischen Stressoren - die aHTN zu deren Abnahme führt, weshalb wir keine quantitative Bestimmung CD133/Flk-1 doppelpositiver EPCs durchführten (De Groot et al. 2004; Huang et al. 2010; Vasa et al. 2001). Daher können bezüglich des Migrationsverhaltens der zirkulierenden EPCs in unserer Studie keine Rückschlüsse gezogen werden. Vielmehr wurden wichtige Marker betreffs ihrer Proliferationsfähigkeit, Zellaktivität und Seneszenz untersucht. Der Apoptosemarker Caspase-3 und Aktivitätsmarker eNOS sowie das Proliferationspotential blieben hierbei in unserer Kohorte jedoch unverändert. Interessanterweise zeigte sich bei vaskulären Traumata - bedingt durch Verbrennungen, kardialen Ischämien oder akuten Nierenversagen - ein akuter signifikanter Anstieg zirkulierender EPCs (Gill et al. 2001; Patschan et al. 2011; Takahashi et al. 1999).

Im Vergleich zu akuten Gefäßtraumata, liegen vaskulären Umbauprozessen langfristige Veränderungen zu Grunde, die sich über viele Jahre erstrecken können. Auch wenn eine Blutdruck- und Sympathikus-senkende Wirkung der BAT nach dessen Aktivierung sehr plötzlich auftritt, scheint sie dennoch keinen prompten Einfluss auf das EPC-System zu nehmen. Trotz einer signifikanten Reduktion des Blutdrucks besteht daher Grund zur Annahme, dass fortbestehende Risikofaktoren einen anhaltend inhibierenden Einfluss auf die EPC-Zellen genommen haben könnten. So sind neben Diabetes mellitus, Hypertriglyzerämie und Atherosklerose die CKD und der Einfluss des fortgesetzten Nikotinkonsums bei der untersuchten Kohorte hervorzuheben. Diese Risikovariablen zeichnen sich durch erhöhte Stressfaktoren wie ADMA, oxidiertes LDL und Urämietoxine aus (Cooke 2005; Sobczak et al. 2009; Vallance et al. 1992, Ito et al. 1999, De Groot et al. 2004). Diese werden als Ursache in Bezug auf die Senkung des endothelialen Proliferationspotential und Hemmung der eNOS diskutiert (Patschan et al. 2009; Palade et al. 2003, Böger et al. 2005; Stuhlinger et al. 2003). 
In der vorliegenden Studie wurde unter anderem der Biomarker ADMA gemessen. Dieser spielt eine bedeutende Rolle im Outcome, unter Intensivtherapie und kardiovaskulärer Endpunkte (Nijveldt et al. 2003; Schnabel et al. 2005). Im Hinblick auf die aHTN zeigt sich ein graduierter Anstieg des ADMA-Spiegels mit positiver Korrelation zu systolischen Blutdruckwerten. Die Einleitung einer anti-hypertensiven oder anti-diabetischen Therapie zeigte in Studien einen signifikanten ADMA-Abfall (Asagami et al 2002; Delles et al. 2002; Ito et al. 2001). Die ADMA-Spiegel unserer Kohorte blieben im Vergleich dazu während des gesamten Beobachtungszeitraums unter einer BAT gleichbleibend ( $p=0,93)$ über dem Normbereich erhöht, wohingegen Grassi et al. bei renal denervierten CKD-Patienten $(n=14)$ eine signifikante Senkung nachwies (Grassi et al. 2015). In Anbetracht dessen könnte der unverändert hohe ADMA-Spiegel in unserer Studie u.a. ein Ausdruck fortbestehender Risikofaktoren sein oder ein signifikanter Unterschied ist aufgrund des kurzen Untersuchungszeitraumes nicht fassbar.

Andere vaskuläre Biomarker, wie VEGF, Ang-1, TGF- $\beta_{1}$, MMP-9, IL-6, CRP, sVCAM und sICAM, zeigen bei hypertonen Patienten ebenfalls eine erhebliche Erhöhung ihrer Blutspiegel (Su et al. 2012; Dhingra et al. 2009; Mahmud und Feely 2005; Tadzic et al. 2013; Derhaschnig et al. 2002; Nadar et al. 2004; Madej et al.2005). In den meisten Studien wurde auch hier ein signifikanter Abfall, nach Einleitung einer medikamentösen antihypertensiven Therapie, beobachtet. Im Falle von proangiogener Faktoren, wie VEGF, Ang-1, TGF- $\beta_{1}$, wird auf vaskuläre und hämodynamische Veränderungen geschlossen, bei MMP-9 auf ein kardiovaskuläres Remodeling und sVCAM sowie sICAM einer Deaktivierung des Endothels, (Nadar et al 2004; Esmatjes et al. 2001; Miyazaki und Takai, 2002; Kostov et al. 2014; Tadzic et al. 2013). So werden sVCAM, IL-6 und CRP als unabhängige Prädiktoren kardiovaskulärer Morbidität und Mortalität erachtet (Harris et al. 1999; Cottone et al. 2007). Darüber hinaus wird der Fibrogenese- und Wachstumsfaktor TGF- $\beta_{1}$ als Progressparameter einer bestehenden hypertensiven Nephropathie betrachtet (Abbate et al. 2002; Scaglione et al. 2002). Die medikamentöse Gabe von Aliskiren zeigte im Mausmodell

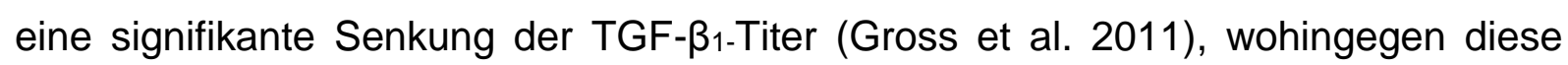
während der BAT lediglich von 37538,1 $\pm 18808,7 \mathrm{pg} / \mathrm{ml}$ auf 30490,5 $\pm 9340,1 \mathrm{pg} / \mathrm{ml}$ $(p=0,10)$ sanken. 
Was die Vasoprotektion angeht, spielen die Biomarker VEGF und Ang-1 eine besondere Rolle. Als Survival- Faktoren bewirken erhöhte Serum-Titer eine Inhibition der Endothelzellapoptose und deuten indirekt auf die Anwesenheit vaskulärer Stressoren hin (Gerber et al. 1998; Kwak et al. 1999).

Die in unserer Studie untersuchten pro- und anti-angiogenen Biomarker blieben im Verlauf der Therapie unverändert. Gleichzeitig ließen die Veränderungen der Faktoren VEGF $(p=0,14), \quad$ TGF- $\beta_{1} \quad(p=0,10) \quad$ und MMP-9 $\quad(p=0,06)$ nicht-signifikante Tendenzen erkennen. Womöglich waren aufgrund der geringen Fallzahl $(n=20)$ die Ergebnisse unterpowert, sodass diese Untersuchung mit Hilfe eines größeren Patientenkollektivs ausgeweitet werden sollte. Eine weitere Einschränkung könnte sich aus dem kurzen Untersuchungszeitraum von sechs Monaten ergeben. Für vaskuläre Umbauprozesse sind längere Zeitabstände anzunehmen. Auch ein durch die Methode relativ hoher, Inter-Assay-Variationskoeffizient von bis zu > $9 \%$, kann besonders an der Grenze zur statistischen Signifikanz einen erheblichen Schwankungsbereich darstellen. Dieser beeinflusst möglicherweise die Ergebnisse. Um das Verhalten der Biomarker zu erfassen, sind bereits eine Fallzahlerhöhung sowie eine Verlängerung der Beobachtungsdauer geplant.

\subsection{Identifizierung prognostischer Marker}

Die Mikroalbuminurie als früher Marker einer renalen Schädigung ist etablierter Bestandteil der klinischen Diagnostik, hat jedoch eine nur geringe Spezifität. Durch den Einsatz von RAAS-Blockern verlaufen bis zu $20 \%$ der diabetischen Nephropathien ohne die Entwicklung einer Mikroalbuminurie ab (Heart Outcomes Prevention Evaluation (HOPE) Study Investigators 2000; Ravid et al. 1998; Gross et al. 2005). Somit ist auch die Sensitivität eingeschränkt. Über die Bestimmung der Mikroalbuminurie hinaus, ermöglicht die Proteomanalyse die Suche nach neuen Biomarkern bzw. Mustern von Biomarkern. Wegen eines Anteils von über $30 \%$ nicht renaler Proteine am Urinproteom, erlaubt die Urin-proteomische Untersuchung teilweise Rückschlüsse auf Biomarker des systemischen Kreislaufes. Durch die Identifizierung von Surrogatparametern ergeben sich aufgrund dieser Analyse Hinweise auf die Senkung des kardiovaskulären Profils sowie einer möglichen Nephroprotektion. 


\subsubsection{Limitierung}

Bei der Detektion von Markerproteinen handelt es sich ausschließlich um Surrogatparameter, die, für sich allein betrachtet, lediglich unsichere Rückschlüsse über eine mögliche Nephroprotektion zulassen. Daher sind Aussagen über die Wirksamkeit der BAT auf Grundlage des Proteoms limitiert. Im Gegensatz dazu ist die Erfassung harter Endpunkte (terminales Nierenversagen, Tod oder NTX) stets zu präferieren, welche jedoch im Hinblick auf unser gewähltes Studiendesign nicht möglich gewesen ist. Im Rahmen dieser Studie ist infolgedessen die Wertung detektierter Biomarker am ehesten im Kontext weiterer wissenschaftlicher Erkenntnisse vorzunehmen. Das Auffinden bereits bekannter Markerproteine und die Betrachtung ihrer Dynamik lassen jedoch erste Schlussfolgerungen bzgl. protektiver Tendenzen zu. Wegen fehlender Validierunguntersuchungen (Bestätigungsmethoden: Western-Blot; Dot-Blot) ist deren Bewertung bis jetzt allerdings nur eingeschränkt möglich. Weitergehende in-vitro und in-vivo Bestätigungstests müssen zeigen, ob den detektierten Markerproteinen eine Relevanz in der organoprotektiven Wirkung unter einer BAT zukommt. Des Weiteren ist die Proteomanalyse durch eine begrenzte Reproduzierbarkeit, der Unvollständigkeit des analysierten Proteoms und der fehlenden Möglichkeit, Proteine absolut zu quantifizieren, charakterisiert (Blüggel 2002). Daher setzten wir die Proteomanalyse als Discovery-Methode ein. Diese Anwendung ist ein bewährtes Verfahren, welches ohne zwingenden Validierungsschritt am Anfang einer gezielten Stufenanalytik steht (Aksu 2003). Mit dem Wissen der o.g. Einschränkungen sichert die für unsere Fragestellung angewandte Methode ein effizientes und verhältnismäßig kostensparendes Vorgehen, um ein Spektrum von bis zu 10.000 Proteinen hinsichtlich dem Verhalten renaler sowie systemischer Parameter zu untersuchen.

\subsubsection{Ausblick auf eine potentielle Nephroprotektion}

In unseren Analysen konnten wir diverse Stressproteine isolieren, deren Dynamik sich unter einer BAT in ähnlicher Weise wie in Studien zur medikamentösen Wirkung von Antihypertensiva hinsichtlich einer möglichen Nephroprotektion verhielt. Trotz ihres überwiegenden Bestandteils in der Vormedikation deutet die BAT daher auf eine zusätzliche nephroprotektive Wirkung hin. 
Zu den pathogenetisch relevanten, identifizierten Biomarkern, die sich in ihrer Menge zu verringern scheinen, zählen die Stressproteine des endoplasmatischen Retikulums (ER) $78 \mathrm{kDa}$ glucose-regulated protein (GRP78), protein disulfide-isomerase A3 (ERP57) und ubiquitin-60S ribosomal protein L40 (UbA-52) sowie das intrazelluläre Transportprotein liver-type fatty acid-binding protein (L-FABP).

GRP78 gehört zur Gruppe der Hitzeschockproteine des ER, das als Chaperon die Faltung neu synthetisierter Proteine schützt und deren transzellulären Transport vermittelt. Im Fall einer Akkumulation ungefalteter ER-Polypeptide wird dessen eigene Synthese reaktiv gesteigert. Als wichtigster Induktor gilt Angiotensin II, welcher sowohl mit einer aHTN als auch und mit einer pathologischen Erhöhung der Symphatikusaktivität assoziiert ist (Hasty et al. 2012). Die Anwendung von ACEHemmern bei an Diabetes mellitus erkrankten Ratten zeigte eine Minderung der tubulären ER-Stress vermittelten Apoptose, bei einer signifikanten Suppression der GRP78 Expression (Sun et al. 2009; Inagi 2011).

Ebenfalls im Verlauf unserer BAT-Studie reduziert stellte sich das intrazelluläre Fettsäure-Transportprotein L-FABP dar. Überwiegend in Hepatozyten und im proximalen Tubulus der Niere vorkommend, zählt dieses als früher Marker der renalen Prognose und des kardiovaskulären Risikos bei Typ II Diabetikern (Araki et al. 2013; Maatman et. al. 1991). Zusammen mit GRP78, ist L-FABP bei einer diabetischen Nephropathie erhöht (Yao 2015, Nielsen et al. 2009). Eine Zunahme des L-FABP im Urin steht im Verdacht, Ausdruck eines gesteigerten Influxes freier Fettsäuren im proximalen Tubulus zu sein, was eine tubulointerstitielle Schädigung induziert bzw. aggraviert. Im Gegensatz dazu bleiben tubulointerstitielle Schäden in L-FABP Knockout-Mäusen unter einer RAAS-Aktivierung nahezu aus (Ichikawa et al. 2014). Sowohl Patienten mit einer diabetischen Nephropathie als auch Hypertoniker mit einer CKD zeigten unter Einnahme von ACE-Hemmern, AT1-Blockern oder Kalziumantagonisten einen signifikanten Abfall erhöhter L-FABP Titer (Kamijo-lkemori et al. 2011, Kamijo-Ikemori et al. 2013; Nakamura et al. 2008; Nakamura et al. 2011). Eine Senkung war mit nephroprotektiven Effekten hinsichtlich einer Minderung der Proteinurie bzw. Albuminurie assoziiert.

Therapie-refraktäre aHTN-Patienten mit einer diabetischen Nephropathie stellten sich nach sechs Monaten BAT in der Proteomanalyse mit einer signifikanten Verminderung von GRP78 und L-FABP dar. Wie dies zu interpretieren ist, kann anhand der 
vorliegenden Untersuchungen nicht sicher beantwortet werden. Weitergehende tierexperimentelle Studien sind hierzu geplant.

Ein weiterer diagnostischer Marker der diabetischen Nephropathie ist das UbiquitinFusionsprotein 52 (UbA-52), welches Bestandteil der 60S-Untereinheit im Ribosom ist und vornehmlich durch oxidativen Stress hochreguliert wird (Brownlee et al. 2001; Dihazi et al. 2007). Im Tiermodell der Forschergruppe Sun et al. stellte sich UbA-52 besonders in renalen Tubuluszellen stark erhöht dar und verhielt sich proportional zum Blutglukosespiegel (Sun et al. 2002). Erstmals konnten wir zeigen, dass UbA-52 unter einer sympathikoinhibierenden BAT bei Patienten mit Therapie-refraktärer Hypertonie und einer diabetischen Nephropathie signifikant absank. Die Annahme, dass eine verminderte UbA-52 Expression eine BAT-vermittelte Sympathikushemmung widerspiegelt oder eine Senkung der oxidativen Stressbelastung mit nephroprotektiver Wirkung auf die Tubuluszellen bewirkt, scheint plausibel, bedarf jedoch des tierexperimentellen Beweises.

Als Ausdruck eines frühen renalen Krankheitsbeginns werden erhöhte Marker der Isomerase ERP57 angesehen. Diese ist an der Bildung von Disulfidbrücken bei der Faltung von Proteinen im ER beteiligt und hat entscheidenden Einfluss an der Akkumulation von zellulärer Matrix und dem Fortschreiten einer Nierenfibrose (Dihazi et al. 2013). Im Mausmodell verhält sich ERP57 mit weiteren ER-Stressproteinen proportional zur renalen Fibroseprogredienz. Ähnlich anderen detektierten Biomarkern, müssen weitere experimentelle BAT-Studien zeigen, ob ein Abfall des Fibrosemarkers ERP57 mit einer Regredienz der renalen Fibrose assoziiert ist. Letztlich kann dieser Aspekt durch die vorliegende Dissertation nicht beantwortet werden. Dazu bedarf es einer Analyse von Nierengewebe und ist somit aus ethischen Gründen nur in einem Tiermodell zu untersuchen. Auf funktioneller Ebene blieb in der Beobachtungszeit die anhand der Literatur zu erwartende Verschlechterung der exkretorischen Nierenfunktion aus. Dies erlaubt jedoch keinen sicheren Rückschluss auf strukturelle Veränderungen der Niere. Bohle et al. zeigten jedoch eine enge Korrelation des Grades der tubulointerstitiellen Fibrose zur exkretorischen Nierenfunktion (Bohle et al. 1987 und 1977).

$\mathrm{Zu}$ weiteren isolierten Biomarkern gehören der Serin-Proteaseinhibitor alpha 1 Antitrypsin, dessen Serumwerte bei Patienten mit einer diabetischen NP erhöht sind (Inoue et al. 1989) sowie das Hämoglobin-bindende Transportprotein Haptoglobin, welches in seiner Eigenschaft als Antioxidans sowohl einen renalen Verlust von 
Eisenionen verhindert als auch nephroprotektiv wirkt (Lim et al. 2000) und dessen Urinkonzentration im Vorfeld einer Makroalbuminurie mit einer Minderung der eGFR korreliert (Bhensdadia et al. 2013). Des Weiteren fanden wir den Lipid mobilisierenden Faktor ZA2G (Rao et al. 2007, Jain et al. 2005), welcher als Co-Faktor von Apolipoprotein A-I für den zellulären Cholesterinabtransport fungiert und bereits bei Kindern als Risikofaktor für ein metabolisches Syndrom bekannt ist (Retnakaran et al. 2006). Ferner das anti-inflammatorische Protein AMBP, dessen nachgewiesene Untergruppe alpha 1-Mikroglobulin im Urin mit einer Dysfunktion der proximalen Tubuli assoziert ist (Rao et al. 2007).

Über die biologische Bedeutung letztgenannter sowie weiterer im Rahmen der BAT analysierter Biomarker kann auf Grundlage vorliegender Ergebnisse noch keine genaue Aussage gemacht werden. Insbesondere das breite Spektrum der analysierten Biomarker gibt einen Ausblick, in welch vielfältiger Weise die BAT Einfluss auf Stoffwechsel, Metabolismus und Pathophysiologie ausüben könnte. Sie wirft damit aber auch viele neue Fragen auf.

\subsection{Studiendesign und -einschränkung}

Die Studie hat einige potentielle Einschränkungen. Da es sich um eine prospektive Beobachtungsstudie handelt, wurden Untersucher und Patienten nicht verblindet. Bei einer Verblindung können Ergebnisse, wie etwa bei der Blutdruck-Messung, signifikant variieren, wie kürzlich bei der Simplicity HTN 3 Studie gezeigt wurde (Bhatt et al. 2014). Ursache hierfür können beispielsweise eine verbesserte Compliance bezüglich der Medikamenteneinnahme oder andere Phänomene, wie eine Regression zur Mitte, sein. Im Fall der Pulswellenanalyse und PWV-Bestimmung, wurde der Effekt des BATSchrittmachers auf die zentrale Hämodynamik durch dessen kurzzeitige Inaktivierung überprüft. Die plötzliche Veränderung hämodynamischer Parameter ließ sich nur durch eine pausierte Barorezeptorstimulation erklären. Studien, die in einem doppelt verblindeten Design genau diese Aspekte untersuchen, könnten diese Fragestellungen klären.

Eine Zwischenauswertung des Patientenkollektivs von 23 Patienten zeigte gegenüber einer Kontrollgruppe nach sechs Monaten BAT bereits einen signifikanten Abfall im BuP und der renalen Eiweißausscheidung (Wallbach et al. 2014). Hinsichtlich der Natriurese war nur eine tendenzielle Zunahme erkennbar, wobei in der vorliegenden 
Kohorte von 31 Patienten die 24h-Natrium-Exkretion signifikant anstieg (Wallbach et al. 2015c). In die Kontrollgruppe wurden Patienten, welche die Einschlusskriterien erfüllten, jedoch eine BAT-Therapie ablehnten, nicht randomisiert und verblindet eingeschlossen. Zusätzlich wirkt die kleine Patientenzahl der Zwischenanalyse einschränkend, da Unterschiede zwischen Patientenkollektiv und Kontrollgruppe nicht signifikant erscheinen können. Eine zusätzliche Anpassung der Kontrollgruppe und deren Vergleich zur vorliegenden Patientenkohorte war jedoch nicht Gegenstand dieser Dissertation. Ein Grund bestand in der Herausforderung, die Kontrollgruppe zu vergrößern, da bei vergleichbaren Patienten mit langjähriger TrHTN ebenfalls eine Indikation zur BAT bestand und ein alleiniges konservatives Therapieregime nicht weiter zu vertreten war. Im Vorfeld der Studiendurchführung entschieden wir uns außerdem, aufgrund eines erheblichen Aufwandes und notwendigen multizentrischen Designs, gegen die Durchführung einer prospektiven, doppel-blinden, randomisierten Interventionsstudie. Ein solches Studiendesign erbrachte bereits im Rheos Pivotal Trial eine signifikante Senkung des systolischen Blutdrucks um $-8 \mathrm{mmHg}$ durch die BAT (Bisognano et al. 2011b), sodass unter Einbeziehung des Kosten-NutzenVerhältnisses das angewandte Studienformat vertretbar scheint. Vor diesem Hintergrund wurde die vorliegende Pilotstudie durchgeführt, obgleich bei fehlender Kontrollgruppe potentielle Störfaktoren verborgen bleiben.

\subsection{Ausblick Forschung}

Ziel weiterführender Forschungen sollte daher die Bestätigung erfasster protektiver BAT-Effekte auf die zentrale Hämodynamik und renale Funktion mittels klinischexperimenteller, randomisiert- kontrollierter Studien sein. Erste Schritte zur Planung eines multizentrischen Studiendesigns wurden bereits unternommen.

Darüber hinaus gilt es, die auf Grundlage von Surrogatparametern formulierten Vermutungen hinsichtlich eines Einflusses der BAT bzgl. vaskulärer und renaler pathogener Prozesse, nachzuweisen. Hierfür sollen Korrelate in zukünftigen tierexperimentellen Projekten mit weiterführenden histologischen sowie molekularen Untersuchungen gesucht werden. Sollte sich in Zukunft eine Protektion gegenüber einem erhöhten Sympathikotonus bestätigen, könnte die BAT neben der Anwendung bei TrHTN eine hilfreiche Therapieoption bei Patienten mit einer CKD und erhöhtem Sympathikotonus trotz kontrolliertem Blutdrucks sein. Hierfür spricht die Bedeutung 
eines erhöhten Sympathikotonus, welcher eigenständig zur Erhöhung des CVRx und zum Fortschreiten renaler Erkrankungen führt 


\section{Zusammenfassung}

Herz-Kreislauferkrankungen sind für $50 \%$ der Todesursachen verantwortlich. Dabei stellt die aHTN den Hauptrisikofaktor für kardiovaskuläre Morbidität und Mortalität dar und zeigt eine Prävalenz von fast 40 \% in der europäischen Bevölkerung. Bei mehr als $50 \%$ der Hypertoniker liegt jedoch eine unkontrollierte aHTN oder sogar eine TrHTN vor.

Die BAT stellt ein neues interventionelles Verfahren zur Behandlung von Patienten mit TrHTN dar. Durch chronische elektrische Stimulation von Barorezeptoren am Karotissinus kommt es bei diesem Therapieverfahren über afferenete Nervenfasern zu einer Modulation des vegetativen Nervensystems. Es resultiert eine Hemmung des sympathischen bei Aktivierung des parasympathsichen Nervensystems.

Die blutdrucksenkenden Effekte der BAT konnten bereits im Vorfeld in einer goßen doppel-blinden Studie (Rheos Pivotal Trial) nachgewiesen werden. Ob sich durch die Inhibition des sympathischen Nervensytems mittels BAT organoprotektive Effekte auf Niere und Gefäße ergeben war bisher nicht bekannt und ist Gegenstand der vorliegenden Doktorarbeit.

Mögliche Nebeneffekte dieser invasiven Therapie wurden ebenfalls bisher nur ungenügend untersucht.

Im Rahmen einer Observationsstudie wurden 31 Patienten vor und 6 Monate nach BAT-Aktivierung untersucht. Während eine signifikante Reduktion des BuP nach 6 Monaten Therapie erreicht werden konnte, zeigte sich bei den 31 Patienten in der ABPM-Messung zwar ein Trend hin zur Reduktion, jedoch wurde zum Zeitpunkt dieser Auswertung keine statistische Signifikanz erreicht. Paralell mit der Blutdruckreduktion konnte eine signifikante Abnahme der Proteinurie und Albuminurie sowie eine Zunahme der Natriurese bei den Patienten mit TrHTN gesehen werden. Darüber hinaus zeigte sich eine signifikante Verbesserung der zentralen Hämodynamik mit Reduktion der zentralen Blutdrücke sowie der Pulswellengeschwindigkeit und des Augmentationsindex. In proteomischen Analysen des Urins mittels 2DGeleketrophorese und Massenspektroskopie zeigte sich eine signifikante Abnahme von ER-Stressproteinen (ERP57; GRP78). Auf die Proliferationsfähigkeit von endothelialen Progenitorzellen sowie pro-angiogenen Markern im Blut hat die BAT im Untersuchungszeitraum dagegen keine Auswirkung. 
Die vorliegende Untersuchung hat potentielle Limitationen, die dazu führen, dass die Ergebnisse zurückhaltend interpretiert werden sollten. Hierbei ist neben der kleinen Fallzahl das offene Studiendesign zu nennen.

Die erhobenen Daten tragen zu einem Konzept bei, bei dem die Hemmung des überaktiven sympathischen Nervensystems bei Patienten mit TrHTN neben blutdrucksenkenden Effekten auch Nephroprotektion und Verbesserung der zentralen Hämodynamik errzielen könnte. Hierduch könnte die BAT zu einer Reduktion von kardiovaskulärem Risiko beitragen. Die vorliegenden Daten könnten Grundlage für weitere große randomisierte, Schein-kontrollierte Studien sein, die die BAT untersuchen und unsere Ergebnisse verifizieren könnten. 


\section{Literaturverzeichnis}

Abbate M, Zoja C, Morigi M, Rottoli D, Angioletti S, Tomasoni S, Zanchi C, Longaretti L, Donadelli R, Remuzzi G (2002): Transforming growth factorbeta1 is up-regulated by podocytes in response to excess intraglomerular passage of proteins: a central pathway in progressive glomerulosclerosis. Am J Pathol $\underline{161}, 2179-2193$

Abraham WT, Zile MR, Weaver FA, Butter C, Ducharme A, Halbach M, Klug D, Lovett EG, Muller-Ehmsen J, Schafer JE et al. (2015): Baroreflex Activation Therapy for the Treatment of Heart Failure With a Reduced Ejection Fraction. JACC Heart Fail $\underline{3}$, 487-496

Acton ST, Wethmar K, Ley K (2002): Automatic tracking of rolling leukocytes in vivo. Microvasc Res $\underline{63}, 139-148$

Aksu S: Identifizierung und Charakterisierung von Brustdrüsengewebeproteinen der Maus und Etablierung einer neuen Kalibrierungsmethode für zweidemensionale Gele. Naturwiss. Diss. Berlin 2003

Alderman MH, Budner N, Cohen H, Lamport B, Ooi WL (1988): Prevalence of drug resistant hypertension. Hypertension 11, II 71-75

Alheid U, Frolich JC, Forstermann U (1987): Endothelium-derived relaxing factor from cultured human endothelial cells inhibits aggregation of human platelets. Thromb Res $\underline{47}, 561-571$

Alnima T, DeLeeuw PW, Tan FES, Kroon AA (2013): Renal responses to long-term carotid baroreflex activation therapy in patients with drug-resistant hypertension. Hypertension $\underline{61}, 1334-1339$

Appel RD, Vargas JR, Palagi PM, Walther D, Hochstrasser DF (1997): Melanie II-a third-generation software package for analysis of two- dimensional electrophoresis images: II. Algorithms. Electrophoresis 18, 2735-2748 
Apperloo AJ, De Zeeuw D, Sluiter HE, De Jong PE (1991): Differential effects of enalapril and atenolol on proteinuria and renal haemodynamics in non-diabetic renal disease. BMJ $\underline{303}, 821-824$

Araki S, Haneda M, Koya D, Sugaya T, Isshiki K, Kume S, Kashiwagi A, Uzu T, Maegawa H (2013): Predictive effects of urinary liver-type fatty acid-binding protein for deteriorating renal function and incidence of cardiovascular disease in type 2 diabetic patients without advanced nephropathy. Diabetes Care $\underline{36}$, $1248-1253$

Asagami T, Abbasi F, Stuelinger M, Lamendola C, McLaughlin T, Cooke JP, Reaven GM, Tsao PS (2002): Metformin treatment lowers asymmetric dimethylarginine concentrations in patients with type 2 diabetes. Metabolism $\underline{51}$, 843-846

Asahara T, Murohara T, Sullivan A, Silver M, van der Zee R, Li T, Witzenbichler B, Schatteman G, Isner JM (1997): Isolation of putative progenitor endothelial cells for angiogenesis. Science $\underline{275}, 964-967$

Asahara T, Takahashi T, Masuda H, Kalka C, Chen D, Iwaguro H, Inai Y, Silver M, Isner JM (1999): VEGF contributes to postnatal neovascularization by mobilizing bone marrow-derived endothelial progenitor cells. EMBO J $\underline{18}$, 39643972

Ashburner M, Ball CA, Blake JA, Botstein D, Butler H, Cherry JM, Davis AP, Dolinski K, Dwight SS, Eppig JT, et al. (2000): Gene ontology: tool for the unification of biology. Nat Genet 25, 25-29

Bailey AS, Jiang S, Afentoulis M, Baumann CI, Schroeder DA, Olson SB, Wong MH, Fleming WH (2004): Transplanted adult hematopoietic stems cells differentiate into functional endothelial cells. Blood 103, 13-19

Bakris GL, Barnhill BW, Sadler R (1992): Treatment of arterial hypertension in diabetic humans: Importance of therapeutic selection. Kidney Int 41, 912-919

Bakris GL, Lindholm LH, Black HR, Krum H, Linas S, Linseman JV, Arterburn S, Sager P, Weber M (2010): Divergent results using clinic and ambulatory blood 
pressures: Report of a darusentan-resistant hypertension trial. Hypertension $\underline{56}$, 824-830

Bakris GL, Nadim MK, Haller H, Lovett EG, Schafer JE, Bisognano JD (2012): Baroreflex activation therapy provides durable benefit in patients with resistant hypertension: Results of long-term follow-up in the Rheos Pivotal Trial. J Am Soc Hypertens $\underline{6}, 152-158$

Bansal N, Tendler BE, White WB, Mansoor GA (2003): Blood pressure control in the hypertension clinic. Am J Hypertens $\underline{16}, 878-880$

Beckett L, Godwin M (2005): The BpTRU automatic blood pressure monitor compared to 24 hour ambulatory blood pressure monitoring in the assessment of blood pressure in patients with hypertension. BMC Cardiovasc Disord $\underline{5}, 18$

Ben-Shlomo Y, Spears M, Boustred C, May M, Anderson SG, Benjamin EJ, Boutouyrie P, Cameron J, Chen C, Cruickshank JK et al. (2014): Aortic pulse wave velocity improves cardiovascular event prediction: An individual participant meta-analysis of prospective observational data from 17,635 subjects. J Am Coll Cardiol $\underline{63}, 636-646$

Bhatt DL, Kandzari DE, O'Neill WW, D'Agostino R, Flack JM, Katzen BT, Leon MB, Liu M, Mauri L, Negoita M et al. (2014): A controlled trial of renal denervation for resistant hypertension. New Engl J Med 370, 1393-1401

Bhensdadia NM, Hunt KJ, Lopes-Virella MF, Michael Tucker J, Mataria MR, Alge JL, Neely BA, Janech MG, Arthur JM (2013): Urine haptoglobin levels predict early renal functional decline in patients with type 2 diabetes. Kidney Int $\underline{83}$, 1136-1143

Bilgutay AM, Lillehei CW (1966): Surgical treatment of hypertension with reference to baropacing. Am J Cardiol 17, 663-667

Bisognano JD, Kaufman CL, Bach DS, Lovett EG, De Leeuw P (2011a): Improved cardiac structure and function with chronic treatment using an implantable device in resistant hypertension: Results from European and United States trials of the Rheos system. J Am Coll Cardiol $\underline{57}$, 1787-1788 
Bisognano JD, Bakris G, Nadim MK, Sanchez L, Kroon AA, Schafer J, de Leeuw PW, Sica DA (2011b): Baroreflex activation therapy lowers blood pressure in patients with resistant hypertension: Results from the double-blind, randomized, placebo-controlled rheos pivotal trial. J Am Coll Cardiol $\underline{58}, 765-773$

Bjorck S, Mulec H, Johnsen SA, Nyberg G, Aurell M (1990): Contrasting effects of enalapril and metoprolol on proteinuria in diabetic nephropathy. BMJ $\underline{300}, 904-$ 907

Blüggel M (2002): Bioinformatik für die Proteomanalyse. BIOspektrum $\underline{8}$, 486-488

Böger RH, Cooke JP, Vallance P (2005): ADMA: An emerging cardiovascular risk factor. Vasc Med 10 Suppl 1, S1-2

Bohle A, Grund KE, Mackensen S, Tolon M (1977): Correlations between renal interstitium and level of serum creatinine. Morphometric investigations of biopsies in perimembranous glomerulonephritis. Virchows Archiv A $\underline{373}, 15-22$

Bohle A, Mackensen-Haen S, Gise H von (1987): Significance of tubulointerstitial changes in the renal cortex for the excretory function and concentration ability of the kidney: a morphometric contribution. Am J Nephrol $\underline{7}, 421-433$

Bohlen L, De Courten M, Weidmann P (1994): Comparative study of the effect of ACE-inhibitors and other antihypertensive agents on proteinuria in diabetic patients. Am J Hypertens $\underline{7}$, 84S-92S

Bonetti PO, Lerman LO, Lerman A (2003): Endothelial dysfunction: a marker of atherosclerotic risk Arteriosclerosis, thrombosis, and vascular biology $\underline{23}$, 168175

Bradford MM (1976): A rapid and sensitive method for the quantitation of microgram quantities of protein utilizing. The principle of protein-dye binding. Anal Biochem 72, 248-254

Brenner BM, Cooper ME, De Zeeuw D, Keane WF, Mitch WE, Parving HH, Remuzzi G, Snapinn SM, Zhang Z, Shahinfar S (2001): Effects of losartan on renal and cardiovascular outcomes in patients with type 2 diabetes and nephropathy. N Engl J Med $\underline{345}, 861-869$ 
Brown DL, Hibbs MS, Kearney M, Loushin C, Isner JM (1995): Identification of 92kD gelatinase in human coronary atherosclerotic lesions. Association of active enzyme synthesis with unstable angina. Circulation $\underline{91}, 2125-2131$

Brownlee M (2001): Biochemistry and molecular cell biology of diabetic complications. Nature $\underline{414}, 813-820$

Buisson AC, Zahm JM, Polette M, Pierrot D, Bellon G, Puchelle E, Birembaut P, Tournier JM (1996): Gelatinase B is involved in the in vitro wound repair of human respiratory epithelium. J Cell Physiol $\underline{166}, 413-426$

Busse R, Luckhoff A, Bassenge E (1987): Endothelium-derived relaxant factor inhibits platelet activation. N-S Arch Pharmacol 336, 566-571

Bussolati B, Dunk C, Grohman M, Kontos CD, Mason J, Ahmed A (2001): Vascular endothelial growth factor receptor-1 modulates vascular endothelial growth factor-mediated angiogenesis via nitric oxide. Am J Pathol $\underline{159}$, 993-1008

Caetano ER, Zatz R, Saldanha LB, Praxedes JN (2001): Hypertensive nephrosclerosis as a relevant cause of chronic renal failure. Hypertension $\underline{38}$, 171-176

Calhoun DA, Jones D, Textor S, Goff DC, Murphy TP, Toto RD, White A, Cushman WC, White W, Sica D et al. (2008): Resistant hypertension: Diagnosis, evaluation, and treatment: A scientific statement from the American Heart Association Professional Education Committee of the Council for High Blood Pressure Research. Circulation 117, e510-26

Carlsten A, Folkow B, Grimby G, Hamberger CA, Thulesius O (1958): Cardiovascular effects of direct stimulation of the carotid sinus nerve in man. Acta Physiol Scand 노, 138-145

Chae CU, Lee RT, Rifai N, Ridker PM (2001): Blood pressure and inflammation in apparently healthy men. Hypertension $\underline{38}$, 399-403

Chesterton LJ, Sigrist MK, Bennett T, Taal MW, Mclntyre CW (2005): Reduced baroreflex sensitivity is associated with increased vascular calcification and arterial stiffness. Nephrol Dial Transplant 20, 1140-1147 
Collins R, MacMahon S (1994): Blood pressure, antihypertensive drug treatment and the risks of stroke and of coronary heart disease. Brit Med Bull $\underline{50}, 272-298$

Collins R, Peto R, MacMahon S, Hebert P, Fiebach NH, Eberlein KA, Godwin J, Qizilbash N, Taylor JO, Hennekens CH (1990): Blood pressure, stroke, and coronary heart disease. Part 2, Short-term reductions in blood pressure: overview of randomised drug trials in their epidemiological context. Lancet $\underline{335}$, 827-838

Cooke JP (2005): ADMA: its role in vascular disease. Vasc Med 10 Suppl 1, S11-17

Cottone S, Mulè G, Nardi E, Vadalà A, Lorito MC, Guarneri M, Arsena R, Palermo A, Cerasola G (2007): C-reactive protein and intercellular adhesion molecule1 are stronger predictors of oxidant stress than blood pressure in established hypertension. J Hypertens $\underline{25}, 423-428$

Cravedi P, Ruggenenti P, Remuzzi G (2012): Proteinuria should be used as a surrogate in CKD. Nat Rev Nephrol $\underline{8}, 301-306$

Cushman WC, Ford CE, Cutler JA, Margolis KL, Davis BR, Grimm RH, Black HR, Hamilton BP, Holland J, Nwachuku C, et al. (2002): Success and predictors of blood pressure control in diverse North American settings: The antihypertensive and lipid-lowering treatment to prevent heart attack trial (ALLHAT). J Clin Hypertens $\underline{4}$, 393-404

De Beus, Bots ML, van Zuilen AD, Wetzels JFM, Blankestijn PJ (2015): Prevalence of Apparent Therapy-Resistant Hypertension and Its Effect on Outcome in Patients With Chronic Kidney Disease. Hypertension 66, 998-1005

De Groot K, Bahlmann FH, Sowa J, Koenig J, Menne J, Haller H, Fliser D (2004): Uremia causes endothelial progenitor cell deficiency. Kidney Int $\underline{66}, 641-646$

De Leeuw PW, Bisognano JD, Bach DS, Lovett EG (2008): Device-Based Reduction in Blood Pressure is Associated with Increased Diameter of the Left Ventricular Outflow Tract: Results from European and United States Trials of the Rheos(R) Hypertension System. Abstract 4426 unter http://circ.ahajournals.org/content/118/Suppl 18/S 887.3 [Zugriff Juli 2016] Circulation $\underline{118}$, S887 
Delles C, Schneider MP, John S, Gekle M, Schmieder RE (2002): Angiotensin converting enzyme inhibition and angiotensin II AT1-receptor blockade reduce the levels of asymmetrical $N(G), N(G)$-dimethylarginine in human essential hypertension. Am J Hypertens $\underline{15}$, 590-593

Derhaschnig U, Shehata M, Herkner H, Bur A, Woisetschlager C, Laggner AN, Hirschl MM (2002): Increased levels of transforming growth factor-beta1 in essential hypertension. Am J Hypertens $\underline{15}$, 207-211

Deutsche Gesellschaft für Kardiologie-Herz- und Kreislaufforschung e.V, Deutsche Hochdruckliga e.V. DHL, Deutsche Gesellschaft für Hypertonie und Prävention: ESC Pocket Guidelines, Leitlinien für das Management der arteriellen Hypertonie. Börm Bruckmeier Verlag, Grünwald 2013

Dhingra R, Pencina MJ, Schrader P, Wang TJ, Levy D, Pencina K, Siwik DA, Colucci WS, Benjamin EJ, Vasan RS (2009): Relations of matrix remodeling biomarkers to blood pressure progression and incidence of hypertension in the community. Circulation $\underline{119}, 1101-1107$

Di Bona GF (2005): Physiology in perspective: The Wisdom of the Body. Neural control of the kidney. Am J Physiol. 289, R633-641

Di Bona GF (2013): Sympathetic nervous system and hypertension. Hypertension $\underline{61}$, $556-560$

Dihazi H, Asif AR, Agarwal NK, Doncheva Y, Müller GA (2005): Proteomic analysis of cellular response to osmotic stress in thick ascending limb of Henle's loop (TALH) cells. Mol Cell Proteomics $\underline{4}, 1445-1458$

Dihazi H, Müller GA, Lindner S, Meyer M, Asif AR, Oellerich M, Strutz F (2007): Characterization of diabetic nephropathy by urinary proteomic analysis: Identification of a processed ubiquitin form as a differentially excreted protein in diabetic nephropathy patients. Clin Chem $\underline{53}, 1636-1645$

Dihazi H, Koziolek MJ, Sollner T, Kahler E, Klingel R, Neuhoff R, Strutz F, Mueller GA (2008): Protein adsorption during LDL-apheresis: Proteomic analysis. Nephrol Dial Transplant 23, 2925-2935 
Dihazi H, Dihazi GH, Bibi A, Eltoweissy M, Mueller CA, Asif AR, Rubel D, Vasko R, Mueller GA (2013): Secretion of ERP57 is important for extracellular matrix accumulation and progression of renal fibrosis, and is an early sign of disease onset. J Cell Sci 126, 3649-3663

Doumas M, Anyfanti P, Bakris G (2012): Should ambulatory blood pressure monitoring be mandatory for future studies in resistant hypertension: a perspective. J Hypertens $\underline{30}$, 874-876

Dudenbostel T, Acelajado MC, Pisoni R, Li P, Oparil S, Calhoun DA (2015): Refractory Hypertension: Evidence of Heightened Sympathetic Activity as a Cause of Antihypertensive Treatment Failure. Hypertension $\underline{66}, 126-133$

Dziewanowski M: Langzeitergebnisse nach Carotisrekonstruktion im Defektstadium der cerebrovaskulären Verschlußkrankheit. Med. Diss. Düsseldorf 2005

Egan BM, Zhao Y, Li J, Brzezinski WA, Todoran TM, Brook RD, Calhoun DA (2013): Prevalence of optimal treatment regimens in patients with apparent treatment-resistant hypertension based on office blood pressure in a community-based practice network. Hypertension $\underline{62}, 691-697$

Elmer PJ, Obarzanek E, Vollmer WM, Simons-Morton D, Stevens VJ, Young DR, Lin PH, Champagne C, Harsha DW, Svetkey LP, et al. (2006): Effects of comprehensive lifestyle modification on diet, weight, physical fitness, and blood pressure control: 18-month results of a randomized trial. Ann Intern Med $\underline{144}$, 485-495

Esler M, Lambert G, Jennings G (1989): Regional norepinephrine turnover in human hypertension. Clin Exp Hypertens 11 Suppl 1, 75-89

Esler M, Straznicky N, Eikelis N, Masuo K, Lambert G, Lambert E (2006): Mechanisms of sympathetic activation in obesity-related hypertension. Hypertension $\underline{48}$, 787-796

Esmatjes E, Flores L, Inigo P, Lario S, Ruilope LM, Campistol JM (2001): Effect of losartan on TGF-beta1 and urinary albumin excretion in patients with type 2 diabetes mellitus and microalbuminuria. Nephrol Dial Transplant 16 Suppl 1, 90-93 
Feig DI, Kang DH, Nakagawa T, Mazzali M, Johnson RJ (2006): Uric acid and hypertension. Curr Hypertens Rep $\underline{8}, 111-115$

Feigin V, Ratnasabapathy Y, Anderson C (2005): Does blood pressure lowering treatment prevents dementia or cognitive decline in patients with cardiovascular and cerebrovascular disease? J Neurol Sci 229-230, 151-155

Ferguson GG, Eliasziw M, Barr HWK, Clagett GP, Barnes RW, Wallace MC, Taylor DW, Haynes RB, Finan JW, Hachinski VC et al. (1999): The North American Symptomatic Carotid Endarterectomy Trial: Surgical Results in 1415 Patients. Stroke $\underline{30}, 1751-1758$

Finnerty FA, Jr. (1972): Hypertensive encephalopathy Am J Med 므, 672-678

Förstermann U (1986): Die Bedeutung der Endothelzellen für die Regulation des Tonus der glatten Gefäßmuskulatur-Bildung eines endothelialen, relaxierenden Faktors. Z Kardiol $\underline{75}$, 577-583

Fraser SDS, Roderick PJ, Mclntyre NJ, Harris S, Mclntyre CW, Fluck RJ, Taal MW (2013): Suboptimal blood pressure control in chronic kidney disease stage 3: baseline data from a cohort study in primary care. BMC Fam Pract $\underline{14}, 88$

Galis ZS, Khatri JJ (2002): Matrix metalloproteinases in vascular remodeling and atherogenesis: the good, the bad, and the ugly. Circ Res $\underline{90}, 251-262$

Galis ZS, Sukhova GK, Lark MW, Libby P (1994): Increased expression of matrix metalloproteinases and matrix degrading activity in vulnerable regions of human atherosclerotic plaques. J Clin Invest $\underline{94}$, 2493-2503

Garg UC, Hassid A (1989): Nitric oxide-generating vasodilators and 8-bromo-cyclic guanosine monophosphate inhibit mitogenesis and proliferation of cultured rat vascular smooth muscle cells. J Clin Invest $\underline{83}, 1774-1777$

Gerber HP, Dixit V, Ferrara N (1998): Vascular endothelial growth factor induces expression of the antiapoptotic proteins Bcl-2 and A1 in vascular endothelial cells. J Biol Chem $\underline{273}, 13313-13316$ 
Gill M, Dias S, Hattori K, Rivera ML, Hicklin D, Witte L, Girardi L, Yurt R, Himel H, Rafii S (2001): Vascular trauma induces rapid but transient mobilization of VEGFR2(+)AC133(+) endothelial precursor cells. Circ Res 88, 167-174

GISEN Group (1997): Randomised placebo-controlled trial of effect of ramipril on decline in glomerular filtration rate and risk of terminal renal failure in proteinuric, non-diabetic nephropathy. Lancet $\underline{349}, 1857-1863$

Grassi G (2010): Sympathetic neural activity in hypertension and related diseases. Am j Hypertens 23, 1052-1060

Grassi G, Seravalle G, Dell'Oro R, Turri C, Bolla GB, Mancia G (2000): Adrenergic and reflex abnormalities in obesity-related hypertension. Hypertension $\underline{36}, 538-$ 542

Grassi G, Quarti-Trevano F, Seravalle G, Arenare F, Volpe M, Furiani S, Dell'Oro R, Mancia G (2011a): Early sympathetic activation in the initial clinical stages of chronic renal failure. Hypertension $\underline{57}, 846-851$

Grassi G, Seravalle G, Dell'Oro R, Mancia G (2011b): Sympathetic mechanisms, organ damage, and antihypertensive treatment. Curr Hypertens Rep $\underline{13}$, 303308

Grassi G, Seravalle G, Brambilla G, Cesana F, Giannattasio C, Mancia G (2014): Similarities and differences between renal sympathetic denervation and carotid baroreceptor stimulation. Curr Vasc Pharmacol 12, 63-68

Grassi G, Seravalle G, Trevano FQ, Spaziani D, Scalise F, Auguadro C, Pizzini P, Tripepi G, D'Arrigo G, Mallamaci F et al. (2015): Asymmetric and symmetric dimethylarginine and sympathetic nerve traffic after renal denervation in patients with resistant hypertension. Clin J Am Soc Nephro, 2015 Jul 2. pii: CJN.01220215. [Epub ahead of print]

Gronda E, Seravalle G, Brambilla G, Costantino G, Casini A, Alsheraei A, Lovett EG, Mancia G, Grassi G (2014): Chronic baroreflex activation effects on sympathetic nerve traffic, baroreflex function, and cardiac haemodynamics in heart failure: a proof-of-concept study. Eur J Heart Fail 16, 977-983 
Gross JL, Azevedo MJ de, Silveiro SP, Canani LH, Caramori ML, Zelmanovitz T (2005): Diabetic nephropathy: diagnosis, prevention, and treatment. Diabetes Care 28, $164-176$

Gross O, Girgert R, Rubel D, Temme J, Theissen S, Müller G (2011): Renal protective effects of aliskiren beyond its antihypertensive property in a mouse model of progressive fibrosis. Am J Hypertens 24, 355-361

Gueyffier F, Boutitie F, Boissel JP, Pocock S, Coope J, Cutler J, Ekbom T, Fagard R, Friedman L, Perry M, et al. (1997): Effect of antihypertensive drug treatment on cardiovascular outcomes in women and men. A meta-analysis of individual patient data from randomized, controlled trials. The INDANA Investigators. Ann Intern Med 126, 761-767

Harris TB, Ferrucci L, Tracy RP, Corti MC, Wacholder S, Ettinger WH, Jr., Heimovitz H, Cohen HJ, Wallace R (1999): Associations of elevated interleukin-6 and C-reactive protein levels with mortality in the elderly. Am J Med $\underline{106}, 506-512$

Hasty AH, Harrison DG (2012): Endoplasmic reticulum stress and hypertension - a new paradigm? J Clin Invest 122, 3859-3861

Heart Outcomes Prevention Evaluation (HOPE) Study Investigators (2000): Effects of ramipril on cardiovascular and microvascular outcomes in people with diabetes mellitus: Results of the HOPE study and MICRO-HOPE substudy. Lancet $\underline{355}, 253-259$

Hering D, Mahfoud F, Walton AS, Krum H, Lambert GW, Lambert EA, Sobotka PA, Böhm M, Cremers B, Esler MD et al. (2012): Renal denervation in moderate to severe CKD. J Am Soc Nephrol 23, 1250-1257

Heusser K, Tank J, Engeli S, Diedrich A, Menne J, Eckert S, Peters T, Sweep F, Haller H, PichImaier AM, Luft FC, Jordan J (2010): Carotid Baroreceptor Stimulation, Sympathetic Activity, Baroreflex Function, and Blood Pressure in Hypertensive Patients. Hypertension 55, 619-626

Hofmeister LH, Perisic S, Titze J (2015): Tissue sodium storage: evidence for kidneylike extrarenal countercurrent systems? Pflugers Arch 467, 551-558 
Holzgreve H (1996): Die therapieresistente Hypertonie. Deutsches Ärzteblatt $\underline{93}$, A2548-2552

Hong C, Hughes K, Chia K, Ng V, Ling S (2003): Urinary alpha1-microglobulin as a marker of nephropathy in type 2 diabetic Asian subjects in Singapore. Diabetes Care 26, 338-342

Hoppe UC, Brandt M, Wachter R, Beige J, Rump LC, Kroon AA, Cates AW, Lovett EG, Haller H (2012): Minimally invasive system for baroreflex activation therapy chronically lowers blood pressure with pacemaker-like safety profile: Results from the Barostim neo trial. J Am Soc Hypertens $\underline{6}$, 270-276

Hou FF, Zhang X, Zhang GH, Xie D, Chen PY, Zhang WR, Jiang JP, Liang M, Wang GB, Liu ZR et al. (2006): Efficacy and safety of benazepril for advanced chronic renal insufficiency. N Engl J Med 354, 131-140

Huang P, Huang S, Chen Y, Lin C, Chiang K, Chen J, Tsai H, Lin F, Chen J, Lin S (2010): Increased circulating CD31+/annexin V+ apoptotic microparticles and decreased circulating endothelial progenitor cell levels in hypertensive patients with microalbuminuria. J Hypertens $\underline{28}$, 1655-1665

Ichikawa D, Kamijo-Ikemori A, Sugaya T, Shibagaki Y, Yasuda T, Katayama K (2014): Renoprotective effect of renal liver-type fatty acid binding protein and angiotensin II type 1a receptor loss in renal injury caused by RAS activation. Am J Physiol Renal Physiol $\underline{306}$ (6),F655-663

Inagi R: Endoplasmic Reticulum: The Master Regulator of Stress Responses in Glomerular Diseases; In: An Update on Glomerulopathies - Etiology and Pathogenesis, edited by Prabhakar S. 247-267: InTech 2011, Rijka, Croatia

Inker LA, Schmid CH, Tighiouart H, Eckfeldt JH, Feldman HI, Greene T, Kusek JW, Manzi J, van Lente F, Zhang YL et al. (2012): Estimating glomerular filtration rate from serum creatinine and cystatin C. N Engl J Med 367, 20-29

Inoue W (1989): Immunopathological analysis of acute phase reactant (APR) proteins in glomeruli from patients with diabetic nephropathy. Nihon Jinzo Gakkai Shi $\underline{31}$, 211-219 
Intengan HD, Schiffrin EL (2001): Vascular remodeling in hypertension: Roles of apoptosis, inflammation, and fibrosis. Hypertension $\underline{38}, 581-587$

Isaksson H, Ostergren J (1994): Prognosis in therapy-resistant hypertension. J Intern Med 236, 643-649

Ito A, Tsao PS, Adimoolam S, Kimoto M, Ogawa T, Cooke JP (1999): Novel mechanism for endothelial dysfunction: Dysregulation of dimethylarginine dimethylaminohydrolase. Circulation $\underline{99}$, 3092-3095

Ito A, Egashira K, Narishige T, Muramatsu K, Takeshita A (2001): Reninangiotensin system is involved in the mechanism of increased serum asymmetric dimethylarginine in essential hypertension. Jpn Circ J $\underline{65}, 775-778$

Jafar TH, Schmid CH, Landa M, Giatras I, Toto R, Remuzzi G, Maschio G, Brenner BM, Kamper A, Zucchelli P et al. (2001): Angiotensin-converting enzyme inhibitors and progression of nondiabetic renal disease. A meta-analysis of patient-level data. Ann Intern Med 135, 73-87

Jain S, Rajput A, Kumar Y, Uppuluri N, Arvind AS, Tatu U (2005): Proteomic analysis of urinary protein markers for accurate prediction of diabetic kidney disorder. J Assoc Physicians India 53, 513-520

James PA, Oparil S, Carter BL, Cushman WC, Dennison-Himmelfarb C, Handler J, Lackland DT, LeFevre ML, MacKenzie TD, Ogedegbe O et al. (2014): 2014 evidence-based guideline for the management of high blood pressure in adults: report from the panel members appointed to the Eighth Joint National Committee (JNC 8). JAMA-J Am Med Assoc 311, 507-520

Kamijo A, Kimura K, Sugaya T, Yamanouchi M, Hase H, Kaneko T, Hirata Y, Goto A, Fujita T, Omata M (2002): Urinary free fatty acids bound to albumin aggravate tubulointerstitial damage. Kidney Int $\underline{62}, 1628-163$

Kamijo-Ikemori A, Sugaya T, Yasuda T, Kawata T, Ota A, Tatsunami S, Kaise R, Ishimitsu T, Tanaka Y, Kimura K (2011): Clinical significance of urinary livertype fatty acid-binding protein in diabetic nephropathy of type 2 diabetic patients. Diabetes Care $\underline{34}, 691-696$ 
Kamijo-Ikemori A, Sugaya T, Ichikawa D, Hoshino S, Matsui K, Yokoyama T, Yasuda T, Hirata K, Kimura K (2013): Urinary liver type fatty acid binding protein in diabetic nephropathy. Clin Chim Acta $\underline{424}, 104-108$

Kawasaki T, Uezono K, Itoh K, Ueno M (1991): [Prediction of 24-hour urinary creatinine excretion from age, body weight and height of an individual and its application]. Nihon Koshu Eisei Zasshi 38, 567-574

Kawasaki T, Itoh K, Uezono K, Sasaki H (1993): A simple method for estimating 24h urinary sodium and potassium excretion from second morning voiding urine specimen in adults. Clin Exp Pharmacol P $\underline{20}, 7-14$

KDIGO Blood Pressure Work Group (2012): KDIGO Clinical Practice Guideline for the Management of Blood Pressure in Chronic Kidney Disease. Kidney int supplements $\underline{2}, 337-414$

Keller A, Nesvizhskii Al, Kolker E, Aebersold R (2002): Empirical statistical model to estimate the accuracy of peptide identifications made by MS/MS and database search. Anal Chem $\underline{74}, 5383-5392$

Kelley GA, Kelley KS (2000): Progressive resistance exercise and resting blood pressure : A meta-analysis of randomized controlled trials. Hypertension $\underline{35}$, 838-843

Khakoo AY, Finkel T (2005): Endothelial progenitor cells. Annu Rev Med $\underline{56}, 79-101$

Kiuchi MG, Maia GLM, De Queiroz Carreira, Maria Angela Magalhães, Kiuchi T, Chen S, Andrea BR, Graciano ML, Lugon JR (2013): Effects of renal denervation with a standard irrigated cardiac ablation catheter on blood pressure and renal function in patients with chronic kidney disease and resistant hypertension. Eur Heart J $\underline{34}, 2114-2121$

Kjaergaard AG, Dige A, Krog J, Tonnesen E, Wogensen L (2013): Soluble adhesion molecules correlate with surface expression in an In vitro model of endothelial activation. Basic Clin Pharmacol Toxicol $\underline{113}$, 273-279

Kobayashi T, Kim H, Liu X, Sugiura H, Kohyama T, Fang Q, Wen FQ, Abe S, Wang X, Atkinson JJ, et al. (2014): Matrix metalloproteinase-9 activates TGF-beta 
and stimulates fibroblast contraction of collagen gels. Am J Physiol 306, L10061015

Kopp C, Linz P, Dahlmann A, Hammon M, Jantsch J, Müller DN, Schmieder RE, Cavallaro A, Eckardt K, Uder M et al. (2013): 23Na magnetic resonance imaging-determined tissue sodium in healthy subjects and hypertensive patients. Hypertension $\underline{61}$, 635-640

Kostov K, Dimitrova A, Grigoryan A, Tisheva S, Ruseva A, Atanasova M, Gospodinov C, Blazhev A (2014): Changes in the serum levels of endothelin1, matrix metalloproteinases-2, -9 and C-reactive protein in patients with mild and severe degree of arterial hypertension. Compt Rend Acad Bulg Sci $\underline{67}$, 427434

Krespi PG, Makris TK, Hatzizacharias AN, Triposkiadis P, Tsoukala C, Kyriaki D, Votteas V, Kyriakidis M (1998): Moxonidine effect on microalbuminuria, thrombomodulin, and plasminogen activator inhibitor-1 levels in patients with essential hypertension. Cardiovasc Drugs Ther 12, 463-467

Kroon A, Bisognano J, Bach D, Kaufman C, de Leeuw P (2010): Baroreflex activation therapy ${ }^{\circledR}$ improves functional capacity and reduces left ventricular mass index: results from european and united states trials of the rheos ${ }^{\circledR}$ System: Abstract unter http://journals.Iww.com/jhypertension/Fulltext/2010/06001/Baror eflex Activation Therapy Improves Functional.779aspx [Zugriff Juli 2016] $\mathrm{J}$ Hypertens 2으, p e278

Krum H, Schlaich M, Whitbourn R, Sobotka PA, Sadowski J, Bartus K, Kapelak B, Walton A, Sievert H, Thambar S et al. (2009): Catheter-based renal sympathetic denervation for resistant hypertension: a multicentre safety and proof-of-principle cohort study. Lancet $\underline{373}, 1275-1281$

Krum H, Schlaich MP, Sobotka PA, Böhm M, Mahfoud F, Rocha-Singh K, Katholi R, Esler MD (2014): Percutaneous renal denervation in patients with treatmentresistant hypertension: Final 3-year report of the Symplicity HTN-1 study. Lancet $\underline{383}, 622-629$

Kubes P, Suzuki M, Granger DN (1991): Nitric oxide: An endogenous modulator of leukocyte adhesion. P Natl Acad Sci USA $\underline{88}, 4651-4655$ 
Kwak HJ, So JN, Lee SJ, Kim I, Koh GY (1999): Angiopoietin-1 is an apoptosis survival factor for endothelial cells. FEBS Lett $\underline{448}, 249-253$

Landsberg L, Young JB (1978): Fasting, feeding and regulation of the sympathetic nervous system. New Engl J Med 298, 1295-1301

Lea J, Greene T, Hebert L, Lipkowitz M, Massry S, Middleton J, Rostand SG, Miller E, Smith W, Bakris GL (2005): The relationship between magnitude of proteinuria reduction and risk of end-stage renal disease: Results of the African American study of kidney disease and hypertension. Arch Intern Med 165, 947953

Lehoux S, Lemarie CA, Esposito B, Lijnen HR, Tedgui A (2004): Pressure-induced matrix metalloproteinase- 9 contributes to early hypertensive remodeling. Circulation $\underline{109}, 1041-1047$

Leitlinien für das Management der arteriellen Hypertonie; Börm Bruckmeier, Grünwald 2013; http://www.hochdruckliga.de/bluthochdruck-behandlungleitlinien.html [Zugriff Juli 2016] (siehe auch: Deutsche Gesellschaft für Kardiologie-Herz- und Kreislaufforschung e.V.)

Leshem S, Cohen-Lulav H, Di-Castro N, Tabenkin H, Steinmetz D (2002): [The frequency and causes of resistant hypertension in primary care practices in the community as compared to those in the district advisory clinic for hypertension] Harefuah $\underline{141}$, 673-676, 764

Levey AS, Coresh J, Greene T, Marsh J, Stevens LA, Kusek JW, Van Lente F (2007): Expressing the modification of diet in renal disease study equation for estimating glomerular filtration rate with standardized serum creatinine values. Clin Chem $\underline{53}, 766-772$

Levey AS, Stevens LA, Schmid CH, Zhang YL, Castro AF, 3rd, Feldman HI, Kusek JW, Eggers P, Van Lente F, Greene T, et al. (2009): A new equation to estimate glomerular filtration rate. Ann Intern Med 150, 604-612

Lewington S, Clarke R, Qizilbash N, Peto R, Collins R (2002): Age-specific relevance of usual blood pressure to vascular mortality: A meta-analysis of individual data for one million adults in 61 prospective studies. Lancet $\underline{360}$, 1903-1913 
Lewis EJ, Hunsicker LG, Clarke WR, Berl T, PohI MA, Lewis JB, Ritz E, Atkins RC, Rohde R, Raz I (2001): Renoprotective effect of the angiotensin-receptor antagonist irbesartan in patients with nephropathy due to type 2 diabetes. New Engl J Med $\underline{345}, 851-860$

Lim SS, Vos T, Flaxman AD, Danaei G, Shibuya K, Adair-Rohani H, Amann M, Anderson HR, Andrews KG, Aryee M, et al. (2012): A comparative risk assessment of burden of disease and injury attributable to 67 risk factors and risk factor clusters in 21 regions, 1990-2010: A systematic analysis for the Global Burden of Disease Study 2010. Lancet 380, 2224-2260

Lim YK, Jenner A, Ali AB, Wang Y, Hsu SI, Chong SM, Baumman H, Halliwell B, Lim SK (2000): Haptoglobin reduces renal oxidative DNA and tissue damage during phenylhydrazine-induced hemolysis. Kidney Int 트, 1033-1044

Linz P, Santoro D, Renz W, Rieger J, Ruehle A, Ruff J, Deimling M, Rakova N, Muller DN, Luft FC et al. (2015): Skin sodium measured with ${ }^{23} \mathrm{Na} \mathrm{MRI}$ at 7.0 T. NMR In Biomed 28, 54-62

Lobov IB, Brooks PC, Lang RA (2002): Angiopoietin-2 displays VEGF-dependent modulation of capillary structure and endothelial cell survival in vivo. Proc Natl Acad Sci U S A $\underline{99}, 11205-11210$

Lohmeier TE, Irwin ED, Rossing MA, Serdar DJ, Kieval RS (2004): Prolonged activation of the baroreflex produces sustained hypotension. Hypertension $\underline{43}$, 306-311

Lüders S, Dechend R, Eckert S, Mengden T, Nürnberger J, Tholl U, Sanner B (2013): 24-h-Langzeitblutdruckmessung (ABDM). Der Kardiologe 푸 194-208

Maatman RG, Van Kuppevelt TH, Veerkamp JH (1991): Two types of fatty acidbinding protein in human kidney: Isolation, characterization and localization. Biochem J 르, 759-766

Madej A, Okopień B, Kowalski J, Haberka M, Herman ZS (2005): Plasma concentrations of adhesion molecules and chemokines in patients with essential hypertension. Pharmacol Rep $\underline{57}$, 878-881 
Magid R, Murphy TJ, Galis ZS (2003): Expression of matrix metalloproteinase-9 in endothelial cells is differentially regulated by shear stress. Role of c-Myc. J Biol Chem 278, 32994-32999

Mahfoud F, Cremers B, Janker J, Link B, Vonend O, Ukena C, Linz D, Schmieder R, Rump LC, Kindermann I et al. (2012): Renal hemodynamics and renal function after catheter-based renal sympathetic denervation in patients with resistant hypertension. Hypertension $\underline{60}, 419-424$

Mahfoud F, Ukena C, Schmieder RE (2013): Ambulatory blood pressure changes after renal sympathetic denervation in patients with resistant hypertension. $J$ Vasc Surg $\underline{58}, 1424$

Mahmud A, Feely $\mathbf{J}$ (2005): Arterial stiffness is related to systemic inflammation in essential hypertension. Hypertension $\underline{46}, 1118-1122$

Maki DD, Ma JZ, Louis TA, Kasiske BL (1995): Long-term effects of antihypertensive agents on proteinuria and renal function. Arch Intern Med 155, 1073-1080

Mancia G, De Backer G, Dominiczak A, Cifkova R, Fagard R, Germano G, Grassi G, Heagerty AM, Kjeldsen SE, Laurent S, et al. (2007): 2007 Guidelines for the management of arterial hypertension: The Task Force for the Management of Arterial Hypertension of the European Society of Hypertension (ESH) and of the European Society of Cardiology (ESC). Eur Heart J $\underline{28}, 1462-1536$

Mancia G, Fagard R, Narkiewicz K, Redon J, Zanchetti A, Bohm M, Christiaens T, Cifkova R, De Backer G, Dominiczak A, et al. (2013): 2013 ESH/ESC Guidelines for the management of arterial hypertension: the Task Force for the management of arterial hypertension of the European Society of Hypertension (ESH) and of the European Society of Cardiology (ESC). J Hypertens $\underline{31}$, 12811357

Mann JF, Gerstein HC, Pogue J, Bosch J, Yusuf S (2001): Renal insufficiency as a predictor of cardiovascular outcomes and the impact of ramipril: The HOPE randomized trial. Arch Intern Med 134, 629-636 
Martell N, Rodriguez-Cerrillo M, Grobbee DE, Lopez-Eady MD, Fernandez-Pinilla C, Avila M, Fernandez-Cruz A, Luque M (2003): High prevalence of secondary hypertension and insulin resistance in patients with refractory hypertension. Blood Press $\underline{12}, 149-154$

Maschio G, Alberti D, Janin G, Locatelli F, Mann JF, Motolese M, Ponticelli C, Ritz E, Zucchelli P (1996): Effect of the angiotensin-converting-enzyme inhibitor benazepril on the progression of chronic renal insufficiency. The AngiotensinConverting-Enzyme Inhibition in progressive renal insufficiency study group. New Engl J Med 334, 939-945

McCubbin JW, Green JH, Page IH (1956): Baroceptor function in chronic renal hypertension. Circ Res $\underline{4}, 205-210$

Michell DL, Andrews KL, Woollard KJ, Chin-Dusting JP (2011): Imaging leukocyte adhesion to the vascular endothelium at high intraluminal pressure. Journal of visualized experiments $\underline{23}, 54$

Mischak H, Kaiser T, Walden M, Hillmann M, Wittke S, Herrmann A, Knueppel S, Haller H, FLISER D (2004): Proteomic analysis for the assessment of diabetic renal damage in humans. Clin Sci 107, 485-495

Miyazaki M, Takai S (2002): Anti-atherosclerotic efficacy of olmesartan. J Human Hypertens 16 Suppl 2, S7-12

Mohan R, Chintala SK, Jung JC, Villar WV, McCabe F, Russo LA, Lee Y, McCarthy BE, Wollenberg KR, Jester JV, et al. (2002): Matrix metalloproteinase gelatinase B (MMP-9) coordinates and effects epithelial regeneration. J Biol Chem 277, 2065-2072

Mosconi L, Ruggenenti P, Perna A, Mecca G, Remuzzi G (1996): Nitrendipine and enalapril improve albuminuria and glomerular filtration rate in non-insulin dependent diabetes. Kidney Int 55 Suppl, S91-3

Mueller CF, Laude K, McNally JS, Harrison DG (2005): ATVB in focus: redox mechanisms in blood vessels. Arterioscler Thromb Vasc Biol 25, 274-278 
Nadar SK, Blann AD, Lip GYH (2004): Plasma and platelet-derived vascular endothelial growth factor and angiopoietin-1 in hypertension: effects of antihypertensive therapy. J Intern Med 256, 331-337

Nakamura T, Inoue T, Sugaya T, Kawagoe Y, Suzuki T, Ueda Y, Node K (2008): Renoprotective effect of telmisartan in patients with chronic kidney disease. Clin Exp Hypertens $\underline{30}$, 662-672

Nakamura T, Sato E, Fujiwara N, Kawagoe Y, Koide H, Ueda Y, Takeuchi M, Yamagishi S (2011): Calcium channel blocker inhibition of AGE and RAGE axis limits renal injury in nondiabetic patients with stage I or II chronic kidney disease. Clin Cardiol 34, 372-377

Neal B, MacMahon S, Chapman N (2000): Effects of ACE inhibitors, calcium antagonists, and other blood-pressure-lowering drugs: results of prospectively designed overviews of randomised trials. Blood Pressure Lowering Treatment Trialists' Collaboration. Lancet $\underline{356}, 1955-1964$

Nesvizhskii Al, Keller A, Kolker E, Aebersold R (2003): A statistical model for identifying proteins by tandem mass spectrometry. Anal Chem $\underline{75}$, 4646-4658

Netchessova TA, Shepelkevich AP, Gorbat TV (2014): Efficacy of single-pill perindopril/indapamide in patients with hypertension and type 2 diabetes. High blood pressure \& cardiovascular prevention the official journal of the Italian. Society of Hypertension 21, 63-69

NICE (National Institute for Health and Care Excellence) (2011): Hypertension in adults: diagnosis and management, clinical guidelines; published: 24 August 2011, Manchester, UK, p. 1-38, siehe auch http://www.nice.org.uk/guidance/ cg127 [Zugriff Juli 2016]

Nielsen SE, Sugaya T, Tarnow L, Lajer M, Schjoedt KJ, Astrup AS, Baba T, Parving H, Rossing P (2009): Tubular and glomerular injury in diabetes and the impact of ACE inhibition. Diabetes Care 32, 1684-1688

Nielsen SE, Persson F, Frandsen E, Sugaya T, Hess G, Zdunek D, Shjoedt KJ, Parving H, Rossing P (2012): Spironolactone diminishes urinary albumin 
excretion in patients with type 1 diabetes and microalbuminuria: a randomized placebo-controlled crossover study. Diabetic Med 29, e184-90

Nijveldt RJ, Teerlink T, Van der Hoven B, Siroen MPC, Kuik DJ, Rauwerda JA, Van Leeuwen (2003): Asymmetrical dimethylarginine (ADMA) in critically ill patients: high plasma ADMA concentration is an independent risk factor of ICU mortality. Clin Nutr $\underline{22}, 23-30$

Nosadini R, Tonolo G (2002): Cardiovascular and renal protection in type 2 diabetes mellitus: the role of calcium channel blockers. J Am Soc Nephrol 13 Suppl 3, S216-23

Okazaki S, Sakaguchi M, Miwa K, Furukado S, Yamagami H, Yagita Y, Mochizuki H, Kitagawa K (2014): Association of Interleukin-6 with the progression of carotid atherosclerosis. A 9-year follow-up study. Stroke $\underline{45}, 2924-2929$

Orth SR, Amann K, Strojek K, Ritz E (2001): Sympathetic overactivity and arterial hypertension in renal failure. Nephrol Dial Transpl 16 Suppl 1, 67-69

Pache M, Kube T, Wolf S, Kutschbach P (2002): Do angiographic data support a detailed classification of hypertensive fundus changes? J Hum Hypertens $\underline{16}$, 405-410

Palade F, Alexa ID, Azoicai D, Panaghiu L, Ungureanu G (2003): Oxidative stress in atherosclerosis. Rev Med Chir Soc Med Nat lasi 107, 502-511

Palatini P, Casiglia E, Gąsowski J, Głuszek J, Jankowski P, Narkiewicz K, Saladini F, Stolarz-Skrzypek K, Tikhonoff V, van Bortel L et al. (2011): Arterial stiffness, central hemodynamics, and cardiovascular risk in hypertension. Vasc Health Risk Manag $\underline{7}, 725-739$

Patschan D, Patschan S, Henze E, Wessels JT, Koziolek MJ, Müller GA (2009): LDL lipid apheresis rapidly increases peripheral endothelial progenitor cell competence. J Clin Apheresis 24, 180-185

Patschan D, Patschan S, Müller GA (2011): Endothelial progenitor cells in acute ischemic kidney injury: strategies for increasing the cells' renoprotective competence. Int J Nephrol 2011, 828369 
Pauca AL, O'Rourke MF, Kon ND (2001): Prospective evaluation of a method for estimating ascending aortic pressure from the radial artery pressure waveform. Hypertension 38, 932-937

Peng F, Wu D, Ingram AJ, Zhang B, Gao B, Krepinsky JC (2007): RhoA activation in mesangial cells by mechanical strain depends on caveolae and caveolin-1 interaction. J Am Soc Nephrol 18, 189-198

Persson PB: Neurovegetative Regulation;in: Physiologie, Kapitel 24; hrsg. v. Klinke R, Pape H, Kurtz A, Silbernagel S, Baumann R, Brenner B, Gay R, Rothenburger A; Georg Thieme Verlag, Stuttgart 2005,6. Auflage, 810-811

Perticone F, Sciacqua A, Maio R, Perticone M, Maas R, Boger RH, Tripepi G, Sesti G, Zoccali C (2005): Asymmetric dimethylarginine, L-arginine, and endothelial dysfunction in essential hypertension. J Am Coll Cardiol $\underline{46}, 518-523$

Pesic I, Stefanovic V, Muller GA, Muller CA, Cukuranovic R, Jahn O, Bojanic V, Koziolek M, Dihazi H (2011): Identification and validation of six proteins as marker for endemic nephropathy. J Proteomics $\underline{74}$, 1994-2007

Pöss J, Ewen S, Schmieder RE, Muhler S, Vonend O, Ott C, Linz D, Geisel J, Rump LC, Schlaich M et al. (2015): Effects of renal sympathetic denervation on urinary sodium excretion in patients with resistant hypertension. Clin Res Cardiol $\underline{104}, 672-678$

Quinn U, Tomlinson LA, Cockcroft JR (2012): Arterial stiffness. JRSM Cardiovasc Dis $\underline{1}, 1-8$

Rao PV, Lu X, Standley M, Pattee P, Neelima G, Girisesh G, Dakshinamurthy KV, Roberts CT, JR, Nagalla SR (2007): Proteomic identification of urinary biomarkers of diabetic nephropathy. Diabetes Care $\underline{30}, 629-637$

Rapoport RM, Draznin MB, Murad F (1983): Endothelium-dependent relaxation in rat aorta may be mediated through cyclic GMP-dependent protein phosphorylation. Nature $\underline{306}, 174-176$

Ravid M, Brosh D, Levi Z, Bar-Dayan Y, Ravid D, Rachmani R (1998): Use of enalapril to attenuate decline in renal function in normotensive, 
normoalbuminuric patients with type 2 diabetes mellitus. A randomized, controlled trial. Ann Intern Med 128, 982-988

Reincke M, Lehnert H, Kolloch RE (2009): Therapierefraktäre und sekundäre arterielle Hypertonie. Siehe auch http://link.springer.com/article/10.1007\%

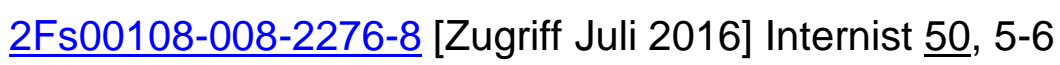

Retnakaran R, Zinman B, Connelly PW, Harris SB, Hanley AJG (2006): Nontraditional cardiovascular risk factors in pediatric metabolic syndrome. $J$ Pediatr $\underline{148}, 176-182$

Riou S, Mees B, Esposito B, Merval R, Vilar J, Stengel D, Ninio E, van Haperen R, de Crom R, Tedgui A, et al. (2007): High pressure promotes monocyte adhesion to the vascular wall. Circ Res $\underline{100}, 1226-1233$

Roberts AB (1995): Transforming growth factor-beta: activity and efficacy in animal models of wound healing. Wound Repair Regen $\underline{3}$, 408-418

Romano M, Sironi M, Toniatti C, Polentarutti N, Fruscella P, Ghezzi P, Faggioni R, Luini W, Van Hinsbergh V, Sozzani S, et al. (1997): Role of IL-6 and its soluble receptor in induction of chemokines and leukocyte recruitment. Immunity $\underline{6}, 315-325$

Rosenberg ME, Hostetter TH (1991): Comparative effects of antihypertensives on proteinuria: Angiotensin-converting enzyme inhibitor versus alpha 1-antagonist. Am J Kidney Dis $\underline{18}, 472-482$

Rosenkranz A (2004): Sympathikus-Überaktivität aus dem Blickwinkel der Nephrologie. J Hyperton, Sonderheft 2, 16-19

Roush GC, Kaur R, Ernst ME (2014): Diuretics: A review and update. J Cardiovasc Pharm T $19,5-13$

Ruilope LM, Bakris, G. L. (2011): Renal function and target organ damage in hypertension. Eur Heart J $\underline{32}, 1599-1604$

Sacks FM, Svetkey LP, Vollmer WM, Appel LJ, Bray GA, Harsha D, Obarzanek E, Conlin PR, Miller ER, 3rd, Simons-Morton DG, et al. (2001): Effects on blood pressure of reduced dietary sodium and the Dietary Approaches to Stop 
Hypertension (DASH) diet. DASH-Sodium Collaborative Research Group. New Engl J Med $\underline{344}, 3-10$

Saklayen MG, Gyebi LK, Tasosa J, Yap J (2008): Effects of additive therapy with spironolactone on proteinuria in diabetic patients already on ACE inhibitor or ARB therapy: results of a randomized, placebo-controlled, double-blind, crossover trial. J Invest Med $\underline{56}, 714-719$

Scaglione R, Argano C, Parrinello G, Colomba D, Di Chiara T, Ferrante A, Di Garbo V, Avellone G, Licata G (2002): Relationship between transforming growth factor beta1 and progression of hypertensive renal disease. J Hum Hypertens $\underline{16}, 641-645$

Scheffers IJ, Kroon AA, Schmidli J, Jordan J, Tordoir JJM, Mohaupt MG, Luft FC, Haller H, Menne J, Engeli S et al. (2010a): Novel baroreflex activation therapy in resistant hypertension: results of a European multi-center feasibility study. $J$ Am Coll Cardiol 트, 1254-1258

Scheffers I, Schmidli J, Kroon A, Toirdoir J, Mohaupt M, Allemann Y, Jordan J, Engeli S, Liebeskind U, Luft F, et al. (2010b): Functional safety in resistant hypertensive patients with baroreflex activation therapy. Abstract unter https://www.researchgate.net/publication/240088771_FUNCTIONAL_SAFETY _IN_RESISTANT_HYPERTENSIVE_PATIENTS_WITH_BAROREFLEX_ACTI ACTIVA_THERAPY_PP33298 [Zugriff Juli 2016] J Hypertens 28 , e-Suppl. A, PP.33.298

Schmieder RE (2010): Hypertoniebedingte Endorganschäden. Dtsch Arztebl Int 107, 866-873

Schmieder RE, Schrader J, Zidek W, Tebbe U, Bramlage P, Paar WD, Bohm M (2006): Subklinische Albuminurie, Mikroalbuminurie und Proteinurie akzeptierte kardiovaskuläre Risikomarker?. Deut Med Wochenschr 131, 26652671

Schnabel R, Blankenberg S, Lubos E, Lackner KJ, Rupprecht HJ, Espinola-Klein C, Jachmann N, Post F, Peetz D, Bickel C, et al. (2005): Asymmetric dimethylarginine and the risk of cardiovascular events and death in patients with 
coronary artery disease: results from the AtheroGene Study. Circ Res $\underline{97}$, e5359

Schuett H, Luchtefeld M, Grothusen C, Grote K, Schieffer B (2009): How much is too much? Interleukin-6 and its signalling in atherosclerosis. Thromb Haemostasis 102, 215-222

Shalia KK, Mashru MR, Vasvani JB, Mokal RA, Mithbawkar SM, Thakur PK (2009): Circulating levels of cell adhesion molecules in hypertension. Indian $\mathrm{J}$ Clin Biochem 24, 388-397

Sobczak A, Goniewicz ML, Szoltysek-Boldys I (2009): ADMA and SDMA levels in healthy men exposed to tobacco smoke. Atherosclerosis $\underline{205}, 357-359$

Stuhlinger MC, Oka RK, Graf EE, Schmolzer I, Upson BM, Kapoor O, Szuba A, Malinow MR, Wascher TC, Pachinger O et al. (2003): Endothelial dysfunction induced by hyperhomocyst(e)inemia: role of asymmetric dimethylarginine. Circulation $\underline{108}$, 933-938

Su W, Gao F, Lu J, Wu W, Zhou G, Lu S (2012): Levels of matrix metalloproteinase9 and tissue inhibitor of metalloproteinase-1 mRNAs in patients with primary hypertension or hypertension-induced atherosclerosis. J Int Med Res $\underline{40}, 986$ 994

Sun HL, Sun L, Li YY, Shao MM, Cheng XY, Ge N, Lu JD, Li SM (2009): ACEinhibitor suppresses the apoptosis induced by endoplasmic reticulum stress in renal tubular in experimental diabetic rats. Exp Clin Endocrinol Diabetes 117, 336-344

Sun L, Pan X, Wada J, Haas CS, Wuthrich RP, Danesh FR, Chugh SS, Kanwar YS (2002): Isolation and functional analysis of mouse UbA52 gene and its relevance to diabetic nephropathy. J Biol Chem 277, 29953-29962

Suri C, McClain J, Thurston G, McDonald DM, Zhou H, Oldmixon EH, Sato TN, Yancopoulos GD (1998): Increased vascularization in mice overexpressing angiopoietin-1. Science $\underline{282}, 468-471$

Symplicity HTN-2 Investigators, Esler MD, Krum H, Sobotka PA, Schlaich MP, Schmieder RE, Bohm M (2010): Renal sympathetic denervation in patients 
with treatment-resistant hypertension (The Symplicity HTN-2 Trial): A randomised controlled trial. Lancet $\underline{376}, 1903-1909$

Tadzic R, Mihalj M, Vcev A, Ennen J, Tadzic A, Drenjancevic I (2013): The effects of arterial blood pressure reduction on endocan and soluble endothelial cell adhesion molecules (CAMs) and CAMs ligands expression in hypertensive patients on Ca-channel blocker therapy. Kidney Blood Press Res $\underline{37}$, 103-115

Takahashi T, Kalka C, Masuda H, Chen D, Silver M, Kearney M, Magner M, Isner JM, Asahara T (1999): Ischemia- and cytokine-induced mobilization of bone marrow-derived endothelial progenitor cells for neovascularization. Nat Med $\underline{5}$, 434-438

Thum T, Hoeber S, Froese S, Klink I, Stichtenoth DO, Galuppo P, Jakob M, Tsikas D, Anker SD, Poole-Wilson PA et al. (2007): Age-dependent impairment of endothelial progenitor cells is corrected by growth-hormone-mediated increase of insulin-like growth-factor-1. Circ Res 100 Suppl., 434-443

Thurston G (2002): Complementary actions of VEGF and angiopoietin-1 on blood vessel growth and leakage. J Anat 200, 575-580

Thurston G, Rudge JS, loffe E, Zhou H, Ross L, Croll SD, Glazer N, Holash J, McDonald DM, Yancopoulos GD (2000): Angiopoietin-1 protects the adult vasculature against plasma leakage. Nat Med $\underline{6}, 460-463$

Tomlinson LA (2012): Methods for assessing arterial stiffness: Technical considerations. Curr Opin Nephrol Hypertens 21, 655-660

Udo EO, Zuithoff NPA, van Hemel NM, Cock CC de, Hendriks T, Doevendans PA, Moons KGM (2012): Incidence and predictors of short- and long-term complications in pacemaker therapy: The FOLLOWPACE study. Heart Rhythm 9, 728-735

UK Prospective Diabetes Study Group (1998): Efficacy of atenolol and captopril in reducing risk of macrovascular and microvascular complications in type 2 diabetes: UKPDS 39. UK Prospective Diabetes Study Group. BMJ 317, 713720 
Vallance P, Leone A, Calver A, Collier J, Moncada S (1992): Accumulation of an endogenous inhibitor of nitric oxide synthesis in chronic renal failure. Lancet 339, 572-575

Vasa M, Fichtlscherer S, Aicher A, Adler K, Urbich C, Martin H, Zeiher AM, Dimmeler S (2001): Number and migratory activity of circulating endothelial progenitor cells inversely correlate with risk factors for coronary artery disease. Circ Res $\underline{89}$, E1-7

Vasan RS, Beiser A, Seshadri S, Larson MG, Kannel WB, D'Agostino RB, Levy D (2002): Residual lifetime risk for developing hypertension in middle-aged women and men: The Framingham Heart Study. JAMA-J Am Med Assoc 287, 1003-1010

Verbeke F, Lindley E, Van Bortel L, Vanholder R, London G, Cochat P, Wiecek A, Fouque D, Van Biesen W (2014): A European Renal Best Practice (ERBP) position statement on the Kidney Disease: Improving Global Outcomes (KDIGO) clinical practice guideline for the management of blood pressure in non-dialysis-dependent chronic kidney disease: an endorsement with some caveats for real-life application. Nephrol Dial Transpl 29 , 490-496

Verdecchia P, Schillaci G, Boldrini F, Guerrieri M, Gatteschi C, Benemio G, Porcellati C (1990): Risk Stratification of Left-Ventricular Hypertrophy in Systemic Hypertension Using Noninvasive Ambulatory Blood-Pressure Monitoring. Am J Cardiol $\underline{66}, 583-590$

Virdis A, Schiffrin EL (2003): Vascular inflammation: a role in vascular disease in hypertension? Curr Opin Nephrol Hy $\underline{12}, 181-187$

Virdis A, Dell'Agnello U, Taddei S (2014): Impact of inflammation on vascular disease in hypertension. Maturitas $\underline{78}, 179-183$

Vollmer WM, Sacks FM, Ard J, Appel LJ, Bray GA, Simons-Morton DG, Conlin PR, Svetkey LP, Erlinger TP, Moore TJ, et al. (2001): Effects of diet and sodium intake on blood pressure: subgroup analysis of the DASH-sodium trial. Ann Intern Med 135, 1019-1028 
Vongpatanasin W, Kario K, Atlas SA, Victor RG (2011): Central sympatholytic drugs. J Clin Hypertens $\underline{13}$, 658-661

Wachter R, Menne J (2015): Interventionelle Strategien zur Behandlung der Hypertonie. Der Internist $\underline{56}, 240-247$

Wahl SM, Hunt DA, Wakefield LM, McCartney-Francis N, Wahl LM, Roberts AB, Sporn MB (1987): Transforming growth factor type beta induces monocyte chemotaxis and growth factor production. Proc Natl Acad Sci USA $\underline{84}$, 57885792

Wahl SM, Hunt DA, Wong HL, Dougherty S, McCartney-Francis N, Wahl LM, Ellingsworth L, Schmidt JA, Hall G, Roberts AB, et al. (1988): Transforming growth factor-beta is a potent immunosuppressive agent that inhibits IL-1dependent lymphocyte proliferation. J Immunol 140, 3026-3032

Wallbach M, Lehnig LY, Schroer C, Helms HJ, Hasenfuß G, Müller GA, Wachter R, Koziolek MJ (2014): Impact of baroreflex activation therapy on renal function - a pilot study. Am J Nephrol $\underline{40}, 371-380$

Wallbach M., Koziolek M. (2015a): Nephroprotektion durch Barorezeptoraktivierungstherapie. Medicom: Nephro-News/Forum für Nephrologie und Hypertensiologie, 2/15, 27-31

Wallbach M, Lehnig LY, Müller GA, Wachter R, Lüders S, Koziolek MJ (2015b): Effects of Baroreflex activation therapy on urinary sodium excretion. 39. Wissenschaftlicher Jahreskongress „Hypertonie Saarbrücken 2015” (19.11.2015 - 21.11.2015); Abstract unter http://reg.mcon-mannheim.de/ onlineprogramm-mmv/render.aspx?kongress $\mid \mathrm{D}=87 \& \mathrm{t}=\mathrm{a} \& \mathrm{n}=42662 \&$ speach $=$ GER [Zugriff Juli 2016]

Wallbach M, Lehnig LY, Schierke K, Dihazi H, Müller GA, Koziolek MJ (2015c): Nephroprotective Effects of Baroreflex Activation Therapy. „Autorenreferate Symposium Junge Niere“, Göttingen 2015 (19.06.2015 - 20.06.2015); Abstract unter http://www.dustri.com/nc/de/deutschsprachige-zeitschriften/mag/nierenund-hochdruckkrankheiten/vol/jahrgang-44/issue/mai-17.html [Zugriff Juli 2016] Nieren- und Hochdruckkrankheiten 44, 236-240 
Wallbach M, Lehnig LY, Schroer C, Lüders S, Böhning E, Müller GA, Wachter R, Koziolek MJ (2016): Effects of Baroreflex Activation Therapy on Ambulatory Blood Pressure in Patients with Restistant Hypertension. Hypertension 67, 701709

Warner HR (1958): The frequency-dependent nature of blood pressure regulation by the carotid sinus studied with an electric analog. Circ Res $\underline{6}, 35-40$

Weber MA, Schiffrin EL, White WB, Mann S, Lindholm LH, Kenerson JG, Flack JM, Carter BL, Materson BJ, Ram CVS et al. (2014): Clinical practice guidelines for the management of hypertension in the community: a statement by the American Society of Hypertension and the International Society of Hypertension. J Clin Hypertens $\underline{16}$, 14-26

Whelton SP, Chin A, Xin X, He J (2002): Effect of aerobic exercise on blood pressure: a meta-analysis of randomized, controlled trials. Ann Intern Med $\underline{136}, 493-503$

WHO (2013): A global brief on Hypertension - Silent killer, global public health crisis. World Health Organization, Geneva, Switzerland; Document number: WHO/DCO/WHD/2013.2

Williams B, MacDonald TM, Morant S, Webb DJ, Sever P, Mclnnes G, Ford I, Cruickshank JK, Caulfield MJ, Salsbury J et al. (2015): Spironolactone versus placebo, bisoprolol, and doxazosin to determine the optimal treatment for drug-resistant hypertension (PATHWAY-2): a randomised, double-blind, crossover trial. Lancet $\underline{386}, 2059-2068$

Wolf S, Risler T (2004): Are all antihypertensive drugs renoprotective? Herz 29, 248254

Wolf-Maier K, Cooper RS, Banegas JR, Giampaoli S, Hense HW, Joffres M, Kastarinen M, Poulter N, Primatesta P, Rodriguez-Artalejo F, et al. (2003): Hypertension prevalence and blood pressure levels in 6 European countries, Canada, and the United States. JAMA-J Am Med Assoc 료, 2363-2369

Wustmann K, Kucera J, Scheffers I, Mohaupt M, Kroon A, Leeuw P, Schmidli J, Allemann Y, Delacrétaz E (2009): Effects of chronic baroreceptor stimulation 
on the autonomic cardiovascular regulation in patients with drug-resistant arterial hypertension. Hypertension $\underline{54}, 530-536$

Xie D, Hou FF, Fu BL, Zhang X, Liang M (2011): High level of proteinuria during treatment with renin-angiotensin inhibitors is a strong predictor of renal outcome in nondiabetic kidney disease. J Clin Pharmacol 51, 1025-1034

Xin X, He J, Frontini MG, Ogden LG, Motsamai OI, Whelton PK (2001): Effects of alcohol reduction on blood pressure: A meta-analysis of randomized controlled trials. Hypertension $\underline{38}, 1112-1117$

Yao F, Li Z, Ehara T, Yang L, Wang D, Feng L, Zhang Y, Wang K, Shi Y, Duan H et al. (2015): Fatty Acid-Binding Protein 4 mediates apoptosis via endoplasmic reticulum stress in mesangial cells of diabetic nephropathy. Mol Cell Endocrinol $\underline{411}, 232-242$

Yokota H, Hiramoto M, Okada H, Kanno Y, Yuri M, Morita S, Naitou M, Ichikawa A, Katoh M, Suzuki H (2007): Absence of increased alpha1-microglobulin in $\lg$ A nephropathy proteinuria. Mol Cell Proteomics $\underline{6}, 738-744$

Zhang M, Wang G, Wang A, Tong W, Zhang Y (2013): Association of hypertension with coexistence of abnormal metabolism and inflammation and endothelial dysfunction. Blood Press 22, 151-157

Zhang Z, Yang K, Jiang F, Zeng L, Jiang W, Wang X (2014): The effects of catheterbased radiofrequency renal denervation on renal function and renal artery structure in patients with resistant hypertension. J Clin Hypertens (Greenwich) $\underline{16}, 599-605$ 


\section{Anhang: Veröffentlichungen}

Teile der Arbeit wurden bereits veröffentlicht:

Originalarbeiten:

Wallbach M, Lehnig LY, Schroer C, Helms HJ, Hasenfuß G, Müller GA, Wachter R, Koziolek MJ (2014): Impact of baroreflex activation therapy on renal function - a pilot study. Am J Nephrol $\underline{40}$, 371-380

Impact factor: 2,646

Wallbach M, Lehnig LY, Schroer C, Helms HJ, Müller GA, Lüders S, Patschan S, Patschan D, Wachter R, Koziolek MJ (2015): Effects of Baroreflex Activation Therapy on Arterial Stiffness and Central Hemodynamics in Patients with Resistant Hypertension. Hypertension $\underline{33}, 181-6$

Impact factor: 4,720

Wallbach M, Lehnig LY, Schroer C, Helms HJ, Müller GA, Wachter R, Koziolek MJ (2015): Long-term effects of Baroreflex Activation Therapy on Glucose Metabolism. Acta Diabetologica $\underline{52}, 829-35$

Impact factor: 2,339

Wallbach M, Lehnig LY, Schroer C, Lüders S, Böhning E, Müller GA, Wachter R, Koziolek MJ (2016): Effects of Baroreflex Activation Therapy on ambulatory blood pressure monitoring. Hypertension $\underline{67}, 701-709$

Impact factor: 6,499

Abstracts/Poster:

Wallbach M, Lehnig L-Y, Schroer C, Patschan D, Patschan S, Helms HJ, Müller GA, Wachter R, Koziolek MJ: Impact of baroreceptor activation therapy on central hemodynamics. 5. Tagung der Deutschen Gesellschaft für Nephrologie, Berlin, Oktober 2013 
Wallbach M, Lehnig L-Y, Schroer C, Dihazi H, Helms HJ, Müller G A, Wachter R, Koziolek MJ: Impact of baroreceptor activation therapy on renal function. 5. Tagung der Deutschen Gesellschaft für Nephrologie, Berlin, Oktober 2013

Wallbach M, Lehnig L-Y, Schroer C, Patschan D, Patschan S, Helms HJ, Müller GA, Wachter R, Koziolek MJ: Einfluss der Barorezeptoraktivierungstherapie auf die zentrale Hämodynamik. 37. Wissenschaftlicher Jahreskongress Hypertonie, Münster, Dezember 2013

Wallbach M, Lehnig L-Y, Schroer C, Dihazi H, Helms HJ, Müller GA, Wachter R, Koziolek MJ: Auswirkungen der Barorezeptoraktivierungstherapie auf die renale Funktion. 37. Wissenschaftlicher Jahreskongress Hypertonie, Münster, Dezember 2013

Wallbach M, Lehnig L-Y, Schroer C, Patschan D, Patschan S, Helms HJ, Müller GA, Wachter R, Koziolek MJ: Impact of baroreceptor activation therapy on central hemodynamics. 120. Kongress der Dt. Gesellschaft für Innere Medizin, Wiesbaden, 26.-29. April 2014

Wallbach M, Lehnig L-Y, Schroer C, Dihazi H, Helms HJ, Müller GA, Wachter R, Koziolek MJ: Impact of baroreceptor activation therapy on renal function. 120. Kongress der Dt. Gesellschaft für Innere Medizin, Wiesbaden, 26.-29. April 2014

Wallbach M, Lehnig L-Y, Schroer C, Patschan D, Patschan S, Helms HJ, Müller GA, Wachter R, Koziolek MJ: Impact of baroreflex activation therapy on endothelial progenitor cells. 6. Tagung der Deutschen Gesellschaft für Nephrologie, Berlin, September 2014

Wallbach M, Kämpfer D, Lehnig L-Y, Wachter R, Müller GA, Koziolek MJ: Baroreflex activation therapy in patients with resistant hypertension who prior underwent renal denervation. 6. Tagung der Deutschen Gesellschaft für Nephrologie, Berlin, September 2014

Wallbach M, Lehnig L-Y, Helms HJ, Schroer C,. Müller GA, Wachter R, Koziolek MJ: Long-term effects of Baroreflex Activation Therapy on Glucose Metabolism. 38. Wissenschaftlicher Jahreskongress Hypertonie, Berlin, Dezember 2014 
Wallbach M, Lehnig L-Y, Schroer C, Hasenfuß G, Müller GA, Wachter R, Koziolek MJ: Impact of Baroreflex Activation Therapy on Renal Function. 38. Wissenschaftlicher Jahreskongress Hypertonie, Berlin, Dezember 2014

Schroer C, Lehnig L-Y, Wallbach M, Koziolek M, Wachter R: Effects of baroreceptor therapy on cardiac structure and exercise performance. 81. Jahrestagung der DGK, Mannheim, April 2015

Wallbach M, Lehnig L-Y, Müller GA, Wachter R, Koziolek MJ: Effects of Baroreflex activation therapy on urinary sodium excretion in patients with resistant hypertension. 7. Tagung der Deutschen Gesellschaft für Nephrologie, Berlin, September 2015

Wallbach M, Böhning E, Lehnig L-Y, Schroer C, Müller GA, Wachter R, Lüders S, Koziolek MJ: Analysis of safety profile in patients undergoing Baroreflex Activation Therapy. 7. Tagung der Deutschen Gesellschaft für Nephrologie, Berlin, September 2015

Wallbach M, Schierke K, Dihazi H, Lehnig L-Y, Müller GA, Wachter R, Koziolek MJ: Urinary Proteomics in patients undergoing Baroreflex Activation Therapy. 7. Tagung der Deutschen Gesellschaft für Nephrologie, Berlin, September 2015

Wallbach M, Lehnig L-Y, Schroer C, Lüders S, Böhning E, Müller GA, Wachter R, Koziolek MJ: Effects of Baroreflex Activation Therapy on ambulatory blood pressure monitoring. 39. Wissenschaftlicher Jahreskongress Hypertonie, Saarbrücken, Dezember 2015

Wallbach M, Lehnig L-Y, Müller GA, Wachter R, Koziolek MJ: Effects of Baroreflex activation therapy on urinary sodium excretion. 39. Wissenschaftlicher Jahreskongress Hypertonie, Saarbrücken, Dezember 2015 


\section{Danksagung}

Großer Dank gilt meinem Doktorvater, Herrn Prof. Dr. med. Michael Koziolek, und meinem Betreuer, Herrn Dr. med. Manuel Wallbach, für die Vergabe des spannenden und faszinierenden Themas.

Ich danke ihnen sehr für ihre umfassende Betreuung während der gesamten Studienphase, ihre vielen Anregungen, ihre Hinweise und Ratschläge zum Verfassen und Erstellen der Abbildungen und Präsentationen und letztlich ihre Unterstützung beim Schreiben der Doktorarbeit. Konkret danke ich innen auch für die freundschaftliche Zusammenarbeit und ihre Wertschätzung, welche großen Anteil daran hatten, die notwendige wissenschaftliche Neugierde $\mathrm{zu}$ wecken und Beharrlichkeit aufzubringen, dem Thema meiner Dissertation im hinreichenden Umfang nachzugehen.

Außerdem möchte ich Herrn Prof. Dr. med. Gerhard Anton Müller danken, in dessen Klinik für Nephrologie und Rheumatologie ich während meiner Dissertation arbeiten durfte. So konnte ich meine experimentellen Arbeiten in den Forschungslaboren durchführen, die unter der Leitung von Herrn Prof. Dr. rer. nat. Hassan Dihazi und Herrn Prof. Dr. med. Daniel Patschan stehen. Sowohl ihnen als auch einigen Labormitarbeitern bin ich zu großem Dank verpflichtet. Hervorzuheben sind hier im Besonderen die Medizinisch-Technischen Assistentinnen Elvira Henze, Elke BrunstKnoblich und die Doktorandin Constanze Altubar, welche für mich eine Schlüsselrolle beim Erlernen der entsprechenden experimentellen Methoden spielten. In diesem Zusammenhang sind ferner Gry Helene Dihazi, Gabriela Wolf, Katrin Schwarze, Sandra Trautmann, Jens Mahrt, Diana Rubel, Renate Klages (endokrinologisches Forschungslabor) sowie die Mitarbeiter aus dem nephrologischen Routinelabor zu nennen. Außerdem möchte ich die Schwestern und Mitarbeiter der nephrologischen Ambulanz und der Blutentnahme Flur 13 Ebene 3 anerkennend erwähnen.

Infolge der interdisziplinären Zusammenarbeit der Universitätskliniken für Kardiologie und Pneumologie, Psychosomatische Medizin und Psychotherapie sowie der ThoraxHerz-Gefäß-Chirurgie in Göttingen möchte ich sowohl Prof. Dr. med. Gerd Hasenfuß, Prof. Dr. med. Christoph Herrmann-Lingen als auch dem Chirurgen Dr. med. Dieter Zenker, welcher die Implantationen der BAT-Schrittmacher vornahm, meinen Dank aussprechen. 
Im besonderen Maße ist ebenso Herr Prof. Dr. med. Rolf Wachter zu erwähnen, welcher für die klinische Durchführung seine kardiologische Studienambulanz zur Verfügung stellte. Angesichts der Unterstützung der Studienschwestern konnten die klinischen Untersuchungen reibungslos erfolgen. Insbesondere Frau Christine Biegler ist hier als Verantwortliche für die Betreuung der BAT-Patienten in der BAT-Ambulanz zu nennen. Anerkennung gilt ebenfalls Anja Eckermann, Doris von Grünhagen, Sabine Math, Janet Kühn, den Doktoranden und Dr. med. Mark A. Weber-Krüger. Für die stationäre Planung und Betreuung möchte ich meine Wertschätzung außerdem Kerstin Hennesen und Birgit Kaczynski vom kardiologischen Case Management sowie den Stationen 2022, 2024 und 3024 aussprechen.

Im Hinblick auf die statistische Begutachtung und Auswertung danke ich HansJoachim Helms von der Abteilung für Medizinische Statistik der Universität Göttingen und den Mitarbeitern der Firma CVRx für ihre technische Unterstützung.

Der Großteil der klinischen Daten wurde mit Unterstützung der Doktorandin Charlotte Schroer erhoben. Ihrer kollegialen und engagierten Zusammenarbeit verdanke ich es, dass dieses Studienprojekt in diesem Umfang erfolgreich durchgeführt werden konnte. 


\section{Erklärung zur Zusammenarbeit der BAT-Doktoranden}

Die Zusammenarbeit von Frau Schroer und Herrn Lehnig umfasste die Einbestellung der BAT-Patienten, die Unterstützung der präoperativen Diagnostik, die stationäre Aufnahme, präoperative Betreuung, Erhebung patientenbezogener, klinischer und psychokardiologischer Daten sowie die Medikamentenanamnese (siehe Tab.3.3). Blut- und Urinproben wurde ebenfalls gemeinsam gesammelt. Die Alliqutierung, Codierung und Lagerung der Proben führte Herr Lehnig durch.

Die Daten der speziell klinisch kardiologischen Untersuchungen wie Echokardiographie, Spiroergometrie, Elektrokardiogramm und 6 Minuten-Geh-Test wurden ausschließlich durch die Doktorandin Charlotte Schroer erhoben. Die klinischen Parameter der SpygmoCor-Messungen sowie alle weiteren experimentellen Methoden wie die Analyse der EPCs, der vaskulären Biomarker und des UrinProteoms wurden vom Doktoranden Lehnig durchgeführt.

Sowohl die Beschreibung des Patientenkollektivs als auch die Auswertung der Patientencharakteristika, Symptome, BuP, ABPM, Antihypertensiva und Routineparameter erfolgte auf Grundlage gemeinsamer Daten, jedoch völlig separat. Die statistische Auswertung der klinischen Verlaufsparameter sowie der Labordaten führten die Doktoranden Schroer und Lehnig separat durch. Die hierbei erhobenen Laborergebnisse der Routine flossen in beide wissenschaftliche Arbeiten ein. Die Daten der speziellen Blut- und Urinuntersuchungen fanden sich entsprechend den wissenschaftlichen Fragestellungen in der jeweiligen Dissertation wieder. Frau Schroer analysierte und disskutierte hierbei ausschließlich Daten des Glukosestoffwechsels (bsp.: HB1c, Nüchtern-Glukose, HOMA-IR, etc.) und kardiale Marker (BNP). Herr Lehnig befasste sich dagegen mit den renalen Funktions- und Auscheidungsparametern, der $\mathrm{Na}^{+}$-Ausscheidung und serologischen Parametern (Aldosteron, Renin, etc.).

Frau Kohlbecker führte eine separate Datenerhebung und -Analyse der BAT-Patienten durch. Eine Kooperation ergab sich lediglich bei der Patientenübergabe, Terminabsprache und der Erhebung psychokardiologischer Daten.

Wir versichern, dass die in unseren Dissertationen erfolgten Analysen, Erhebungen und Auswertungen, mit Ausnahme der oben genannten Kooperationen, ausschließlich eigenständig und unabhängig durchgeführt wurden. 